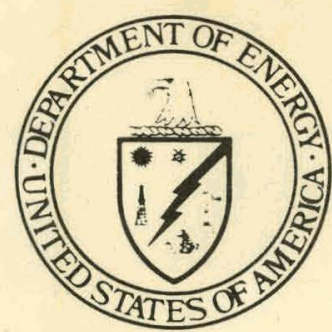

\title{
Technical and Economic Feasibility of Alternative Fuel Use in Process Heaters and Small Boilers
}

February 1980

Prepared for:

U. S. Department of Energy

Energy Information Administration

Assistant Administor for Applied Analysis

Under Contract No. DE-AC01-79EI10547 


\section{DISCLAIMER}

This report was prepared as an account of work sponsored by an agency of the United States Government. Neither the United States Government nor any agency Thereof, nor any of their employees, makes any warranty, express or implied, or assumes any legal liability or responsibility for the accuracy, completeness, or usefulness of any information, apparatus, product, or process disclosed, or represents that its use would not infringe privately owned rights. Reference herein to any specific commercial product, process, or service by trade name, trademark, manufacturer, or otherwise does not necessarily constitute or imply its endorsement, recommendation, or favoring by the United States Government or any agency thereof. The views and opinions of authors expressed herein do not necessarily state or reflect those of the United States Government or any agency thereof. 


\section{DISCLAIMER}

Portions of this document may be illegible in electronic image products. Images are produced from the best available original document. 


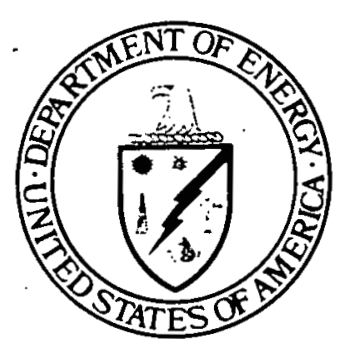

\section{Technical and Economic Feasibility of Alternative Fuel Use in Process Heaters and Small Boilers}

February 1980

Prepared by:

Energy and Environmental Analysis, Inc.

1111 North 19th Street

Arlington, Virginia 22209

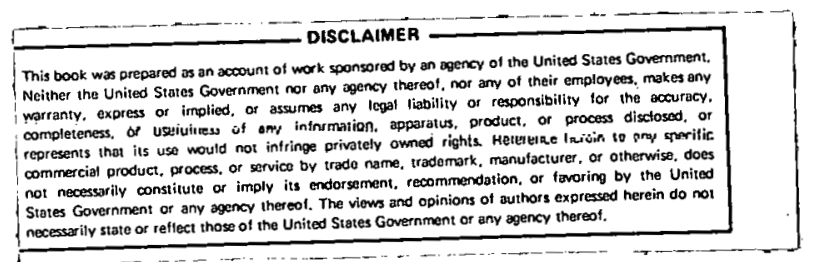

Prepared for:

U.S. Department of Energy

Energy Information Administration

Assistant Administrator for Applied Analysis

Office of Energy Use Analysis

Transportation, Industrial and Model Coordination Division

Washington, D.C.

Under Contract No. DE-AC01-79El10547 


\section{PREFACE}

The Energy Information Administration of the U.S. Department of Energy has been asked by the Secretary of. Energy to prepare a study report in. response to section 747 of the Powerplant and Industrial Fuel Use Act of 1978 (PIFUA). This study report evaluates the technical and economic feasibility of using alternate fuels - fuels other than oil and natural gas -- in combustors not regulated by PIFUA. The combustors considered in this report comprise approximately 45 percent of the industrial fuel demand projected in 1990. The report was prepared by Energy and Environmental Analysis, Inc. (contract No. DE-AC01-79EI10547) under the technical project guidance of Barry N. Cohen. 
TABLE OF . CONTENTS

Page.

1. EXECUTIVE SUMMARY . . . . . . . . . . . . . . . . . 1- 1

2. INTRODUCTION AND OVERVIEW . . . . . . . . . . . . . . 2- 1

3. CHARACTERIZATION OF INDUSTRIAL ENERGY USE . . . . . . . . . . 3 - 1

3.1 Introduction . . . . . . . . . . . . . 3- 1

3.2 Gerieral Overview of 1974 Energy Consumption . . . . . . 3- 1

3.3 Energy Consumption in Small Boilers . . . . . . . . 3-9

3.4 Energy Consumption in Process Heaters . . . . . . . . 3-14

3.5 Sumnary . . . . . . . . . . . . . . . 3-31

4. ALTERNATIVES TO OIL AND GAS IN THE INDUSTRIAL SECTOR $. . . \quad 4-1$

4.1 Alternative Fuel Sources . . . . . . . . . . . . 4- 2

4.1.1 Low- and Medium-Btu Gases . . . . . . . . . 4 4- 2

4.1.2 Solid Solvent Refined Coal . . . . . . . . . 4- 9

4.1.3 Liquid Solvent Refined Coal . . . . . . . . . . 4-17

4.1.4 Coal/Oil Mixtures . . . . . . . . . . . . . 4-22

4.1.5 Methanol .................. 4-30

4.1.6 Direct Coal .................. 4-37

4.1.7 Wood and Wood Waste.............. 4-41

4.1.8 Munfcipàl Solid Waste............ . 4-45

4.2 Alternative Sources of Heat . . . . . . . . . 4-58

4.2.1 Atmospheric Fluidized Bed Combustion . . . . . 4-58

4.2.2 Indirect Heat .. . . . . . . . . . . . . . 4-68

4.2.3 Electrification ............. . 4-74

4.2.4 Solar Technology . . . . . . . . . . . . 4-88 
5. TECHNICAL FEASIBILITY OF SUBSTITUTING ALTERNATIVE FUEL

IN INDUSTRIAL PROCESS HEATERS AND SMALL BOILERS......$\quad$ 5- 1

5.1 General Factors that Affect Fuel Use . . . . ...... . 5- 1

5.2 Process-Specific Assessments . . . . . . . . . . 5- 4

5.3 Technical. Feasibility of Alternative Fuels in Small Boilers .............. . . 5-28

5.4 Summary .................. . . 5-30

6. ECONOMIC ASSESSMENT OF ALTERNATIVE ENRGY SOURCES . . . . . . . 6- 1

6.1 Introduction . . . . . . . . . . . . . . 6- 1

6.2 Base Case Scenario.............. . 6- 3

6.3 Fuel Choice in the Base Case............ . 6-20

6.4 Summary . ................. . 6-35

7. ANALYSIS OF POTENTIAL INCENTIVE PROGRAMS . . . . . . . . . . 7 - 1

7.1 Economic Incentivcs . . . . . . . . . . . . . 7- 2

7.2 Regulatory Measures . . . . . . . . . . . . 7-11

7.3 Other Options to Encourage Reduction of Oil and Gas

Use in Process Heaters . . . . . . . . . . . . . 7-17

7.4 Summary .................. . . 7-18

\section{APPENDICES}

APPENDIX A: Industrial Fuel Choice Analysis Model . . . . . A- 1

APPENDIX B: Environmental Regulations Affecting Coal Use in Process Heaters and Small Boilers ... . . . B- 1

APPENDIX C: Process Description. . . . . . . . . . . . C- 1

APPENDIX D: Cost Calculations and Data Used for

Economic Comparisons ... . . . . . . . . D- 1

APPENDIX E: Glossary of Terms ............... E- 1 


\section{EXECUTIVE SUMMARY}

\subsection{SCOPE}

This report evaluates the technical and economic feasibility of using alternate fuels -- fuels other than oil and natural gas -- in combustors not regulated by the Powerplant and Industrial Fuel Use Act of 1978 . (FUA). FUA requires coal or alternate fuel use in most large new boilers and in some existing boilers. Section 747 of FUA authorizes a study of the potential for reduced oil and gas use in combustors not subject to the act: small industrial boilers with capacities less than $100 \mathrm{MMBtu} / \mathrm{hr}$, and process heat applications. This report examines alternative fuel use in combustors not regulated by FUA, analyzes the impact of several measures to encourage the substitution of alternative fuels in these combustors, and identifies the primary processes in which significant fuel savings can be achieved. Since feedstock uses of oil and natural gas are considered raw materials, not fuels, feedstock applications are not examined in this analysis.

The combustors evaluated in this study comprise approximately 45 percent of the fuel demand projected in 1990 (see Table 1.1). These uses would account for more than 3.5 million barrels per day equivalent fuel demand in 1990 .

\subsection{BACKGROUND}

Historically, process heaters and small boilers primarily have burned oil and natural gas. In small boilers, coal has comprised only 13 percenl of total steam capacity. Other than the use of wood waste in the paper industry, most of the remaining fuel demand has been satisfied by oil and gas. In process heaters, less than 10 percent of the fuel demand has been met with coal. Byproduct fuels, refinery gas, coke oven gas, and blast furnace gas have accounted for an additional 20 percent of demand. The 
TABLE 1.1

COMPARISON OF FUEL USE COVERED IN THIS STUDY WITH

FUEL USE TARGETED BY FUA: 1990

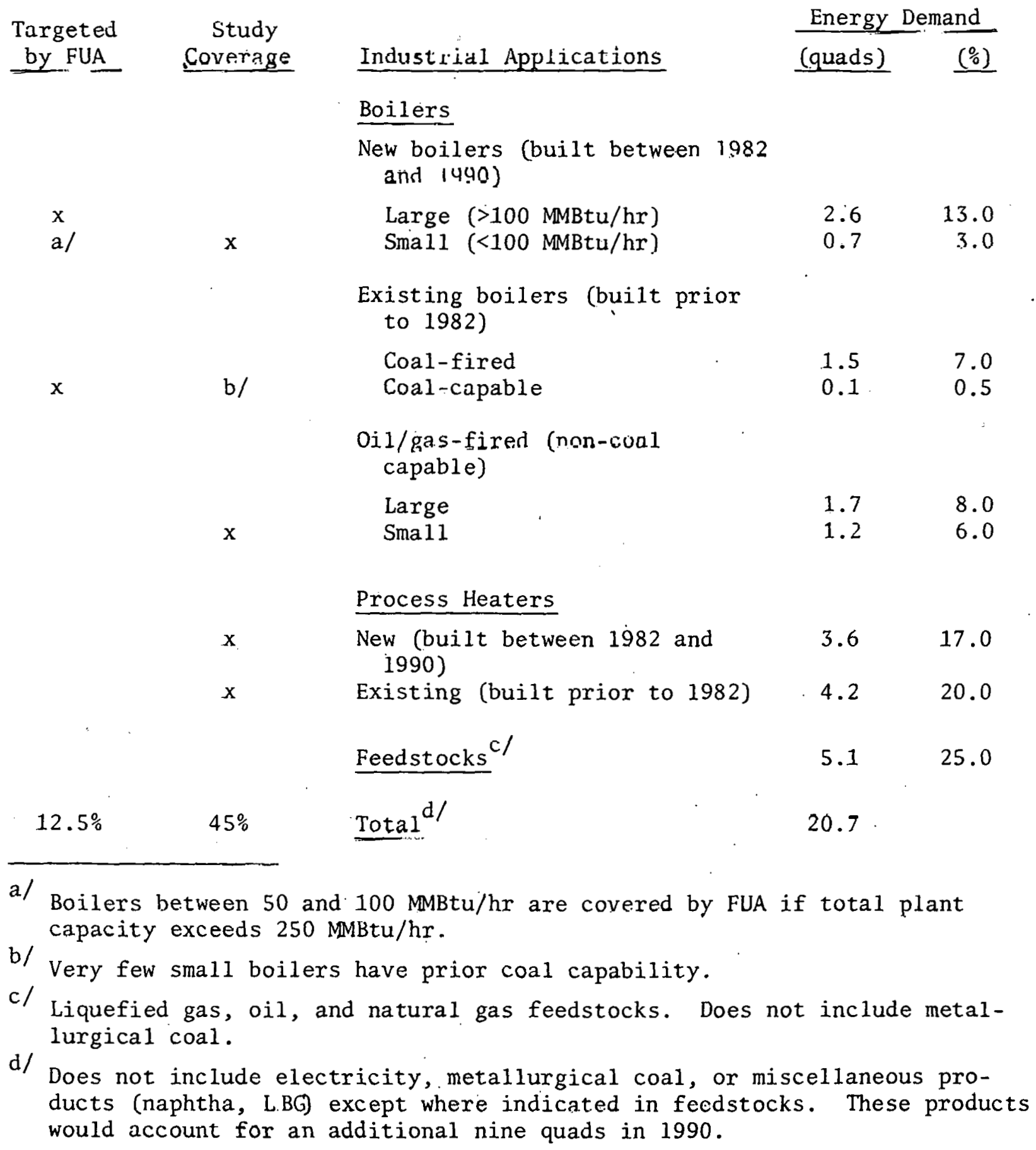


remaining 70 percent of process heat energy requirements have been met by oil and gas.

Projected fuel use estimates for these combustors through 1990 show continued reliance on oil and gas as primary energy sources. Under current economic and regulatory conditions, small boilers are projected to require 0.7 quads of new fuel from 1982 to 1990,80 percent of which will be oil or gas. New process heater growth is projected to require 3.6 quads of fuel. Byproduct fuels will maintain their share of new fuel use, and direct coal will meet 15 percent of the new fuel demand.

\subsection{FACTORS CONSTRAINING ALTERNATIVE FUEL USE}

Alternate fuel use in small boilers and process heaters is limited by technical constraints, lead time for development of new technologies, and economics. In small boiler use, the major constraint to increased alternate fuel use is economics. Direct coal is the primary nonscarce fuel alternative in small boilers, with atmospheric fluidized bed combustion competing in the portion of the coal market subject to stringerit environmental regulations. Low-Btu gas and electricity are proven alternative fuels, but they are not now economically competitive with coal, oil, or gas. Wood waste and municipal waste are competitively priced in situations in which site-specific condtions are favorable.

Replacement of scarce fuel use in process heaters is severely limited by a combination of technical, economic, and lead time factors. The following discussion illustrates how direct coal, a competitively-priced alternative fuel in some applications, is competitive in only 29 percent of the new process heat market due to technical limitations (see Table 1.2). This discussion also illustrates how site-specific economics, lead time to commercialization, and industry characteristics interact with technical feasibility judgments in this analysis. 
TABLE 1.2

ALTERNATE FUEL CONVERSION CAPABILITY AS A PERCENT OF TOTAL FUEL USE IN NEW AND RETROFIT PROCESS HEATERS: 1990 (percent)

N1ternale Fuel

Luw: and meidium-Btu gas

Methanol

Liquid solvent refined coal

Coa1/oil mixture

Solid solvent refined coal

Direçt coa 1

Municipal solid waste

Atmospheric fluidized bed cumbustion

Indirect heat

Electrification

Solar
New

75

75

51

35

35

29

16

5

21

80

8 $\underline{\text { Retrofit }}$

71

71

28

19

18

18

3

7

1 
The technical feasibility judgments in Table 1.2 were developed by matching the heat and process requirements of several applications with the heat delivery properties and operating characteristics of each fuel alternative. This table does not reflect accurately the lead time associated with adoption of new fuel technologies in applications in which alternate fuels have not been burned. Even in some cases in which a fuel is listed as "technically feasible," lead time will be required to prove the technical feasibility and verify the cost and reliability of the process. For example, direct coal use in tubestill heaters used in atmospheric distillation is listed as feasible in new applications in Table 1.2. Before coal can be burned in these processes, however, the following steps would have to be taken:

- Furnace redesign - solid fuel burners would have to be fired vertically downward as opposed to the upward or horizontal firing used to increase safety and reliability in modern refineries

- Operation of a burn test facility to determine critical operating parameters, fuel characteristics, and control requirements

- Experience on a commercial-scale test facility to prove feasibility in large-scale operations, reliability, and commercial availability

- Introduction to industry - to increase market penetration while the industry operators gained experience.

This series of steps would have to be duplicated for each alternative energy technology currently not operating. Although it is difficult to estimate accurately the lead time required, it is optimistic to assume that this process can be accomplished by 1990 for those fuel uses that are not already in the burn test stage today. 
Table 1.2 does illustrate accurately the importance of industry growth in eyaluating alternate fuel feasibility. Except for coal gases and methanol, the technical feasibility of retrofitting most technologies is considerably lower than the feasibility of using alternative technologies in new applications. This is because new applications can be designed to accomodate the undesirable features of alternative fuels, while existing combustors are much less flexible in their redesign and might suffer substantial derating, furnace wear, plugging, or even spacc limitations.

Sinec two of lhe llafor process heat industries -- petroleum and steel --are expected to grow slowly in. the $1980^{\prime} \mathrm{s}$, it is important to evaluate the potentiàl for oill and gas reduction in retrofit units in 1985/1990.

In addition to lead time and industry growth characteristics discussed above, site-specific. factors affect the economic feasibility of alternative fuel use. For example, in petroleum refineries, where facilities sprear. out over several miles, the dispersion of small process heaters throughout the facility limits alternative fuel use more than in boilers, which often are consolidated in a separate powerhouse. To adopt a solid fuel such as direct coal or solid solvent refined coal, a costly fuel handling system that traveled throughout the plant network might have to be developed. Although this would not limit the technical feasibility, this fuel handling system would increase substantially the fuel conversion costs.

The technical applicability, technology lead time, and cost factors shown in Table 1.3 provide a usefu1. framework to discuss the various fuel technologies considered in this study. As shown in the table, low-Btu gas, medium-Btu gas, and methanol technically can compete in a broad range of markets (over 70 percent of industrial processes), but the lead time required for development of medium-Btu gas and methanol is expected to be eight to 10 years. Low-Btu gas, currently being tested in several applications, is a near-term alternative, although the application costs are high relative to current oil and gas prices. As mentioned, direct coal use 
TABLE 1.3

TECHNOLOGY RANKING FOR USE IN PROCESS HEATERS

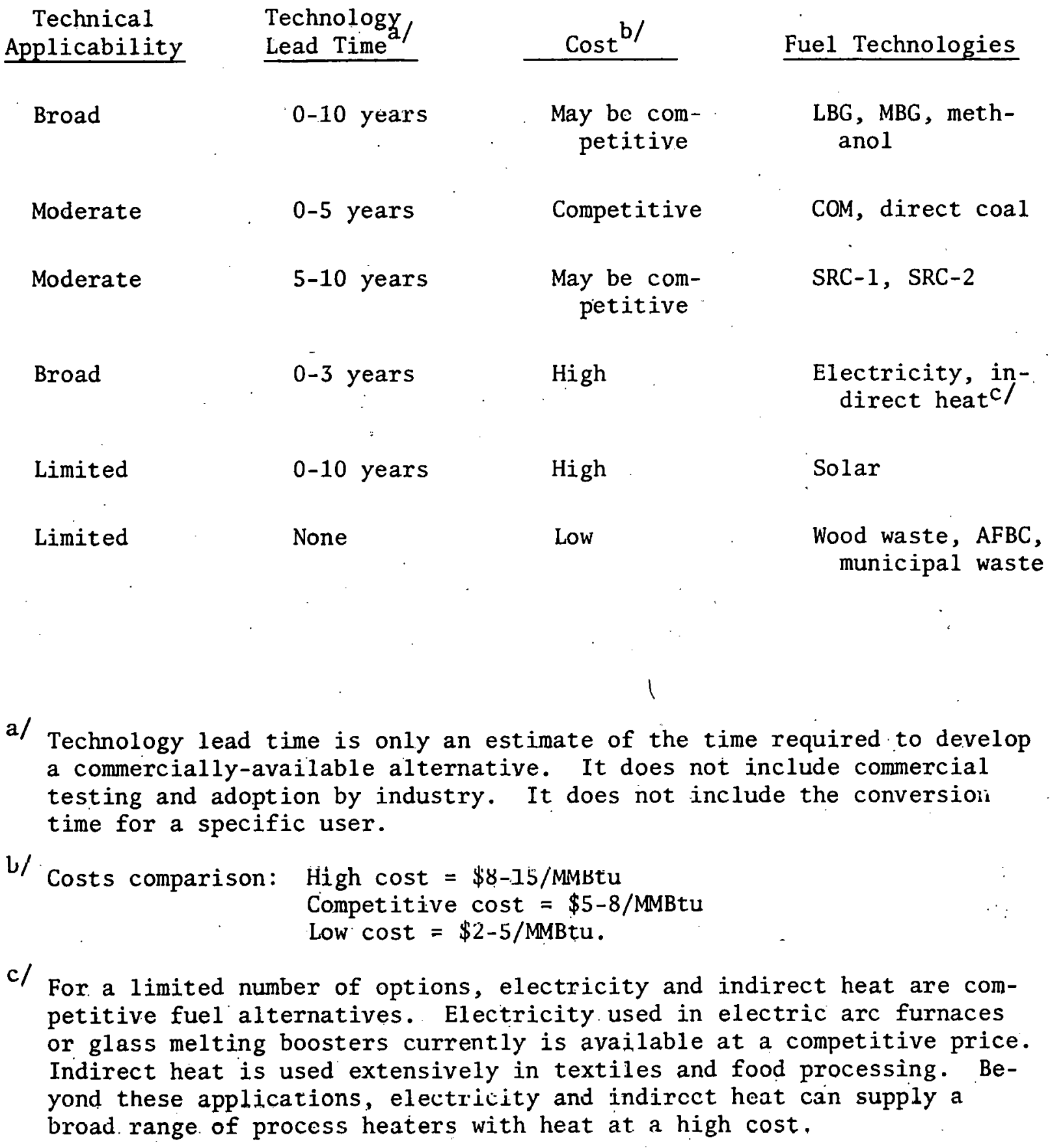


has a moderate technical applicability (29 percent) and a zero to five year lead time for development, depending on the current status of each process, and is competitively priced in some applications.

Solvent refined coal in solid and liquid form technically can be used in a moderate number of processes but will not be commercially available until 1988-1990 at the earliest. Electricity and indirect heat compete economically in a limited number of processes such as glass melting and textile drying, respectively. For the majority of the processes shown as technically feasible in Table 1.2, electricity and indirect heat are high-cost alternates. Even where technical feasibility is possible, lead time and costs will limit the adoption of several alternatives in the $1985 / 1990$ time frame.

\subsection{POLICIES TO STIMULATE SUBSTITUTION OF OIL AND NATURAL GAS}

The two policy alternatives considered in this analysia axe all investinent tax credit (ITC) and extending the FUA coverage to include small boilers and process heaters. While small ITC's are relatively ineffective, a large. (50 percent) ITC could double the alternative fuel demand in small boilers built between 1982 and 1990. An ITC also could provide a significant incentive for industry to scrap existing oil- and gas-fired boilers and replace them with new coal-fired boilers. The ITC will be less effective, however, as a measure to discourage oil and gas use in process heaters because most of the coal-capable combustors (cement and lime kilns) are using coal under existing economic conditions. The ITC does not provide a sufficient incentive to encourage widesprcad use of low-Btu gas or electricity. Although capital-intensive fuel alternatives such as methanol or liquid solvent refined coal would receive substantial incentives from an ITC, their market penetration is limited by a five to 10 year lead time.

The difficulty with an ITC in both boiler and process heater applications is that it effectively subsidizes the expected conversions in addition to 
the increased conyersions that result from the program. For new combustors built between 1982 and 1990 , base case coal use is 0.7 quads, while the alternative demand stimulated by the ITC is 0.3 quads.

An extension of the regulatory program also is more effective for sma11 boilers than for process heaters. An extended regulatory program potentially could decrease new oil and gas demand by 50 percent in new small boilers ( 0.5 to 0.25 quads). However, most of this decreased demand is in boilers between 50 and $100 \mathrm{MMBtu} / \mathrm{hr}$ which already might be covered by FUA if their plant capacity is greater than $250 \mathrm{MMBtu} / \mathrm{hr}$.

An extension of the FUA coverage to process heaters would pose several problems. The regulation could not target broad process groups since technica1 feasibility is often a site-specific determination. The costs of implementing a regulatory program would be high because the design differences in process heaters would require case-by-case consideration. The final problem would be to determine the technically proven alternatives that could compete in process heaters. Even direct-fired coal use is not technically proven in most process heat applications.

End-use incentive programs could effectively.reduce oil and gas use by only 0.3-0.5 quads by 1990. Either option considered in this analysis would incur either high administrative costs or subsidies to users who would select alternative fuels in any case. Other alternatives beyond the scope of this study, such as increased research and development programs and fuel subsidies, may increase the practical number of alternative fuels available to the industrial market. 


\section{INTRODUCTION AND OVERVIEW}

The Powerplant and Industrial Fuel Use Act of 1978 (FUA) requires coal use in most large new boilers and some existing boilers. Although FUA does not regulate fuel consumption in small boilers and various other combustors, Section 747 of the act calls for a study of the use of oil and natural gas in combustors not subject to FUA.

This report discusses the technical and economic feasibility of using a1ternative fuels (fuels other than oil or gas) in combustors not regulated by FUA: small industrial boilers with capacities less than $100 \mathrm{MMBtu} / \mathrm{hr}$ and process heaters. This report also describes the expected impacts of several possible measures to encourage the substitution of alternative fuels in these combustors and identifies the primary processes in which significant conventional fuel savings can be realized. The use of oil and natural gas as feedstocks is not discussed because oil and gas are considered raw materials, not fuels, in feedstock applications.

There are several stages to the following discussion of the primary issues associated with stimulating alternative fuel use in process heaters and small industrial boilers. First, the quantity and nature of energy use in the industrial sector are characterized, focusing on process heaters and small boilers. Second, each alternative energy technology option is describer, it.s status of development summarized, the range of available cost estimates given, and the critical technical and environmental issues affecting further development mentioned. The applicability of each alternative technology then is examined to determine where new energy sources can be used and what the potential for their use is. Finally, some possible policy measures designed to encourage substitution for oil and gas are discussed, and the range of resultant oil and gas savings is estimated. 
The fuel conversion alternatives analyzed in this report are listed below:

- Coal - conventionally fired

- Coal - atmospheric fluidized bed

- Low- and medium-Btu coal gasification

- Indirect heat substitution

- Electrification

- Solvent refined coal - solid

- Solvent refined coal - 1iquid

- Coa1/oil mixture

- Solar

- Wood waste

- Municipal waste

- Methanol.

The ability of each of these technologies to displace current oil and gas consümption is analyzed in general technical terms for 17 representative process categories in the seven most energy-intensive industries: chemicals, petroleum, primary metals, paper, food, textiles, and stone, clay and glass.

This report is presented in seven sections. Section 3 characterizes energy use in the industrial sector, particularly in process heaters and small boilers. Section 4 describes the fuel conversion alternatives considered. The technical feasibility of using alternative technologies in specific industrial processes and in small boilers is covered in section 5 . Section 6 identifies the primary economic factors that affect fuel switching and estimates the penetration of alternative energy sources under base case assumptions. Finally, Section 7 discusses the potential oil and gas savings that could result from implementing economic or regulatory incentives to encourage alternative fuel use in boilers and process heaters. Specific categories of process heaters are identified according to their economic and technical capability to shift away from scarce fuels in the $1985 / 1990^{\circ}$ timeframe. 


\section{CHARACTERIZATION OF INDUSTRIAL ENERGY USE}

\subsection{INTRODUCTION}

This section characterizes industrial energy use by industry, fuel type, and functional use, focusing primarily on energy consumed by process heaters and small boilers. The following discussion of current energy use is based on 1974 data, the most recent year for which comprehensive and disaggregated industrial energy data are available. Projected 1985/1990 energy requirements in process heaters and small boilers were estimated using the Midrange Energy Forecasting System (MEFS) model to provide the macroeconomic and multisectoral data and the Industrial Fuel Choice Analysis Model (IFCAM) to provide industry sector detail. $1 /$

\subsection{GENERAL OVERVIEW OF 1974 ENERGY CONSUMPTION}

Net energy consumption* in the U.S. in 1974 was approximately 70 quadrillion Btu. ${ }^{2 /}$ The industrial sector (excluding fuel use for transportation) accounted for 36 percent of total fuel consumption in 1974. Table 3.1 summarizes net energy consumption in 1974 by fuel type and sector. Petroleum products provided 46 percent of the nation's total heat, power, and feedstock requirements in 1974. Natural gas contributed 29 percent and coal provided 18 percent of the energy ronsumed. The manufacturing sector was the largest consumer of natural gas and electricity and the second largest consumer of coal and oil. The manufacturing sector is, then, the leading energy consumer among all economic sectors in the U.S.

\subsubsection{Functional Uses of Energy in the Manufacturing Sector}

Energy is used in the manufacturing sector as a means to generate process heat, as a boiler fuel, and as feedstock. Examples of process heaters

\footnotetext{
*Consumption less production.
} 
TABLE 3.1

1974 NET ENERGY CONSUMPTION IN THE U.S. ${ }^{\text {a/ }}$

$\left(10^{15} \mathrm{Btu}\right)$

\begin{tabular}{|c|c|c|c|c|c|c|}
\hline Sector & Coa1 & Oi1 & $\begin{array}{c}\text { Natura } 1 \\
\text { Gas } \\
\end{array}$ & $\begin{array}{c}\text { Elec- } \\
\text { tricity }\end{array}$ & NSK/NEC ${ }^{b /}$ & Total \\
\hline Residential & $-c /$ & 3.8 & 5.3 & $\quad 2.0$ & - & 11.1 \\
\hline Commercial & 0.1 & 1.1 & 2.3 & 1.8 & 0.1 & 5.4 \\
\hline Industrial: & 3.7 & 7.6 & 8.6 & 2.4 & 2.9 & 25.3 \\
\hline Manufacturing & 3.6 & $4.4^{\mathrm{d} /}$ & 7.1 & 2.1 & $2.8^{3 /}$ & $20: 1$ \\
\hline Mining & - & 0.3 & $1.4^{f /}$ & 0.1 & - & 1.9 \\
\hline Construction & 0.0 & 1.8 & 0.0 & - & 0.0 & 1.9 \\
\hline Agriculture & - & 1.1 & 0.2 & 0.1 & 0.0 & 1.4 \\
\hline Transportation: & 0.0 & $16.1^{\mathrm{g} /}$ & 0.7 & $\underline{-}$ & 0.0 & 16.8 \\
\hline Private (residentia1) & 0.0 & 10.3 & 0.0 & 0.0 & 0.0 & 10.3 \\
\hline Industrial/commercial & 0.0 & 5.8 & 0.7 & 0.0 & $n . n$ & 6.5 \\
\hline Electric utilities. & 8.6 & 3.3 & 3.5 & -6.4 & 2.2 & 11.2 \\
\hline TOTAL. & 12.4 & 32.0 & 20.4 & .0 .2 & 5.2 & 69.8 \\
\hline
\end{tabular}

SOURCE: Energy Consumption Data Base, vol. I, Summary Document, prepared for FEA by EEA, Inc., Arlington, Virginia, June 9, 1977.

\footnotetext{
a) Consumption less production. The energy used to produce electricity, steam, coke oven gas, and blast furnace gas is counted only once.

b/ Not specified by kind/not elsewhere classified. NSK can contain coal, oil, gas, electricity, or sther fuels, $\Lambda$ c cxample of NEC would be black liquor used in the pulp and paper industry.

c/ Denotes less than 50 trillion Btu.

d) Excludes 231 trillion Btu of asphalt.

e/ Includes 865 trillion Btu of wood residuals and 1042 trillion Btu of refinery (still) gas. The balance may be natural gas used in small industries.

f/ May be underistated by nearly half a quad.

g/ Excludes approximately 0.9 quads of military consumption.

h/ Approximately 152 trillion Btu are unaccounted for.
} 
include furnaces, ovens, dryers, kilns, and tubestill heaters. Boilers are used to generate hot water and steam for space heating, process steam, and electricity generation. Other minor functional uses (primarily of electricity) include electrolytic processes, machine drive, cooling, and lighting.

The primary feedstock uses of fuels occur in the chemicals and iron and steel industries. Metallurgical coal is used as a raw material in the iron and steel industry to produce coke. Natural gas, liquified petroleum gas (LPG), naphtha, and gas/oils are used as feedstocks in the chemicals industry to produce such chemicals as ammonia, ethylene, and methanol.

Table 3.2 characterizes industrial energy consumption in 1974 by functional use and fuel type. Current legislative initiatives have focused primarily on the large boiler population because they have the maximum flexibility to fire a variety of fuels. However, Table 3.2 illustrates that small boilers and selected process heaters potentially could provide significant oil and gas savings. Process heat equipment requires nearly 25 percent of industrial fuel requirements. Boilers consume an additional 25 percent of industrial fuel, with small boilers (below $100 \mathrm{MMBtu} / \mathrm{hr}$ ) accounting for at least a third of that total. Therefore, the current regulatory program addresses only 17 percent of total industrial fuel use, omitting 33 percent of the industrial fuel use that may have conversion capability.

\subsubsection{Major Energy-Intensive Industry Groups}

This analysis focuses on the seven major energy-intensive manufacturing groups that accounted for roughly 68 percent of total coal, natural gas, and distillate and residual fuel oil consumption (excluding raw material and feedstock uses) in the manufacturing sector in 1974 (see Table 3.3). Most of the major process heat uses of energy within these groups were characterized. Since small boilers are common in the less energy-intensive industries, small boiler energy use was analyzed for a broader group of industries, including those listed in Table 3.4 . 
TABLE 3.2

CHARACTERIZATION OF INDUSTRIAL ENERGY CONSUMPTION IN 1974

$$
\left(10^{15}\right. \text { Btu) }
$$

Functional Use

Fue1 Type

Coa1

Oi.1.

Distillate fuel oil

Residual fuel oil

Uther ${ }^{b /}$

Natural gas

Electricity

other $c /$

TOTAL

$\frac{\text { Functional Use }}{\text { Raw Process }}$

\begin{tabular}{|c|c|c|c|c|}
\hline Boilers & Materials & Heat & other ${ }^{a /}$ & Total \\
\hline
\end{tabular}

1.1

2.3

0.3

3.7

1.2

2.8

1.6

$\underline{2.1}$

7.6

0.2

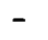

0.2

0.7

1.1

1.0

$-$

0.6

1.5

$\begin{array}{ll}- & 2.8\end{array}$

0.8

$-$

5.0

3.4

0.5 ,

2.8

1.4

8.6

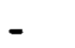

$-$

0.1

1.9

2.4

1. 1

$=$

0.8

2.3

2.9

6.8

5.6

5.6

7.6

25.3

SOURCE: Energy Consumption Data Base, prepared for FEA by EEA, Inc., Arlington, Virginia, June 9, 1977.
a) Miscellaneous and unclassified uses.
b/ Includes LPG, gasoline, diesel fuel, asphalt, and miscellaneous petroleum products.
c/ Includis 0.9 quads of wood residuals and 1.0 quads of refinery (stil1) gas. The balance may be natural gas used in small industries in small boilers.


TABLE 3.3

INDUSTRIAL FOSSIL FUEL CONSUMPTION IN 1974 BY MAJOR INDUSTRYa/ 1

$$
\left(10^{12} \mathrm{Btu}\right)
$$

\begin{tabular}{|c|c|c|c|c|c|}
\hline Industry & Coal & $\begin{array}{c}\text { Natural } \\
\text { Gas } \\
\end{array}$ & $\begin{array}{c}\text { Distillate } \\
\text { Fuel Oil } \\
\end{array}$ & $\begin{array}{l}\text { Residual } \\
\text { Fue1 Oil } \\
\end{array}$ & Total \\
\hline Food & 75.3 & 475.6 & 66.8 & 65.5 & 683.2 \\
\hline Textiles & 22.0 & 102.1 & 26.0 & 36.7 & 186.8 \\
\hline Paper & 208.8 & 414.3 & 25.2 & 488.6 & $1,136.9$ \\
\hline Chemicals & 322.2 & $1,617.2$ & 120.1 & 165.1 & $2,224.6$ \\
\hline Petroleum refining & 5.3 & $1,111.4$ & 50.3 & 281.5 & $1,448.5$ \\
\hline Stone, clay and glass & 234.0 & 696.3 & 76.0 & 49.5 & $1,055.8$ \\
\hline Steel & 170.3 & 681.9 & 14.8 & 249.6 & $1,116.6$ \\
\hline Aluminum & $31: 0$ & 411.2 & 17.0 & 17.0 & 476.2 \\
\hline other ${ }^{b /}$ & 24.74 & $2,652.5$ & 760.0 & 190.8 & $3,850.7$ \\
\hline TOTAL & $1,316.3$ & $8,162.5$ & $1,156.2$ & $1,544.3$ & $12,179.3$ \\
\hline
\end{tabular}

SOURCE: Energy Consumption Data Base, prëpared for FEA by EEA, Inc., Arlington;

a/ Excludes raw material and feedstock uses.

b/ Includes miscellaneous manufacturing, agriculture, mining, and construction industries. 
TABLE 3.4

INDUSTRIAL FOSSIL FUEL CONSUMPTION IN MISCELLANEOUS INDUSTRIES IN 1974

$$
\left(10^{12} \text { Btu }\right)
$$

\begin{tabular}{|c|c|c|c|c|c|}
\hline Industry & Coal & $\begin{array}{c}\text { Natural } \\
\text { Gas } \\
\end{array}$ & $\begin{array}{l}\text { Distillate } \\
\text { Fuel Oil }\end{array}$ & $\begin{array}{l}\text { Residual } \\
\text { Fuel Oil } \\
\end{array}$ & Total \\
\hline Tobacco & 5.5 & 4.5 & 1.1 & 4.1 & 15.2 \\
\hline Appare 1 & 1.0 & 15.4 & 4.3 & 1.4 & 22.1 \\
\hline Lumber & 2.8 & 72.9 & 34.1 & 8.3 & 118.1 \\
\hline Furniture & 2.8 & 25.3 & 5.1 & 2.5 & 35.7 \\
\hline Rubber & 29.6 & 86.6 & 18.3 & 25.7 & 160.2 \\
\hline Leather & 1.3 & 5.2 & 3.0 & 3.3 & 12.8 \\
\hline Primary metals ${ }^{a /}$ & 74.8 & 221.9 & 9.3 & 14.5 & 320.5 \\
\hline Machinery & 20.1 & 164.3 & 17.0 & 16.5 & 217.9 \\
\hline Electrical machinery & 13.2 & 96.9 & 11.1 & 10.3 & 131.5 \\
\hline Transportation equipment & 47.6 & 144.1 & 16.7 & 23.8 & 232.2 \\
\hline Measuring equipment & - & 15.8 & 3.3 & 9.4 & 28.5 \\
\hline $\begin{array}{l}\text { Miscellaneous manu- } \\
\text { facturing }\end{array}$ & 0.8 & $18: 8$ & 14.4 & 4.1 & 28.1 \\
\hline SUBTOTAL & 199.5 & 871.7 & 127.7 & 123.9 & 1322.8 \\
\hline Unaccounted for & 10.6 & 239.5 & 27.7 & 18.3 & 296.1 \\
\hline $\begin{array}{l}\text { TOTAL MISCELLANEOUS } \\
\text { MANUFACTURING }\end{array}$ & 210.1 & 1111.2 & 155.4 & 142.2 & 1618.9 \\
\hline Agriculture & 0.7 & 168.1 & 487.5 & - & 656.3 \\
\hline Mining & 36.5 & $1373.2^{\mathrm{b} /}$ & 117.1 & 48.6 & 1575.5 \\
\hline TOTAL & 274.4 & 2652.5 & 760.0 & 190.8 & 3850.7 \\
\hline
\end{tabular}

SOURCE: Energy Consumption Data Base, prepared for FEA by. EEA, Inc., Arlington,
a/ Excludes steel and aluminum industries.
b/ Includes 1046.7 trillion Btu of lease and plant fuel. 
In 1974, the seven major manufacturing groups identified relied on natura1 gas as their primary fossil fuel for heat and power except for the paper industry. Paper plants on the east coast relied primarily on residual fuel oil in 1974; paper plants in the midwest, south, and west, however, purchased more natural gas than any other fuel type (except wood wastes). Coal was used primarily as a boiler fuel except in the stone, clay and glass industry in which coal was burned in kilns to calcine raw materials for cement and lime production.

\subsubsection{Trends in Industrial Fuel Use}

Table.3.5 illustrates overall fuel switching trends that have developed from 1974 to 1978. During this time, state and Federal environmental regulations were revised, a strike disrupted coal availability, several areas of the country experienced significant gas curtailments, and imported oil prices remained roughly constant in real terms. As a result, coal and gas consumption has declined in recent years while oil and electricity use has risen slightly. Total energy demand has declined overall since 1974.

It is too early to predict accurately the impact of the National Energy Act (NEA) on fuel choice patterns. The incremental pricing provisions of the Natural Gas Policy Act (NGPA) should reinforce the trend away from natural gas use even though more gas will be available under the new wellhead pricing provisions. The combination of FUA requirements, the financial incentives under the Energy Tax Act (ETA), and the increased gas price under NGPA should reverse effectively the trend away from coal use in large industrial boiler applications. The impact of these regulations on small boilers and process heaters involves much uncertainty and is discussed in detail in Section 6 . 
TABLE 3.5

ENERGY CONSUMPTION TRENDS IN THE INDUSTRIAL SECTOR ${ }^{a /}$

$$
\left(10^{15} \mathrm{Btu}\right)
$$

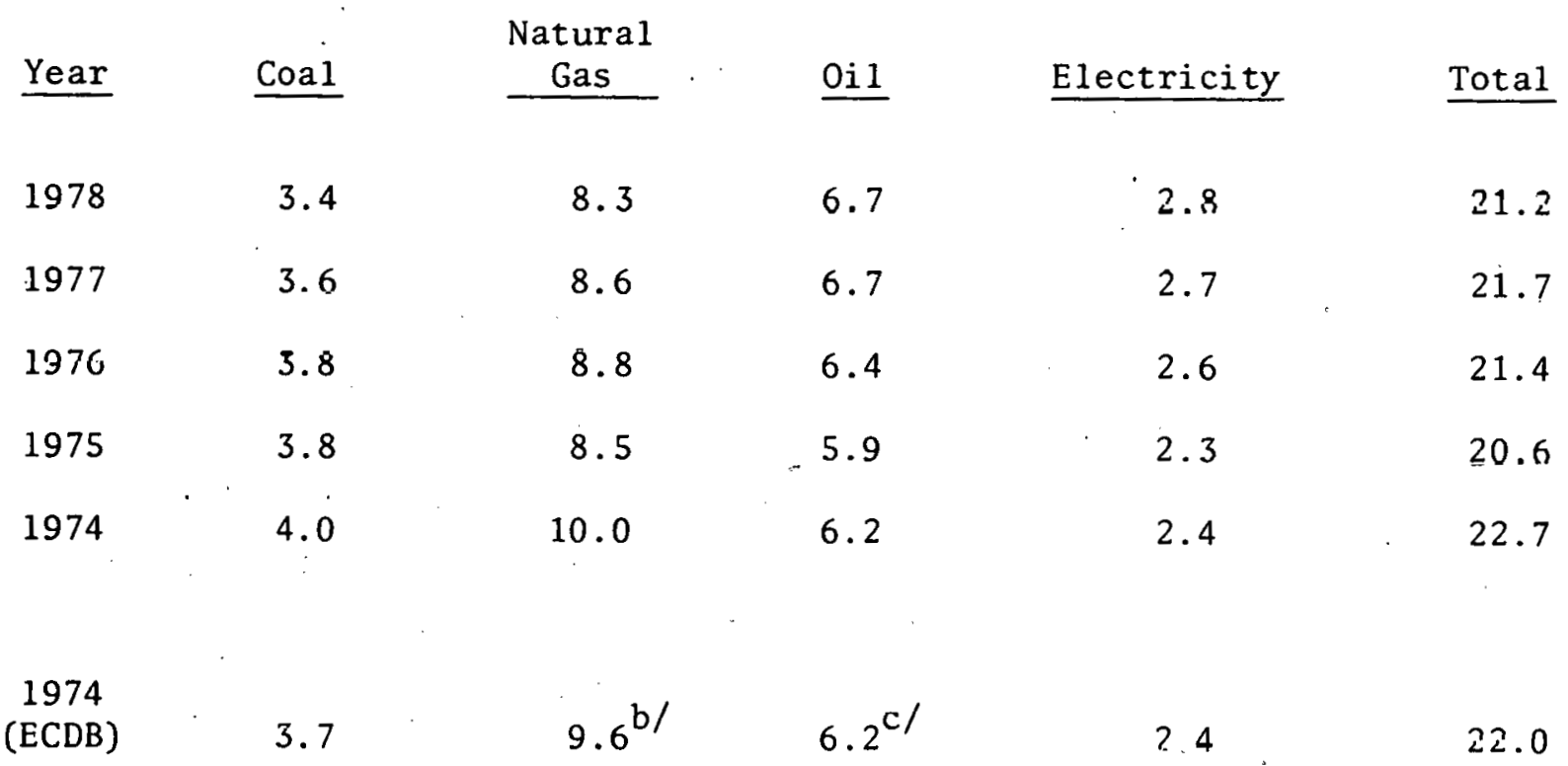

SOURCE: Office of Energy Data, Energy Information Administration, DOE, Monthly Energy Review, March 1979, p. 25.

\footnotetext{
a/ Excludes wood residuals and refinery gas.

b/ Includes 1.0 quads nf natural gas classifiud as "other" luel ill Census dara.

c/ Excludes 1.4 quads of gasoline and diesel fuel classified as oil in the transportation sector in the DOE estimates.
} 


\subsection{ENERGY CONSUMPTION IN SMALL BOILERS}

\subsubsection{Genera 1}

Historical fuel. use in boilers is shown in Table 3.6. Natural gas was the dominant boiler fuel in 1974. During the past three years, however, more new oil boilers have been purchased than either gas- or coal-fired boilers. Figure 3.1 shows the decline of natural gas boiler purchases and the rise of oil boilers since 1975 .

Table 3.7 presents the projected fuel requirements for boilers in the seven major industry classifications. Most of the growth shown in this table for 1985 is in the industries which have large boiler fuel demand in . 1974. Those industries (food, paper, chemicals, and petroleum) comprise over 80 percent of the new boiler growth in 1980-1990.

\section{3 .2 Small Boilers}

Unlike large boilers which have been studied and surveyed extensively, no comprehensive data on small boiler distribution exist. The Major Fuel Burning Installation Survey $3 /$ (MFBI) conducted by FEA in 1974 characterized boilers over $100 \mathrm{MMBtu} / \mathrm{hr}$. By combining the detailed characterization of the MFBI with the Energy Consumption Data Base (ECDB) data, small boilers (below $100 \mathrm{MMBtu} / \mathrm{hr}$ ) can be estimated to comprise roughly one-third of the total boiler fuel use in 1974. American Boiler Manufacturers Association (ABMA)sales data ${ }^{4 /}$ for watertube boiler sales also show small boiler sales (below $100 \mathrm{MMBtu} / \mathrm{hr}$ ) to be one-third of the total sales in 1965-1977. The National Emissions Data System ${ }^{5 /}$ (NEDS), the only survey of existing boiler use to cover small boilers, agrees with the MFBI and ABMA data: None of these data sources include firetube boilers. The PEDCo data, ${ }^{6 /}$ which cover both firetube and watertube boilers, suggest that small boilers actually may comprise close to 50 percent of total installed boiler capacity. The actual share of small boilers is probably between one-third and one-half of the total boiler population. Due to the uncertainty involved in all the 
TABLE 3.6

FOSSIL FUEL CONSUMPTION IN INDUSTRIAL BOILERS BY INDUSTRY IN $1974^{\text {a/ }}$ $\left(10^{12}\right.$ Btu)

\begin{tabular}{|c|c|c|c|c|c|}
\hline Industry & Coa1 & $\begin{array}{c}\text { Natural } \\
\text { Gas } \\
\end{array}$ & $\begin{array}{c}\text { Distillate } \\
\text { Fuel 0il } \\
\end{array}$ & $\begin{array}{l}\text { Residual } \\
\text { Fue1. Oi1 } \\
\end{array}$ & Total \\
\hline Food & 75.3 & 339.1 & 44.8 & 45.5 & 504.7 \\
\hline Textiles & 22.0 & 70.3 & 23.8 & 33.6 & 149.7 \\
\hline Paper & 208.8 & 287.1 & 15.4 & 411.8 & 923.1 \\
\hline Chemicals & 322.2 & 987.8 & 54.1 & 84.1 & 1448.2 \\
\hline Petroleum refining & 5.3 & 273.3 & 12.7 & 74.8 & 366.1 \\
\hline Stone, clay and glass & 1.4 & 4.2 & 0.5 & 0.3 & 6.4 \\
\hline Steel & 157.0 & 170.0 & - & 39.0 & 366.0 \\
\hline Aluminum & 31.0 & 220.4 & - & 9.6 & 261.0 \\
\hline Üther & 247.4 & $1027.8^{b /}$ & $88.5^{c /}$ & 346.4 & 1710.1 \\
\hline TOTAL & 1070.4 & 3380.0 & 239.8 & 1045.1 & 5713.3 \\
\hline
\end{tabular}

a) Excludes about 0.8 quads of wood residuals in the paper industry and about 0.3 quads of refinery gas in the petroleum refining industry.

b/ May be understated by as much as 1.0 quad in small builcra.

c/ May be understated by as much as 0.4 quads in small boilers.

SOURCE: Energy Consumption Data Base, prepared for FEA by EEA, Inc., Arlington, Virginia, June 9; 1977. 
FIGURR 3.1

BOILER SALES BY FUEL TYPE ${ }^{a /}$

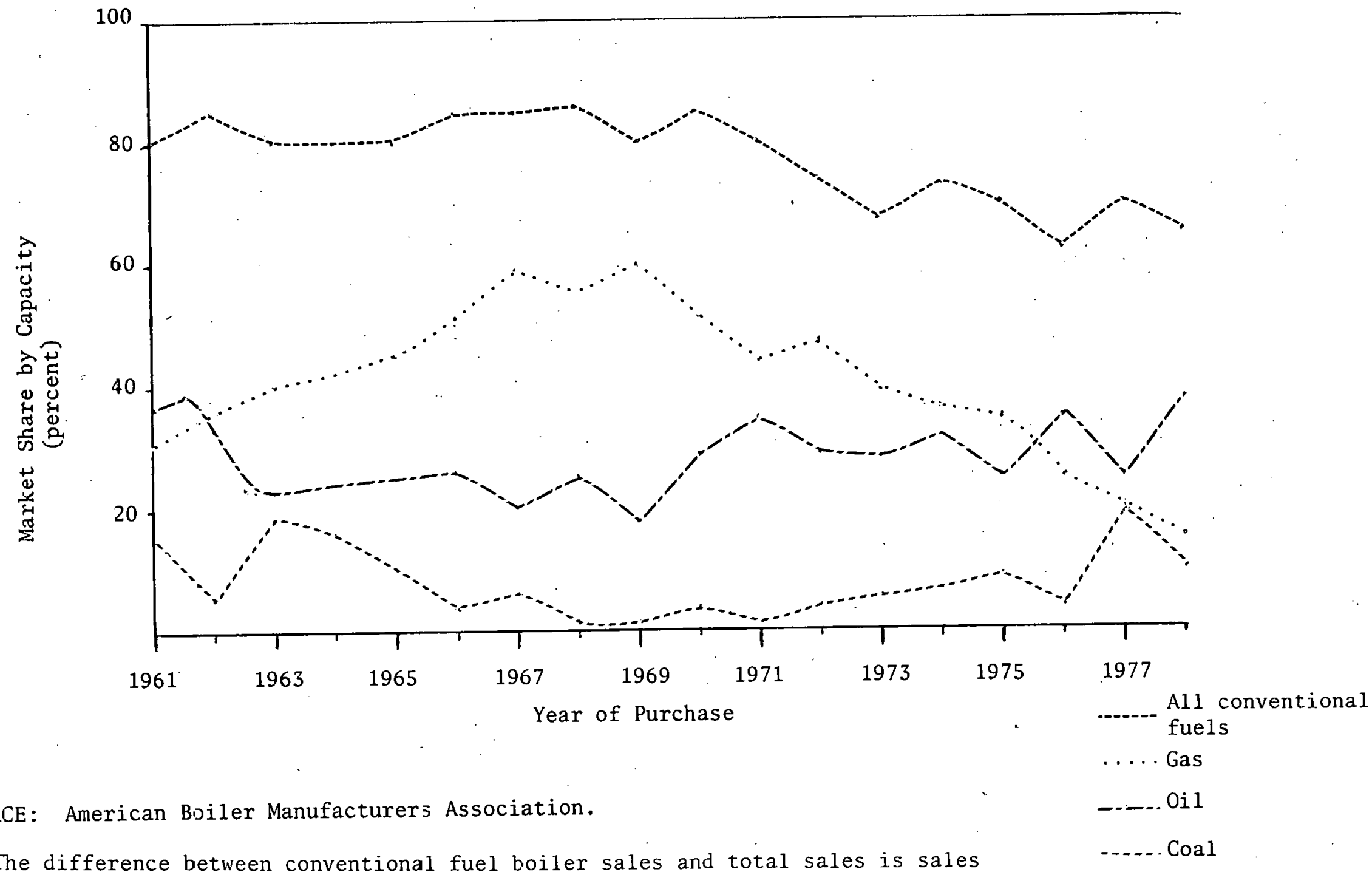

SOURCE: American Bijler Manufacturers Association. of boilers fired with waste and byproduct fuels. 
Tatle 3.7

PROJJETED BOILER FUEL REQUIREMENTS, BY INDUSTRY

$$
\left(10^{12} \mathrm{Btu}\right)
$$

Industry

Food

Textiles

Paper

Chemicals

Petroleum

Stone, Clay, \& G1ass

Stee 1

Aluminum

A11 Other

TOTAL

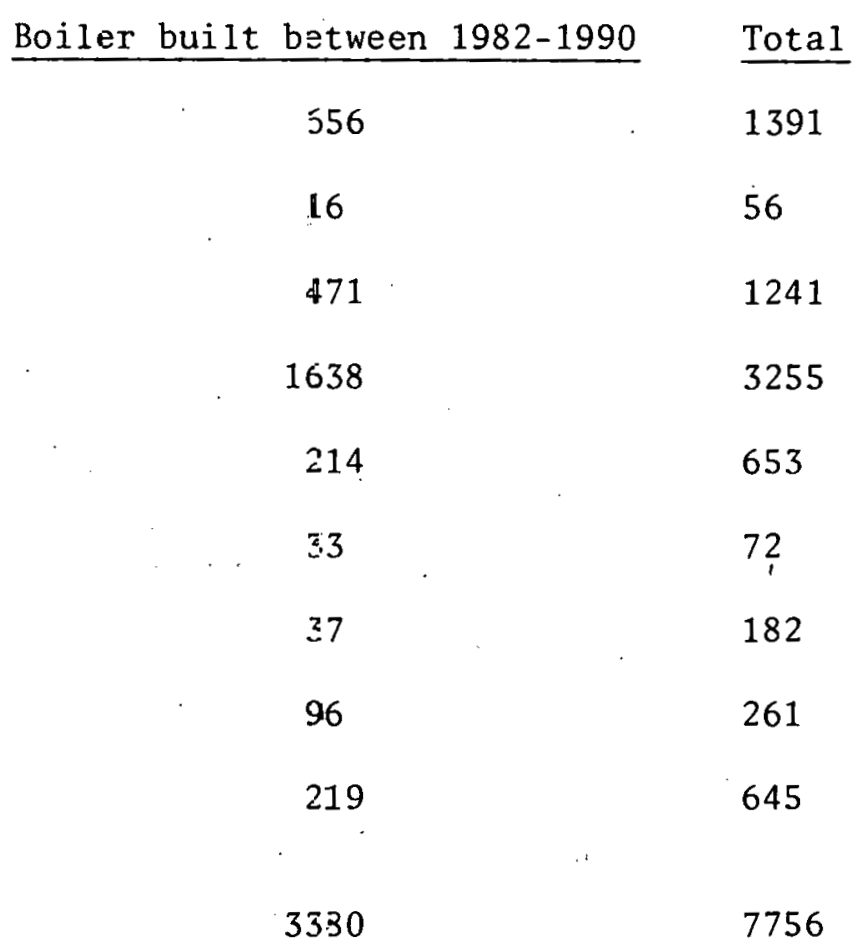

735

40

770

1617

439

39

145

165

426

4376

SOURCE: EEA, Industrial Fuel Choice Analysis Mode:. Run generated December 17,1979. 
TABLE 3.8

INDUSTRIAL BOILER CAPACITY ${ }^{\text {a/ }}$

(percent)

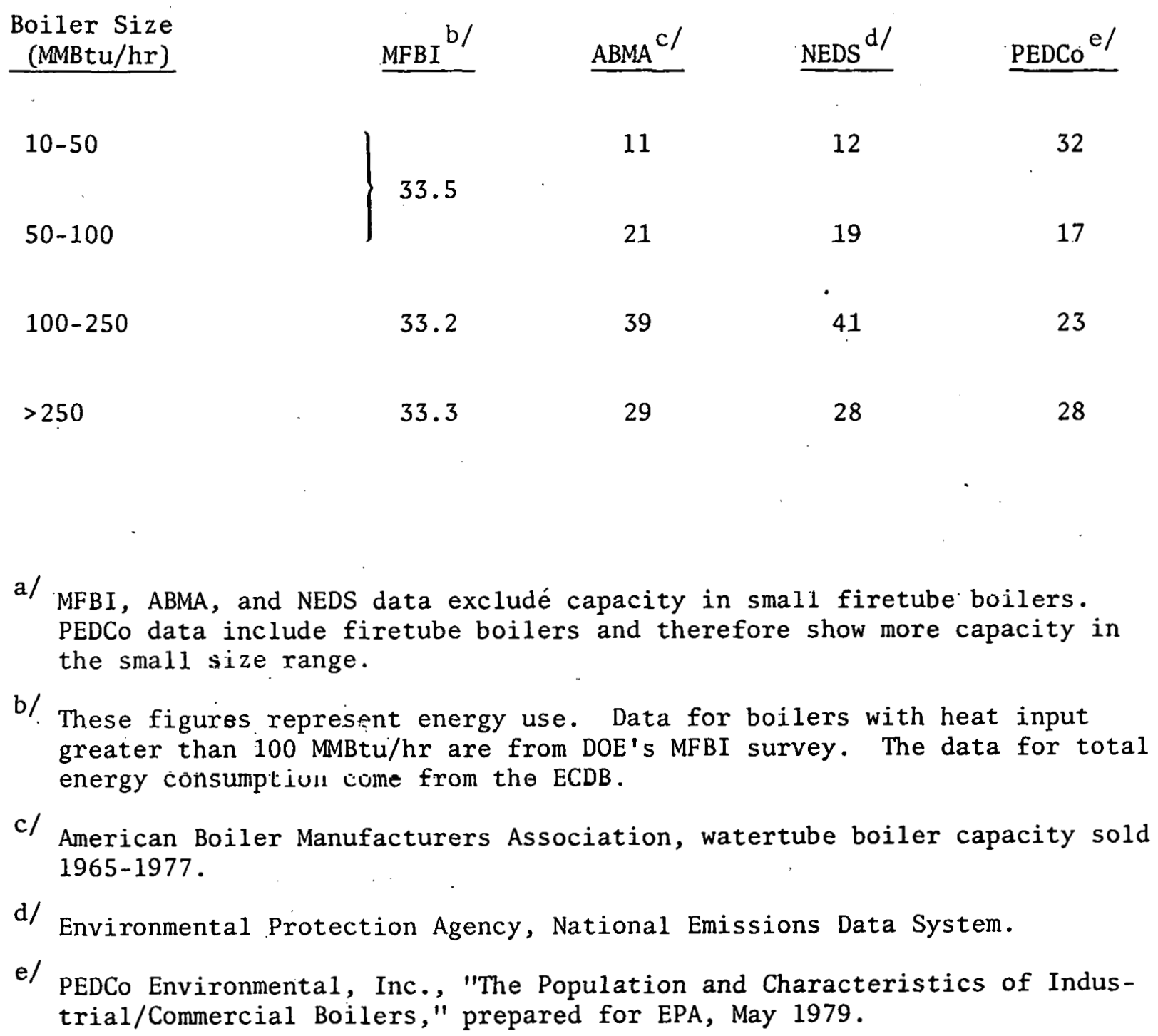


estimates, the MFBI estimate was assumed to be reasonably indicative of the large versus small boiler mix, while the PEDCo data were used to describe the distribution of boilers in the small sizes.

Table 3.9 shows the distribution of small industrial boilers by size and primary fuel type, and Table 3.10 shows the distribution by size and boiler type. These data were compiled by PEDCo Environmental, Inc. from several previous studies and data sources. The data shown probably are based on fuel consumption patterns in 1974. Natural gas-fired boilers account for almost 50 percent of the industrial mall builer capacity, followed by residual oil-fired boilcrs at about 30 percent. The top four capacity ranges shown in Table 3.9 all have a relatively even share of the total small boiler capacity.

Table 3.10 shows that while 75 percent of small boilers have capacities below $1.5 \mathrm{MMBtu} / \mathrm{hr}$, only about 12 percent of the small boiler capacity comes from these boilers. Approximately 50 percent of total small boiler capacity is in watertube boilers, although these boilers comprise ondy abuul 0.5 percent of small boiler units. Firetube boilers represent about 40 percent of total small boiler capacity, while smaller cast iron boilers comprise roughly 10 percent of that totil.

\subsection{ENERGY CONSUMPTION IN PROCESS HEATERS}

\section{4 .1 General}

Process heaters comprise a large portion of industrial energy demand as discussed in the previous sections. The major uses of fuel in process: heaters can be identified in the seven major induslry groups shown in Table 3.11. These industries consume over 70 percent of the total process heater fuel requirements. Despite the concentration of process heaters in seven industry groups, process heaters are a difficult.subsct of cumbustors to affect through regulatory or financial incentive programs. This difficulty 
TABLE 3.9

CAPACITY DISTRIBUTION OF SMALL INDUSTRIAL BOILERS BY SIZE AND FUEL TYPE $(\mathrm{MMBtu} / \mathrm{hr})$

\begin{tabular}{|c|c|c|c|c|c|c|c|c|}
\hline $\begin{array}{c}\text { Primary } \\
\text { Fuel Type } \\
\end{array}$ & $<0.4$ & $0.4-1.5$ & $1.5-10$ & $10-25$ & $25-50$ & $50-100$ & Tota1 & $\%$ \\
\hline Coal & 4,100 & 14,260 & 25,250 & 26,280 & 75,980 & 95,200 & 241,070 & 13.0 \\
\hline Residual & 10,300 & 42,520 & 117,840 & 98,660 & 154,120 & 121,650 & 545,090 & 29.5 \\
\hline Distillate & 6,400 & 22,740 & 63,180 & 47,170 & 35,010 & 14,660 & 189,160 & 10.2 \\
\hline Natural Gas & 26,400 & 88,830 & 199,740 & 164,700 & 210,810 & 182,880 & 873,360 & 47.2 \\
\hline TOTAL & 47,200 & 168,350 & 406,010 & 336,810 & 475,920 & 414,390 & $1,848,680$ & 99.9 \\
\hline Percent & 2.6 & 9.1 & 22.0 & 18.2 & 25.7 & 22.4 & 100.0 & \\
\hline
\end{tabular}

SOURCE: PEDCo Environmental, Inc., "The Population and Characteristics of Industrial/Commercial Boilers, prepared for Environmental Protection Agency, May 1979, Tables 2-9, 2-11, 2-13. 
TABLE 3.10

DISTRIBUTICIN OF SMALL INDUSTRIAL 3OILERS BY SIZE AND BOILER TYPE

(capacity in MMBtu/hr)

\begin{tabular}{|c|c|c|c|c|c|c|c|c|}
\hline \multirow[b]{2}{*}{ Boiler Type } & \multicolumn{7}{|c|}{ Capacity Range (MMBtu/hr) } & \multirow[b]{2}{*}{$\%$} \\
\hline & $<0.4$ & $0.4-1.5$ & $1.5-10$ & $10-25$ & $25-50$ & $50-100$ & Total & \\
\hline \multicolumn{9}{|l|}{ Cast iron. } \\
\hline \# units & 194,196 & 76,435 & 24,667 & 0 & 2 & 0 & 295,298 & 58.8 \\
\hline Capacity & $47, \geq 00$ & 60,700 & 71,500 & 0 & 3 & 0 & 179,400 & 9.7 \\
\hline Firetube & & & & & & & & \\
\hline$\#$ units & 0 & 103,088 & 54,007 & 14,268 & 2,573 & 0 & 173,936 & 34.7 \\
\hline Capacity & 0 & 103,100 & $29 \varepsilon, 800$ & 250,100 & 96,500 & 0 & 748,500 & 40.5 \\
\hline \multicolumn{9}{|l|}{ Watertube } \\
\hline \# units & 0 & 3,839 & 7,626 & 5,240 & 10,306 & 5,640 & 32,651 & 6.5 \\
\hline Capacity & 0 & 4,550 & 35,710 & 86,710 & 379,420 & 414,390 & 920,780 & 49.8 \\
\hline \multicolumn{9}{|l|}{ TOTAL } \\
\hline \# units & 194,196 & 183,362 & 86.300 & 19,508 & 12,879 & 5,640 & 501,885 & 100.0 \\
\hline Capacity & 47,200 & 168,350 & 406,010 & 336,810 & 475,920 & 414,390 & $1,848,680$ & 100.0 \\
\hline$\%$ units & 38.7 & 36.5 & $=7.2$ & 3.9 & 2.6 & 1.1 & 100.0 & \\
\hline$\%$ capacity & 2.6 & $9: 1$ & 22.0 & 18.2 & 25.7 & 22.4 & 100.0 & \\
\hline
\end{tabular}

SOURCE: PEDCo Envi ronmental, Inc., "The Population and Characteristics of Industrial/Commercial Boilers, prepared for Environmental Protection Agency, May 1979, Tables 2-9, 2-11, 2-13. 
TABLE 3.11

COAL, GAS, AND FUEL OIL CONSUMPTION IN PROCESS HEAT

APPLICATIONS IN 1974 BY INDUSTRY

$\left(10^{12} \mathrm{Btu}\right)$

Industry

Natural Distillate Residual Total

Food

Coal $\begin{array}{r}\text { Gas } \\ 94 \\ 26\end{array}$

Textiles

80

Paper

436

Chemicals

Ammonia

252

Methano 1

53

Other

130

Petroleum refining

130
799

Fuel Oil

Fue1 Oi1 Fue1 Oi1

Stone, clay and glass

Glass

$\underline{258} \quad \underline{688}$

234

$167 \quad 205$

Cement

88

62

Brick

Clay refractories

3

54

17

Other

96

Primary metals

Steel

Aluminum

Foundaries

other

6 $\quad \frac{687}{468}$

167

6

52

31

60

60

4

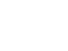

17

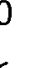

2

$\begin{array}{lll}31 & 42 & 73\end{array}$

\begin{tabular}{rrr}
29 & 196 \\
\hline
\end{tabular}


occurs because there are well over 100 distinct combustor types with widely varying technical requirements (often depending on the age of the unit or the plant that is using it) and economic differences.

Furnaces, kilns, and other process heaters have widely varying characteristics due to the diversity of their applications. Some major process heat uses include the following: heating, melting, and treating in the primary metals industry; transforming feedstocks in the chemicals and petroleum refining industries; singeing, drying, and heat setting in the textiles industry; baking and cooking in the food industry; and calcining, drying, firing, and melting in the stone, clay and glass industry.

\subsubsection{Process Energy Use Characterization}

Energy use in process heaters can be described by examining process heat use first in boiler-intensive industries and then in the industries that primarily use process heaters. The boiler-intensive industries include food, textiles, paper, and the chemical industries while industries with large process heat loads are pet.rnleum; stone; clay and glass; steel; and aluminum. Although most of the data shown in the following section are from 1974, process heat energy use patterns probably have not shifted significantly since then.

\subsubsection{Process Heat Use in Boiler-Intensive Industries}

In 1974, 94.1 trillion Btu of natural gas were consumed in the food industry in direct process heat applications. Table 3.12 summarizes the distribution of gas consumption by major application in this industry. As shown in the table, the predominant direct heat requirement in food manufacturing is drying, with cooking as a secondary energy requirement. These processes are low contamination, low temperature processes.

The textile industry consumed 27 trillion Btu of natural gas in process heat applications in $1974.7 /$ Most of this energy consumption was for 
TABLE 3.12

ENERGY CONSUMPTION IN SELECTED DIRECT HEAT APPLICATIONS

IN THE FOOD INDUSTRY IN 1974

$\left(10^{12} \mathrm{Btu}\right)$

Application

Cooking and smoking sausage and prepared meats 3.0

$\begin{array}{ll}\text { Drying whey } & 7.0\end{array}$

Drying powdered milk $\quad 5.0$

Dehydrating fruits' and vegetables 5.0

Dryịng corn fiber $\quad 3.0$

$\begin{array}{ll}\text { Dehydrating alfalfa } & 18.0\end{array}$

$\begin{array}{ll}\text { Baking bread } & 7.0\end{array}$

Drying beet pulp 16.0

Drying soybeans and soybean meal 9.0

Drying barley grain 9.0

Misccllaneous $\quad 12.1$

$\begin{array}{ll}\text { TOTAL } & 94.1\end{array}$

SOURCE: "Technical Feasibility of Coal Use in Industrial Process Heat Applications," draft report prepared for DOE by EEA, Inc., Arlington, Virginia, May 22, 1978 . 
drying and heat setting fabric; a small amount also was used to singe fabric. $8 /$ Like the food industry, these processes are low temperature, low contamination processes.

In 1974, the paper industry consumed 80 trillion Btu of gas and 67 trillion Btu of residual fuel oil in direct heat applications ${ }^{9 /}$ for pulp and paper drying and to fuel lime kilns. Paper is the one industry in which the fuel mix has changed significantly in the past few years. Since 1974, pulp and paper mills have moved from 42 percent oil and gas to only 38 percent. Wood waste and paper byproducts have displaced most of this gas and oil.

Natural yas is used extensively in the chemicals industry to fuel reformers and tubular pyrolysis furnaces. In 1974, 252 trillion Btu of natural gas were consumed in process heat applications for ammonia production and 53 trillion Btu in the production of methanol. ${ }^{10 /}$ These two chemicals accounted for 70 percent of the natural gas used in process heat applications in the chemicals industry in 1974. In addition, 31 trillion Btu of distillate fuel oil and 42 trillion Btu of residual fuel oil were consumen in direct heat applications in the manufacture of other chemicals in 1974.

\subsubsection{Petroleum Refining}

Direct heat has two principal uses in petroleum refineries: 1) to preheat the process feedstocks to a temperature sufficient for physical separation by distillation and 2) to initiate a chemical reaction such as cracking, which uses heat to break down large branched molecules into lower weight molecules. These direct heat applications accounted for over 70 percent of total fossil fuel consumption at oil refineries in 1974 . Tables 3.13 and 3.14 sumblirize this oil and gas consumption by fuel type and by major production process. A critical element of fuel consumption in refineries is that refinery off-gas comprises a large share (over 40 percent) of the fuel used in process heaters. Refinery gas and natural gas are interchangeable, and together they comprise a large majority of the fuel fired in refinery process heaters. 
TABLE 3.13

ENERGY CONSUMPTION IN DIRECT HEAT APPLICATIONS IN PETROLEUM REFINERIES IN 1974, BY FUEL TYPE

$$
\left(10^{12} \mathrm{Btu}\right)
$$

$\begin{array}{lr}\text { Crude oil } & -{ }^{a /} \\ \text { Distillate fuel oil } & 29 \\ \text { Residual fuel oil } & 196 \\ \text { Natural gas } & 799 \\ \text { LPG } & 29 \\ \text { Refinery gas } & 755 \\ \text { TOTAL } & 1808\end{array}$

SOURCE: "Technical Feasibility of Coal Use in Industrial Process Heat Applicatinns," draft report prepared for DOE by EEA, Inc., Arlington, Virginia, May 22, 1978.

\section{a) 170 MMBtu.}


TABLE 3.14

OIL AND GASEOUS FUEL CONSUMPTION IN DIRECT HEAT APPLICATIONS IN THE PETROLEUM REFINING INDUSTRY IN 1974, BY PROCESS

$$
\left(10^{12} \mathrm{Btu}\right)
$$

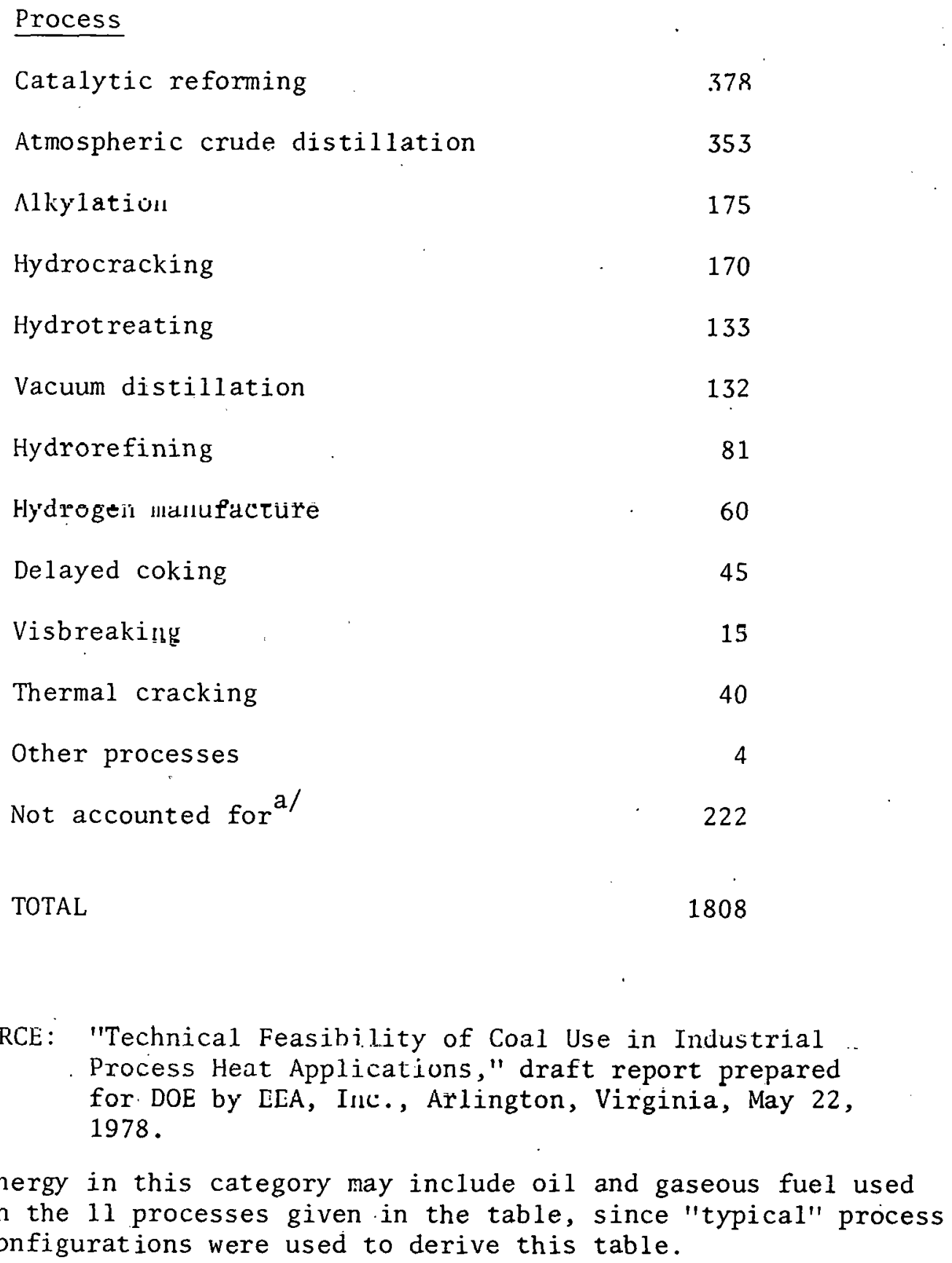




\subsubsection{Stone, Clay and Glass}

The stone, clay and glass industry includes a variety of establishments producing cement, lime, glass, brick, clay, and other products. In the stone, clay and glass industry, fossil fuel is consumed almost exclusively for direct heat purposes. Boiler heat consumption for this industry is minimal (see Table 3.6). In addition, cement and lime kilns in this industry group are the only significant users of coal among industrial process heat applications.

Natural gas is the preferred fuel type in the glass industry for melting and annealing. Primary combustors in this industry include unit and regenerative melters and annealing lehrs. In the cement and lime industries, fossil fuels are used exclusively in the calcination process and primarily in rotary kilns. Other major process heat uses include drying and firing bricks and clay refractories in tunnel and periodic kilns.

\subsubsection{Steel}

The iron and steel industry also uses more oil and natural gas in process heat equipment than in boilers. In 1974, 468 trillion Btu of natural gas, 13 trillion Btu of distillate fuel oil, and 208 trillion Btu of residual fuel oil were consumed in process heat applications. Table 3.15 summarizes oil and natural gas consumption by major process heat equipment.

A significant amount of byproduct fuels supplement oil and gas consumption in the steel industry. Coke oven gas is used to fuel soaking pits, blast furnace hydrocarbon injection, and reheat, annealing, and open hearth furnaces as well as coke ovens. Much of the natural gas used in steel production is blended with the in-house generated coke oven gas to produce a cheap, high-quality gas for use in steel industry processes. Blast furnace gas is used to fuel coke ovens, soaking pits, and heat treating furnaces as well as blast furnace stoves. Tar and pitch, byproducts from coke production, also are used for blast furnace hydrocarbon injection and to fuel open hearth furnaces. 
TABLE 3.15

MAJOR PROCESS HEAT EQUIPMENT CONSUMERS OF OIL AND NATURAL GAS IN THE IRON AND STEEL INDUSTRY IN 1974

$\left(10^{12} \mathrm{Btu}\right)$

$\begin{array}{lc}\begin{array}{lc}\text { Process Equipment } \\ \text { Reheat furnaces }\end{array} & \begin{array}{c}\text { Oil and } \\ \text { Natural Gas } \\ \text { Consumed }\end{array} \\ \begin{array}{lc}\text { Blast furnaces } \\ \text { Stoves }\end{array} & 246 \\ \text { Hydrocarbon injection } & 100 \\ \text { Open hearth furnaces } & 90 \\ \text { Annealing and other heat treating furnaces } & 62 \\ \text { Iron ore agglomeration } & 38 \\ \text { Soaking pits } & 17 \\ \text { Othror } & 39 \\ \text { TOTAL } & \end{array}$

SOURCE: "Technical Feasibility of Coal Use in Industrial Process Heat Applicurions," dratt report prepared for DOE by EEA, Inc., Arlington, Virginia, May 22, 1978. 


\subsubsection{Aluminum}

The major uses of oil and gas in direct heat applications in the aluminum industry are listed in Table 3.16. In this industry, slightly more oil and gas were consumed in boilers in 1974 than in process heat equipment. In addition, a significant amount of electricity was consumed in the reduction of alumina to aluminum. As a result, natural gas use ranks second to electrical energy consumption in this industry.

\subsubsection{Foundries}

Energy consumption in independent foundries ${ }^{11 /}$ totaled about 200 trillion. Btu in 1974. Oil and gas supplied over half of this total; electricity and coke contributed most of the balance. Melting, molding and coremaking, and heat treating are the process heat applications that account for nearly half of the total oil and gas process use in this industry (see Table $3.17)$.

There are four types of melting furnaces in foundries: the cupola, open hearth furnace, electric arc, and air (reverberatory) furnace. Cupolas (vertical shaft furnaces) are the largest consumers of oil and gas among these furnace types. $0 i 1$ and gas are consumed primarily to preheat combustion air; these fuels also are used, to a sma1l extent, to ignite the coke bed in the cupola, to fire forehearths (holding furnaces), and to preheat scrap.

Oil and gas are consumed in molding and coremaking ovens to bake cores (sand shapes which form the contours of castings for complex cavities) and to dry molds. Fuel also is required to dry and preheat ladles, molds, and runners and to dry sand in casting, shakeout, and cleaning processes.

\subsubsection{Technical Characteristics of Fuel Consumption in Process Heaters}

The process heaters described in the preceding section are summarized in Table 3.18. This list was shortened to a more manageable number of pro- 
TABLE 3.16

OIL AND NATURAL GAS CONSUMPTION IN PROCESS HEAT EQUIPMENT

IN THE ALUMINUM INDUSTRY IN 1974

$$
\left(10^{12} \mathrm{Btu}\right)
$$

Equipment

Lime rotary 'calciner

Aluminum rotary calciner

Anode prebake oven

Reverberatory furnace

Heat treating furnace

TOTAL
Natural Gas

3

35

7

55

67

167

10

SOURCE: "Technical Feasibility of Coal Use in Industrial Process Heat Applications," draft report prepared for DOE by EEA, Inc., Arlington, Virginia, May.22, 1978. 
TABLE 3.17

OIL AND NATURAL GAS CONSUMPTION IN PROCESS HEAT EQUIPMENT IN THE IRON AND STEEL FOUNDRIES INDUSTRY IN $1974^{\mathrm{a} /}$

$$
\left(10^{12} \mathrm{Btu}\right)
$$

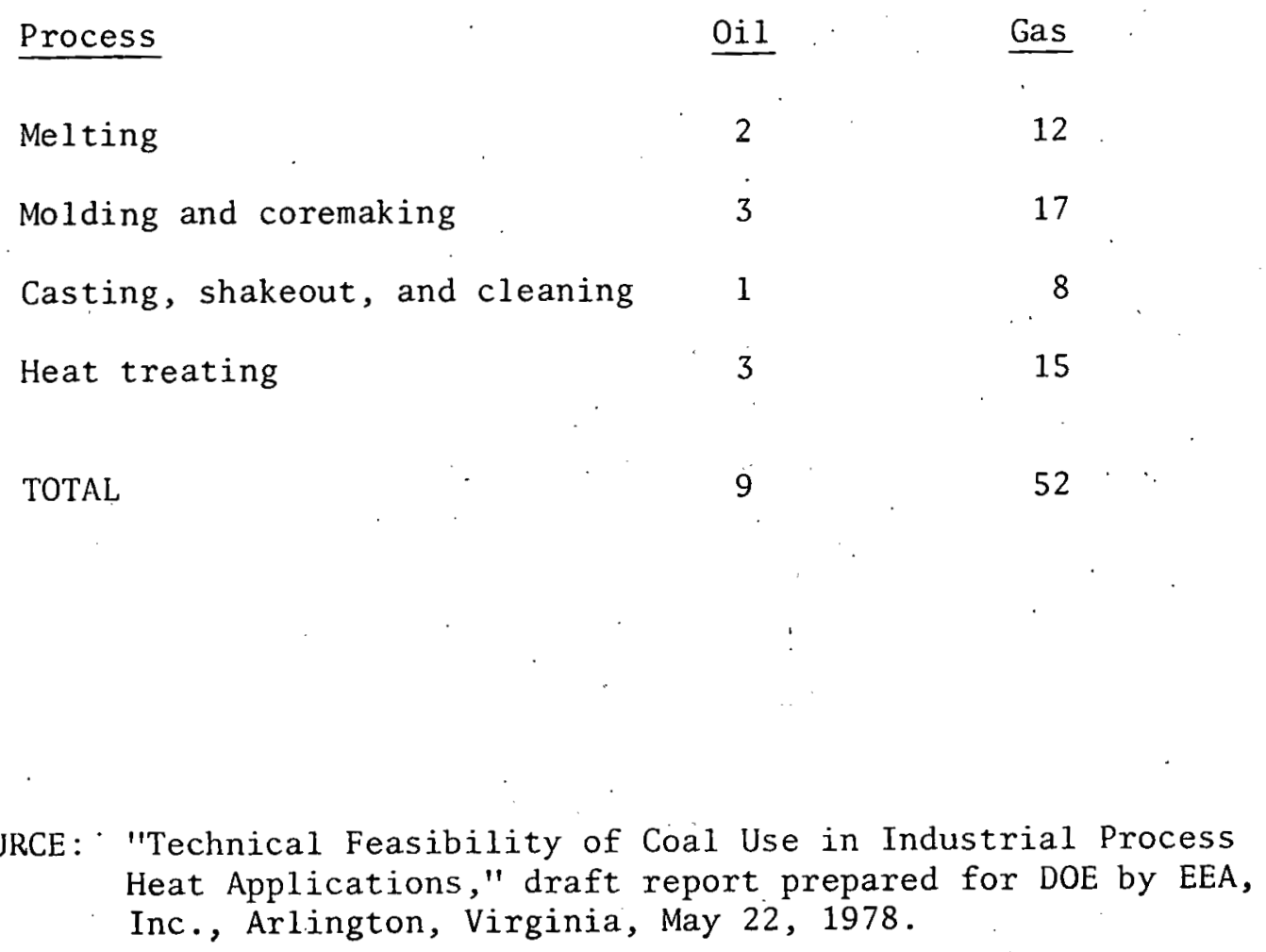

a/ Independent foundries only. 
TABLE 3.18

ESTIMATED 1974 PROCESS FUEL CONSUMPTION

IN MAJOR PROCESS HEAT APPLICATIONS

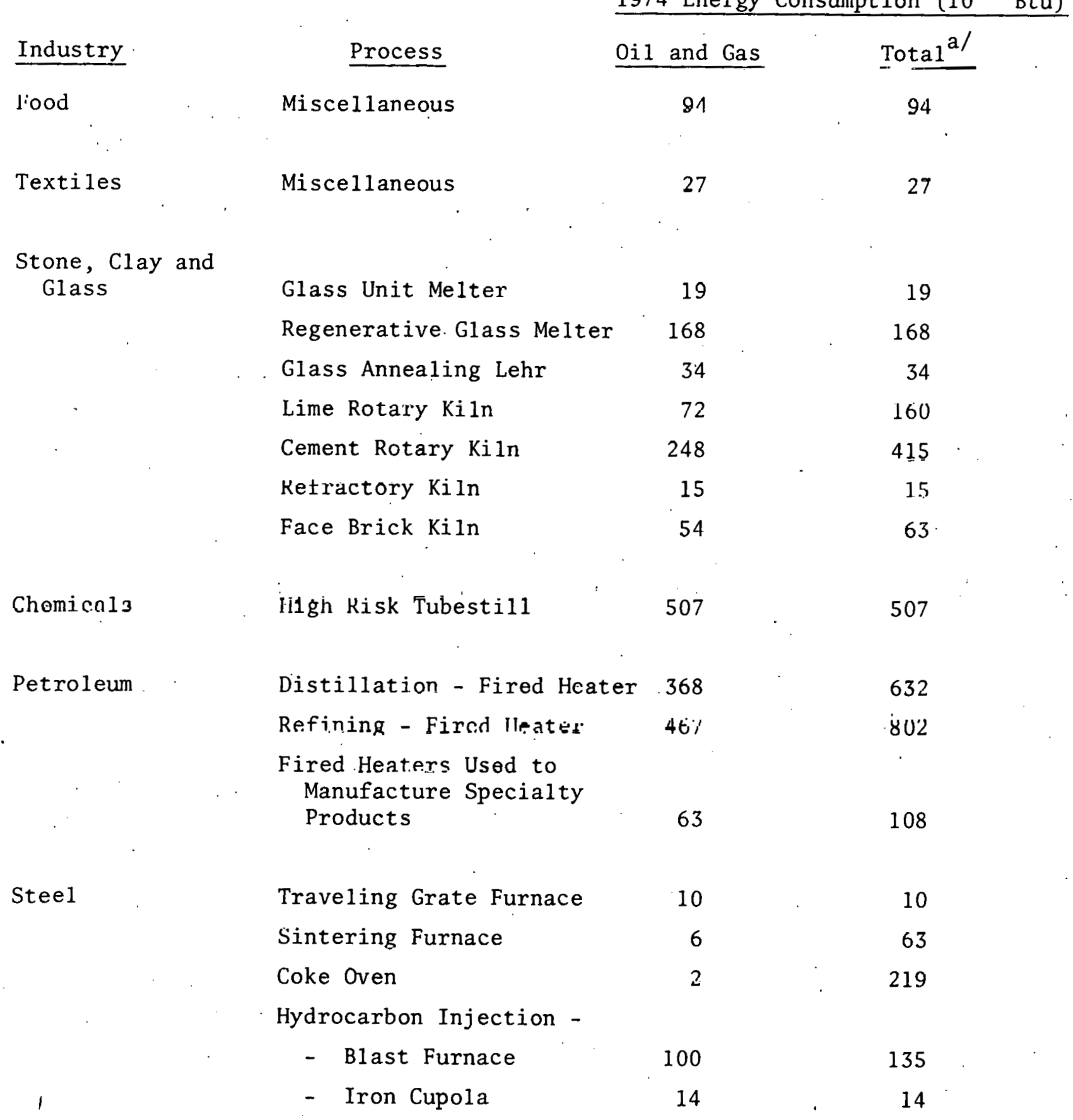


TABLE 3.18 (Continued)

ESTIMATED 1974 PROCESS FUEL CONSUMPTION

IN MAJOR PROCESS HEAT APPLICATIONS

Industry

Aluminum

Aluminum Rotary Kiln

1974 Energy Consumption $\left(10^{12} \mathrm{Btu}\right)$

Anode Pebake Oven

Oil and Gas

Total a/

Blast Furnace Stove

24

Vertical Shaft Furnace Stove 7

280

Pelletizing Grate Kiln

20

7

Open Hearth Furnace

90

20

Soaking Pit

17

115

Reheat Furnace

266

142

Heat Treating Furnace

80

350

Coremaking Oven

20

99

Heat Treating Furnace

38

38

8

8

67

67

a) Difference in total column and oil and gas columns reflects coal used or byproduct fuel use.

SOURCE: "Technical Feasibility of Coal. Use in Industrial Process Heat Applications," draft report prepared for DOE by EEA, Inc., Arlington, Virginia, May 22, 1978. 
cesses before the technical and economic attractiveness of alternative fuels was assessed. The major energy-intensive processes were grouped into 17 categories based primarily on characteristics that affect the feasibility of burning various alternative fuels. While grouping the processes will reduce the number of technical and economic assessments, it should not reduce greatly the accuracy of the data.

The following criteria were used to evaluate the technical feasibility of burning alternate fuels in industrial processes and to group process heat applications:

- Heat flux

- Heat distribution

- Fuel contaminants

- Process temperature

- Mode of material charging

- Form of fuel

- Firing rate.

The importance of these criteria, the rationale used for grouping the industrial processes, and the groups themselves are described in Section 5 .

The oil and gas consumed in the processes considered in this study equal about 64 percent of the total industrial process heat oil and gas use in 1974. These same processes consumed about 73 percent of the total fossil energy consumed in industrial process heaters. Coal and byproduct fuels account for the nine percent difference. The remaining 36 percent (or roughly 1.6 quads) of the oil and gas use was consumed in miscellaneous processes in the energy-intensive industries and in smaller, $1 \mathrm{cas}$ energyintensive industries. This unspecified energy consumption is very difficult to assign to specific processes because it was consumed in a large variety of primarily small process units. 


\subsubsection{Projected Process Heat Energy Requirements}

New process heaters represent a potentially large market in which coal or alternative fuels could displace oil and gas use. Table 3.19 shows that fired heaters in the petroleum and chemical industries and furnaces in the stone, clay and glass industries are the fastest-growing process uses.

Although the steel industry comprises several of the largest current energyconsuming process heaters, low overall industry growth probably will limit the number of new steel furnaces built between 1985 and 1990 .

These energy consumption estimates are based on the following projections: growth in industrial output, energy conservation by industry, and total enérgy demand.

\subsection{SUMMARY}

Table 3.20 summarizes the projected fuel demand in combustors that are included within the scope of this study. Roughly 45 percent of industrial fossil fuel and feedstock use is included in small boilers and process heaters. By comparison, the existing FUA covers only 12.5 percent of the projected 1990 fossil fuel and feedstock demand. The following sections will define several alternative fuel techniques that could penetrate the small boiler and process heater market as well as the technical and economic difficulties that limit fuel switching potential in those markets. 
TABLE 3.19

PROJECTED NONBOILER DEMAND IN 1974. AND 1990

$$
\left(10^{12} \mathrm{Btu}\right)
$$

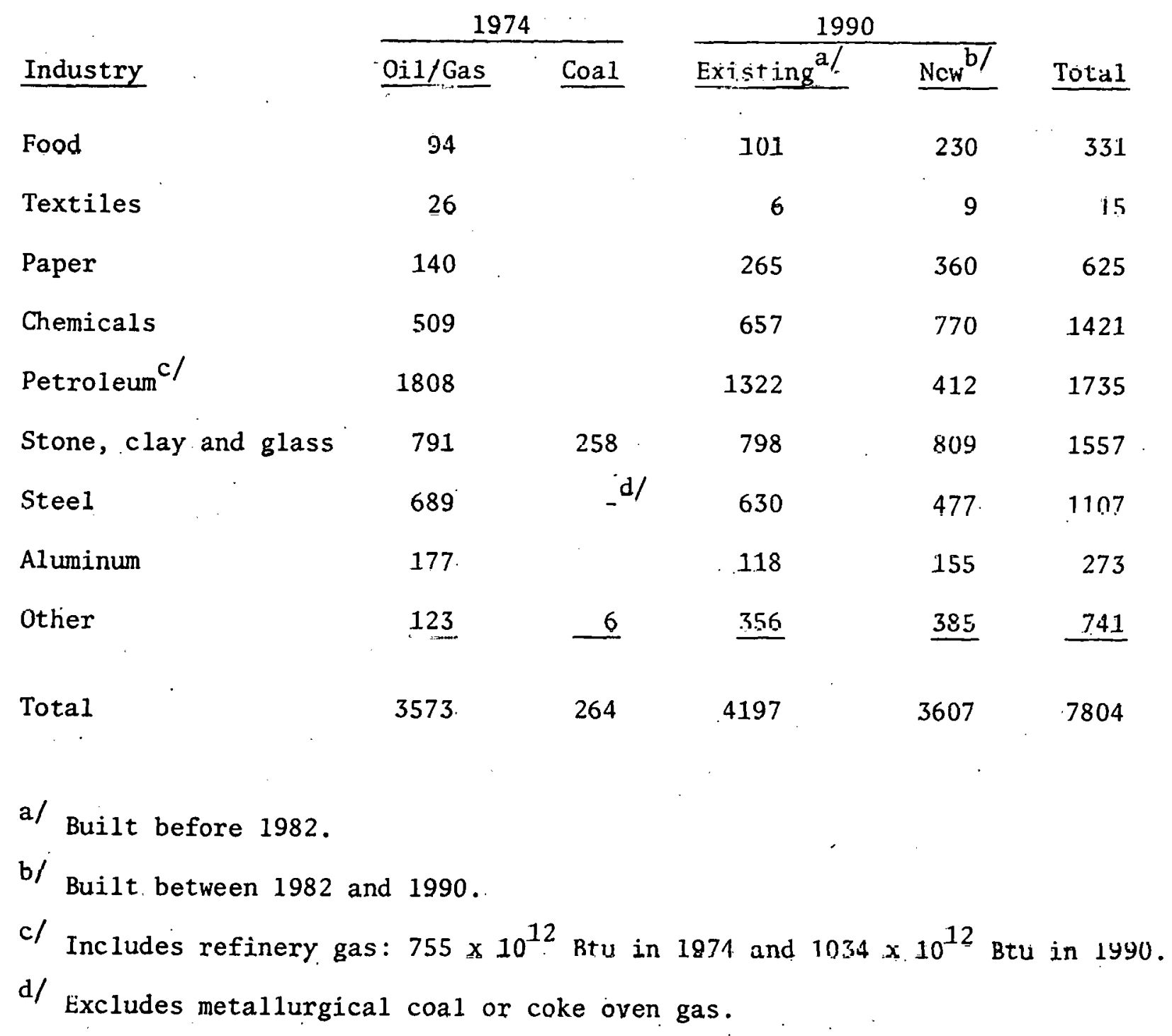

SOURCE: "Industrial Fuel Choice Analysis Model," draft report prepared for DOE by EEA, Inc., Arlington, Virginia, January 8, 1979 . 
TABLE 3.20

COMPARISON OF FUEL USE COVERED IN THIS STUDY WITH

FUEL USE TARGETED BY FUA: 1990

\begin{tabular}{|c|c|c|c|c|}
\hline \multirow{2}{*}{$\begin{array}{l}\text { Targeted } \\
\text { by FUA }\end{array}$} & \multirow{2}{*}{$\begin{array}{l}\text { Study } \\
\text { Coverage }\end{array}$} & \multirow[b]{2}{*}{ Industrial Applications } & Energy & Demand \\
\hline & & & (quads) & $(\%)$ \\
\hline & , & Boilers & & \\
\hline & & $\begin{array}{l}\text { New boilers (built between } 1982 \\
\text { and 1990) }\end{array}$ & & \\
\hline $\begin{array}{l}x \\
a /\end{array}$ & $\mathbf{x}$ & $\begin{array}{l}\text { Large }(>100 \mathrm{MMBtu} / \mathrm{hr}) \\
\text { Small }(<100 \mathrm{MMBtu} / \mathrm{hr})\end{array}$ & $\begin{array}{l}2.6 \\
0.7\end{array}$ & $\begin{array}{r}13.0 \\
3.0\end{array}$ \\
\hline & & $\begin{array}{l}\text { Existing boilers (built prior } \\
\text { to } 1982 \text { ) }\end{array}$ & & \\
\hline $\mathbf{x}$ & $\mathrm{b} /$ & $\begin{array}{l}\text { Coal-fired } \\
\text { Coal-capable }\end{array}$ & $\begin{array}{l}1.5 \\
0.1\end{array}$ & $\begin{array}{l}7.0 \\
0.5\end{array}$ \\
\hline & & $\begin{array}{l}\text { Oil/gas-fired (non-coal } \\
\text { capable) }\end{array}$ & & \\
\hline & $\mathbf{x}$ & $\begin{array}{l}\text { Large } \\
\text { Small }\end{array}$ & $\begin{array}{l}1.7 \\
1.2\end{array}$ & $\begin{array}{l}8.0 \\
6.0\end{array}$ \\
\hline & & Process Heaters & & \\
\hline & $x$ & $\begin{array}{l}\text { New (built between } 19.82 \text { and } \\
1990 \text { ) }\end{array}$ & 3.6 & 17.0 \\
\hline & $\mathbf{x}$ & Existing (built prior to 1982) & 4.2 & 20.0 \\
\hline & & Feedstocks & 5.1 & 25.0 \\
\hline $12.5 \%$ & $45 \%$ & Tota $1^{\mathrm{d} /}$ & 20.7 & $\because$ \\
\hline
\end{tabular}

a/ Boilers between 50 and $100 \mathrm{MMBtu} / \mathrm{hr}$ are covered by FUA if total plant capacity exceeds $250 \mathrm{MMBtu} / \mathrm{hr}$.

b/ Very few small boilers have prior coal capability.

c/ Liquefied gas, oil, and natural gas feedstocks. Does not include metallurgical coal.

d/ Does not include electricity, metallurgical coal, or miscellaneous products (naphtha, LBG) except where indicated in feedstocks. These products would account for an additional nine quads in 1990. 
FOOTNOTES

1. EEA, Inc., "Industrial Fuel Choice Analysis Mode1," draft report prepared for DOE, January 8; 1979. MEFS is a.DOE model used to.forecast energy demand.

2. Energy Consumption Data Base, vo1. I, Summary. Document, prepared for

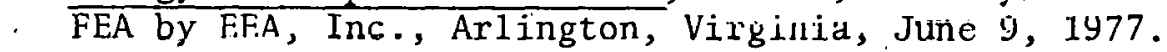

3. FEA, Office of Fuel Utilization, Major Fuel Burning Installation Coal Conversion Report, FEA C-602-S-0.

4. All ABMA data were derived from confidential sales records.

5. These data are from the NEDS computer file and are not available in printed form.

6. PEDCo Environmental, Inc., "The Population and Characteristics of Industrial/Commercial Boilers," prepared for EPA, May 1979.

7. ECDB, op. cit.

8. EEA, Inc., "Technical Feasibility of Coal Use in Industrial Process Heat Applications:" draft report prepared for DUE, May 22, 1978.

9. $E C D B$, op. cit.

10. "Technical Feasibility of Coal Use," op. cit."

11. Foundries which manufacture castings on a job-order basis for sale to others. This category does not include captive foundries which pro- . duce castings only for in-house use. 
This section characterizes 12 alternative fuel sources and sources of heat that could substitute for conventional fuels in industrial process heaters and small boilers. The following fuel and heat sources are discussed:

- Alternative fuel sources

- Low- and medium-Btu gas

- Solid solvent refined coal (SRC-1)

- Liquid solvent refined coal (SRC-2)

- Coal/oil mixtures

- Methano1

- Direct coal

- Wood waste

- Municipal waste

- Alternative sources of heat

- Atmospheric fluidized bed combustion (AFBC)

- Indirect heat

- Electrification

- Solar technology.

Each alternative fuel source or energy technology is discussed generically, apart from any specific application. The discussion of each fuel source is divided into.five subsections. The first provides an overview of the processes involved and the general characteristics of each technology. The next subsection explains the combustion characteristics that are important in determining the technical feasibility of burning the alternative fuel. Any technical issues that may constrain or delay the commercialization of each technology are highlighted in the third subsection. The fourth subsection describes the status of development of each technology, including the pilot plants that may. be planned or operational and the groups with 
interests in those projects. Finally, the range of estimated costs for each technology is shown in addition to the parameters influencing these costs.

Each cost section discusses the major factors affecting the cost of each fuel and then presents the fuel cost (in $\$ / M M B t u$ ) and the cost of raising steam (in $\$ / \mathrm{KPPH}$ ) using that technology or fuel. The fuel cost shown represents a selling price to an industrial user excluding transportation charges. The steam cost represents the total cost of producing steam from a boiler fired with the specific fuel. Steam costs may be a better basis for, economic comparisons among technologies because they inr.lure all the costs associated with burning each fuel.

The cost figures shown for each alternative technology should not be regarded as precise estimates of future costs due to the difficulties in predicting costs for technologies still being developed. As each technology is developed further, it is likely that engineering problems will be handled differently, and expected costs will change. Accordingly, the costs shown in this report should be used to indicate the relative costs of each alternative. For a more detailed explanation of the costs shown for each fuel source and energy technology, see Appendix D.

\subsection{ALTERNATIVE FUEL SOURCES}

\subsubsection{Low- and Medium-Btu Gases}

\subsubsection{Technology Description}

All coal-derived gases are produced by injecting a hot bed of coal with oxygen and steam. Medium-Btu gas (MBG), manufactured using oxygen from an oxygen plant, has heating values ranging from 200-500 Btu/scf (British thermal unit/standard cubic foot). Low-Btu gas (LBG), manufactured using air as the source of oxygen, has a heating value between 100 and 200 
Btu/scf. The lower heating value of LBG is due primarily to the nitrogen content of the air used in the process. Nitrogen, comprising approximately 80 percent of air, is carried along in the gasification process, diluting the concentration of the combustible constituents (carbon monoxide, hydrogen, and methane). Heat for the reaction is produced internally so that the steady-state operation of the process requires no fuel use other than the coal being gasified and the fuel required to produce the steam.

The efficiency of the gasification process generally varies between 65 and 92 percent. The degree of efficiency depends on the design of the coal bed and the composition of the coal being gasified. The overall efficiency of LBG is higher than that of MBG since the energy required to produce oxygen for the latter process is not consumed in the former.

There are three major types of coal beds that have been developed for gasifying coal:

- Fixed bed gasifier

- Fluid bed gasifier

- Entrained bed gasifier.

The first type of gasifier, the fixed bed, currently is used in the U.S. The bottom of the gasifier consists of a revolving grate through which steam and air/oxygen enter the bed. This grate also facilitates ash removal from the bed. Coal is loaded to the top of the gasifier. The general flow of gas is upward in the reactor; the flow of coal is down through the reactor. The fixed bed reactor generally has a'long residence time, low capacity, low temperature, and high conversion efficiency. Although the gasifier typically requires noncaking coals, eastern caking coals could be used with a stirrer in the gasifier. Lurgi, Wellman-Galusha, and Willpute produce fixed bed gasifiers.

In a fluidized bed gasifier, the steam and air/oxygen are introduced at the bottom of the bed at a sufficiently high velocity to suspend the coal par- 
ticles, thus forming an ebullient bed. The size of the feedstock is 10-20 mesh. The fluid bed gasifier has a shorter residence time and a higher temperature than the fixed bed gasifier. The conversion efficiency of the fluid bed gasifier (approximately 67 percent $^{1 /}$ ) is lower than that of the fixed bed because some unreacted coal unavoidably is carried off from the bed by the high velocity gas. Winkler gasifiers are fluid bed combustors, best suited for reactive coals such as subbituminous coals and lignite.

Entrained bed gasifiers are significantly different in design from the lixed or fluid bed gasifiers described above. In entrained bed gasifiers, pulverized coal is mixed with oxygen and steam and injected at high veloc= 1Ey into the reaction chamber. Gasifiers of this type have multiple burners positioned opposite one another on the same axis to ensure that their discharge will converge. Entrained bed gasifiers (also known as suspension flame gasifiers) operate with short residence times, high capacity, and high temperatures. The conversion efficiency of the entrained bed is estimated to be between 61 and 78 percent, ${ }^{2 /}$ depending on design and operation. These processes usually use oxygen rather than air and producc MBC. The most prevalent type of entrained bed gasifier is the Koppers-Totzek design. These gasifiers can use a wide range of coals, including untreated, highly caking coàls.

The composition of LBG and MBG varies significantly both among and within processes, depending on the type of coal fed to the gasifier and the way in which the gasifier is operated. The primary advantage of coal gas is that it enables the use of coal in furnaces designed for oil/gas. Coal gas can be cleaned of particulates, sulfur, tars, and oils to minimize contamination and degradation of furnaces and furnace products.

LBG is considered an onsite technology due to the cost of transportation and the need for preventing condensation of tars and oil that may be formed during transportation. MBG is considered an offsite technology. Due to 
its oxygen requirements, only large production of MBG will make this technology competitive; MBG facilities probably would serve an industrial park.

\subsubsection{Combustion Properties}

The distinction between gases combusted straight from the gasifier (raw coal gas) and those which are cleaned before combustion is sufficient to warrant separate consideration of their combustion properties. The differences between LBG and MBG, although significant in some areas, are not considered sufficiently significant to require a distinction when evaluating generic technical feasibility. Table 4.1 lists typical combustion characteristics and properties of both LBG and MBG.

\subsection{Raw Coal Gas}

Raw coal gas is LBG combusted directly from the gasifier without any sulfur or particulate clean-up. To maximize fuel efficiency and minimize operational problems, the gasifier usually is located close to the combustor. Raw gases are combusted at high temperatures $\left(600-900^{\circ} \mathrm{F}\right)$ and, because they do not cool, they contain heavier tars and oils that are in the vapor state. As a result of these heavier constituents and carbon particles in the gas stream, raw coal gas produces a flame more luminous than the flame produced by clean coal gas and sometimes more luminous than natural gas flames. The flame produced by raw rnal gas is typically short, characteristic of most gaseous fuels. Generally, good turndown ratios can be achieved due to the gaseous nature of the fuel.

The flame temperature of hot raw gases from coal, especially LBG, typically is lower than the flame temperature of natural gas, resulting in lower furnace efficiency. The volume of combustion products from coal gas usually is larger than that from natural gas or fuel oil. Coupled with the low radiance of the gaseous fuel flame, the conversion of a combustor to coal gas usually reduces or "derates" the productive capacity of the unit. 
TABLE 4.1

FUEL GF.S COMPOSITIONS AND PROPERTIES

(fercent)

Fue1

Natural gas

MBG-1 (Koppers-Totzex)

MBG-2 (Lurgi)

LBG-1 (Wellman-Galsher and other fixed bed) ${ }^{c}$

LBG-2 (Wink1er)
Molecular Species ${ }^{a /}$

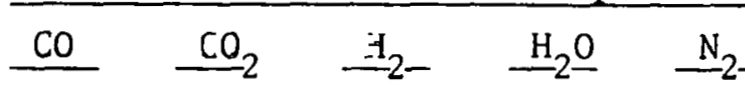

$-\quad \div$ race

0.53

ثrace

$-$

0.19

0.09

0.35

$-$

0.29

0.40

0.02

trace

$0.9 \bar{\top}$

0.01

0.01

0.01

0.01

0.09

0.47

0.03

0.57

0.01
Heating Value $\mathrm{b}^{\mathrm{b}}$ (Btu/scf)

LHV HHV

$920 \quad 1022$

$267 \quad 287$

$255 \quad 287$

$\begin{array}{lllllllll}0.26 & C .07 & 0.14 & 0.02 & 0.47 & 0.03 & - & 149 & 159 \\ 0.21 & C .07 & 0.13 & 0.02 & 0.57 & 0.01 & - & 109 & 117\end{array}$

a/ Totals across rows may not total to 1 due to rounding.

b/ Standard temperature is $60^{\circ} \mathrm{F}$.

c/ LBG compositions are for cold clean gas. Sensible heat of hot gas is about $20 \mathrm{Btu} / \mathrm{scf}$.

SOURCE: "Technical Design. Evaluation of Costs and Markets for Low- and Medium-Btu Gas from Coal in Direct-Fired Industrial Processes." Table [I-1, p. 135, prepared for DOE by EEA, Inc., Arlington, Virginia, October 23, 1979. 
The level of sulfur and particulate emissions from raw coal gas combustors depends on the sulfur in the parent coal and the particulate and heavy fractions carried from the gasifier to the combustor. The formation of $\mathrm{NO}_{\mathrm{x}}$ is greater in burning hot raw gas than in cold raw gas due to the higher flame temperatures of the former.

\subsection{Clean Coal Gas}

Clean coal gases are LBG and MBG that have had the sulfur, particulates, and $\mathrm{NO}_{\mathrm{x}}$ removed between gasification and combustion. Clean gas processing wi11 reduce the temperature of the gases to ambient temperature prior to the fuel's arrival at the combustor. In addition, this gas processing will diminish variability in the composition of the product gas resulting from short term variations in gasifier operation.

The flame produced by clean coal gas is short and non-radiant. During the gas clean-up phase, the heavy tars and oils which cause some radiation condense and are removed from the gas. Therefore, clean gases are less radiant than raw coal. gases and thus transfer energy less efficiently. A wide turndown ratio usually can be achieved with clean coal gas.

The flame temperature of clean coal gas, especially LBG, can be as much as $400-500^{\circ} \mathrm{F}$ lower than that of natural gas. As with raw coal gas, the volume of combustion products per Btu of clean coal gas is higher than that for. natural gas or fuel oil. As a result of large combustion volume, nonradiant flames, and low flame temperature, clean coal gases can cause a significant derate, more significant than raw coal gas, in the productive capacity of a furnace.

The advantage of clean coal gas is that it is clean. Sulfur, ash, and particulates are removed prior to combustion, as is $\mathrm{NO}_{x}$ formed in the gasification step. The formation of $\mathrm{NO}_{\mathrm{x}}$ in combustion also is reduced due to the low flame temperature. 


\subsubsection{Technical Issues}

Low- and medium-Btu gasification has existed for seyeral decades, and no significant technical problems remain unresolved. Some of the technical issues requiring further investigation include use of a wider range of coals, the optimization of gasifier parameters to yield higher throughputs, and lower costs. These factors, however, do not inhibit the commercialization of coal gas as an industrial fuel.

\subsubsection{Technology Status}

Coal gasifiers producing coal gas for use as an industrial furnace tuel are a commercially proven and available tochnology. Fresently, there are four types of coal gasifiers commercially available in the U.S.:

o Wellman-Galusha fixed bed

- Lurgi fixed bed

o Koppers-Totzek entrained bed

- Winkler fluidized bed.

In addition, some other types of gasifiers have been dosigned and are belng operated on a small scale.

One of the barriers, in addition to price and aval lahility, to tlie production of alternate fuels is the lack of design and operating experience. The government has initiated a "gasifiers-in-industry" program to produce data to evaluate the feasibility of gasifying coal, particularly different types of coals, and using different types of gasifiers. Entrained bed gasifiers offer greater flexibility in turndown and type of coal than do fixed and fluidized bed gasifiers; therefore, the R\&D presently focuses on developing entrainer bed gasificrs. The lead time for the design, construction, and start-up of LBG gasifiers ranges from two to three years.

Presently, there are 40-50 Wellman-Galusha ${ }^{3 /}$ gasifiers in the world, including 15 in the U.S. There are 60-70 Lurgi $4 /$ gasifiers and six Winkler 
gasifiers in the world, none of which are in the U.S. There are 50 KoppersTotzek $5 /$ gasifiers presently operating..

\subsubsection{Technology Cost}

The operating and capital costs of the gasification and gas cleaning equipment constitute the major cost factors in MBG and LBG production. The cleaning equipment removes tars, oils, and sulfur which can be sold to reduce operating costs. Significant economies of scale are realized with increased plant capacity. The cost of feedstock coal is another important cost component.

The costs for onsite LBG plants from studies by Radian, Gilbert/Commonwealth, and Brewer, et al, are shown and referenced in Table 4.2. These costs are for cold clean gas produced in various sizes of fixed bed gasifiers. The costs reflect the gasifier economies of scale.

The steam costs are estimated using a new natural gas-type boiler with no pollution control equipment. For the sample economic comparisons, MBG was used at a cost of $\$ 4.34 / \mathrm{MMBtu}$. This cost is based on DOE estimates (referenced in Table 4.2) for the MBG produced from a plant using the commercial Lurgi technology and eastern coal. The plant is assumed to produce $50 \times 10^{6}$ MMBtu of MBG per year at a 75 percent conversion efficiency and 90 percent capacity utilization.

\subsubsection{Solid Solvent Refined Coal}

\subsubsection{Technology Description}

Solid solvent refined coal (SRC-1) is produced by blending pulverized coal with a coal-derived solvent. The coal solvent (40 percent coal to 60 percent solvent) slurry is pumped in the presence of hydrogen at a pressure of 1500 pounds per square inch over atmospheric pressure (psig) through a gas-fired preheater. After being heated to $750-780^{\circ} \mathrm{F}$, the slurry flows 
TABLE 4.2

COAL GASIFICATION COSTS

P1ant

Production

Rate

Source

(MMBtu/hr)

75

200

DOE ${ }^{d /}$

6342
22

78

104

$2.86-3.45$

$(3.02-3.61)$

$7.54(8.68)$

$3.83(4.71)$

Gilbert/

Commonwealth ${ }^{\mathrm{c} /}$
Boiler

Size

(KPPH)

Steam Cost

(1978 \$/MMBtu)

175

$(8.40-8.73)$

325

$(6.54)$

50

9.54

175

5.08

$3.91-4.62$

175

$3.91-4.62$

325

5.76

a/

William C. Thomas, "Synfuels from Coal as Emission Contro1 Techniques for Industrial Boilers," prepared for EPA by Radian Corporation, Austin, Texas, January 1979.

b/ Brewer, Rucker, and Moore, "Economic Evaluation of ATC/Wellman Incandescent Two Stage LPG Gas Producer," presented at Coal Technology Converence $19 \% 8$, Houston, l'exas:

c/ "Fixed Bed Coal Gasification for Production of Industrial Fuel Gas," prepared for ERDA by Gilbert/Commonwealth, July 1977.

d/ Based on interim costs used in analysis of National Energy P1an II, A Report to Congress, prepared by U.S. Department of Energy, May 1979. 
into a vessel allowing sufficient time for the coal to dissolve in the solvent. In the dissolving step, the coal molecules are broken down, freeing organic sulfur compounds. This reaction is exothermic (heat producing), raising the temperature of the mixture to about $850^{\circ} \mathrm{F}$.

The coal solution then is cooled to $600-650^{\circ} \mathrm{F}$, and the pressure is reduced to 200 psig. Gases are flashed (released) and separated from the liquid for recycling back to the slurry charge. The liquid is filtered to separate it from the undissolved matter which then is distilled to recover the solvent and to produce an additional side stream of distillate liquid. The remaining liquid is $S R C$, which can be solidified at about $355^{\circ} \mathrm{F}$.

The energy efficiency of the conversion plant is expected to be approximately 65 percent. When made from high sulfur bituminous coal, SRC-1 contains approximately 0.15 percent ash and 0.84 percent sulfur on an asreceived basis. SRC-1 has a higher heating value of $15,700 \mathrm{Btu} / \mathrm{lb}$, melting point of $350^{\circ} \mathrm{F}$, bulk density of $351 \mathrm{~b} / \mathrm{ft}^{3}$, and a hardgrove index (measure of hardness) of 180 .

The principal advantage of SRC-1 over coal is that it contains smaller amounts of ash and sulfur. The smaller ash content prevent's the fouling/ slagging of combustors and, therefore, would potentially increase the availability of each boiler. This lower ash content also makes the use of SRC-1 possible in some combustors in which coal use is infeasible because of the quantities of ash produced during combustion. The lower sulfur content eliminates the need to install a'flue gas desulfurization (FGD) system. Due to its low ash and sulfur content, SRC-1 use in new and existing units complies with New Source Performance Standards (NSPS). Whether SRC- 1 is cost effective with competing technologies such as direct coal combustion with FGD, however, remains to be determined. 
SRC-1 has been transported in open-top hopper rail cars. A Latex coating must be sprayed to minimize windage loss. SRC-1 has been handled by conventional unloading and conveying equipment.

\subsubsection{Combustion Characteristics}

The combustion characteristics of SRC-1 were observed in an 18-day test at Georgia Power's Plant Mitchell facility. SRC-1 produces a long, lazy, radiant flame that is a combination of a pulverized conl and a fuel oil flame; the SRC-1 flame can be characterized as a hybrid between a liquid and solid diffusion flame. Initially, SRC-1 burns similarly to No. 6 oil, with vapors being distilled from each particle and igniting immediately as they travel from the core of the particle. After all the volatiles are driven off and combusted, the flame becomes a solid diffusion flame similar to that produced from coal burning.

An SRC-1 flame is relatively stable but not highly controllable; thus, even heat distribution may be difficult to achieve. The minimum size of a burner combusting pulverized SRC-1 must be approximately $25 \mathrm{MMBtu} / \mathrm{hr}$, and it must be water-cooled due to the low melting temperature $\left(350^{\circ} \mathrm{F}\right)$ of the solid.

The burn tests of SRC-1 indicate that the ash contained in the fuel is composed of 77-89 percent carbon. This high carbon content minimizes the amount of ash adhering to walls and tubes, and the ash's light weight prevents accumulation of dust in the furnace. Although this high carbon content is beneficial, it could be reduced somewhat to decrease unburned carbon loss. With suitable burner adjustments, the producers of SRC-1 expect that the carbon in the ash could bc reduced lo approximately 75 percent, an amount still sufficient to prevent adherence and accumulation of ash. During the burn tests, the firebox and superheater sections of the boiler were relatively clean and required no sootblowing; in aduition, little bottom ash was collected. These observations indicate that the SRC-1 
ash particles are light and not corrosiye or exosiye and thus may reduce the possibility of checkerwork plugging and refractory wall slagging in industrial combustors. An effective electrostatic precipitator (1ow resistivity of high carbon ash) or a baghouse, however, would be needed to control particulate emissions. Soot formation is not considered to be a problem in SRC-1 combustion.

\subsubsection{Technical Issues}

The major technical areas to be addressed in developing designs for commercial facilities are:

- Solids separation

- Primary reactor scale-up

- Equipment life, maintenance, and operating difficulties.

None of these areas are viewed as barriers to the construction and operation of commercial facilities. Since SRC-1 use has been demonstrated sufficiently at the pilot plant stage, engineers are able to define potential problems and suggest feasible and effective solutions. Much of the remaining uncertainty involves scaling up to commercial size a unit operation that which has been proven on the pilot plant scale. The following details the major technical issues listed above.

Solids Separation. Solids separation is the key step in the SRC-1 process. At the pilot plant scale, the process generally used filtration at high temperature and moderate pressure to separate ash from the SRC-1 product. Four filtration systems have been tested at the pilot plant stage: two rotary drum filtration units and two pressure leaf filtration units. All have required significant amounts of filter aid precoat, a1though the filter aid required for leaf filtration has been greatly reduced from that required in early experience. Efforts to improve filtration and to develop other mechanical systems such as hydroclones, centrifuges, and combined systems are continuing. There are also several non-mechanical 
systems with considerable promise. Present engineering studies are being conducted so that either a continuous de-ashing system or a pressure leaf filtration system can be installed in a demonstration plant.

Primary Reactor Scale-up. Scale-up of the primary reactor is a significant technical challenge. Flow patterns of a three-phase (gas, liquid, and solid) mixture through the reactors, uncertain reaction rates, catalytic effects of the ash, and other factors make it difficult to predict the performance of a large-scale reactor. These problems, however, are typical of reactor design problems that have been resolved by the petroleum industry in large catalytic hydrocracking units. A continuing research program at the pilot plant level will improve the reliability of designs in this area.

Equipment Life, Maintenance, and Operating Difficulties. The abrasive nature of slurries produced in the SRC-1 process can cause rapid wear and equipment malfunctions in components such as heat exchangers, slurry pumps, pressure letdown valves, and flow control valves. This problem has been identified at the pilot plant, and effective improvements have been achieved by the use of special valve seats, pump impellers, and other fittings. Work at the pilot plant continues to provide further solutions to these problems.

\subsubsection{Status of the Technology}

The SRC-1 process has been developed at two pilot plants. A six ton per day (TPD) pilot plant was completed in 1973 at Wilsonville, Alabama, under the sponsorship of the electric utility industry, initially through the Edison Electric Institute (EEI) and later through the Electric Power Research Institute (EPRI). A 50 TPD pilot plant later was completed at Ft. Lewis, Washington (near Tacoma), under the sponsorship of the U.S. Energy Research and Development Administration (ERDA). Operation of the Wilsonville facility is continuing for the purpose of testing new ash separation 
processes, investigating fundamental principles of reaction chemistry, and attaining process optimization.

In an effort to promote alternate energy technologies, DOE contracted with Southern Company Services, on July 10, 1978, for a four-part demonstration program to prove the technical, economic, and commercial feasibility of SRC-1. The SRC-1 contract with DOE is intended to result in the full commercialization of the technology by the late 1980's. Under Phase 1 of the contract, the team will prepare a detailed design of a 6000 TPD demonstration plant to be built on the Green River near Newman in Davies County, Kentucky. The demonstration. will be replicated, without further scale-up of components, to a multi-module commercial plant consisting of five modules with a capacity to process approximately_30,000 TPD of coal.

\subsubsection{Technology Cost}

The total cost of SRC-1 production is distributed fairly evenly between capital, operating, and coal feedstock costs. Since no commercial plants are in operation, cost estimates are relatively uncertain. Larger offsite production plants will be favored by economies of scale.

The cost estimates of Wheelabrator-Frye and Radian are presented in Table 4.3. The steam costs assume that the SRC-1 is fired in a new pulverized coal boiler. Since SRC-1 estimated costs have increased recently, two cost estimates were used for the SRC economic analysis in Section 6 . One estimate reflects the higher capital costs now expected. The lower $\$ 4.06 /$ MMBtu estimate is based on capital and O\&M figures shown in the Radian Corporation report for a plant producing $168 \times 10^{12} \mathrm{Btu} / \mathrm{yr}$ of SRC-1 at 70 percent conversion efficiency and 80 percent capacity utilization. $6 /$ This $\$ 4.06$ figure used in the economic analysis in Section 6 is higher than the two original estimates shown in Table 4.3 for two reasons: the annualized fuel cost stream is higher, and the original estimates excluded the cost of transporting the SRC-1 to an industrial end-user. The higher $\$ 4.85 / \mathrm{MMBtu}$ 
TABLE 4.3

SRC-1 . COSTS

Plant

Production

Rate

Source

$\underline{(\mathrm{MMBtu} / \mathrm{hr})}$

$\operatorname{Radian}^{\mathrm{a} /}$

Air Products $b /$

Radian $c /$
24,042

27,803

24.042
Adjusted

Fuel Cost

(1978 \$/MMBtu)

3.45

3.28

$4.06-4.85$
Boiler

Size

(KPPH)

325

325

5.39

325

$5.49-6.29$

a/ William C. Thomas, "Synfuels from Coal as Emission Control Techniques for Industrial Boilers," draft report prepared by Radian Corporation for EPA, January 1979.

b/ A.P. Flask and J.A. Pryor (Air Products/Wheelabrator Frye), "SRC Solids; Boiler Fuel and Building Block," paper presented at the Sixth Energy Technology Conference, Washington, D.C., February 1979.

c/ Costs used in economic analysis in Section 6. Radian's costs were adjusted further to include transportation costs and a highcr fuel cost stream. The second estimate also includes a higher capital cost estimate. 
TABLE $4.4^{\circ}$

COMPOSITION OF SRC

SRC-1 \begin{tabular}{lll} 
Parent & Parent \\
Coala/ & SRC-2 & Coal ${ }^{\mathrm{b} /}$ \\
\hline
\end{tabular}

Ultimate analysis (\%)

Carbon

87.3

80.4

86.6

72.2

Hydrogen

5.8

5.6

8.38

5.0

Nitrogen

1.7

1.6

1.12

1.4

0.8

4.0

0.28

3.6

Ash

c/

0.008

10.5

Oxygen

4.4

8.4

3.63

7.3

Higher heating value (HHV) (Btu/1b)

15,800

14,480

17,040

13,150

API gravity $\left(60^{\circ} \mathrm{F}\right)$

N/A

N/A

8.3

Viscosity SUS $\left(140^{\circ} \mathrm{F}\right)$

N/A

N/A

35.6

\footnotetext{
a/ Western Kentucky bituminous.

b/ Kentucky bituminous.

c/ Moisture- and ash-free analysis.
}

SOURCE: SRC-1 composition derived from Babcock and Wilcox Company, and Gilbert/Commonwealth. SRC-2 composition derived from KVB, Inc. 
estimate assumes that capital costs are 70 percent higher than those in the $\$ 4.06$ estimate.

\subsubsection{Liquid Solvent Refined Coal}

\subsubsection{Technology Description}

The liquid solvent refined coal (SRC-2) process is a modification of the SRC-1 process. SRC-2 starts with the blending of a recycled coal/coal liquid slurry into the incoming pulverized coal stream. The resulting slurry then is heated and reacted with hydrogen at about $875^{\circ} \mathrm{F}$ and 2000 psig pressure. As the conal molecules are broken duwn in this reaction, organic sulfur and 1ight hydrocarbons are released and evolved as gases.

The liquid product of this step then is separated by vacuum distillation to produce the liquid fuel products and the heavy bottoms that are gasified to produce hydrogen for the process. Vacuum distillation also is used to separate the ash from the fuel. This process is estimated to be about 65 percent efficient, i.e., 65 percent of the energy in the coal remains in the product fuels.

The product slate can be altered by changing the operating conditions. Typically, 75 percent of the liquid product mix can be used for low sulfur industrial fuel, 19 percent for refinery feedstocks, and six percent for residential and commercial heating oil. This study will consider only the percentage used for low sulfur industrial fuel. The composition of SRC-2 is 1 isted in Table 4.4. The low sulfur (0.26 percent) and ash $(0.008$ percent) contents should be noted. The nitrogen and oxygen contents are relatively higher than in petroleum-based fuel oils.

The reduced ash and sulfur composition of SRC-2 alleviates operational and aix pollution problems experienced with raw coal combustion. SRC-2 is considered to be a low sulfur, low ash fuel; it usually does not require the 
installation of an FGD unit. The liquid form of the fuel also allows the use of coal-derived energy in equipment which does not have the capability of using coal directly.

\subsubsection{Combustion Characteristics}

Several test burns of SRC-2 have been conducted, including a test by Consolidated Edison of New York in a large utility boiler. In general, SRC-2 burns with a long, luminous flame similar to the flames established by No. 2 or No. 6 fuel oil. The handling systems and burners used for SRC-2 are similar to those used for fuel oil and are subject to the same burner size and control constraints.

Particulates, sulfur, and unburned hydrocarbons have not been a problem in SRC-2 burn tests. However, $\mathrm{NO}_{\mathrm{x}}$ emissions in these tests have been higher than $\mathrm{NO}_{x}$ emissions usually resulting from fuel oil combustion. Measures to reduce $\mathrm{NO}_{x}$ emissions, specifically two-stage combustion, have produced "smoky" flames, also an undesirable environmental characteristic. The high NO $x$ emissions are primarily a result of the higher composition of nitrogen in the fuel. Mixtures of SRC-2 with petroleum fuel oil, which is lower in fuel nitrogen, have produced environmentally acceptable emission rates. ${ }^{N O}{ }_{x}$ emissions also are increased if the air for combustion is preheated, a common energy conservation procedure.

For the purposes of this study, the combustion characteristics of SRC-2 will be considered similar to residual (No.6) fuel oil when assessing the technical feasibility for SRC-2 use.

\subsubsection{Technical Issues}

Since the SRC process is related to the Bergius process developed in Germany in the early 1900 's, the chemistry is well known. However, as with any emerging process, there are areas which require further investigation and development. These areas are: 
- Reactor scale-up

- Erosion/corrosion of process equipment.

Although not trivial, these issues are not expected to pose major technical barriers to the further development of SRC-2 to a commercial process. These areas are being examined in the pilot plant and will continue being investigated in the demonstration plant. A more detailed discussion of these issues follows below.

Primary Reactor Scale-Up. It is difficult to understand the gas, liquid, and solid flows in the dissolver unit due to the uncertainty about the reactions occurring in the vessel. Experimental work at the pilot plant will increase the accuracy of the design models and reduce the uncertainty in the larger demonstration plant unit.

Erosion/Corrosion of Process Equipment. The chemical and physical nature of the materials handled in the process has caused both erosion and corrosion of process equipment. This problem has been especially acute in valves, pumps, heat exchangers, and the vacuum distillation unit. Although progress has been made, further work is required to insure the reliable operation of a commercial facility. This effort will involve finding the proper materials for the equipment and redesigning certain pieces of equipment to minimize destructive situations.

\subsubsection{Technology Status}

The bulk of the development work on SRC-2 has been conducted at a 30 TPD pilot plant at Ft. Lewis, Washington, by the Gulf Mining and Resources Company (a subsidiary of Gulf Oil) under contract to nחE. The Ft. Lcwis facility originally was constructed to produce SRC-1 and was converted to SRC-2 in early 1977. So far, the facility has used only eastern bituminous coals, primarily from Gulf's resources in western Kentucky, as feed coal for the process. The performance of the process using other types of coal 
is unknown. Experimental work is continuing at the plant to resolve some of the existing technical problems and to optimize the process.

In July of 1979, Congress decided to provide funds for the design phase of a project to construct a 6000 TPD demonstration plant, probably to be located near Morgantown, West Virginia. The construction of a full-scale commercial facility would not require any development work other than the demonstration plant since it will consist of five modules similar in size and operation to the demonstration plant. The capacity of the commercial plant is expected to be about 30,000 TPD of coal, which would produce 80,000 barrels (bb1) of liquid products.

\subsubsection{Technology Cost}

The costs of an SRC-2 production facility are uncertain since there currently are no commercial SRC-2 operations. Estimates indicate that fuel and capital costs will constitute about 75 percent of fuel production costs. Large offsite facilities will be favored by economies of scale. Many of the factors affecting costs in the production of SRC-2 1ie in the results of the operation of the demonstration plant. Solutions to problems encountered in the pilot plant and problems anticipated in the demonstration plant may or may not prove adequate. If the solutions are not adequate, the costs of SRC-2 could rise rapidly. The primary areas of concern are the material requirements of the liquids processes and refining equipment. If these units require high-grade stainless steels to perform adequately, their cost could increase more than twofold, in addition to the availability problems encountered with some grades of high quality alloys.

An estimate of SRC-2 costs by Air Products/Wheelabrator-Frye is shown in Table 4.5. The steam cost assumes that the 1iquid SRC-2 is fired in a new residual-oil type boiler without any pollution control equipment. 
TABLE 4.5

SRC -2 COSTS

Plant

Production Adjusted

Rate Fuel Cost

Boiler Size

Steam Cost

Source

(MMBtu/hr)

(1978 \$/MMBtu)

(MMBtu/hr)

(1978 \$/KPPH)

Air P
$\mathrm{DOE}^{\mathrm{b} /}$

23,072

3.78

50

5.21

175

5.17 .

14,967

$3.99-5.14$

50

$5.50-7.08$

a/ A.P. Flask and J.A. Pryor (Air Products/Wheelabrator. Frye), "SRC Solids, Boiler Fuel and Building Block," paper presented at the Sixth Energy Technology Conference, Washington, B.C., February 1979.

b/ Based on interim costs used in analysis of National Energy Plan II, A Report to Congress, prepared by U.S. Department of Energy, May 1979: The higher estimate reflects recent higher capital cost estimates. 
Due to recent increases in SRC-2 cost estimates, two costs for SRC-2 were used in the sample economic comparisons, one based on existing DOE data and one on which the same capital costs. were increased by 70 percent. The older estimate is $\$ 3.99 /$ MMBtu based on an average cost to produce coal liquids from three processes now under development: SRC-2, H-Coal, and Exxon Donor Solvent (EDS). The plant is assumed to produce $118 \times 10^{6} \mathrm{MMBtu} /$ year at a 70 percent conversion efficiency and 90 percent capacity utilization. The higher estimate is $\$ 5.14 / \mathrm{MMBtu}$.

\subsubsection{Coal/Oil Mixtures}

\subsubsection{Technology Description}

Coa1/oil mixtures (COM) have been developed as a hybrid fuel to enable the use of significant amounts of coal in processes otherwise incapable, without major renovation, of using solid fuels. To form COM, finely pulverized coal (200 mesh) is blended with residual oil in a homogeneous slurry. The coal composition of the mixture usually varies, between 20 and. 50 percent, depending on process requirements. When heated, this mixture shares many characteristics with residual oil and can be pumped using similar equipment. At higher coal compositions, however, the mixture behaves less like oil and is more difficult to handle. This can increase costs and the potential that the fuel will be incompatible with specific processes.

If $\mathrm{COM}$ is allowed to stand, the coal particles in the mixture settle. Since a nonhomogeneous mixture can cause problems in storage, pumping, and combustion, the mixture must be agitated constantly or constituents must be added to the mixture to increase the ability of the coal to remain in suspension, thus maintaining homogeneity.

Varying types of additives are used to maintain the coal in suspension. The most prevalent type of additive contains about six percent water and an 
emulsion agent. (These additives displace oil rather than coal.) other suspension processes involve a surfactant which constitutes only about one percent of the mixture.

COM can be produced both onsite and offsite. Use of an offsite facility requires trains, trucks, or barges to transport the COM. The decision to produce COM onsite or offsite depends on several economic-related factors which are discussed at the end of this technology section.

\subsubsection{Combustion Properties}

Since COM is a slurry mixturc in which the coal particles are hcld in suspension, the more homogeneous the mixture, the better the fuel performs both in combustion and in handling. Residual, rather than distillate, oil musl be used since the viscosity of distillate oil is too low to maintain the coal particles in suspension. Like residual oil, COM must be heated to $150-170^{\circ} \mathrm{F}$ to be pumped and to about $220^{\circ} \mathrm{F}$ to be sent to the burner. The heating value of the fuel is somewhat lower than that of residual oil due to the lower heating value nf coal on a Btu/volume basis.

The combustion characteristics of COM with coal fractions varying between 20 and 50 percent resemble the comburtion charactcristics of the parent fuels. A long, luminous flame resembling a residual oil flame is established near the burner; as the lighter fractions of the fuel burn off, leaving the solid coal particles, the flame becomes more like a pulverizer coal flame. The length of the flame varies between that of a residual oil flame and a coal flame, depending on the coal composition of the mixture and the conditions under which combustion occurs. It is eștimated that the minimum rate of heat input from a single burner would vary from $20 \mathrm{MMBtu} / \mathrm{hr}$ with a low percentage of coal to $40 \mathrm{MMBtu} / \mathrm{hr}$ with a high percentage of coal. The higher the firing rate, the more stable the flame will be. There should be no instability or variabillty from the fuel if it is handled properly, but the flame pattern will change if the mixture is allowed to settle or agglomerate. 
Because COM requires a larger volume for complete combustion than either gas or oil require, a furnace originally designed for oil/gas firing may undergo derating (burn fewer Btu's per unit time than the design capacity). The extent of derating can vary from one to 10 percent, depending on many factors. Insufficient burn tests have been conducted to facilitate systematic evaluation of the derating process.

The ash and sulfur emissions from the combustion of COM will vary directly with the amount and type of sulfur and ash that are in the coal and residual oil that make up the mix. Nevertheless, these emissions almost always will be high enough to raise concerns about ash deposition and sulfurinduced corrosion. NO formation in COM combustion is much the same as in combustion of the parent fuels; the mixture is somewhat higher than fuel oil and somewhat lower than coal on a per Btu basis.

\subsubsection{Technical Issues}

There are no major engineering problems. which seriously impede the use of COM. However, there are two problems which make the use of COM somewhat difficult and costly: fuel handling and system wear problems.

The solid particles contained in COM present several problems. If the fuel is allowed to sit, the coal particles can settle or agglomerate, making suhsequent handling difficult and causing uneven combustion. Alternative$1 y$, if the additives in the mixture are sufficient to hold the mixture in suspension, the fluidity of the mixture could be reduced greatly after long periods of standing.

The severity of erosion in pipes and pumps resulting from fuel handing and the effert.s of this erosion on plant operation are unknown. Nevertheless, pumps designed to handle abrasive fluids will be required in the COM plant. In addition, the piping configuration of the plant will have to be evaluated and possibly redesigned to minimize bends and low spots that cause erosion and particle sedimentation. 


\subsubsection{Technology Status}

COM is not a new technology; research was initiated several decades ago and still is continuing. Two projects which yielded significant data on the characteristics of COM are the Florida Power Corporation/Dravo ${ }^{7 /}$ and the General Motors ${ }^{8 /}$ projects. Although both projects provided valuable information on handling and combustion of COM, neither project was operated at full-scale commercial levels. Furthermore, there have been no tests that have burned COM for prolonged periods of time. Due to this lack of data, questions persist about COM system wear (erosion/corrosion), derating, reliability (plugging), fucl handling (scttling), and emissions.

Several projects are underway to test COM performance in commercial boiler operations; only one currently is testing COM performance in a process heater. The major boiler research effort is a long-term test of a 50 percent COM mixture prepared onsite. The test is being performed by the Acurex Corporation on an $80,000 \mathrm{PPH}$ boiler that was designed for only gas and oil firing. ${ }^{9 /}$ A major industrial furnace test is being conducted by Interlake, Inc., in which a 50 percent COM is being used as a hydrocarbon injectant in a blast furnace that processes 1200 tons of metal per day. The COM used in the Interlake project also is prepared onsite.

Presently, there are no commercial plants using COM. Although there are no major unresolved engineering problems constraining this technology, it is considered unproven due to remaining questions relating to burn tests.

\subsection{Lead Time Issues}

The lead time to commercialization of a COM facility depends on seyeral variables, primarily whether the COM is preparcs onsilu ur officite. If COM is produced onsite, the lead time is projected to be two to three years, compared to a lead time of one to two years for conventional oil. If COM is prepared offsite, the combustor modifications at the facility could bc implemented in six months to one year. The major lead time constraint 
would be the development of COM producing facilities. DOE currently is compiling a list of COM producers, but production capacity in the next five to 10 years is unclear.

\subsubsection{Technology Costs}

Technology costs for COM depend on a variety of factors. Since COM is most economically viable in the retrofit market, technology costs and the factors affecting these costs will be examined in existing combustors. Regardless of how the mixture is produced, equipment changes will be required to burn COM in combustors previously designed to fire only conventional fossil fuels. These costs have been estimated at around $\$ 300,000-500,000$ (\$0.10-0.20/MMBtu) for a $100 \mathrm{KPPH}$ boiler. System response, i.e., increased downtime and/or derating, also will contribute to the cost of burning COM. The annualized per MMBtu conversion costs may double if 20 percent derating occurs. $10 /$

The cost of preparing and transporting COM depends on whether the mixture is produced onsite or offsite. This discussion does not provide either definitive cost estimates or the precise combustor size dictating the economic feasibility of onsite or offsite production, but rather provides a range of cost estimates to illustrate the magnitude of that range and the factors that affect costs. Table 4.6 illustrates the conversion costs for a $500 \mathrm{KPPH}$ boiler burning COM produced offsite and a $100 \mathrm{KPPH}$ boiler burning COM produced onsite. In the case of the onsite preparation, the table shows that COM preparation and fuel handling contribute over half of the total capital costs; actual boiler retrofit costs comprise a very small percentage of total costs. Therefore, items that affect COM preparation and handling, i.e., use of wet or dry grinding, coal type, and storage, will affect significantly the economics of COM use in onsite applications.

For the offsite case, the table illustrates that the total conversion cost, $\$ 303,000$, is small relative to major boiler investments. The operation 
TABLE 4.6

REPRESENTATIVE COSTS OF CONVERSION TO COM FOR

TWO SAMPLE SIZE UNITS

$(\$ 19.78)$

$\underline{\text { Equipment }}$

$50.0 \mathrm{KPPH}$ Boiler

$100 \mathrm{KPPH}$ Boiler

$=$ Onsite COM offsite COM

Coa1 receiving, storage, reclaim

$$
350,000
$$

COM prcparatioì

$1,3(1), 000$

Stack gas cleanup

500,000

160,000

Boiler retrofit.

$$
50,000 \text {. }
$$

$25,0.00$

Plant facility

165,000

14,000

Plant utility

235,000 .

20,000

Total construction

$2,600,000$

220,000

Initial coal and sodium

bicarbonate requirements

230,000

36,000

Indirect charges ${ }^{a /}$

590,000

47,000

TOTAL INVESTMENT

$3,420,000$

303,000

a/ Interest, working capital.

SOURCE: Arthur McKee \& Company, "Coal-Oil Mixture (COM): A Preliminary U.S. Market Study," First International Symposium on COM Combustion, St. Petersburg, Florida, May 1978. 
and maintenance (O\&M) cost (including fuel) of using COM will be the primary determinant of COM economics. For a $100 \mathrm{KPPH}$ boiler, the O\&M costs of burning COM generated offsite can be characterized roughly on a percentage basis as follows:

$\begin{array}{lc}\text { Cost of COM } & 86 \% \text { of total O\&M } \\ \mathrm{NaHCO}_{3} & 6 \% \\ \text { Variable O\&M costs } & 5 \% \\ \text { Fixed O\&M costs } & 1 \% \\ \text { Ash disposal } & 1 \% \\ \text { Power } & 1 \text { less than } 1 \%\end{array}$

The major consideration in reviewing COM costs is the cost of the mixture itself. Even in an onsite facility, the cost of coal and oil used to produce COM accounts for over 80 percent of the annual O\&M costs.

A COM preparation plant is subject to significant economies of scale. Both annual operating and capital costs per barrel of COM produced decrease significantly as the production capacity of a facility increases. This factor favors large offsite COM production facilities. However, the costs of feedstock coal and oil constitute the major fraction (over 70 percent) of total COM production costs. Since COM is a liquid fuel in which coal is substituted for residual oil, the economics of COM improve as the price diffcrential between residual oil and coal increases.

Table 4.7 reflects the plant economies of scale in the original cost estimates presented in COM studies by the Pittsburg Energy Research Center (PERC) and McKee for offsite production facilities (see references in Table 4.7). Also shown are the costs adjusted to incorporate current prices of coal and residual oil. The costs do not include transportation of COM.

These costs are for a 50 percent (by weight) coal fraction. The cost of additives to enhance coal suspension is assumed to be $\$ 0.10 / \mathrm{MMBtu}$. The steam production costs assume that COM is fired in a new residual oil-type 
TABLE 4.7

COAL/OIL MIXTURE COSTS

\begin{tabular}{|c|c|c|c|c|}
\hline Source & $\begin{array}{c}\text { Production } \\
\text { Plant Size } \\
\text { (gal/hr) } \\
\end{array}$ & $\begin{array}{c}\text { Adjusted } \\
\text { Fuel Cost } \\
(1978 \text { \$/MMBtu }) \\
\end{array}$ & $\begin{array}{l}\text { Boiler } \\
\text { Size } \\
\text { (KPPH) }\end{array}$ & $\begin{array}{c}\text { Steam } \\
\text { Cost } \\
(\$ / \mathrm{KPPH})\end{array}$ \\
\hline \multirow[t]{2}{*}{ PERC $^{\mathrm{a} /}$} & 144,000 & 2.36 & 50 & 4.86 \\
\hline & & & 175 & 4.70 \\
\hline \multirow[t]{3}{*}{$\mathrm{McKee}^{\mathrm{b} /}$} & 1,440 & 3.09 & 50 & 6.37 \\
\hline & 12,500 & 2.76 & 175 & 5.26 \\
\hline & 81,500 & 2.64 & 325 & 5.03 \\
\hline Mc Kee $e^{c /}$ & 1,440 & 3.94 & 50 & 7.22 \\
\hline
\end{tabular}

a/ P.D. Bergman (Pittsburg Energy Research Center), "Economic Considerations for Industrial Firing of Coal-Oil Mixtures," presented at First International Symposium on COM Combustion, St. Petersburg, Florida, May 1978.

b/ Christie, Wills, and Winklepleck (Arthur G. McKee \& Co.), "Coal-Oil Mixture (COM): A Preliminary U.S. Market Study," presented at First International Symposium on COM Combustion, St. Petersburg, Florida, May 1978 .

c/ Cost used in economic analysis in Section 6. Cost includes transportation costs and higher fuel price streams not included in initial McKee data. 
boiler with FGD and electrostatic precipitation (ESP) pollution control equipment. The total steam cost is the sum of unit fuel, capital, and operating costs for the boiler.

The COM price used for economic comparisons with existing technologies is $\$ 3.94 / M M B t u$. Although this.figure is based on McKee's capital and O\&M cost data, fuel cost projections were made independently and then annualized.

The conversion plant is assumed to produce $1.5 \times 10^{6} \mathrm{MMBtu} /$ year of COM fuel at 70 percent capacity utilization.

\subsubsection{Methano1}

\subsubsection{Technology Description}

The derivation of methanol from coal processes involves three major steps:

- Gasification: forming synthesis gas (a mixture of carbon monoxide -- $\mathrm{CO}$ - - and hydrogen -- $\mathrm{H}_{2}$ ) by partial oxidation of coal using oxygen and steam as the oxidizing agents

- Shift reaction: increasing the ratio of $\mathrm{H}$ to $\mathrm{CO}$ in the gaseous mixture by the synthesis gas shift reaction

- Methano1 synthesis: catalytically synthesizing the H-enriched gases to form methanol.

Although there are a number of subprocesses involved. in the production of methanol, ranging from the preparation of coal at the input stage to the refining and storage of the methyl fuel, the three processes listed above are of major technical concern in a commercial coal conversion facility. Thus, each of these three steps is detailed below.

To formulate synthesis gas, washed and prepared coal is pumped into the gasifying unit and oxidized at high temperatures in a combustion chamber. The pressure in the gasifying unit depends on the design of the gasifier. This process produces synthesis gas containing a mixture of $\mathrm{CO}$ and $\mathrm{H}$. This raw synthesis gas is washed and scrubbed to remove fly ash and other pollutants. A number of coal gasifier designs are available for the gasifi- 
cation process. Each design differs in regard to operating conditions, peripheral equipment design, and capacity. Several gasifier designs are compared in Table 4.8 .

In the shift reaction stage, the cleaned synthesis gas from the gasifier is enriched with $H$ in the shift unit. This enrichment is required to give a high yield in the methanol synthesis reactor downstream of the shift unit. The enrichment process, which increases the H-to-Co ratio from 0.5 to 2.0 , takes place at approximately $900^{\circ} \mathrm{F}$. This enrichment is achieved by shifting most (approximately 70 percent) of the co to carbon dioxide $\left(\mathrm{CO}_{2}\right)$. The resulting enriched gas contains certain acid gases and thus is fed through an acid gas removal process before entering the methannl synthesis reactor.

Methanol synthesis occurs when, in the presence of a catalyst and under high temperatures, the purified synthesis gas is combined with hydrogen under pressure and synthesizes to form methanol vapor. This vapor is purified and liquefied to produce various grades of methy 1 fuel. There are several variations of the methanol syntheris reactor. These vaidaliuns result from the degree of efficiency that can be obtained by using different catalysts and different reaction conditions. The overall thermal efficiency of the methanol conversion plant varies betwcen 45 and 55 percent.

Methanol combines with other higher alcohols to form methyl fuels. The Wentworth, Inc. version of methyl fuel contains 97.5-98.5 percent methann1, one to two percent higher alcohols including ethanol, propanol, and butanol, and up to 0.5 percent water. ${ }^{11 /}$ The physical and chemical properties of methanol and methyl fuel are basically the same. The properties of methanol relevant to this study are listed in lable 4.9 .

The advantages of using methanol over coal are the ease with which it is transported, lower emissions, ${ }^{12 /}$ and the use of the liquid fuel in most 
TABLE 4.8

GASIFIER DESIGNS

\begin{tabular}{|c|c|c|c|c|}
\hline Manufacturer & Type & $\begin{array}{c}\text { Overall } \\
\text { Thermal } \\
\text { Efficiency } \\
\end{array}$ & $\begin{array}{l}\text { Operating } \\
\text { Pressure } \\
\end{array}$ & Capacity \\
\hline Davy Corp. & $\begin{array}{l}\text { Fluidized } \\
\text { bed } \\
\text { Winkler }\end{array}$ & $69 \%$ & Atmospheric & Moderate \\
\hline BCG/Lurgi & Fixed bed & $69 \%$ & 450 psi & Moderate \\
\hline Koppers-Totzek & Entrained & $77 \%$ & Atmospheric & Moderate \\
\hline HYGAS & $\begin{array}{l}\text { Fluidized } \\
\text { bed }\end{array}$ & -- & $1000 \mathrm{psi}$ & High \\
\hline \multicolumn{5}{|l|}{1} \\
\hline $\begin{array}{l}\text { Atomics } \\
\text { International }\end{array}$ & $\begin{array}{l}\text { Molten } \\
\text { carbonate }\end{array}$ & $73 \%$ & Atmospheric & Moderate \\
\hline Texaco & Entrained & $70 \% \mathrm{~b} /$ & $1550 \mathrm{psi}$ & High \\
\hline
\end{tabular}
a) Overall thermal efficiency $=\frac{\mathrm{HHV} \text { of net product gas }}{\mathrm{HHV} \text { of feedstock }}$
b/ Estimate. 
TABLE 4.9

PROPERTIES OF METHANOL $\left(\mathrm{CH}_{3} \mathrm{OH}\right)$

Molecular weight

Specific gravity $\left(60^{\circ} \mathrm{F}\right)$

Density (16/gal)

Boiling temperature $\left({ }^{\circ} \mathrm{F}\right)$

Plash point $(\mathrm{O})$

Automotive ignition temperature $\left({ }^{\circ} \mathrm{F}\right)$

Flammability limits (volume percent of a1r):

\section{Lower}

Higher

Stoichiometric air/fuel ratio

HHV $(B t u / 1 b)$

Latent heat of vapor $\left(B t u 1 / 1 b\right.$, at $\left.68^{\circ} \Gamma\right)$

Uctane NO (research)

Vapor pressure at $70^{\circ} \mathrm{F}$ (psi)
32.04

0.796

6.63

140

52

867

6.7

36.0

6. 45

9750

506

112

1.9

SOURCE: American Petroleum Institute,: Alcohols, A Technical Assessment of their Application as Fue1s, Publication No. 4261, July 1976 
combustors designed for gas use. ${ }^{13 /}$ The major disadvantage of the technology is the 45-55 percent loss of heating value in the conversion process.

\subsubsection{Combustion Characteristics}

Fuel grade methanol or methyl fuel is predominately methyl alcohol with some heavier hydrocarbons present in small amounts. The flames produced from methanol combustion are relatively short for a liquid fuel. In addition, methanol does not produce the soot or unburned carbon which cause the luminous characteristic of heavier liquid fuels. The flame temperature of methanol is about $100^{\circ} \mathrm{F}$ lower than that of natural gas, a relatively minor difference.

The rate of heat release from the burner is highly controllable so that the fuel creates no problems with heat distribution and heat flux. Burner design does not present any major obstacles, atomization of the liquid is relatively easy due to its low viscosity.

Methanol is an extremely clean burning fuel. The formation of particulates is negligible, and low $\mathrm{NO}_{x}$ formation can be achieved. (To increase the radiance of methanol flames, the mixture of pulverized coal particles has been proposed; however, this would increase $\mathrm{NO}_{\mathrm{x}}$ formation due to the increase in fuel-bound nitrogen. $^{14 /}$ No sulfur is emitted from combustion since the fuel has had all sulfur removed.

\subsubsection{Technology Status}

As mentioned earlier, the most sensitive area in a coal-to-methanol conversion process is the coal gasification step. Currently, there are no commercially operative coal gasification plants in the U.S. There are, however, several units in Europe and India which gasify coal to produce various chemicals and synthetic fuels. Presently, the only commercially nperative indirect coal liquefaction plant (capable of producing methyl 
fuels) is the SASOL facility in South Africa. Details concerning the operations of the plant are not well documented. Wentworth Brothers, Inc., Davy McKee Córp., and Badger, Inc. have produced conceptual designs of coal-to-methanol conversion facilities. $15 /$ No such methanol production facility currently is operating in the U.S.

\subsubsection{Technology Cost}

Coal-to-methanol conversion facilities are very capital-intensive: Annualized capital costs, which are dependent upon the method of financing, may constitute 30-50 percent of the total annualized costs. This capital cost is subject to economies of scale, favoring large offsite production facilities. The cost of coal feedstock is the other major methanol cost factor.

The estimated costs for offsite fuel-grade methanol production from Badger and McKee are shown in Table 4.10 (see table for references). The normalized costs have been adjusted with respect to coal costs and financing, so that the estimates are more directly comparable. The large difference in the cost estimates can be attributed partly to the economies of scale achieved by the Badger plant. However, different assumptions concerning capital and operating costs probably are the most important factors.

In the sample economic calculations, methanol was assumed to cost $\$ 5.63 /$ MMBtu. The coal-to-methanol conversion plant was assumed to use an advanced gasifier producing $32 \times 10^{6}$ MMBtu of methanol per year at 60 percent efficiency and 90 percent capacity utilization. Steam costs also are shown in Table 4.10 as the sum of methanol costs and capital and operating costs for a new residual o1l-type boiler with no pollution control equipment. 
TABLE 4.10

METHANOL COSTS

1. FUEL COSTS

Source

Davy McKee ${ }^{a /}$

Badger $^{b /}$

$\mathrm{DOE}^{\mathrm{C} /}$ (used in eco-

nomic calculations)
Plant

Production

Rate

(MMBtu/hr)

5,728

43,756

4,059
Adjusted

Fuel Cost

(1978 \$/MMBtu)

6.36

3.41

5.64

2. STEAM COSTS

Boiler Size

(KPPH)

50

175
Steam Cost (1978 \$/KPPH)

\begin{tabular}{ccc}
\hline Davy McKee & Badger & DOE \\
\hline 8.31 & 4.75 & 7.47 \\
8.19 & 4.63 & 7.34
\end{tabular}

a/ Based on,E.E. Bailey, "Methanol from Coal: An Adaptation from the Past," presented at the Sixth Annual International Conference on Coal Gasification, Liquefaction, and Conversion to Electricity, at the University of Pittsburg, Davy McKee Corporation.

b/ Based on "Conceptual Design of a Coal to Methanol Conversion Plant," Executive Summary of Interin Final Report prepared for DOE by Badger Plants, Inc., Cambridge Massachusetts, February 1978.

c/ Based on costs from unpublished DOE estimates used in developing the second National Energy Plan. Includes small transportation charge. 


\subsubsection{Direct Coal}

Coal is one of the most abundant and least expensive energy sources in the U.S. Although U.S. reliance on coal has declined from nearly one-half of our energy supply after World War II to less than 20 percent today, ${ }^{16 /}$ coal use is expanding in both the industrial and utility sectors due to increasingly expensive and scarce oil and gas supplies. To help evaluate the feasibility of direct coal use in process heaters and small boilers, the following describes the physical characteristics of coal, particularly its combustion and heat delivery properties; technical issucs that constrain coal use; the current status or commercial availability of coal combustion; and any geographical, transportation, or cost factors that affect coal use.

\subsubsection{Combustion Characteristics}

Although coal has the same combustion steps as oil, the reactions involved in coal burning are more complicated, and combustion time is longer. Coal can be burned on a grate in lumps or in suspension as a powder. Grate firing is quite slow due to the low surface to volume ratio of the coal lumps. Pulverized solid combustion is faster than grate firing but slower than heavy oil firing due to the solid particle size and the number of steps between the initial heat input and final combustion. Combustion time can be increased by grinding the powder to a smaller size and by using turbulence to burn the flame.

Coal has difficulty meeting heat distribution requirements due to flame size and instability. In order for coal to produce a steady flame pattern, it must be fired in burners larger than $50 \mathrm{MMBtu} / \mathrm{hr}$. Coal can be used in burners smaller than $50 \mathrm{MMBtu} / \mathrm{hr}$ only if a short turbulent flame pattern is not required. For many applications, such as petroleum refining and chemical industry process heat applications, coal use is precluded due to the minimum burner size requirement. 
Coal also has more difficulty meeting heat distribution requirements than do gaseous and liquid fuels because heat released from an individual coal burner cannot be held constant. This is because coal, like all solid fuels, is an heterogeneous mixture. The fuel delivery system cannot control the amount of fuel delivered within the accuracy needed for some heaters because the pulverized particle size varies with the quality of the coal feed. Furthermore, coal feed distribution systems are less reliable and more difficult to control than feeding systems for other fuels. The varying Btu content of coal also results in swings of heat input into the burner despite a steady fuel feed rate. In some installations, such as brick kilns, only the average heat release is important. Furnaces such as the ethylene furnace, however, cannot tolerate fluctuating heat release rates.

Coal combustion emits large amounts of particulate matter; $\mathrm{SO}_{2}$, and $\mathrm{NO}_{\mathrm{x}}$. ${ }^{N O}{ }_{x}$ and particulate emissions are greater for pulverized coal firing than for stoker firing, but in process heaters, coal almost always will be fired in suspension. ESP and FGD units can be used to reduce emissions, but the use of FGD adds significantly to the cost of coal firing.

\subsubsection{Technical Constraints to Coal Use}

There are several technical issues constraining coal use in some furnace applications. As discussed above, burner size limitations and uncontrolled heat distribution are two major factors impeding coal use. The third major factor inhibiting coal use is its fuel contaminants, primarily sulfur, vanadium, and ash. These contaminants can impair product quality, accelerate the corrosion of the furnace interior, and clog parts of the furnace and heat recovery systems. These adverse effects tend to increase costs, decrease equipment durability, and impair equipment safety and reliability. In some applications, these problems result only in increased costs and maintenance problems; in others, they prohibit coal use. 
Coal has more severe contamination problems than do gaseous and oil fuels. For example, the sulfur content of coal varies between 0.5 and five percent and the ash content ranges from four to 20 percent of the fuel by volume. In contrast, heavy fuel oil contains a maximum of two percent sulfur and 0.015-0.02 percent ash. Technical difficulties caused by coal ash include product contamination, furnace corrosion, accumulation on refractory walls, and plugging.

\subsubsection{Current Status of Coal Use}

Despite a 30 year decline in its use, coal once again is becoming an important energy source. Although projections vary depending on energy, envirumental, and cost scenarios, coal use is expected to increase to approximately one billion tons in 1985 and $1.1-1.3$ billion tons by $1990.17 /$ The utility sector, already heavily dependent on coal, is expected to continue dominating coal demand. In. 1985 and 1990, utility coal demand is estimated to account for two-thirds or more of all coal consumption. $18 /$

The use of coal in the industrial sector has grown more slowly due t.n high capital costs and operating problems. From the current level of 60 million tons per year, industrial coal demand could increase to 105 million tons per year in 1985 and 165 million tons per year in 1990.19/ Much of this growth will occur in industrial boilers, which comprise most of the industrial market in which coal use is technically feasible. The boilers most likely to use coal are large new boilers in which coal is economically attractive and boilers subject to Federal legislation mandating coal use.

A proven technology in only a few process heat applications and technically infeasible in 45 percent of new process heat applications, cual is not likely to be a significant energy source in industrial process heaters until after 1990. Approximately 37 percent of fossil fuel demand in new process heaters is considered technically low- or high-risk, thus requiring the deyelopment of new process designs and a demonstration period before 
acquiring commercial availability. It should be emphasized that the time from inception of deyelopment to commercial implementation ranges from three to 10 years. This time frame includes the inception of active development programs (initiated by either the public or private sector), the preparation of new equipment designs, the building and successful operation of demonstration facilities, and commercial implementation. In addition to proving technical viability, technology development programs also must confirm economic viability and must consider environmental control problems.

\subsubsection{Technology Cost}

Unlike other alternative supply sources considered in this study, there are no technological barriers to the supply of coal. Coal currently is used primarily because of its low cost. On a Btu basis, the fuel cost of coal is less than half that of any conventional fuel substitute such as gas or oil. Coal costs may rise due to possible transportation cost increases and possible stricter environmental requirements, but the large difference between coal costs and oil and gas costs is not expected to diminish significantly. For this study, the coal costs used were those projected in DOE's MEFS model. 20/

The costs that will determine how economically attractive coal use will be are those extra costs associated with coal firing over those associated with oil or gas firing. Although O\&M costs also are high, the capital cost of coal-capable process heaters and boilers currently is the major factor that constrains coal use in proven applications. Since coal contains many contaminants and is burned in a solid form, it requires more auxiliary equipment than the other fuels considered in this study. The capital cost of coal-fired boilers, when required auxiliary equipment is included, can be more than three times the total capital cost of oil-fired boilers. Coal-fired process heater costs also are significantly higher than oil- or gas-fired heater costs. The capital costs for process heaters and boilers used in this study are taken from IFCAM. ${ }^{21 /}$ 


\subsubsection{Wood and Wood Waste}

\section{s. \\ 4.1.7.1 Technology Description}

The major source of wood fuel is the residues which result from manufacturing processes in the forest products industries (FPI). The FPI includes the pulp and paper, lumber (sawmills, boards, plywood, etc.), and furniture industries. The manufacturing residues may be bark, wood chips, shavings, sawdust, endtrims, or pulping 1iquors. There is a substantial volume of forest residues that currently are not utilized. When trees are harvested for pulp or lumber, residues ranging from small, crooked, or rotten material to large tree sections just below the limits of merchantability are left on the harvest site. In addition to harvest residues, there are rough, rotten, and dead trees standing throughout forest regions that are available for use as, fuel.. The third existing source of wood fuel is standing forests that are more valuable as fuels than as raw materials for forest products. In standing forests, whole trees could be harvested and chipped specifically for fuel. The creation of energy plantations in which trees are grown for their energy value may provide additional wood fuel in the future. The plantations would employ high yield, short rotation tree varieties, and intensive management practices to maximize energy production. Although energy plantations have not yet been developed in the U.S., the following aspects of energy plantations are being researched: tree varieties, management practices, land requirements and availability, and the overall economics of energy plantations.

\subsubsection{Combustion Characteristics}

Wood may be used as either a solid fuel in direct combustion or as a feedstock for thermochemical conversion processes. There is significant variation in the moisture content and physical size of wood residues suitable for use as a fuel. The wood must be homogeneous in size to ensure compatibility with combustion equipment. The larger pieces are passed through a hogger or chipper. Stoker-spreader boilers are designed to handle this 
chip size material. Further size reduction is required for suspension firing. The advantages of direct combustion of wood include low energy conversion costs, extensive experience with wood combustion systems, and the cleanliness of wood emissions relative to coal. The disadvantage of hogged wood fuel is that it is more difficult to handle, transport, and meter than fossil fuels because its density, size, and moisture content are variable.

The density and consistency of wood fuel can be increased by densification. The densification process produces a homogeneous fuel with a density 1.3 times that of hogged fuel $\left(30-40 \mathrm{lb} / \mathrm{ft}^{3}\right)$ and a moisture content of about 12 percent. The wood residues are dried, shredded, and fed through a density mill under pressure to produce small pellets. The pellets flow freely and can be metered easily by volume. Densification increases the economical transportation distance of wood fuel. The pellets may be burned directly, ground for suspension firing, or used for feedstock in a gasification or pyrolysis process. 221

Commercial processes are available which produce gaseous and liquid fuels from wood. LBG with a representative heating value of $140 \mathrm{Btu} / \mathrm{scf}$ could be produced in a gasifier using wood as feedstock.

Pyrolysis, the heating of wood in the absence of oxygen, produces LBG, pyrolytic oil, and char. The proportions of these products are determined by the design of individual systems. These derived wood fuels could be used in several applications. This study, however, will focus on the use of wood in direct combustion rather than as a feedstock.

\subsubsection{Technical Issues}

The heating value of wood depends on the wood's fiber, resin; and moisture content, all of which vary with tree variety. Dry wood, which is rarely available, has an average heating value of $8800 \mathrm{Btu} / 1 \mathrm{~b}$, while wood with a 
40 percent moisture content has an average heating value of $5400 \mathrm{Btu} / \mathrm{lb}$. Freshly-cut wood usually has a moisture content between 35-50 percent. In comparison, coal has a heating value of $8500-12,500 \mathrm{Btu} / 1 \mathrm{~b} .^{23 /}$

There are about 1500 industrial wood waste boilers operating in the U.S. with a total capacity of $200,000 \mathrm{MMBtu} / \mathrm{hr}$. The boiler capacity is distributed in the FPI sectors as follows: 54 percent in pulp and paper, 39 percent in lumber, and seven percent in furniture. ${ }^{24 /}$ There are three general. design categories of boiler systems: spreader-stoker, suspension firing, and fluidized bed combustion. Spreader-stoker systems account for over 50 percent of the boilers in use. Most of the boilers are co-fired with oil, coal, or natural gas. $25 /$

Spreader-stoker boilers range in size from 25,000-500,000 1b/hr of steam. Most of the boilers are designed to fire chip size pieces or smaller. In a spreader-stoker boiler, the chips are spread pneumatically or mechanically. Some of the wood burns in suspension, while the larger pieces burn on the floor grate. If the fuel is processed to very small pieces with a low moisture content, suspension firing is possible. The primary advantage uf suspension firing is low capital costs due to the elimination of grate cleaning. However, suspension firing increases fuel processing and fly ash control costs.

Fluidized bed systems are more tolerant of nonuniform fuels containing noncombustible materials whose moisture content is greater than 50 percent. The fluidized bed is established and maintained by air flowing through an inert material, such as sand or pebbles. Fuel is fed slowly into the bed from above, and air is introduced from the bottom. Technological advances in fluidized bed coimbustion are occurring rapidly.

The average properties of dry wood and bark are: 51 percent carbon, six percent hydrogen, 0.1 percent sulfur, 40 percent oxygen, 0.2 percent ni- 
trogen, and 2.9 percent ash. The low sulfur content of wood eliminates $\mathrm{SO}_{\mathrm{x}}$ control problems. Only particulate and visible emissions currently are regulated for wood-fired boilers. Slagging and fouling may occur when bark is fired due to the presence of sand, salt, and dirt picked up in harvest and storage. In addition, slagging may be increased by the combination of wood or bark ash with that of another fuel to form ash that has a low melting point and, hence, adheres easily to furnace walls. ${ }^{26 /}$

\subsubsection{Supply Potential}

Manufacturing residues are the most accessible source of wood fuel. The cost of the fuel is low because the harvest and transportation costs are paid for by the production of primary products. Manufacturing residues also are suitable for some fiber product uses. The increasing value of these residues for fuel and fiber products will promote the full utilization of these wastes in the near future.

After manufacturing residues are utilized fully, the next increment of supply will be harvest residues that are not profitable for use under current costs and prices. $27 /$ The harvest residues are relatively concentrated and accessible. Cull and dead trees, however, are scattered too widely to be recovered economically. Deterrents to the economical utilization of harvest residues are low volumes per acre, access difficulties, small wood pieces, and long distances to residue use sites.

Energy plantations could be expected to yield five to 12 dry tons per acreyear or 16-20 dry tons per acre-year under intense management. Tremendous areas of land would be required to produce a significant amount of energy. With a yield of 9.5 dry tons per acre-year, about 4.5 million acres (7000 sq $\mathrm{mi}$ ) would be required to provide one percent of U.S. energy requirements. An ERDA study in 1977 estimated that only three million acres were available for wood plantations. $28 /$ The shortage of land available for energy plantations will limit the future production of wood fuel by this method. 
The supply of wood energy available each year in the future will have a significant impact upon energy use in the FPI. The FPI is a prime canditate for using the wood fuel supply because it has a large energy need, access to the wood, an established materials flow system, and the technical expertise to convert economically the wood to suitable energy forms. In 1978, bark, wood, and spent pulping liquors provided 45.9 percent of the total energy requirements of the U.S. pulp, paper, and paperboard industry. The impact of wood energy in other industries will be significant only in locally forested areas where fossil fucls are relatively expensive.

\subsubsection{Technology Costs}

Costs incurred in the harvest and transportation of wood represent the major components of the delivered price of wood fuel. The low energy content and wide scattering of wood in the field are responsible for this cost structure. The cost and availability of wood fuel is subject to tremendous variation with geographical location. Currently', the only wood fuel source with the potential for supplying large boilers outside the FPI is standing forests. The forests could be harvested and chipped for boiler use.

Cost estimates for whole tree chips from Mitre, Battelle, and the USDA Forest Service are shown in Table 4.11. The Mitre 1978 costs are for wood fuel in the FPI. The Battelle costs are from studies for $50 \mathrm{MW}$ wood-burning powerplants in Vermont. The steam costs are calculated assuming the wood is fired in a stoker-fired boiler with a 65 percent efficiency.

\subsubsection{Municipal Solid Waste}

\subsubsection{Technical Description}

Municipal solid waste (MSW) is defined in this paper as the residential and commercial refuse normally collected by a municipality or private collection firm. Industrial wastes are not included. The average composition of 


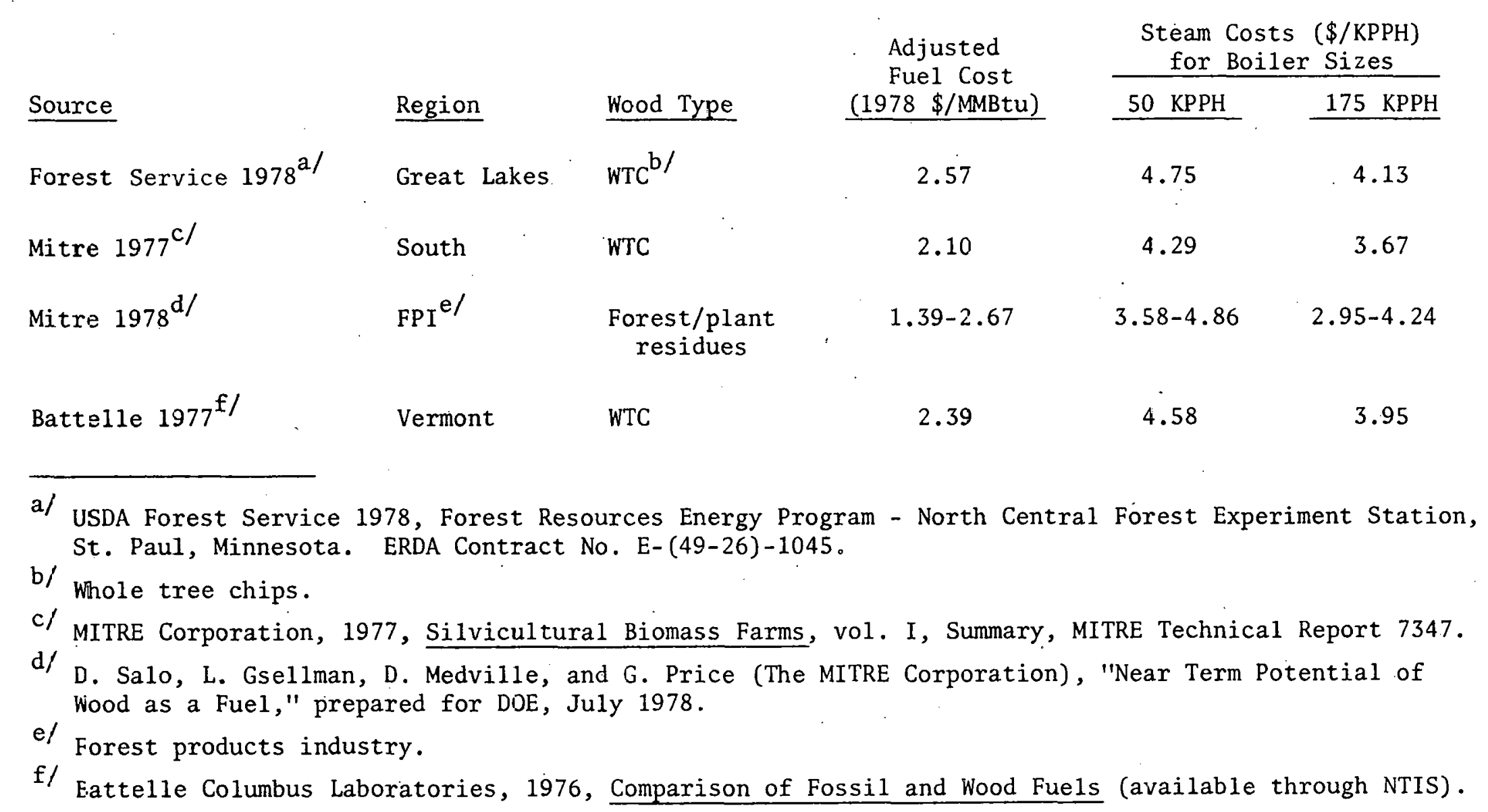


MSW as collected is shown in Table 4.12. Raw MSW can be expected to vary in piece size, heating value, chemical composition, moisture content, and physical characteristics. Significant variations also can occur due to seasonal and geographical changes.

The following discusses the energy recovery processes in which raw MSW is converted to a useful fuel. The following discussion is categorized into the three forms of the resultant fuel: solid, liquid, and gaseous. The discussion focuses primarily on the physical conversion processes that produce a solid fuel because that technology is more highly developed and commercialized, more reliable, and less expensive than the thermochemical conversion process used to produce liquid and gaseous fuels from MSW.

\subsection{Solid Fuel Forms}

The simplest solid fuel process is mass burning. Mass burning is the combustion of raw, unsorted refuse on a grate in a stoker-fired boiler or waterwall incinerator. Prior to combustinn, the refuse may be roducod to a uniform size. The refuse is fed continuously onto a traveling or reciprocating grate for combustion in the furnace. Ferrous material recovery by magnetic separation may occur before incineration if the waste is shredded or from the ash after incineration. The energy product of mass burning. usually is steam.

Smali-scale modular incineration has been used in small comminities generating less than 150 TPD of MSW. In this method, small modular furnaces are grouped together to achieve the desired capacity. Raw MSW is burned to produce a combustible gas and solid residue. The gas then is burned with an auxiliary fuel (oil or gas) in a secondary combustion chamber. The hot combustion gases pass on to a boiler or heat exchanger to produce steam, hot water, or hot air. The two-stage combustion helps to reducc particulate emissions. $29 /$ 
TABLE 4.12

MATERIAL COMPOSITION OF MUNICIPAL SOLID WASTE

$\%$ of Total Weight

(approximate)

\begin{tabular}{lr} 
Paper & 32.4 \\
Glass & 10.1 \\
Ferrous Metal & 8.3 \\
Aluminum & 0.7 \\
Other nonferrous metal & 0.3 \\
Plastics & 3.2 \\
Rubber & 2.1 \\
Leather & 0.5 \\
Textiles & 1.5 \\
Wood & 3.5 \\
Food Waste & 16.8 \\
Yard Waste & 19.1 \\
Other & 1.5 \\
\hline ToTAL & -100.0 \\
\hline
\end{tabular}


Solid refuse-derived fuel (RDF) is produced when the organic combustible fraction of MSW is separated by a wet or dry process. Most RDF plants also recover one or more of the following materials: ferrous metal, aluminum, glass, or mixed nonferrous metals. RDF provides a more consistent heating value and chemical composition than the raw refuse used in mass burning. The final fuel product can be fluff, powdered, densified, or "wet" RDF.

In a dry RDF process, the raw refuse first is shredded to pieces eight inches or less in size. The refuse then is passed through an air classifier which separates the light and heavy fractions. The light fraction contains 87 percent of the raw refuse by weight and consists mainly of cumbustible organic material. The light fraction then goes through a rotating screen or trommel to remove abrasive fine sand, glass, and grit. The ferrous metals are removed by magnetic separation from the heavy ma. terials isolated by the air classifier and trommel. Aluminum, glass, and mixed nonferrous metals also may be removed. The light fraction then goes to a secondary shredder which reduces the piece size to 1.5 inches or 1 css. The resulting material is called fluff RDF and has a heating value of 5500 Btu/lb. RDF (either tluff or with only primary shredding) can be fired as the sole fuel in a semi-suspension boiler or co-fired with coal in a suspension, semi-suspension, or spreader-stoker fircd boiler.

Fluff RDF can be mechanically pelletized or briquetted to produce densified RDF (d-RDF), which has a heating value of $7700 \mathrm{Btu} / 1 \mathrm{~b}$. The increased density and homogeneous size of d-RDF improves transportation, storage, and handling. The d-RDF pellets can he stoker-fired or ground for suspensiun firing. Powdered RDF is produced by adding a chemical embrittling agent to fluff RDF which then is ground to a fine powder in a ball mill. This proprietary process produces a dry, free-flowing fuel with a particle size of about $0.15 \mathrm{~mm}$. Powdered RDF may be suspension-fired with coal or pelletized to form d-RDF. 
A wet process has been developed to produce RDF with a heating value of $4100 \mathrm{Btu} / 1 \mathrm{~b}$. Initially, the refuse and process water are fed continuously to a hydrapulper resembling a giant blender. The waste is shredded to about one sq in. The waterwaste slurry leaves the hydrapulper and is passed through a magnetic separator. A cyclone is used to separate the heavy fraction of noncombustibles. The light fraction is sorted into organic and inorganic matter by liquid, heavy media separation. Aluminum and glass are separated from the inorganic stream. The glass is colorsorted as well. The light organic fraction is dewatered prior to combustion.

The refuse sent to the landfill is reduced 97 percent by volume and 85 percent by weight. The energy recovery process produces a fuel with a heating value of $4100 \mathrm{Btu} / \mathrm{lb}$ and a moisture content of 50 percent while recovering 48 percent of the glass, 80 percent of the aluminum, and 90 percent of the ferrous metals. Although this fuel is lower in heating value than the dry process fuel, the consistency in heating value and moisture content aids in process control. This wet RDF can be burned alone or as a supplement to coal.

\subsection{Liquid and Gaseous Fuel Forms}

Pyrolysis systems produce both liquid and gaseous fuels. Pyrolysis generally can be defined as thermal decomposition in an oxygen-starved environment. High temperatures and an oxygen-deficient environment cause a breakdown of organic materials into three parts: a gas consisting primarily of hydrogen, methane, and carbon monoxide; a liquid fuel containing acetic acid, acetone, and methanol; and a char consisting of pure carbon plus inorganic impurities. The design of an individual pyrolysis system determines which of the above outputs will be dominant. Principal characteristics of pyrolysis processes include bed type, heating method, temperature, and pressure. $30 /$ 
The potential advantages of waste pyrolysis systems include the production of storable fuels, the conversion of char to activated carbon or synthesis gas, lower air pollution control costs than for refuse combustion, and a residue that is environmentally more acceptable than refuse ash. An organically contaminated wastewater stream and fine particulate emissions represent potential disadvantages of pyrolysis. $31 /$

Two systems, anaerobic digestion and methane production from landfills, employ biological decomposition of MSW to proluce mcthane. Anaerobic digestion is a process whereby organic matter decomposes in a regulated oxygen-deficient environment. The products of the decomposition are 50-60 percent methane and 40-50 percent carbon dioxide. An anaerobic digestion system consists of feed preparation, digestion in a large tank, gas treatment, and effluent disposal. Digestion requires about seven days at $140^{\circ} \mathrm{F}$. About three scf of gas $(600 \mathrm{Btu} / \mathrm{scf})$. can be expected from one pound of refuse. The solid residue occupies 25 percent of the feedstock volume. $32 /$

A 50-50 mix of methane and carbon dioxide produced by the decomposition of MSW can be recovered from landfills. The gas can be withdrawn from wells drilled into the landfill if geological characteristics are satisfactory. The gas must be treated to remove moisture, hydrogen sulfido, othes contaminauls, and the carbon dioxide to provide pipeline quality methane.

\subsubsection{Technology Status}

Only the solid fuel technologies described above are commercially operational. There are existing full-scale commercial plants in continuous operation employing mass burning, modular incineration, and solid RDF technologies. There are four proprietary pyrolysis processes currently in the development phase. Three of the processes are being demonstrated in the U.S. in Baltimore, Maryland; San Diego County, California; and South Charleston; West Virginia. The methane recovery from landfill processes is being developed in Palos Verdes, California. A demonstration facility for anaerobic digestion of MSW currently is operating in Pompano Beach, Florida. 
Table 4.13 lists the status, number of operational facilities, and number of planned facilities for each of the energy recovery processes. 33/

\subsubsection{Status of Development}

Nashville, Tennessee, was the first U.S. city to sell steam produced from its MSW. A mass burning facility has been in operation since 1974. In 1972, Nashville was planning a district heating and cooling plant for 28 downtown office buildings. A solid waste disposal problem. created by a tougher Tennessee landfill law led to the decision to use MSW as a fuel for the new plant.

The combustors used in the heating and cooling plant are two Babcock and Wilcox boilers with Detroit Stoker Co. reciprocating grates. Each of the boilers, after recent modifications, has a capacity of 530 TPD. At this rate, each will produce $135,000 \mathrm{lb} / \mathrm{hr}$ of steam at $400 \mathrm{psig}$ and $600^{\circ} \mathrm{F}$. The raw refuse is discharged from delivery trucks into an $8500 \mathrm{yd}^{3}$ storage pit. The refuse is fed to the furnace grates without processing. The reciprocating grates tumble the refuse to improve combustion. $0 i 1$ and gas backup burners are used only for extremely wet refuse. Combustion temperatures are maintained in the range of $1400-1800^{\circ} \mathrm{F}$, and the overall efficiency is 67.7 percent. The combustion gases pass through a four-field ESP to reduce particulate emissions. Measured emissions are reported at $0.024 \mathrm{lb} / \mathrm{MMBtu}$, we11 below the Federal standard of $0.094 \mathrm{lb} / \mathrm{MMBtu}$. In the past two years, MSW has provided 94 percent of the fuel used in the heating and cooling plant. In 1978, the plant operated at 400 TPD, seven days per week. $34 /$

Fluff RDF is prepared for co-firing with coal at a resource recovery plant in Milwaukee owned and operated by the Americology Division of American Can Company. The plant has a design capacity of 1600 TPD but currently is operating at 600-900 TPD. Refuse processing consists of primary shredding, air classification, and secondary shredding of the light fraction. The light fraction then is passed through magnetic separation and screening 
TABLE 4.13

SUMMARY OF MSW ENERGY RECOVERY PROCESSES

\begin{tabular}{|c|c|c|c|}
\hline & Status & $\begin{array}{l}\text { Operational } \\
\text { Facilities } \\
\end{array}$ & $\begin{array}{c}\text { Planned } \\
\text { Facilities } \\
\end{array}$ \\
\hline Anaerobic Digestion & Experimental & 1 & $?$ \\
\hline Methane from Landfill & Developmental & 1 & 1 \\
\hline Pyrulysis & Developmental & 3 & $?$ \\
\hline Mass Burning & Commercial & 6 & 5 \\
\hline \multicolumn{4}{|l|}{ RDF } \\
\hline - fluff RDF & Commercial & 9 & 8 \\
\hline$-d-R D F$ & Commercial & * & * \\
\hline Eco-Fue I II & Commercial & 2 & 1 \\
\hline Wet-RDF & Commercial & 1 & 1 \\
\hline
\end{tabular}

* Commercial pelletizing process available. No information available on current or planned facilities. 
steps. Ninety-five percent of the fluff RDF fuel is under $3 / 4$ inch. The fuel has an ash content less than 20 percent and a heating value over 5000 Btu/1b. About 50 percent of the incoming refuse becomes fuel. The fluff RDF is trucked to a utility powerplant. The fuel is fed pneumatically into the boiler by means of separate nozzles above the pulverized coal feed points. The RDF is fired at five to 15 percent of the heat input. The boiler produces $2000 \mathrm{KPPH}$ of steam at $2620 \mathrm{psig}$ and $1050^{\circ} \mathrm{F}$. The final screening of the RDF is done to alleviate a slagging problem caused by the high ash content (30 percent) of the unscreened fuel. 35 /

The Black-Clawson wet process method of RDF preparation is employed at a 2000 TPD plant in Hempstead, New York. The facility pulps refuse into a water slurry which then passes through several separation steps. The fuel then is mechanically dewatered to a 50 percent moisture content and has a heating value of $4100 \mathrm{Btu} / \mathrm{lb}$. The wet $\mathrm{RDF}$ is fired alone in two Babcock France boilers generating $400 \mathrm{KPPH}$ of steam at $600 \mathrm{psig}$ and $750^{\circ} \mathrm{F}$. The fuel is fed to the spreader-stoker boilers through airswept spouts. The steam powers two onsite $20 \mathrm{MW}$ turbogenerators. The electricity is sold to Long Island Lighting Company. A 3000 TPD wet RDF plant is under construction in Dade County, Florida.

Combustion Equipment Associates developed the proprietary process to manufacture ECO-FUEL II. A plant in East Bridgewater, Connecticut, currently is producing the powdered RDF fuel from 1200 TPD of MSW. The MSW is shredded, air classified, magnetically separated, chemically embrittled, and pulverized. The ECO-FUEL II produced is being shipped to a CEA plant which provides electricity, steam, and hot water to Century Brass in Waterbury, Connecticut.

ECO-FUEL II has an ash content of nine percent, a sulfur content of 0.3-0.5 percent, and is claimed to have a higher heating value of $7740 \mathrm{Btu} / \mathrm{lb}$. The moisture content is only two percent and the density is about $32 \mathrm{lb} / \mathrm{cu} \mathrm{ft}$. The fuel is suspension-fired in pulverized coal boilers, either alone or 
with coal or oil. It also can be compacted into briquettes and fired like lump coal. ECO-FUEL II plants are being planned in Bridgeport, Connecticut, and Newark, New Jersey.

The most promising nonboiler RDF application is the firing of RDF in cement kilns. Browning-Ferris Industries is testing the use of fluff RDF in a Houston cement kiln. Testing also is being done by Blue Circle Group in Shoreham Works, Sussex, U.K. The RDF is co-fired with coal. Whatever ash is formed from the fuel becunes part of the clinker. The manufacture of cement is very energy-intensive, providing great potential for kDF application. In addition, every large population center, where large quantities nf MSW arc produced, has at. least onc ccment kiln nearby.

Both raw refuse and RDF are nonhomogeneous fuels with respcct to muisture content and heating value. The average heating value of raw refuse is about $4700 \mathrm{Btu} / 1 \mathrm{~b}$ but may vary from 2300-7600 Btu/1b. Fluff RDF has an average heating value of about $5500 \mathrm{Btu} / \mathrm{lb}$ with less variation. The nonhomogeneity of the fuels decreases process control. In addition, the metals and other inorganic constituents present in the fuel contribute to corrosion. Each step in the preparation of RDF improves the fucl quality and reduces corrosion potential. Co-firing with coal helps to neutralize corrosive refuse ash.

Data have been collected on corrosion and emisgions at many facilities in the U.S. At an Ames, Iowa, co-fired utility boiler, slagging and fouling were found to increase relative to coal firing alone. This is due to a decrease in ash softening temperature with an increase in RDF. Improved front end glass removal helps alleviate this problem. 'The polyvinyl chloride in refuse increases halogen (chlorine) corrosion. In general, furnace temperature must be lower when refuse is fired to reduce corrosion. $36 /$ 
Uncontrolled particulate emissions from the Nashville mass burning incinerator were measured to range from 1.105-1.97 $1 \mathrm{~b} / \mathrm{MMBtu} . \mathrm{SO}_{2}$ emissions were measured at an average of $0.0557 \mathrm{lb} / \mathrm{MMBtu}$. Data concerning RDF emissions relative to coal have been obtained at the Ames and St. Louis co-fired powerplants. Particulate emissions increase with RDF due to lighter particulates and greater air flow. In addition, the fly ash content of lead, zinc, chromium, antimony, arsenic, barium, cadmium, copper, bromine, and chlorine increases with $\mathrm{RDF} . \mathrm{SO}_{2}$ and $\mathrm{NO}_{\mathrm{x}}$ emissions decrease with an increase in RDF. CO emissions are unchanged by an increase in RDF; hydrocarbon emissions are reduced by the use of RDF. $37 /$

The greatest potential for an energy recovery facility is in an area where both conventional fuels and landfill disposal are expensive. The first step when considering such a facility is to determine who owns the waste. In New York State, for example, once refuse is placed on the curb it becomes the property of the municipality (if it does its.own collection) or the private collection firm. This is not true in all states. The wasteto-energy facility may be owned, operated, and financed either publicly or privately.

When regional facilities are being considered, additional complications may surface. For example, some state and local governments prohibit the transport of wastes across their boundaries. These laws originally were enacted to prevent another jurisdiction's refuse from entering for disposal in a landfill.

The key to the feasibility of any facility is the establishment of a reliable refuse supply and a secure market for the energy product. Long-term contracts of at least 10 years should be acquired. This may present a problem in some communities in which the length of waste disposal contracts are limited by 1 aw. 


\subsubsection{Technology Cost}

The economics of an energy and materials recovery facility depend on system costs and on the revenues generated from three sources: the sale of steam, electricity, and/or RDF; the sale of recovered materials such as metal and glass; and tipping fees. As discussed earlier, it is best to tailor the energy product to the available customers. The refuse should be processed as little as possible to reduce costs. When an existing boiler is used to fire the fuel, capital costs are decreased greatly.

The only commercially operated material recovery technologies are for ferrous metals and low-grade fiber. Aluminum and glass recovery systems have yet to maintain continuous operation in a facility. The revenues from materials recovery vary due to fluctuating scrap prices, the cost of delivery to buyers, and the potential for beverage container deposit legislation.

Tipping fees are the charges for dumping MSW at a landfill or energy recovery facility. These fees must be kept low for an energy recovery facility to compete with other disposal practices. Typical processing costs (operating plus capital) for material recovery and RDF preparation are \$1521 input ton. Energy and ferrous metal revenues are $\$ 5-9$ and $\$ 1-3 /$ input ton. The resulting tipping fees which must be charged are \$4-16/input ton. Tipping fees for a mass burning facility are $\$ 9-17 /$ input ton. $38 /$

The tipping fee is determined by the difference in processing costs and energy and materials revenues. Under average conditions, no system can produce sufficient revenues from recovered energy and materials to be economical without charging a substantial tipping fee.

The decision by a community to recover energy from wastes is an economic one. Under most local conditions, traditional disposal practices are less costly at the present time. However, as the price of fossil fuels in- 
creases, so does the value of the energy content of MSW. Resource recovery practices are relatively new in the U.S. and are approached with caution by industry, utilities, and municipalities. However, the implementation of new facilities should increase as existing facilities demonstrate the reliability and cost effectiveness of resource recovery.

Two cost estimates presented in an Office of Technology Assessment (OTA) study of municipal waste-to-energy systems are shown in Table 4.14. The capital and operating costs are combined with high and low values of tipping fees to provide bounds for estimated steam production costs. Also shown in the table are the 1978 capital and operating costs and tipping fee of a waterwall incinerator in Nashville, Tennessee. The higher steam cost for this facility is due to operation at a low load factor. These costs have been normalized with respect to financing method.

\subsection{ALTERNATIVE SOURCES OF HEAT}

\subsubsection{Atmospheric Fluidized Bed Combustion}

\subsubsection{Technology Description}

Atmospheric fluidized bed combustion (AFBC) consists of burning coal or other fuels in a bed of non-combustible material maintained in a fluid-1ike state by the flow of combustion air through the bed. The particle bed may consist of inert materials such as sand or a reactive material such as limestone used to capture $\mathrm{SO}_{2}$ as it is generated during the combustion process. AFBC can be used for various applications such as steam generation and heating process fluids.

AFBC originally was developed to reduce the boiler size required for coal combustion and, therefore, reduce cost, lessen fuel preparation needs, and produce a system capable of burning a diversity of fuels. Due to recent attention to environmental regulations, the intent has shifted toward 
TABLE 4.14

NEW STEAM COSTS

\begin{tabular}{|c|c|c|c|c|c|}
\hline Source & $\begin{array}{c}\text { Plant } \\
\text { Capacity } \\
\text { (TPD) } \\
\end{array}$ & $\begin{array}{c}\text { Capital } \\
\text { Cost } \\
(\$ / \text { ton }) \\
\end{array}$ & $\begin{array}{c}\text { Operating } \\
\text { Cost } \\
(\$ / \text { ton }) \\
\end{array}$ & $\begin{array}{l}\text { Tip Fee } \\
(\$ / \text { ton }) \\
\end{array}$ & $\begin{array}{l}\text { Steam Cost } \\
\left(\$ 110^{3} \mathrm{Ib}\right)\end{array}$ \\
\hline Nashville $\mathrm{a} /$ & 1060 & \multicolumn{2}{|c|}{28.56} & 9,31 & $3.87^{\mathrm{b} /}$ \\
\hline OTA-Schultz ${ }^{c /}$ & 1000 & 17.26 & 12.60 & 8.49 & 3.75 \\
\hline & & 17.26 & 12.60 & 16.04 & 2.42 \\
\hline $\begin{array}{c}\text { OTA - Black } \\
\text { Veatch }\end{array}$ & 1000 & 17.18 & 8.14 & 8.49 & 2.95 \\
\hline & & 17.18 & 8.14 & 16.04 & 1.63 \\
\hline
\end{tabular}

a/ J. Frank Bernheisel, "Nashville - A Successful Refuse to Energy Program," National Center for Resource Recovery Bulletin, Washington, D.C.: March, 1979 .

b/ In 1978, steam from the Nashville incinerator was sold to a customer buying less than $200,000 \mathrm{lb} /$ month for $5.73 / 10^{3} \mathrm{lb}$.

c/ Helmut W. Schulz, et. a1., "Resource Recovery Technology for Urban Decisionmakers," prepared for the National Science Foundation by the Urban Technology Center, Columbia University, January 1976.

d/ Black, Veatch, and Franklin Associates, Ltd., "Detailed Technical and Ecunumic Analysis of Selected Resource Recovery Systems, " report to the Mid-America Regional Council, Kansas City, Missouri, 1978. 
evolving $A F B C$ as a potential alternative to $F G D$ in coal-fired systems. In addition to firing all grades of coal, some AFBC designs can fire wood, wood waste, fuel oils, and natural gas; a combination of fuels also may be fired simultaneously.

Figure 4.1 is a generalized schematic of a coal-fired AFBC system. Typical system components are those linked by solid lines; key components include the bed, primary cyclone, and secondary dust collection device. Coal is introduced above, below, or directly into the bed by mechanical or pneumatic-type feeders. Ash and spent bed material continuously are removed through downcomers in the bed. Combustion heat is absorbed by boiler tubes immersed in and above the fluidized bed. The combustion gases, containing fly ash, some unburned coal, and entrained bed material, flow overhead to particulate removal equipment. The unburned carbon in the particulates collected overhead is either burned in a separate "cell (commonly known as a carbon burnup cel1) or recycled to the bed.

$A F B C$ systems for production of steam have the following advantages over conventional coal boilers:

- High heat transfer coefficients and volumetric heat release rates (about three times or more compared to conventional pulverized coal which can:

- reduce boiler size by one-half or two-thirds of a conventional unit

- enable units generating up to $200 \mathrm{KPPH}$ of steam to be shop-manufactured (conventional coal-fired units above $50 \mathrm{KPPH}$ steam cannot be shop-manufactured)

- The use of limestone as bed material, which provides a means of situ $\mathrm{SO}_{2}$ removal (removal efficiencies of 90 percent or more can be achieved by using appropriate amounts of limestone)

- The high heat transfer coefficients in the bed allow lower operating temperatures $\left(1500-1750^{\circ} \mathrm{F}\right)$, which potentially can decrease ${ }^{\mathrm{NO}} \mathrm{x}$ emissions

o The firing of a variety of fuels, including all grades of coal, wood and wood waste, fuel oils, and gas. 
FIGURE 4.1

ATMOSPHERIC FLUIDIZED BED COMBUSTION SCHEMATIC FLOW SHEET

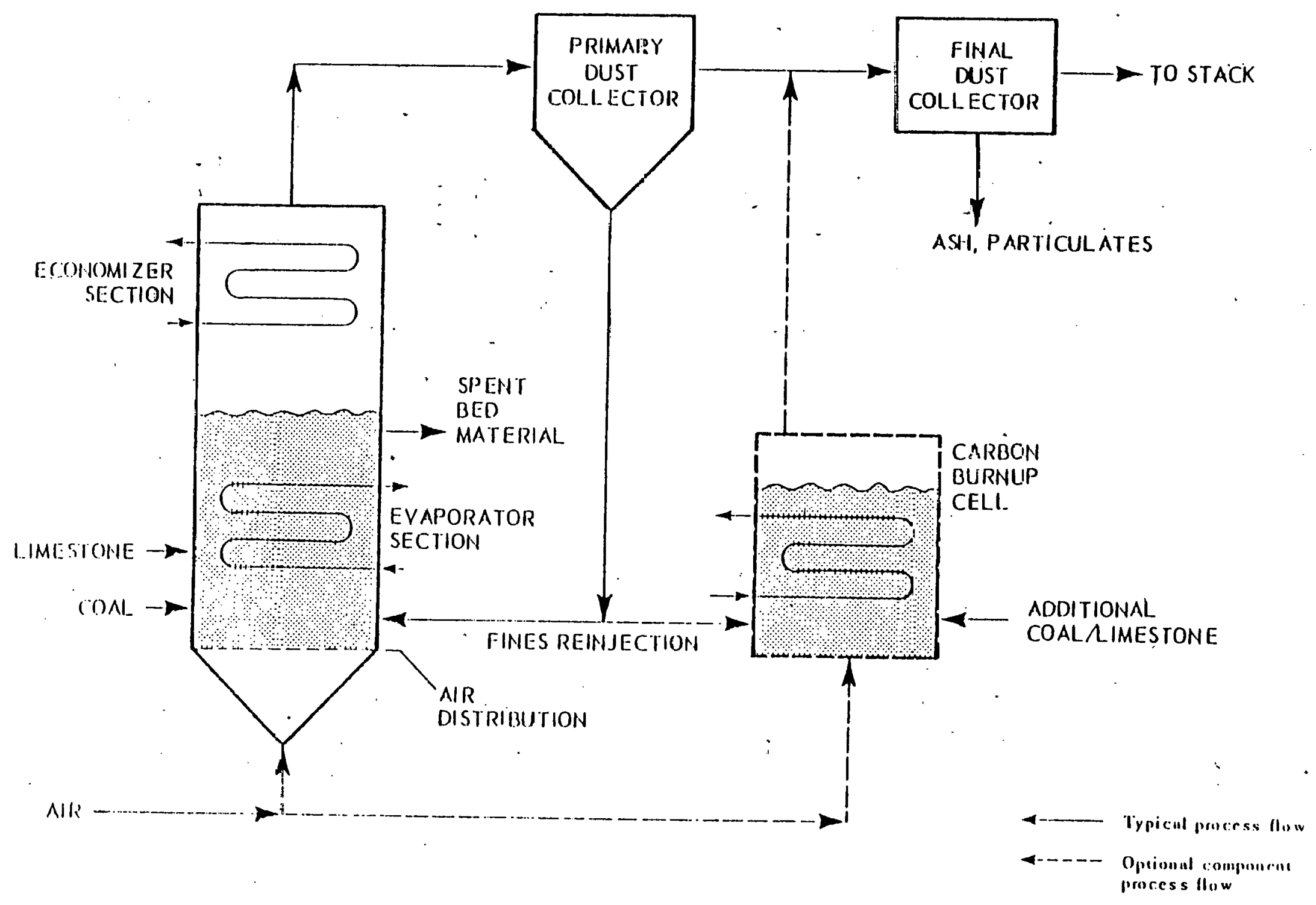




\subsubsection{Combustion Characteristics}

Most of the AFBC systems being developed are coal-based and utilize water/ steam as the medium of heat transfer. In these systems, the heat transfer surface is immersed in the fluidized bed, via vertical or horizontal tubes, and the heat is transferred to a fluid flowing within the tube. The heat transfer surface serves two functions: extracting the heat of combustion from the bed and controlling the bed temperature to a desired level. Since the heat release rates in the bed are quite high, it is essential that the heat transfer medium extract a sufficient quantity of heat to maintain the bed temperature within desired limits.

The maximum temperature to which fluids can be heated depends on the bed temperature. A fairly narrow range of operating temperatures has been established for the fluidized bed boilers burning coal. A bed temperature of approximately $1500^{\circ} \mathrm{F}$ is considered optimum for $\mathrm{SO}_{2}$ removal. Temperatures over $1400^{\circ} \mathrm{F}$ are desirable to achieve rapid combustion and $\mathrm{SO}_{2}$ removal; at temperatures above $1600^{\circ} \mathrm{F}$, however, sulfur removal activity of the limestone drops. At even higher temperatures, alkali metals volatilize and $\mathrm{NO}_{\mathrm{x}}$ generation increases rapidly. Deposition of ash on the heat transfer surface also poses a potential problem.

Bed temperatures higher than $1600^{\circ} \mathrm{F}$ can be employed, however, when burning fuels containing relatively low amounts of sulfur. This would reduce the noed for So, removal and enhance the rate of combustion and heat transfer, thus reducing the $A F B C$ size.

In terms of heat delivery, AFBC offers two advantages over conventional combustion systems burning the same fuels:

- High heat release rates per unit volume of the combustor

- High heat transfer coefficients (for a given heat transfer surface result in more heat delivered to the heat transfer fluid). 
Two disadvantages of the AFBC heat delivery system include the following:

o Heat can be transferred only to fluid media

- High local heat transfer coefficients can adversely affect certain process fluids such as heavy petroleum feedstocks when there is possibility of coke formation inside the heat transfer tubes.

\subsubsection{Technical Issues}

In most cases, optimum energy performance must be balanced carefully with pollution control objectives. Several technical factors influence both the energy and environmental performance of the coal-fired AFBC system. These critical operational parameters include bed design, operating temperature, superficial bed velocity, coal and additive characteristics, and fuel delivery.

The bed design, perhaps the most important aspect of an AFBC unit, is responsible for the unit's key performance characteristics. The critical parameters of bed design are temperature, particle size of coal and bed material, superficial bed velocity, and excess air ratio. Due to its bed design, an AFBC unit can obtain higher fuel throughput than comparablysized conventional coal boilers.

There are some technical uncértainties regarding coal feeding mechanisms which influence particle distribution and sorbent (reactive bed material that removes sulfur) utilization. It is necessary for the AFBC coalfeeding mechanisms to provide reliahle and uniform fucl distribuliun over the bed cross section. Although both mechanical and pneumatic feeders are being used with AFBC units, the use of mechanical feeders may be limited to smaller size units.

\subsubsection{Status of Development}

Although no major technical obstacles appear to bar the commercial application of AFBC units, coal-fired AFBC units with sulfur removal have been 


\section{$4-65$}

demonstrated only on a small scale. Due to the lack of operating experience with large-scale commercial units, uncertainties exist concerning long-term operating performance. In addition, the performance of $\mathrm{AFBC} \mathrm{SO}_{2}$ removal has not been proven reliable, especially at high degrees (over 90 percent) of sulfur removal. To obtain industrial experience with AFBC, the government has issued cost-sharing proposals to industry. The results of this initiative would be significant in the commercialization of this technology.

A large number of AFBC units of varying sizes are in operation or in the design/construction stage in the U.S. and abroad. A partial list of manufacturers offering AFBC boilers commercially in the U.S. includes the following:

- Energy Resources Company, Inc. (Cambridge, Massachusetts)

- Fluidyne Engineering Corp. (Minneapolis, Minnesota)

- Foster Wheeler Corp. (Livingston, New Jersey)

- Johnston Boiler (Ferrysburg, Michigan)

- Babcock and Wilcox, Ltd. (England)

o Mustad and Sons (Norway)

- Stone-Platt, Ltd. (England)

- Jolur Zinc (Oklahoma)

o Babcock Contractors, Inc. (Pittsburg, Pennsylvania)

- Riley Stoker Corp. (Worcester, Massachusetts).

Although most manufacturers offer units capable of supplying up to $60 \mathrm{KPPH}$ (75 MMBtu/hr), some companies are willing to offer units as large as 500 KPPH (steam capacity).

The major government support of AFBC in this country is provided by EPA and DOE. EPA's involvement primarily stems from the environmental evaluation program, and DOE's involvement has culminated in the construction and initial start-up of a 30 MWe pilot AFBC plant at Rivesville, West Virginia (presently in a shakedown phase). The Rivesville plant is a multicell unit 
containing three primary cells and one carbon burnup cell. It is the largest AFBC unit in the world, having an input rate of 15 tons/hr (designed for utility applications). Thus far, start-up problems have hindered base-load testing of the system.

DOE also sponsors a "Component Test and Integration Unit" (CTIU) which is to be constructed at the Morgantown Technology Research Center. This plant (sized at six MWe) will have a number of vertically-stacked beds and a wide flexibility for handling technical problems which may arise during testing of the Rivesville unit. The CTIU is expected to begin opcration in late 1979 or early 1980. A $100 \mathrm{KPPH}$ AFBC industrial-type unit has just started up àt Georgetown University, Washington, D.C. Other institutions in the U.S. involved in FBC development include TVA (funding preliminary design of a 250 MWe FBC unit), EPRI (funding a nine sq ft AFBC combustor development facility), and American Electric Power (planning a 170 MWe pressurized AFBC demonstration plant in Brilliant, Ohio). Development of AFBC under these programs is directed primarily toward utility applications: In addition, Johnston Boilers has operated a $10 \mathrm{KPPH}$ firetube boiler, as a prototype, since September 1977. A $20 \mathrm{MMBtu} / \mathrm{hr}$ unit is operated by Babcock and Wilcox Company in Alliance, Ohio. Several pilot-scale test units also are in operation.

Outside of the U.S., the major' funding for AFBC development originates in the United Kingdom. The Babcock and Wilcox plant at Renfrew, Scotland, operating for more than 5000 hours as a prototype and test unit, has demonstrated 90 percent $\mathrm{SO}_{2}$ retention and a steam generating capacity of over 40 $\mathrm{KPPH}$. A plant raising $80 \mathrm{KPPH}$ of steam by Mustad, at Enkoping, Sweden, currently is operating.

The environmental implications of AFBC have been discussed extensively, parlticularly its $\mathrm{SO}_{2}$ removal capability while burning coal. Basic research in this area is concentrated around improving sulfur retention ability of the sorbent. Although considerable research has been directed 
to studying the regeneration potential of the limestone, it is unlikely that AFBC will be operated with regeneration of limestone, mainly because sulfur retention activity of regenerated sorbent decays very rapidly as it is recycled. The potential for regenerable synthetic sorbents also is being studied.

Several RED and demonstration programs also have been undertaken to ascertain the potential of $A F B C$ for diverse industrial applications. These applications include use of AFBC for process heating (e.g., heating of crude oil), cogeneration, and heat treatment of steel.

Packaged AFBC units with capacities up to $60 \mathrm{KPPH}$ of steam are available commercially. The procurement, installation, and commissioning time for small packaged AFBC units probably will be similar to that for conventional packaged boilers once there is a substantial market. This lead time currently is longer, primarily because most of the AFBC units manufactured are being produced for the first time.

\subsubsection{Technology Cost}

The annual operating, capital, and fuel costs of an AFBC unit all are significant factors in the total steam production costs. The capital costs are subject to economies of scale and should decrease as experience with AFBC increases. Included in the operating costs is the cost of limestone, which is proportional to the level of $\mathrm{SO}_{2}$ removal.

Cost estimates by McKee, Exxon, and GCA are shown in Table 4.15. The Exxon costs are substantially higher due to the inclusion of a full-time backup AFBC unit. 
TABLE 4.15

AFBC COSTS

Source

McKee $^{\text {a/ }}$

Exxnn $\mathrm{b}$ !

$\mathrm{GCA}^{\mathrm{c} /}$
Boiler Size

$(\mathrm{KPPH})$

100

4.64

100

7.0 .3

150
Steam Cost

$(1978 \$ / \mathrm{KPPH})$

a/ "100,000 Pound per Hour Boiler Cost Study," prepared for DOE by Arthur G. McKee \& Company, June 1978.

$\mathrm{b} /$

M.H. Farmer, E.M. Magee, and F.M. Spooner, "Application of Fluidized-Bed Technology to Industrial Boilers," prepared for FEA, ERDA, and EPA by Exxon Research and Engineering Company, Linden, New Jersey, January 1977.

c/ Charles W. Young, et., al., "Technology Assessment Report for Industrial Boiler Applications: Fluidized Bed Combustion," draft prepared for EPA by GCA/Technology Division, Bedford, Massachusetts, July 1979. 


\subsubsection{Indirect Heat}

\subsubsection{Technical Description}

Indirect heating is a method of separating a process heat sink from the source of heat generation through an intermediate heat carrier. Processes that cannot be fired directly by heavy hydrocarbon fuels and coal may utilize indirect firing since the process is separated from the heat source. Thus, by changing the firing method, coal and heavy hydrocarbon fuels may be used in processes now capable of burning only oil and gas.

In indirect heating systems, a working fluid, such as steam, picks up heat energy from a combustor and then flows through a piping network to distribute the heat throughout the process plant. The heat then can be transferred to the process equipment as needed. Thus, there is no direct energy transfer from the combustor to the process; instead, energy is transferred through an intermediate step by way of the working fluid. After the heat has been released to the process, the working fluid is collected and returned to the combustor to repeat the cycle. Closed-loop operation of the working fluid is typical of indirect heating systems.

Indirect heating systems. range from smal1 specialty units smaller than 10 $\mathrm{MMBtu} / \mathrm{hr}$ to large steam boilers of several hundred MMBtu/hr. Since the heat is transported through a distribution network, many small heat sinks can be accommodated with one indirect heating system having a single centrally-located combustor. Figure 4.2 is a.simplified diagram of an indirect heating system that uses steam as the working fluid. Several process heat sinks are shown.

Various working fluids can be used in indirect heating systems. While steam is used in the majority of indirect heating systems, other materials also used include hot water, air, Dowtherm, mineral oil, molten salts, and molten metals. 
FIGURE 4.2

SIMPLIFIED INDIRECT HEATING SYSTEM

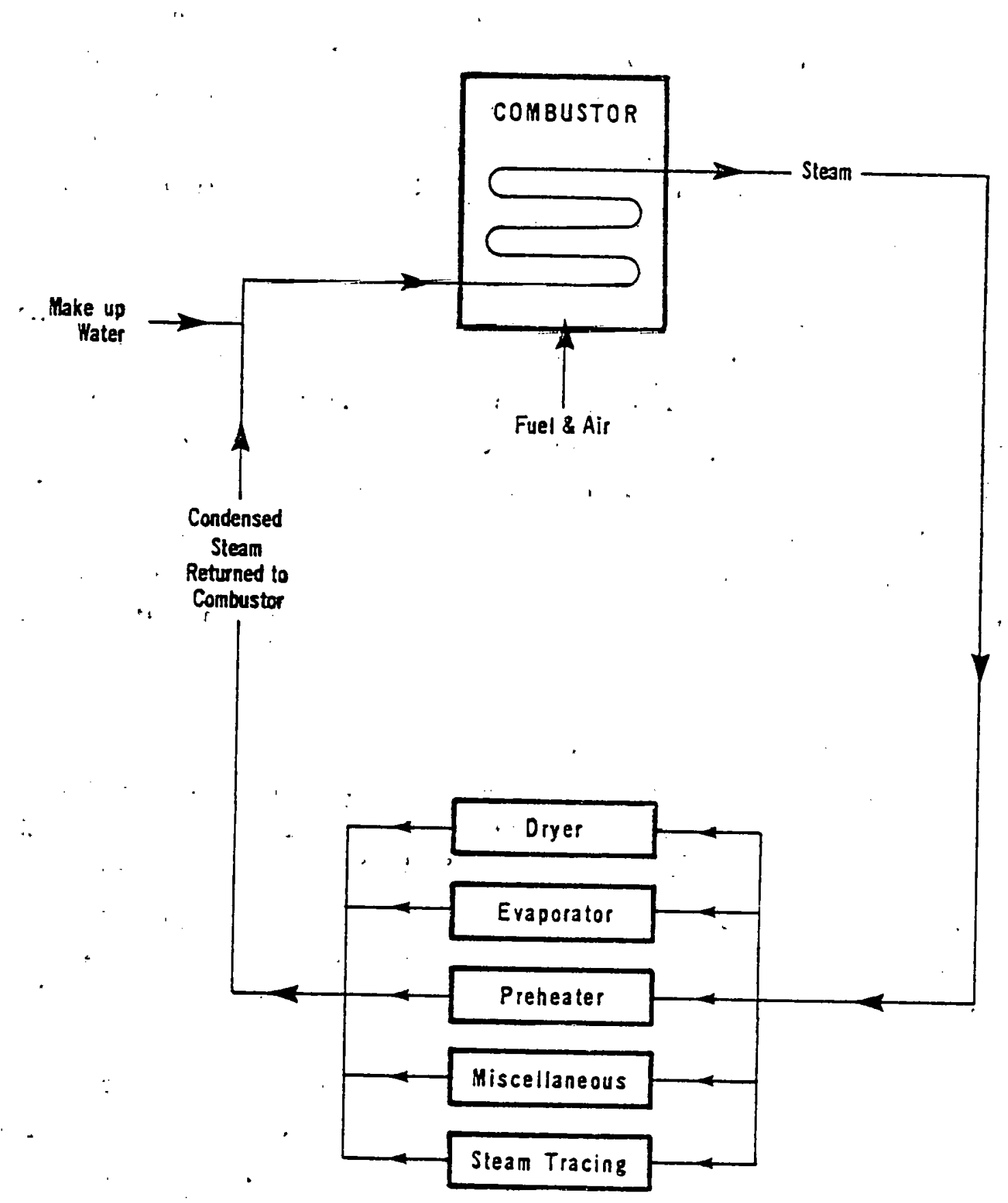


The selection of a particular working fluid depends on the desired temperature and the cost and availability of the fluid. For example, fatty acid distillation columns are operated at approximately 550-600 $\mathrm{F}$. Dowtherm frequently is selected as the working fluid for these systems since the distribution network can operate at atmospheric pressure. If steam were used in this service, the distribution network pressure would be over 700 psig. On the other hand, an isopropyl alcohol distillation column operates at $140^{\circ} \mathrm{F}$. In this system, the steam pressure would be less than 50 psig. Steam would be chosen over Dowtherm in this system because of the high cost of Dowtherm (\$8-9/ga1). See Table 4.16 for a list of working fluids and their application ranges.

The efficiency of an indirect heating system primarily depends on the overall combustor efficiency. The system efficiency for an indirect heating system ranges from 60 to 85 percent. Included in this percent is an efficiency impairment of two to five percent due to heat losses in the working fluid distribution network.

The main advantages of indirect heat over direct heat are heat distribution control and cleanliness of the delivered heat. Since there are numerous heat sinks on an indirect heating network, each heat sink has a small effect on the overall heating system and, thus, a wide turndown range permitting precise temperature control. The turndown on a direct heat system is limited since each heat sink is tied directly to a combustor. In addition to providing temperature control, an indirect heating syslem provides a clean heat supply. In contrast, many systems cannot use direct heating because of product contamination from ash and other impurities in the fuel.

The principal disadvantage of indirect heat is that it requires a two-step energy transfer to transmit the heat from the original fuel to the heat sink. A direct heat process requires only one transfer of energy. 'Since 
TABLE 4.16

APPLICATION RANGES OF WORKING FLUIDS

Working Fluid

Steam

Hot water

Dowtherm

Mineral oll

Molten salts

Molten metals
Operating

Temperature

$(\mathrm{F})$

$200-700$

$300-400$

$30.0-750$

$30-600$

$300-1000$

$400-1000$ 
some heat is lost to the surroundings whenever an energy transfer takes place, the overall energy efficiency of an indirect heat system generally is lower than the efficiency of a direct heat process.

Heat always is transferred from a high temperature source to a heat sink at a lower temperature. The rate of heat transfer is airectly proportional to the temperature difference between the heat source and the heat receiver. The greater the temperature differential, the greater the rate of heat transfer. Since flame temperatures in direct-fired systems are considerably greater than temperatures in indirect systems, the latter requires larger areas for an equivalent amount of heat transfer. This makes indirect-fired systems bulkier and more expensive than direct-fired systems.

As mentioned, the working fluids used in indirect heating systems have upper temperature limits. For example, the heat transfer characteristics of steam deteriorate above $700^{\circ} \mathrm{F}$. Dowtherm, mineral oils, and molten salts begin to decompose as they reach their upper temperature limits (see Table 4.16). Molten metals are very reactive and are incompatible with conventional piping systems above $1000^{\circ} \mathrm{F}$. Therefore, processes that require temperatures above $1000^{\circ} \mathrm{F}$ cannot use conventional indirect heating due to the various working fluids' temperature limitations.

\subsubsection{Heat Delivery}

In indirect heating systems, the working fluid is introduced into the process through special heat transfer equipment. The exact equipment configuration depends on the objective of the heating and the temperature and type of working fluid. Steam systems usually heat a bundle of tubes or a vessel through which heat is transferred to the feedstock. The steam condenses into water, and the water is fed back to the boiler. The temperature to which the feedstock can be heated depends on the initial temperature of the working fluid and the design of the heat transfer equipment. 


\subsubsection{Technical Issues}

Since indirect heat systems have been used for several years, there are no unresolved technical problems. The systems are operated easily and are highly reliable. The heat transfer mechanism is well understood; therefore, scale-up to larger facilities is reliable.

If indirect heating systems were used in more severe applications, some technical problems could arise. The temperatures encountered in existing systems occasionally reach the point at which working fluids begin to decompose. As temperature requirements are pushed higher, new types of working fluids would need to be developed. Also, the suitability of heat. transfer equipment or construction materials would need to be evaluated.

\subsubsection{Status of Development}

Commercial-scale installations of indirect heating systems have been used extensively throughout industry. While new applications for these systems will arise, the existing technology should be adequate for similar systems with operating temperatures lower than $700^{\circ} \mathrm{F}$.

Indirect heat transfer systems that can operate over $1000^{\circ} \mathrm{F}$ are being developed. For example, molten metal heat transfer systems that can operate over $1000^{\circ} \mathrm{F}$ are being developed in the nuclear industry. The present piping systems are limited to temperatures below $1000^{\circ} \mathrm{F}$. Refractory metal alloys of niobium, tantalum, molybdenum, and tungsten are being evaluated for the liquid metal distribution piping.

Since the technology for indirect heating systems already is available on a commercial scale, the technology's lead time is the time required for the installation of a boiler for a steam system. A packaged coal-fired boiler may take a year to be assembled; a large field-erected boiler may take as long as $2 \frac{1}{2}$ years. 


\subsubsection{Technology Cost}

The investment cost of an indirect heating system is directly related to the amount of energy transferred by the system. The larger the system is, the greater the investment cost is. Since certain investment and operating cost savings can be made if one larger system supplies many users, the cost per unit of heat transferred is lower for larger systems.

To a lesser extent, the working fluid used and the system operating temperature will affect the cost of a facility. For example, a Dowtherm system operating at $500^{\circ} \mathrm{F}$ will run at atmospheric pressure. Since Dowtherm costs $\$ 8-9 / g a 11$ on, the initial investment in Dowtherm will be high, and care must be taken to minimize losses from the system. In contrast, consider a steam system operating at $500^{\circ} \mathrm{F}$ at $700 \mathrm{psi}$. While this system necessitates more expensive heat transfer equipment, the cost of the water used to create the steam is negligible.

Steam production costs in conventional coal-fired boilers are distributed evenly among capital, operating, and fuel costs. Note that the costs of pollution control equipment (ESP and FGD) constitute 40-50 percent of the operating and capital costs. The cost of steam production in conventional coal-fired boilers is shown in Table 4.17. The boilers listed are equipped with sufficient pollution control equipment to meet existing environmental iegulations.

\subsubsection{Electrification}

\subsubsection{Technology Description}

Electric heating can be achieved through one of four processes:

- Resistance

- Induction

- Arc

- Dielectric and microwave. 
TABLE 4.17

INDIRECT HEAT COSTS ${ }^{a /}$

Boiler Size

(KPPH)

50

175

325
Pollution

Control

Equipment

FGD

FGD ESP

FGD ESP
Steam Cost

$(\$ / \mathrm{KPPH})$

4.61

4.119

3.55

a/ Capital cost of heat distribution network excluded.

SOURCE: "Industrial Fuel Choice Analysis Model, Primary Model Documentation," prepared for DOE by EEA, Inc., Arlington, Virginia, January 1979. 
There are inefficiencies associated with any energy conversion process. Since electric heat production requires two energy conversion processies, it generally is more inefficient than the single conversion of fossil fuel to heat. An explanation of each of these four electric thermal conversion processes follows.

\subsection{Resistance Heating}

Resistance heating is produced by passing electricity through a semi-conducting material (resistance element). Heat is generated within the resistance element when the flow of electrical current is greater than the element's ability to conduct it; the resulting excess is turned into thermal energy or heat. Probably the most well-known application of resistance heating is the toaster.

The product receives heat from the resistance element by one or more heat transfer mechanisms: conduction, convection, and radiation. The heating chamber's design and its application determine the types of heat transfer that are most important.

Resistance heating is the simplest and oldest form of electric heat generation. For this reason, resistance heating is regarded as highly reliable.

Three of the main components of resistance heating affect furnace efficiency: voltage transformer, resistance element, and furnace enclosure. The voltage transformer and resistance element have efficiencies of 96-99 percent each (electric Btu converted to thermal Btu), but there are thermal losses in the heat transfer. The amount of heat lost in this manner primarily determines the resistance furnace's overall efficiency, which can vary widely (10-95 percent) depending on the furnace's design and application.

One of the main advantages of resistance heating is its high temperaturc operation. The maximum attainable temperature of operation depends on the 
type of material used in the resistance element. Materials such as nichrome, kanthal, and silicon carbide frequently are used in industry at operating temperatures between 2000 and $2800^{\circ} \mathrm{F} .39 /$ Molybdenum silicide and platinum alloys can be used for higher temperature applications but are relatively expensive. Resistance elements do wear out periodically, and their frequency of replacement is increased at high operating temperatures. Resistance heating is limited in its capacity to produce heat by the size and number of resistance elements used.

The advantages of resistance heating over fossil fuels are listed below:

- Safety and convenience

- Cleanliness, absence of hydrocarbons and turbulence in the furnace

- Rapid response and uniformity of temperature, which can be controlled precisely

- Absence of oxidizing conditions in most cases

- Facility and flexibility in producing heat where desired

- Ability to operate in a vacuum, neutral, or reducing atmosphere.

The disadvantages of resistance heating are as follows:

- Maintenance may be required more often, since resistance elements require periodic replacement

- Economics usually do not favor resistance heating over fossil fuels despite all other advantages.

\subsection{Induction Heating}

Induction heating is based on electromagnetic physics. Electricity can be produced within an electrically conductive material by placing the material within a changing magnetic field. If more electricity is produced within the product material than. it can conduct electrically, then the excess electric energy converts to heat energy (resistance heating principle). In short, induction heating is a variation of resistance heating in which the product itself is the resistance element. 
Induction heating comprises two main components: the power source and the magnetic field applicator. The power source converts the frequency and voltage of the electricity supplied by the local utility to the operating frequency and voltage required by the magnetic field applicator. The magnetic field applicator consists of a coil of wire large enough to surround the heated product. When electricity is passed through this wire, a magnetic field is created. It is this magnetic field that produces electricity and subsequently thermal energy within the product material.

The heat produced by this method is generated on the surface of the product material. From the surface, the heat then conducts (migrates) to the centen. Hence the product material must be electrically conductive, limiting the heating applications in which induction heating can be used. Some typical examples of product materials using induction heating are steel, copper, and liquid glass. The principal advantage of induction heating is the speed at which heat is produced within the product. Since heat is generated within the product itseif, the time and inefficiencies associated with the heat transfer from a heat source to the product are eliminated.

The efficiency of induction heating depends on its power source, magnetic field applicator, and the product material being heated. Overall conversion efficiencies (electric Btu to thermal Btu) are 55-65 percent for steel and 30-40 percent for copper. ${ }^{40 /}$ This difference in efficiency is due to the varying electric conductivity of these two product materials. Since copper is more conductive tham steel, the electric current within copper produces less heat energy than the electric current in steel.

Due to the physics involved in this process, induction furnaces are designed and built to meet the requirements of each specific application. Product material, size, shape, heating time, and temperature requirements determine the specific design. Maximum operating temperatures and heating rates in induction furnaces are limited by the type of product material being heated and the furnace design itself. Operating temperatures up to 
$4000-5000^{\circ} \mathrm{F}$ in the ceramics industry are attained, while temperatures up to $2800-3000^{\circ} \mathrm{F}$ are common in the steel industry: $41 /$

The depth of heat generation in the product material is dependent on the induction furnace's operating frequency. The operating frequency influences the rate of heat generation because the power source output is limited at higher frequencies. In the steel industry, some large induction furnaces can provide up to six MMBtu/hr at 60 cycles pcr secoml (cps). At higher frequencles, above $200 \mathrm{cps}$, maximum heat flux is limited to three $\mathrm{MMBtu} / \mathrm{hr}$. The operating frequency is determined by the process requirements of the product: Sixty cps, a low frequency, is used in melting applications in which deep heat penetration is desired. Higher frequencies $\left(10^{5}-10^{6} \mathrm{cps}\right)$ are used in applications in which only the product's surface requires heating. For example, in the surface hardening of steel in which only the surface volume needs to be heated, a high operation frequency is used so that heat is generated only on the surface of the material. Because heat is generated at the product surface, there is very lit.tle energy wasted compared to fossil fuel processes which heat up a greater percentage of the work material to accomplish the same results.

The advantages of induction heating over fossil fuel use are listed below:

- Limited parts or surfaces of a metal piece can be heated instead of the entire piece

- Energy is used only in the heating of the product material and is not wasted in furnace start-up and idling time

- Accurate control of temperature is accomplished by controlling power input. Fossil fuel-fired furnaces equipped with pyro-

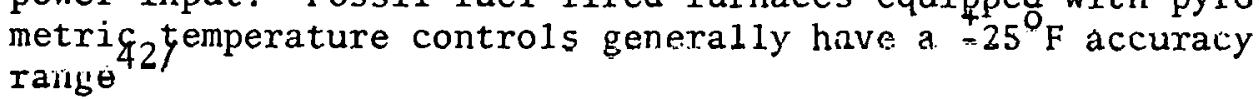

- There is no contamination of the product from combustion gases

- Heating can take place in any atmosphere, including a vacuum

- Induction furnaces incorporate easily into production situations. Induction furnaces lend themselves to automation, 
good reproduction of temperatures, rapid heating, and environmental comfort due to lack of noise and heat loss

- Induction furnaces cause minimum oxidation of material surfaces in metallurgical applications.

The disadvantages of induction furnaces are listed below:

- These furnaces lack flexibility since each induction furnace is designed for its specific application

- The product's size is limited both in dimension and weight, due to physical limitations of the magnetic field applicator (coil) size and power supply output, respectively

- Product materials are limited to those which are electrically conductive

- Heat input rates usually are small (six MMBtu/hr and less).

\subsection{Arc Heating}

When an electric current is interrupted by an air gap, electricity will continue to flow through the circuit by jumping the gap when the electric voltage is high enough. This is the principle upon which spark plugs in an internal combustion engine work. At very high temperatures, the electric spark (in larger applications, an arc) converts electric energy to heat energy. Due to their high operation temperature, arc furnaces are preferred over fossil fuel furnaces in some industrial applications.

There are two types of arc furnaces: direct and indirect. Indirect arc heating has two electrodes near the material being heated. The electrodes and arc between them do not come in contact with the product material. Heat is transferred. from the arc to the product principally by radiation and partially by convection heat transfer mechanisms. In direct arc heating, the electrical arc jumps from the electrode to the product. The electricity then flows through the product material to its containment vessel and then back to the electrical circuit. Heat is produced and transferred in two ways. First, as in indirect arc furnaces, heat is produced and then radiated from the electric arc to the product. In ad- 
dition, heat also is produced by resistance as the electricity flows through the material. Direct arc furnaces are limited in their applications to electrically-conductive product materials. The metallurgical and glass industries are two users of direct arc heating.

The arc heating process requires two relatively simple components for operation: a power source and a furnace. The power source (voltage transformer) converts utility line voltage to the operational voltage required for the process. The electrodes receiving the operational voltage are part of the furnace. Arc furnaces, because of their high temperature operation, are used almost exclusively in melting applications.

The simplicity of axc heating results in high energy efficiency. The product material and the furnace design primarily determine the furnace efficiency, typically 55-75 percent. An average steel smelting operation incorporating an arc furnace operates from 65-75 percent efficiency. In glass applications, direct arc furnaces operating on a continuous basis liave cfficiencles ranging from 65 to 80 percent.

High temperature potential is an arc furidice's strongest selling point. High arc Lemperatures enable high furnace temperatures to reach $6000^{\circ} \mathrm{F}$ in some vacuum furnace applications and $5400^{\circ} \mathrm{F}$ in an atmospheric furnace used in the production of magnesium oxide. Most arc furnaces used in the production of steel operate from $2800-3400^{\circ} \mathrm{F}$, while arc furndces used in the production of copper operate near $2000^{\circ} \mathrm{F} .43 /$

Metallurgical industries are the largest users of arc furnaces. Large arc furnaces in this industry can contain 500 tons of material and have heating rates of up to $100 \mathrm{MBBtu} / \mathrm{hr}$. Smaller applications have capacities of $500-$ $1000 \mathrm{lb}$ with a heating rate of $0.25 \mathrm{MMBtu} / \mathrm{hr}$. A common arc furnace size in the steel smelting industry is 30-40 tons. ${ }^{44 /}$ 
The advantages of arc heating over fossil fuels are:

- High temperature potential

- Rapid temperature response

- Cleanliness due to absence of hydrocarbons.

The disadvantages of arc heating include the following:

- Direct arc furnaces require electrically-conductive product material

- Arc furnaces are limited to high temperature applications (usually melting).

\subsection{Dielectric and Microwave Heat Generation}

Dielectric and microwave heat generation involve the vibration of molecules to produce heat. Product material molecules vibrate when subjected to an alternating electric field at very high frequencies. Vibration among the molecules creates friction and subsequently heat throughout the material's volume. The composition of the product material determines the frequency of the alternating electric field needed to effect molecular vibration. The distinction between dielectric and microwave heat generation is the frequency of operation, $10^{6}-10^{8} \mathrm{cps}$ and $10^{9}-10^{11} \mathrm{cps}$, respectively. Only some materials can be heated by this method; for example, electricallyconductive materials cannot be heated by microwaves or dielectrics.

Dielectric or microwave heat generation systems require two components for operation. A power supply is needed to convert the frequency and the voltage of incoming utility electricity to the frequency and voltage required by the electric field applicator. The second component, an electric field applicator, subjects the product to an alternating electric field. The electric field applicator consists of two plates or a series of rods situated on opposite sides of the product. 
The efficiency of these systems is determined by heat losses which, in turn, depend on electric conversion losses in the power supply as well as electric field application losses. Overall efficiency (electric Btu converted to thermal Btu) of most dielectric applications ranges from 55 to 65 percent at rated output and 45-55 percent at half-load. ${ }^{45 /}$ Microwave applications are typically 50-60 percent efficient. ${ }^{46 /}$

Most industrial applications use dielectric or microwave ovens in low and medium temperature ranges. Drying, curing, baking, bonding, and gluing are typical processes using dielectrics or microwaves. The temperature of operation required depends on the physical properties of the product material.

The advantages of dielectric and microwave heat generation over fossil fuels are listed below:

- The principal advantage is quick and even heating, resulting in shorter process cycle, improved quality, and greatcr productivity

- The operation frequency is tuned to heat one material composition

- High efficiency is obtained because power is consumed only in the product material. There is no heat waste during start-up and idling time as there is in fossil fuel furnaces

- Once the product material is dried, cured, or polymerized, the chemistry change in the product material will neutralize the heating mechanism (heating physics)

The disadvantages of these applications are as follows:

- Heat flux capacity is limited in both dielectric and microwave applications

- Product material is limited to non-electrically conductive materials. 


\subsubsection{Technology Status}

All four types of electric heat generation technologies are being used in industrial applications and are commercially available. There are no major technical issues inhibiting the commercial acceptance of these technologies. Established industries currently are working full-time on the design, building, and installation of each of these heating types. While all four types of electric heat conversion furnaces are available, they are not necessarily applicable to all end users. Product material requirements and furnace economics limit electric furnace applications.

Resistance heating is adaptable to most industrial applications in new units. It is not widely used, however, because of its relative economics compared to fossil fuels. Resistance heating is utilized in industry, usually when $i_{j}$ ts performance advantages (due to its heating characteristics) outweigh the economic disadvantages associated with its use. Resistance furnaces are used quite frequently in the metallurgical industry where high temperatures and accurately controlled atmospheres are desirable. Other applications include the annealing of glass, brazing of metal parts, and the enameling of porcelain. Laboratories almost exclusively use this form of heating because it is convenient, readily controlled, and clean.

The application of induction heating in industry is restricted to materials which are electrically conductive, thus limiting its use almost exclusively to metallurgical applications. An exception to this is the glass industry, where induction heating is used to anneal molten glass (which is electrically conductive). Induction heating provides a very even heat to the glass by producing heat within it. In the metallurgical industry, induction heating is used in melting, forging, annealing, surface hardening, brazing, and soldering operations.

The metallurgical industry is the largest user of arc furnaces. The greatest use is in the manufacture of special steels, but it also is used in nina 
smelting processes and for the production of refractory metals such as titanium and molybdenum. Both these materials oxidize very easily; a vacuum atmosphere as well as a high temperature is needed in their melting process. Glass production incorporates a combination direct arc and fossil fuel furnace. Fossil fuel is used to melt a small portion of raw materials, then is replaced by direct arc heating herause moltcn glass is elcctricaliy conductive. Arc heating in this application provides a faster maltrown, thus increasing furnace throughput. The electrochemical and abrasive industries also use arc furnaces in their industrial uperations.

Dielectric and microwave heat generation applications are used to dry paper and webs and to cure resin in sand coves used for metal casting and particle board and panel.

\subsubsection{Technology Cost}

The economics of electric heat generation primarily depend on the type of electric heat generation used, its capacity and application, and on local utility rates.

In an industrial situation capable of utilizing process steam in the $300-$ $800^{\circ} \mathrm{F}$ range, cogeneration can improve the economics of electric heat generation. Cogeneration involves generating electricity onsite in industry. Both the electricity and the waste heat produced by the electric generation process are utilized within the industrial plant. The utilized waste heat replaces heat energy that otherwise would have to be derived from some other tuel source. The result is that in industrial plants able to use waste heat from electricity generation $\left(300-800^{\circ} \mathrm{F}\right.$ steam), the energy lost in electricity generation is about half that normally lost by utilities. The savings in fuel cost usually outweigh the extra cost involved in installing and operating a cogeneration facility. Thus, electricity produced by this method makes electric heat generation economically more desirable to the industrial user. 
Product material handling systems are an additional factor to consider in the cost analysis of electric heat generation applications. An electric furnace can heat and melt product material but it needs additional equipment to load and unload its contents. This additional equipment can be quite expensive, depending on the industrial application. Some induction furnace applications which melt metals require material handling equipment that costs 50-100 percent of the furnace cost alone. Since the cost of material handling equipment depends on its application and since electric heat generation is used in a wide range of industries, the cost of this equipment is not included in the cost range presented below.

Resistance. Electric resistance heating can be adapted to a wide range of industrial applications operating below $2700^{\circ} \mathrm{F}$. For this reason, it is difficult to attach dollar signs to such a wide variety of applications. Generally, a resistance furnace's installed capital cost is somewhat lower than an equivalent fossil fuel furnace, but its operational cost is higher. Operational costs are higher for electric energy because electricity costs more than fossil fuel for each thermal unit of energy de1 ivered.

Induction. There are two main components to an induction furnace: its power supply and the furnace itself. A current rule of thumb in metallurgical melting applications is that a power supply costs $\$ 1000 / \mathrm{kW}$ of power output. Furnaces, on the other hand, become progressively less expensive per ton as they become larger. Some current uninstalled furnace costs are $\$ 22,000$ for one ton capacity, $\$ 60,000$ for five ton capacity, and $\$ 200,000$ for a 60 -ton furnace. ${ }^{47 /}$ The power supply is the major cost component of an induction furnace process. In order to utilize the power supply to its greatest degree, some industrial users have two furnaces for each power supply. In this way, the power supply is always in use, heating at least one furnace. 
Arc Cost Range. Metallurgical, abrasive, glass, and electrochemical industries use electric arc furnaces in their industrial processes. Due to this wide variety of applications, it is difficult to provide representative cost ranges. A manufacturer of arc furnaces for the metallurgical industry quoted a 40-ton capacity steel furnace capable of melting 20 tons of steel/ hour (12.8 MMBtu/hr) at a cost of approximately $\$ 1.1$ million (uninstalled). $48 /$

Dielectric and Microwave Cost Range. Cost for this type of clectric heat generation generally is split into two categories: power supply (frequency generator) and the frequency applicator. In most industrial applications, the power supply cost accounts for the majority of the total unit price. An average industry rule of thumb cost for a dielectric power supply is $\$ 1000 / \mathrm{kW} ;{ }^{49 /}$ a microwave power supply costs approximately $\$ 2000 /$ kW. ${ }^{50 /}$ The frequency applicator applies the generated frequency furnished by the power supply to the product material. The applicator is engineered to each particular industrial use, and its cost depends on the size and complexity of its application. The frequency application in most instances is minor in cost relative to the power supply.

Electric Boilers. The capital costs of electric hnilcry genorully are lower than those for coal-fired units with pollution control equipment. In addition, $O \& M$ is less cost1y. The cost of electricity, however, can result. in a higher steam cost. Certain specific boiler operating requirements, such as low cápacity utilization and strict emissions regulations, may justify the use of an expensive fuel such as electricity. The normalized cost estimate from a report by Gilbert/Commonwealth for a $300 \mathrm{KPPH}$ boiler plant consisting of three $100 \mathrm{KPPH}$ electric boilers is $\$ 9.56 / \mathrm{KPPH}$. This normalized steam cost assumes an electricity price of $\$ 0.0291 / \mathrm{kWh}$. The cost of electricity accounts for 89 percent of the total steam cost. 


\subsubsection{Solar Technology}

\subsubsection{Technical Description}

The basic concept behind solar industrial process heat (IPH) systems is the conversion of solar radiative energy into thermal energy and the application of this thermal energy as process heat or steam. A heat transfer fluid, e.g., air, water, silicon oil, or hydrocarbon oil, absorbs incoming radiation as it circulates through a collector or receiver pipe. The working fluid then is transported for direct use or is passed through a heat exchanger to generate process heat or steam before being recirculated through the collector or absorber pipe.

In industrial application, the use of storage and/or a fossil-fired backup energy system is required for most solar applications. Cloudy weather or air pollution can reduce or eliminate solar collection and conversion by diffusing or scattering direct radiation. At such times, energy will have to be drawn from storage or provided by a conventional backup system. Further, seasonal output fluctuations may need to be dampened by storage or a backup capability.

Due to the cycling between sunlight and darkness, the maximum capacity utilization of a solar boiler without storage is only about one-third. In areas of limited sunlight (i.e., the northeast U.S.), the capacity utilization could be less. To raise capacity utilization above one-third, storage or backup systems will be required.

Solar systems may provide steam at a variety of temperatures and pressures or process heat. Variations in the properties of heat delivered are a function of two factors discussed below: the type of collector employed and the system configuration. 


\subsection{Collectors}

Collectors may be divided into three categories: stationary nontracking collectors; single-axis concentrating collectors; and dual-axis concentrating collectors. $51 /$ stationary collectors most commonly include solar ponds and flat plate collectors which are used for low temperature hot air or water applications. They collect both direct and diffuse radiation.

Solar ponds are typically 10 feet wide and no more than one foot deep. Water is contained in large flat plastic bags on a foundation of sand or gravel. Generally, the ponds are covered with bowed panels of rigid transparent plastic to increase energy retention via a greenhouse effect and to protect the pool. Water temperatures of $150^{\circ} \mathrm{F}$ can bc achicved by. this method. For flat plate collectors, the absorption plate (usually made of copper or aluminum) is painted black or coated to maximize absorption and minimize radiation losses. Thermal energy is removed by a heattransfer material moving along the plate. When water is used, tubing is bonded thermally to the plate; when air is used, the air is blown over the front of the plate. The temperature of working fluids can range between $1.5 n$ and $200^{\circ} \mathrm{F}$ 。

The most prevalent type of one-axis concentrating collector is the parabolic trough. These collectors track the sun throughout the day along one axis, usually east to west. The direct radiation is concentrated by a factor of between 20 and 50 by reflecting and focusing it onto a linear absorber tube at the focal point of the collector. $52 /$ In many designs, the absorber tube is placed inside a larger glass tube, and the air between the two is evacuated to insulate the absorber tube from convective and conductive heat losses. 53/ Conversion efficiency of current models is approximately 60 percent. Temperatures may range from $150-650^{\circ} \mathrm{F}$ and are a function of the concentration ratio (area of the collection surface to area of receiver tube) and the flow rate of the fluid through the receiver pipe. The lower the flow rate, the higher the temperature. To maintain a con- 
stant temperature output, flow rates must be varied to account for daily and seasonal changes in insolation.

Double-axis collectors generally are more efficient than single-axis collectors. They can maximize their exposure to the sun by moving both eastwest and north-south. Two basic types of double-axis tracking collectors are being developed: large parabolic dish collectors and heliostats.

Large parabolic (point-focusing) dish collectors focus sunlight onto an absorber element several meters above the collector at the focal point of the dish. Approximate operating temperatures vary between $400-1500^{\circ} \mathrm{F} .54 /$ Heliostats are employed in a central receiver configuration, i.e., a central receiver boiler mounted on a tower is surrounded by a heliostat field, which focuses sunlight on the receiver unit. A heat transfer fluid (steam, liquid sodium, molten salt, or hydrocarbon oil) carries the thermal energy down the tower and to the process. Working fluid temperatures can reach $2500^{\circ} \mathrm{F} .55 /$

\subsection{Basic Configurations}

The above collector types can be employed in several configurations to provide low (below boiling point) temperature air or water to much higher temperature and pressure steam or high temperature process heat. The solar portion of the facility may be sized to meet the full output capacity of a boiler/heater or, alternatively, may be sized at a fraction of the output capacity, in which case the difference is provided by a conventional system operating simultaneously with the solar system. Solar systems also may be used in a preheat mode.

Process efficiencies, as measured by the ratio of useful Btu output to Btu impinging on collector aperture, vary considerably depending on the particular application. Total system efficiencies are a function of several factors (collector cfficiencies, thermal losses from piping, losses in heat 
exchange units) and are sufficiently variable to make generalization difficult. A crude estimate for the efficiency of parabolic trough systems would be around 30 percent. ${ }^{56 /}$ Central receiver process efficiencies are higher due to less extensive piping and reduced thermal losses from this source.

'The productivity of solar systems is affected most by insolation characteristics. The output of systems in areas of frequent cloud cover, high relative humidity, or pollution problems will be reduced. This issue is significant for all solar applications, but especially for industrial systems given the poor insolation characteristics of areas where most major industry is located. Low temperature flat plate systems are affected by poor insolation to a lesser degree than concentrating systems, which can use only direct insolation. The ratio of diffuse to direct insolation increases with such factors as cloud cover, relative humidity, and pollution.

Solar process heating is an onsite technology because of the type of energy produced. Steam, hot water, and hot air are the probable energy products of solar energy; these products cannot be transportcd economically over long distances. The quality (temperature and pressure) of energy produced depends on the solar technology employed, and the end use of these energy sources in direct or indixect applications depends on the quality of the energy produced.

Solar energy use in the industrial sector has several potential advantages over fossil energy use. Fixst, snlar energy is an incxhanstable energy source and its use could diminish the use of scarce fuels. Second, solar energy is produced with minimal environmental impact, unlike the energy produced by burning fossil fuels, especially coal. The principal reasnns why the industrial sector presently is not using solar energy are:

- The novelty of solar technology

- The relative economics of generating steam/hot water by solar versus fossil fuels 
- The extensive space requirements for a solar energy system compared to an equivalent size steam generator. For example, the land required for a central receiver system capable of genergying $1000^{\circ} \mathrm{F}$ steam at a rate of $50 \mathrm{MMBtu} / \mathrm{hr}$ would be 55-60 acres. An equivalent or larger amount of land would be necessary for a parabolic trough system to generate lower temperature steam at the same rate (because system efficiencies are lower).

\subsubsection{Technical Issues}

Viable solar process heat technologies in the 1980-1990 time frame include low temperature air or water applications using stationary collectors and possibly intermediate temperature applications employing parabolic troughs. For such applications, there are no major unresolved technical issues as there are for higher temperature systems employing heliostats or pointfocusing dishes (e.g., material stresses in boiler due to temperature fluctuations caused by sunlight variability). One possible exception is an advanced storage system (e.g., chemical and battery storage). However, current thermal storage technology should be adequate for the 1980-90 time frame, so that unresolved issues surrounding storage are not critical for near-term applications.

Even though there are no strictly technical obstacles to the commercialization of viable solar technologies, there are several technical issues that could affect penetration into the marketplace. These issues mostly involve cost trade-offs of improving collector efficiencies and reliability. For example, the efficiency of parabolic trough collectors can be improved from the current 60 percent level to 80 percent if $60 \mathrm{mill}$ silvered glass is substituted for aluminum as the reflective surface. The trade-off is that silvered glass is more expensive than aluminum (a pattern that holds true for all high reflectivity materials), and it is doubtful that collector efficiency improvements above the current level will reduce costs appreciably for this reason. Further, durability of silvered glass over the operating life of the plant is not certain. Glass collectors may be pitted or broken by blowing sands, winds, and hail, which degrade collector per- 
formance (especially for concentrating collectors) and increase costs due to the more rapid turnover time of collectors. These factors are not resolved at the present time.

Another unresolved collector-related technical problem (for concentration systems) involves the collector support structure. Support structures must be exceptionally rigid so that collectors retain their precise tracking orientation during high winds, Lightwright honeycombed support struclures are being improved to reduce support materials requirements. Again, there is a cost trade-off in that lighter support materials are more expensive. Efficiency and cost reductions for tracking systems are critical, given the collector field's high cost and its high proportion of total system cost.

\subsubsection{Technical Status}

The technical status and short-term commercialization potential of solar energy systems vary considerably based on the temperature requirement. of the process. Lower temperature applications, such as thc dehydration of foods, concrete block curing, hot water production for can washing, and other applications in which temperatures are less than the boiling point for water, currently are being demonstrated in a number of facilities. $58 /$ The quality of energy in these applications is basically similar to heating and cooling in the residential and commercial sectors.

Intermediate temperature applications, e.g., steam from $150-550^{\circ} \mathrm{F}$, using parabolic troughs have not yet been demonstrated.' Four industrial process steam experiments are being conctructed. Thesc nor fairly luw tempcrature and pressure applications, less than $400^{\circ} \mathrm{F}$ and 135 psig. ${ }^{59 /}$ Operation of thcse facilities should begin during 1980. Three other projects are in the design stage and will begin operation in 1981. Parabolic troughs them= selves have undergone testing at Sandia's solar thermal test facility, and 200,000-300,000 sq $\mathrm{ft}$ of trough have been manufactured thus far by four primary collector manufacturers. $60 /$ However, the problems of collector 
performance and reliability are still unresolved. Due to the limited operational experience of complete systems, considerable further deyelopment is needed.

Higher temperature applications involving point-focusing dishes and heliostats (central receiver systems) are less advanced in terms of process heat application than the lower temperature systems. Point-focusing dishes have been tested at Sandia's laboratory but have not been used in systems experiments to date. However, three small-scale projects (approximately 400 $\mathrm{kW}$ ) involving electricity generation and waste heat recovery are scheduled to begin operating in the next year. ${ }^{61 /}$ Currently, heliostats and different central receivers are being tested at Sandia's 5 MW thermal test facility. A low MWe pilot plant is scheduled to generate electricity to begin operating in $1982.62 /$

Ongoing R\&D is fócused primarily on collector testing and initial demonstration of lower temperature hot air and hot water systems, with some experiments beginning for parabolic trough, point-focusing dish, and central receiver systems as mentioned. These efforts could lead to a commercial capability of lower temperature hot air and hot water systems in the 1985-1990 time frame and, to a lesser degree, some intermediate temperature (parabolic trough) systems.

Higher temperature systems (above $550^{\circ} \mathrm{F}$ ), employing heliostats and pointfocusing dishes, will not be commercially available in the 1985-1990 time frame due to their incomplete development. At the present time, these systems are being considered exclusively in the context of total energy. systems (cogeneration) and utility generation, without any plans for demonstration specifically for industrial process heat applications. Thus, unless the focus of the program is changed, these systems are unlikely to be adapted to the industrial sector in the near future. 


\subsubsection{Technology Costs}

Solar system costs will be exceedingly variable. Factors affecting costs are discussed below.

Geographic Locality. "Geographic 1ocality will affect the costs of systems enormously. Efficiency reductions from poor insolation charactcristics must be compensated for by additional collectors. Collector costs are a major capital cost. Deterioration of collector surfaces by particulate buildup will require more frequent cleaning, an additional cusl factor. Systems costs in Houston, an area of relatively poor insolation, are more than twice as high as costs in Phoenix, an area of high insolation. Regional fuel price variability (which exceeds insolation variability in maguitude) also is an important geographic determinant of solar system costs.

Systems Temperature. System costs escalate with the temperaturc generated. This is attributable to two factors: declining collector efficiencies and higher piping costs. Collector efficiencies decline from increased heat losses at higher temperatures. The efficiency declino of parabolic trough collectors, for example, is as follows: $200^{\circ} \mathrm{F}, 67$ percent efficiency; $400^{\circ} \mathrm{F}, 65$ percent efficiency; and $600^{\circ} \mathrm{F}, 58$ percent efficiency. $63 /$ Piping costs increase because working fluid pressures escalate with increasing temperatures, and piping able to withstand additional pressures is cxpcnsive. Piping costs represent approximately one-third of the system's costs. The use of therminol or other hydrocarbon working fluid can reduce pressures, but concomitant piping cost savings may be offset by the increased expense of these fluids. System costs for a parabolic trough system producing low pressure steam at $267^{\circ} \mathrm{F}$ may be 70 percent lower than for the cost of high pressure steam at $360^{\circ} \mathrm{F} .64 /$

Future Collector Costs. Collector costs comprise more than 50 percent of the cost of solar systems. Future cost reductions, particularly for 
parabolic troughs and other higher efficiency collectors, will be necessary to make the systems competitive. Since most of the cost of collectors is in the material, the potential for mass production techniques to reduce collector costs is uncertain. Installed costs of collectors currently range from $\$ 25-30 / \mathrm{sq}$ ft. Systems costs will depend significantly on the ultimate costs of collectors.

Storage Costs. Systems costs will depend to some extent on whether storage is incorporated versus an auxiliary fossil fired backup. Cost differences in this case will be determined largely by site-specific factors.

Land Costs. Land costs will be an important cost variable in solar process heat applications given its relative unavilability and high cost in industrial areas.

Financing and Incentive Structure. The current structure of financing in the industrial sector and possible future changes will affect the de facto cost of solar process heat systems. Most industries evaluate investments by short-term discounted cash flow criteria, e.g., payback period or return on investment. Payback periods of three years or less are required. 65/ Capital costs of solar process heat systems (except very low temperature applications employing solar ponds) are extremely high even on a life-cycle basis; paybacks within a three-year period are out of the question. Additionally, fuel costs are deductable as an operating expense. The present value of fuel cost deductions is larger than those accruing from depreciation schedules applying to the capital costs of solar equipment. 66/ Thus, there is no incentive for industry to install solar systems. If tax changes are instituted, e.g., ITC's or accelerated depreciation, solar systems will be more viable. System costs are relatively sensitive to these factors. ${ }^{67 /}$ Predicting the possibility of such changes is difficult at present. 
Given the above factors, costs for solar industrial process heat systems will be variable and extremely hard to predict at this time with a comfortable degree of reliability. The cost of producing $360^{\circ} \mathrm{F}$ saturated steam (153 psi) for Phoenix and Houston, respectively, has been estimated at $\$ 19.40$ and $\$ 41.39 / \mathrm{MMBtu}(\$ 23$ and $\$ 49 / \mathrm{KPPH}$, in 1976 dollars). 68/ Assumptions for these estimates are shown in Table 4.18. Note the assumed installed system costs of $\$ 19 / \mathrm{sq} f t$. which is considerably less than the current installed costs of collectors alone as noted above. These estimates must be regarded with the utmost caution, given the uncertainties previously noted.

For example, Table 4.19 shows steam cost estimates in $\$ / \mathrm{KPPH}$ as presented by Battelle and Mitre for a single axis parabolic trough and a dual axis parabolic dish, respectively. In both cases, the collector capital cost constituted the major cost component. The large difference between the normalized costs is attributable to a large difference in estimated collector heat production. Even though the Dallas and Houston insolation rates are similar, the Mitre study assumed an annual collector heat production four times greater than that of the Battelle study. A portion of this difference is due to the higher efficiency of the parabolic dish collector. 
TABLE 4.18

ASSUMPTIONS OF COST ESTIMATES

1. Total installed system cost: $\$ 19 / \mathrm{ft}^{2}$

2. Before-tax costs based on:
a. $10 \%$ reai after-tax return
b. 20-year life
c. Straight-line depreciation
d. $1 \%$ of the capital cost for $0 \& M$, replacement, and insurance
e. $50 \%$ Federal and state tax
f. $10 \%$ initial investment tax credit
g. Zero inflation rate
h. Zero salvage after 20 years

3. No storage provided

SOURCE: E. Ha11, "Survey of the Applications of Solar Thermal Energy Systems to Industrial Process Heat," prepared for ERDA by Battelle Columbus Laboratories, Columbus, Ohio, 1978. 
TABLE 4.19

SOLAR COST

(\$1978)

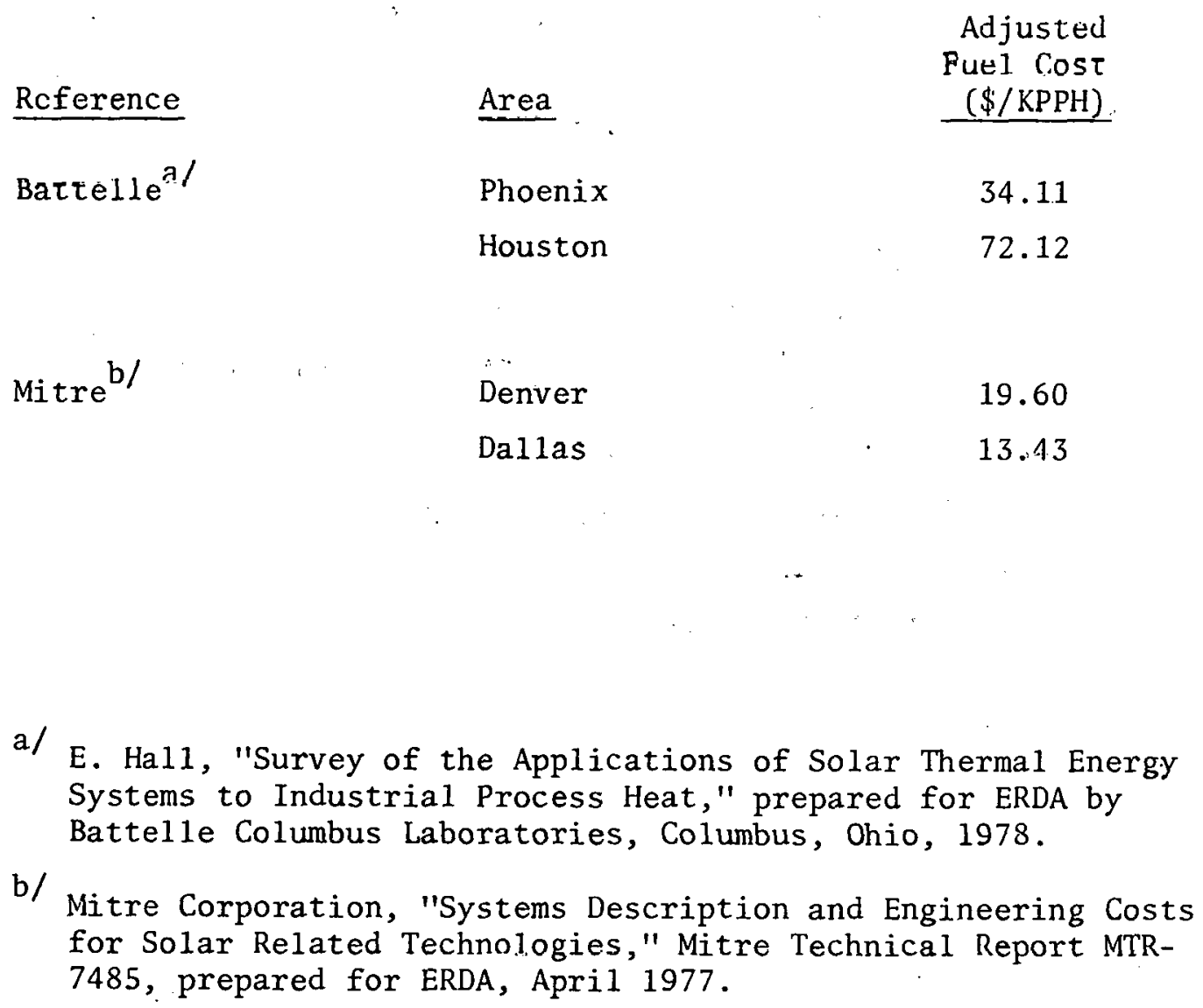


FOOTNOTES

1. "Technical Alternatives to Flue Gas Desulfurization," preliminary report prepared by Battelle Columbus Laboratories, Columbus, Ohio, December 1977.

2. Ibid.

3. Conversation with Dr. Kirt C. Byas, McDoue11-We11man Company.

4. American Lurgi Corporation, "Lurgi Pressure Gasification Performance Record," October 1979.

5. Kopper Company, "Gasification Plants using the K-T Process."

6. William C. Thomas, "Synfue1s from Coal as Emission Control Techniques for Industrial Boilers," draft report prepared by Radian Corporation for EPA, January 1979.

7. Larry A. Rogriguez and Fred R. Se11, "Florida Power ,Corp./Dravo Corp. Coal/Oil Composite Fuel Program," presented to the First International Symposium on Coa1/Oil Mixture, St. Peetersburg, Florida, May 7-9, 1978.

8. A. Brown, Jr. (Ed.), "Final Report of the Genera1 Motors Corp. Powdered Coal-In-Oil Mixture Program,"' FE-2267-2, August 1977.

9. A.B. Shimiza and T.L. Derbridge, "A Demonstration of Coa1-0il Mixture Combustion in an Industrial Scale Boiler," presented at the First International Symposium on Coal/Oil Mixture, St. Petersburg, Florida, May $7-9,1978$.

10. Arthur G. McKee Company, "Coal/Oil Mixture: A Preliminary U.S. Market Study," presented to the First International Symposium on Coa1/0il Mixture, St. Petersburg, Florida, May 7-9, 1978.

11. J.B. Reed and R.M. Lermer, "Methanol: A Versatile Fuel for Immediate . Use," Science (192:4119), December 28, 1973

12. King, Stoker, and William, "Methanol - Fuel or Chemical," Hydrocarbon Processing, June 1978.

13. D.L. Hagen, "Methanol as a Fuel: A Review with Bibliography," Society of Automotive Engineers, Inc., Abstract \#770792, 1977.

14. R.G. Schweiger, "Burning Tomorrow's Fuels," Power, February 1979. 
15. Ibid.

Bailey, E.E., "Methanol from Coal: An Adaptation from the Past," presented at the Sixth Annual International Conference on Coal Gasification, Liquefaction, and Conversion to Electricity, University of Pittsburgh, Pittsburgh, Pennsylyania, by Davy McKee Corp., Cleveland, Ohio.

"Conceptual Design of a Coal to Methanol Conversion Plant," Executive Summary, interin final report, prepared for DOE by Badger Plants, Inc., Cambridge, Massachusetts, February 1978.

16. "Coal, The Fact Book," prepared for the President's Commission on Coal by EEA, Inc:, Arlington, Virginia, 1978.

17. Ibid.

18. Charles E. Mann and James N. Heller, Coal and Profitability (Coal Week, McGraw-Hill Publications Company: 1979), p. 101.

19. Ibid.

20. MEFS runs CAMB913H, CAMC913H, CAMD913H.

21. "Industrial Fuel Choice Analysis Mode1: Appendices to Primary Model Documentation," draft report prepared for DOE by EEA, Inc., Arlington, Virginia, January 8, 1979.

22. D. Salo et. al., "Near Term Potential of Wood as a Fuel," Mitre Corporation, July 1978 .

23. J. Watson et. al., "Source Category Survey: Waste-Fired Boilers," Acurex Corporation, March 1979.

24. Ibid, Section 4 .

25. D.C. Junge, "Combustion Characteristics of Ponderosa Pine Bark," Oregon State University, December 1978.

26. J. Watson, 오. cit.

27. H. Gus Wahlgren and T.H. Ellis, "Potential Resource Availability with Whole-Tree Utilization," TAPPI, November 1978.

28. Solar Program Assessment: Environmental Factors, "Fuels from Biomass," ERDA 77-47/7, March 1977.

29. Materials and Energy from Municipal Waste, Office of Technology Assessment, July 1979 . 
30. "Power from Waste," Power, February 1975.

31. K.P. Ananth, et. al., "Environmental Assessment of Waste-to-Energy Processes: Source Assessment Document," August 19.77.

32. "Power from Waste," Power, February 1975.

33. Materials and Energy from Municipal Waste, Office of Technology Assessment, July 1979 .

34. K.P. Ananth, op. cit.

"Nashville: A Successful Refuse tọ Energy Program," NCRR Bulletin (9: 1) March 1979.

35. Renard, Marc L., "Refuse Derived Fuels and Densified Refuse-Derived Fuel," The National Center for Resource Recovery, RM77-2, June 1978. This source was used to identify the status of all the applications discussed on this page.

36. J.L. Ha11, "Operation and Emissions of a Stoker-Fired Boiler While Burning Refuse Derived Fuel and Coal Mixtures," 1978.

37. Ibid.

38. Materials and Energy from Municipal Waste, Office of Technology Assessment, Ju1y 1979 .

39. J.D. Gilchist, Fuels, Furnaces, and Refractories (Pergamon Press: 1977)

40. Conversation with Mr. Bob Low, Ajax Magnethermic Corp., Warren, Ohio, July 16,1979 .

41. Ibid.

42. R.E. Jennings, "Forging Heat by Induction?," American Machinist, November 1978, pp. 98-99.

43. Conversation with Mr. Oakland, Whiting Corp., Chicago, Illinois, July 11, 1979 .

44. Thid.

45. R. Serota, "Heating with Radio Waves," Automation, September 1973.

46. Conversation with Mr. Gray, Radio Frequency Co., Medfield, Massachusetts, July 11, 1979. 
47. Conversation with Mr. Eckert, Inductotherm Corp., New Jersey, July 11, 1979 .

48. Conversation wịth Mr. Oakland, Whiting Corp., Chicago, Illinois, July $11,1979$.

49. Conversation with Mr. E. Anderson, Gerling-Moore, Inc., Santa Clara, California, July 11, 1979.

50. Conversation with Mr. Gray, Radio Frequency Co., Medfield, Massachusetts, July 1979 .

51. Application of Solar Technology for Today's Energy Needs, vol. 1, Office of Terchnology Assessment, June 1978.

52. F. Kreith and J.F. Kreider, Principles of Solar Fngineering (Hemis... phere Publishing Corporation, Washington, D.C.: 1978).

53. Application of Solar Technology for Today's Energy Needs, vol. 1, Office of Technology Assessment, June 1978.

54. S.A. Stadjuhar, "Feasibility Evaluation for Solar Industrial Prociess Heat Applications," Solar Energy Research Institute, Golden, Colorado, 1979.

55. Ibid

56. Persona1 communication with Georgc Kannape1, Suntec Systems, Inc., July 12, 1979.

57. Calculaleal from prócess information contuined in ronreptulal design studies tor DUE's 10 MWe pilot test plant. Prepared by Boeing, Honeywe11, Martin Marietta, and McDonnell Douglas for Sandia Laboratories, 1977.

58. Solar Energy for Agricultural and Industrial Process Heat, MnE, 1978.

59. Ibid.

60. Letter from George Kannapel, Syntec Systems, Inc., to Kerry Krutilla, EEA, Inc., Arlington, Virginia, July 19, 1979,

61. Multi-Year Solar Thermal Energy Power Systems Program Plan, DOE, 1979.

62: Ibid.

63. From data provided by Suntec Systems and Accurex Corporation.

64. E. Hall, "Survey of the Applications of Solar Thermal Energy Systems to Industrial Process Heat," Battelle Columbus Laboratories, Columbus, Ohio, 1978. 
65. Ibid.

66. Ibid.

67. W.C. Dickenson and K.C. Brown, "Economic Analysis of Solar Industrial Process Heat Systems: A Methodology to Determine Annual Required Revenue and Internal Rate of Return," Lawrence Livermore Laboratory, Livermore, California, August 1979.

68. E. Hall, op. cit. 


\section{TECHNICAL FEASIBILITY OF SUBSTITUTING ALTERNATIVE FUEL \\ IN INDUSTRIAL PROCESS HEATERS AND SMALL BOILERS}

\subsection{GENERAL FACTORS THAT AFFECT FUEL USE}

This section discusses the technical feasibility of converting major fuelconsuming industrial processes to the alternative energy technologies detailed in Section 4. For the purposes of this study, technical feasibility is defined as the ability of a technology to produce safely and reliably the same quality product as a conventionally-fueled unit. Site-specific requirements, including space limitations and local environmental regulations, will not be discussed in this section.

This technical evaluation also excludes economic and lead time factors except when those factors eliminate the practical consideration of an alternate fuel in certain applications. Since generally these site-specific factors and the economics of conversion will be most crucial in determining the practicality of a technically feasible option, any significant factors that strongly affect the practicality of a technically feasible option will be noted.

The following discussion distinguishes between retrofit fuel decisions and new combustor fuel choices. New units have considerable flexibility in designing a process to burn various fuel alternatives. Retrofit fuel decisions, however, are much more limited by the existing design of the combustor and the plant configuration. For example, in many cases when conventional coal is considered as an alternative retrofit application, coal use would require completely replacing the existing combustor.

Seven critical factors were considered in evaluating technical feasibility:

- Heat flux

- Heat distribution 
- Fuel contaminants.

- Process temperature

- Mode of material charging

- Form of fuel

o firing rate.

Heat flux, the amount of heat transferred per area and per time, indicates how "concentrated" the heat is from a technology. The heat flux from indirect heating is 1 imited to a maximum of $30,000 \mathrm{Btu} / \mathrm{hr} / \mathrm{sq} \mathrm{ft}$. This means that over $30 \mathrm{sq} \mathrm{ft}$ of heat transfer area will be required for each MMBtu/hr transferred. Since high firing rates will require an enormous amount of heat transfer area, many industrial processes will not be able to reach production rates sufficiently high for practical operation when using alternative energy technologies.

Heat distribution is the ability of an energy system to provide controlled yet variable temperatures and rates of heat flux over time and for the entire volume of the furnace chamber. Heat distribution requirements vary by process and by energy. system. For example, certain applications which use tubestill heaters in the chemicals industry require even and constant heat flux over the whole combustor. Consequently, fuels with varying composition, such as coal gas directly from the gasifier (raw coal gas), cannot be used since they cannot maintain a sufficiently constant heat flux. In another example, the ends of face brick tunnel kilns are maintained at much lower temperatures than the rest of the kiln so that the brick will be slowly heated and cooled to minimize thermal stresses in the ware. Due to these low (less than $500^{\circ} \mathrm{F}$ ) temperature requirements, it may not be possible to combust coal through the length of the furnace chambcr.

Fuel contaminants are the impurities present in fuel and released during combustion. Two primary fuel contaminants are sulfur and a.sh. These impurities can affect processes in two ways: degrade the furnace product 
(for example, the oxidation and resulting metal loss of slabs in a steel reheat furnace caused by ash deposited on the workpiece during processing). and degrade the furnace chamber (for example, a metallic heat recovery device can be corroded by sulfur compounds condensing on metal surfaces, and ash can physically plug the flow passages in the device if allowed to accumulate).

The temperature to which the furnace product (known as the load) is heated is defined as the process temperature. Specific process temperatures are required to ensure that appropriate chemical or physical changes can take place. Examples of this change could be the heat required to induce a chemical reaction in a petroleum refinery, or the heat required to bring a billet of steel to the temperature at which it can be worked into a different shape. Several of the technologies considered in this study have maximum process temperature limitations. For example, AFBC systems burning coal are subject to a $1500^{\circ} \mathrm{F}$ maximum process temperature because the combustion bed must be maintained below that temperature to attain proper levels of sulfur removal from the flue gas. Indirect heating systems cannot reach temperatures above the $800-1000^{\circ} \mathrm{F}$ range on the process side because heat transfer fluids cannot operate at much higher temperatures.

The physical properties of the load to be heated, the mode of material charging, can preclude the use of certain energy technologies. The mode used is especially significant with AFBC units. Since the load in these units flows in tubes running through the bed, it must flow freely; specifically, the load must be a liquid or a gas. AFBC units will not be able to accept other types of loads in the foreseeable future.

The form of a fuel during firing is extremely important in determining the compatibility of a fuel with a process. Fuels such as municipal waste and wood cannot be pulverized and must be combusted as pellets, usually in a stoker-type configuration. This type of combustion system generally is inappropriate for industrial process heat systems which now use conven- 
tional burners because it provides less control and flexibility in adjusting heat input.

The maximum and minimum firing rates for a fuel can limit the applicability of certain fuels. For pulverized solid fuels, the minimum firing rate through a single burner is considered to be in a range of 25-50 MMBtu/hr. There also are lower limits on liquid fuel burners that vary with fuel type, burner design, and combustor design.

If a fuel is able to satisfy sufficiently all of the above criteria and no other identifiable barriers exist to the application of an alternate energy technology, that technology will be classified as technically feasible. However, if a technology fails to meet any of the above criteria and is not expected to meet the criteria by 1990, it will be judged technically infeasible. Due to the diversity of designs within a process category, the variation in product types produced in similar. processes, and the variation in heat delivery between designs of an alternate technology, it is not always possible to judge definitively the feasibility of a certain conversion. In such cases, the conversion will be identified as sometimes feasible, and fuel use will be disaggregated as much as possible to help determine the potential fuel use with the conversion. Using the above criteria, the following discussion details the technical feasibility of using alternative fuels and energy systems. These feasibility assessments are conducted on a process-specific basis.

\subsection{PROCESS-SPECIFIC ASSESSMENTS}

\subsubsection{Methodology for Industrial Process Selection and Aggregation}

This study considers fuel alternatives on a process-specific basis. Only at this level can fuel choices be assessed reasonably. In order to maintain the study at a manageable level, the following criteria were used to select approximate process categories: 
- Process units which are very energy-intensive and account for a large portion of energy use in the industrial sector

o Industrial areas which have similar fuel requirements but not similar equipment designs.

Due to the similarities between certain processes, several categories of fuel use were aggregated to test technical feasibility. The following major criteria were considered for the aggregation of process categories:

- Process equipment

- Process product

- Firing rate

o Heating objective.

Process equipment configuration refers to the general design of the equipment and the way the product material flows through the unit.. For example, the configurations of cement, lime, and alumina rotary kilns and the fired section of an iron ore grate kiln are quite similar, but these kilns are very different from fired heaters in the petroleum industry.

The product which is being processed through the process unit sometimes is sensitive to the heat source and material that may be carried along with the heat source, hence the requirements of the product must be considered.

The typical rate a.t. which fuel or heat is input to a process is important to consider since certain energy alternatives are limited in the quantity and rate at which they can deliver heat to a process.

Heating objective refers to the type of processing the unit is performing (i.e., melting, heating, drying) and the type of heat characteristics that are required to achieve that type of processing.

It was not necessary for all of these criteria to be similar for processes to be grouped; however, iff any of these factors revealed that the differences between processes were significant enough to result in differing 
technical feasibility decisions for an alternate technology, the processes were not aggregated. For example, the many fired heaters in the petroleum and chemical industries were combined into five categories based on differences in products and firing rates, even though these heaters are similar in basic configuration and heating objective.

Based on the above criteria, the major energy-intensive processes described in Section 3 were categorized into the 18 groups listed below:

- Food

- ovens, drying

- Textiles

- drying, dyeing

- Stone, clay and glass

- glass unit melter

- regenerative melter/aluminum reverberatory furnace $e^{1 /}$

- annealing lehr rotary kiln/grato $\mathrm{kiln}^{2 /}$

- refractory $\mathrm{kiln/coremaking} \mathrm{oven}$

- face brick kiln

- Petroleum and chemicals

- high-risk fired heater

- medium-risk fired heater

- low-risk fired heater

- Stee 1 and aluminum

- traveling grate/sinter furnace coke oven/anode prebake oven

- blast furnace/iron cupola (hydrocarbon injection)

- blast furnace/shaft furnace (stove)

- soaking pit/reheat furnace

- heat treating furnace

- alumina rotary kiln. 
Table 5.1 summarizes the technical. feasibility of using each alternate fuel in new process applications. The feasibility of retrofitting existing. processes to alternative fuels is summarized in Table 5.2. The following subsections describe how the technical feasibility for each alternate fuel was assessed for each process group.

\section{2 .2 Food}

Most of the diverse processes in the food industry utilizing direct firing are constrained by strict requirements for clean fuels and fuels that are highly controllable. To achieve even, controlled heating in direct-fired combustors, many small pre-mix burners often are used. To avoid contamination which would seriously impair product quality, heavy hydrocarbon fuels containing ash and sulfur and those which form soot cannot be utilized. Natural gas is the major fuel used for direct firing in the food industry. ${ }^{3 /}$ Distillate oil has been used when natural gas was unavailable, but it requires an expensive unit to vaporize the fuel prior to combustion.

In addition to natural gas, clean coal gas is the only fossil fuel clearly feasible in the food industry. Although methanol may be used if vaporized before combustion, its toxicity may add sufficient risk to render its use infeasible. $4 /$

Electricity, indirect heating, and solar energy are considered feasible in the food industry. In fact, electric heat and indirect heating with steam already are used extensively. Note, however, that some applications such as spray drying may require extensive modifications to accomplish the same function using indirect heat. Retrofitting to solar energy use would be possible in hot water applications and in processes which can use "sun drying;" consequently, solar is classified as sometimes feasible. $5 /$

AFBC is considered infeasible due to the mode of material charging for solid products and because it requires temperatures too hot for most liquid 
TABLE 5.1

TECHNICAL FEASIBILITN' ASSESSMENTS FOR NEW UNITS

\begin{tabular}{|c|c|c|c|c|c|c|c|c|c|c|c|c|c|}
\hline \multirow[b]{2}{*}{ Industry } & \multirow[b]{2}{*}{ Process } & \multicolumn{8}{|c|}{ Fuels } & \multicolumn{4}{|c|}{ Heat Sources } \\
\hline & & $\begin{array}{l}\mathrm{LBG} / \\
\mathrm{MBG} \\
\end{array}$ & Methanol & $\begin{array}{r}\text { SRC-2 } \\
\text { (liquid) } \\
\end{array}$ & COM & $\begin{array}{c}\text { SRC-1 } \\
\text { (solid) } \\
\end{array}$ & Coal & $\begin{array}{l}\text { Wood and } \\
\text { Wood Waste }\end{array}$ & $\begin{array}{c}\text { Municipal } \\
\text { Waste } \\
\end{array}$ & $\underline{A F B C}$ & $\begin{array}{c}\begin{array}{c}\text { Indirect } \\
\text { Heat }\end{array} \\
\end{array}$ & $\begin{array}{l}\text { Electri- } \\
\text { fication }\end{array}$ & Solar \\
\hline Food & Ovens, dryers & $\mathrm{F}$ & $\mathrm{F}$ & $\mathrm{I}^{\mathrm{a} /}$ & I & I & I & I & I & I & $\mathrm{F}$ & $\mathrm{F}$ & $\mathrm{F}$ \\
\hline Textiles & Drying & $\mathrm{F}$ & $\mathrm{F}$ & I & I & I & I & I & I & I & $F$ & $\mathrm{~F}$ & $F$ \\
\hline \multirow[t]{3}{*}{ Glass } & Unit melter & $F$ & $F$ & $\mathrm{SF}^{\mathrm{b} /}$ & $S F$ & SF & $\mathrm{SF}$ & I & I & 1 & I & $\mathrm{F}$ & I \\
\hline & Regenerative melter & $\mathrm{F}$ & $\mathrm{F}$ & $\mathrm{SF}^{\mathrm{b} /}$ & SF & $\mathrm{SF}$ & $\mathrm{SF}$ & $\mathrm{t}$ & I & 1 & I & + & I \\
\hline & Anncaling lehr & $\mathrm{F}$ & $F$ & I & 1 & I & I & I & 1 & 1 & I & $F$ & I \\
\hline $\begin{array}{l}\text { Lime \& } \\
\text { Cement }\end{array}$ & Rotary kiln & $\mathrm{F}$ & $F$ & $F$ & $\mathrm{~F}$ & $\mathrm{~F}$ & F & $\mathrm{SF}$ & $\mathrm{SF}$ & I & I & I & $\mathrm{I}$ \\
\hline \multirow[t]{2}{*}{$\begin{array}{l}\text { Brick \& } \\
\text { Clay }\end{array}$} & $\begin{array}{l}\text { Refractory kiln, } \\
\text { coremaking oven }\end{array}$ & . $F$ & $\Gamma$ & $\mathrm{SP}^{\mathrm{cl}}$ & St & SF & $\dot{S} F$ & 1 & I & I & I & $p$ & 1 \\
\hline & race brick kiln & $\mathrm{F}$ & $\mathrm{F}$ & $\mathrm{F}$. & $\mathrm{F}$ & $\mathrm{F}$ & $F$ & I & I & I & I & $F$ & I \\
\hline Chemicals & $\begin{array}{l}\text { High-rish fired } \\
\text { heaters }\end{array}$ & $\mathrm{SF}^{\mathrm{d} /}$ & $F$ & SF & I & I & I & I & 1 & 1 & $F^{e /}$ & $\mathrm{r}$ & I \\
\hline \multirow[t]{7}{*}{ Petroleuni } & $\begin{array}{l}\text { Highl-r'ssk piréd } \\
\text { heaters }\end{array}$ & $\mathrm{SF}^{\mathrm{d} /}$ & F & SF & I & I & 1 & 1 & 1 & I & $\mathrm{F}^{\mathrm{e} /}$ & $\mathrm{F}$ & I \\
\hline & $\begin{array}{l}\text { Medium-risk fired } \\
\text { heaters: }\end{array}$ & & & & & & & & . & & & & \\
\hline & $>50 \mathrm{MMBtu} / \mathrm{hr}$ & $\mathrm{F}$ & $\mathrm{F}$ & $\mathrm{F}$ & I & $\mathrm{J}$ & 1 & I & 1 & I & $F^{e /}$ & $\mathrm{F}$ & 1 \\
\hline & $\angle 50 \mathrm{MMRtu} / \mathrm{hr}$ & $F$ & $\mathrm{~F}$ & $\mathrm{~F}$ & 1 & $I$ & I & 1 & I & I & $\mathrm{F}^{\mathrm{e} /}$ & $\mathrm{F}$ & I \\
\hline & $\begin{array}{l}\text { Low-risk fired } \\
\text { heaters: }\end{array}$ & & & & & & & & & & & & \\
\hline & ,50 NABitu/hr & r & $\mathrm{F}$ & $\mathrm{F}$ & $F$ & $F$ & $\mathrm{~F}$ & I & 1 & $F$ & $\mathrm{~F}^{\mathrm{e} /}$ & $F$ & I \\
\hline & $=50 \mathrm{MMBtu} / \mathrm{hr}$ & $\mathrm{r}$ & $F$ & $\mathrm{~F}$ & I & 1 & I & 1 & I & $\mathrm{F}$ & $F^{e / /}$ & $F$ & I \\
\hline \multirow[t]{9}{*}{$\begin{array}{l}\text { Stccl \& } \\
\text { Aluninum }\end{array}$} & $\begin{array}{l}\text { Traveling grato and } \\
\text { sinter furnace }\end{array}$ & $\vec{F}$ & $F$ & $F$ & F & 5 & $\mathrm{r}$ & I & 1 & 1 & I & I & I \\
\hline & $\begin{array}{l}\text { Coke oven anode } \\
\text { prebake }\end{array}$ & $\mathrm{F}$ & $\mathrm{F}$ & 1 & I & 1 & I & I & 1 & I & I & I & I \\
\hline & $\begin{array}{l}\text { Blast furnace/iron } \\
\text { cupola }(H-1)\end{array}$ & $\mathrm{F}$ & $\mathrm{F}$ & F & $\mathrm{F}$ & $\mathrm{F}$ & $\mathrm{F}$ & 1 & I & I & I & I & I \\
\hline & $\begin{array}{l}\text { Soaking pit/reheat } \\
\text { furnace }\end{array}$ & $\mathrm{r}$ & $\mathbf{F}$ & $F$ & SF & $S F$ & $\mathrm{SF}^{\mathrm{f}}{ }^{\prime}$ & I & I & I & I & $\mathrm{F}$ & 1 \\
\hline & Heat treat furnace & $\mathrm{F}$ & $F$ & 1 & $\mathrm{~T}$ & $\mathrm{I}$ & 1 & $\mathrm{I}$ & I & I & $r^{e l}$ & $\tilde{I}$ & I \\
\hline & Alumina rotary kiln & $\mathbf{F}$ & $\mathrm{F}$ & I & 1 & 1 & 1 & I & I & I & 1 & I & I \\
\hline & $\begin{array}{l}\text { Aluminum reverhera- } \\
\text { tory furnace }\end{array}$ & $\mathrm{F}$ & $\mathbf{F}$ & $\mathrm{SF}^{\mathrm{b} /}$ & $\mathrm{SF}$ & $\mathrm{SF}$ & SF & I & I & I & $\vdots$ & $F$ & I \\
\hline & Grate kiln & $\mathrm{F}$ & $\mathrm{F}$ & $\mathrm{F}$ & $F$ & $\mathrm{~F}$ & $\mathrm{~F}$ & I & 1 & I & $\mathrm{I}$ & I & $I$ \\
\hline & $\begin{array}{l}\text { Blast furnace/shaft } \\
\text { furnace stove }\end{array}$ & $\mathrm{F}$ & $\mathrm{F}$ & $\mathrm{F}$ & I & $\mathrm{F}$ & I & $\mathrm{I}$ & I & 1 & I & $F$. & 1 \\
\hline
\end{tabular}

af It should be noted that there are some food processes, such as grain drying, where residual oil has been used. However, these processes account for only a small portion of food process heat use.

b/ Feasible in many unit melters in the container glass industry and selected pressed and blown glass products. Product specifications in most of the flat glass industry preclude the use of fuels with high ash content. A very rough estimate would be 75 percent feasible, 25 percent infeasible.

c/ Feasible except for high alumina brick production and refractories fired at over. $2450^{\circ} \mathrm{F}$. This accounts for roughly half the fuel in this category.

d/ Listed as infeasible because the feedstock processed is volatile and requires precise temperatures to ensure safe handing. Current alternatc fuel use would be inadequate to ensure proper safety.

e/ Feasible for temperatures under $800^{\circ} \mathrm{F}$.

f) Infeasible in most cases due to scaling. 
TABLE 5.2

TECHNICAL FEASIBILITY ASSESSMENTS FOR RETROFIT UNITS

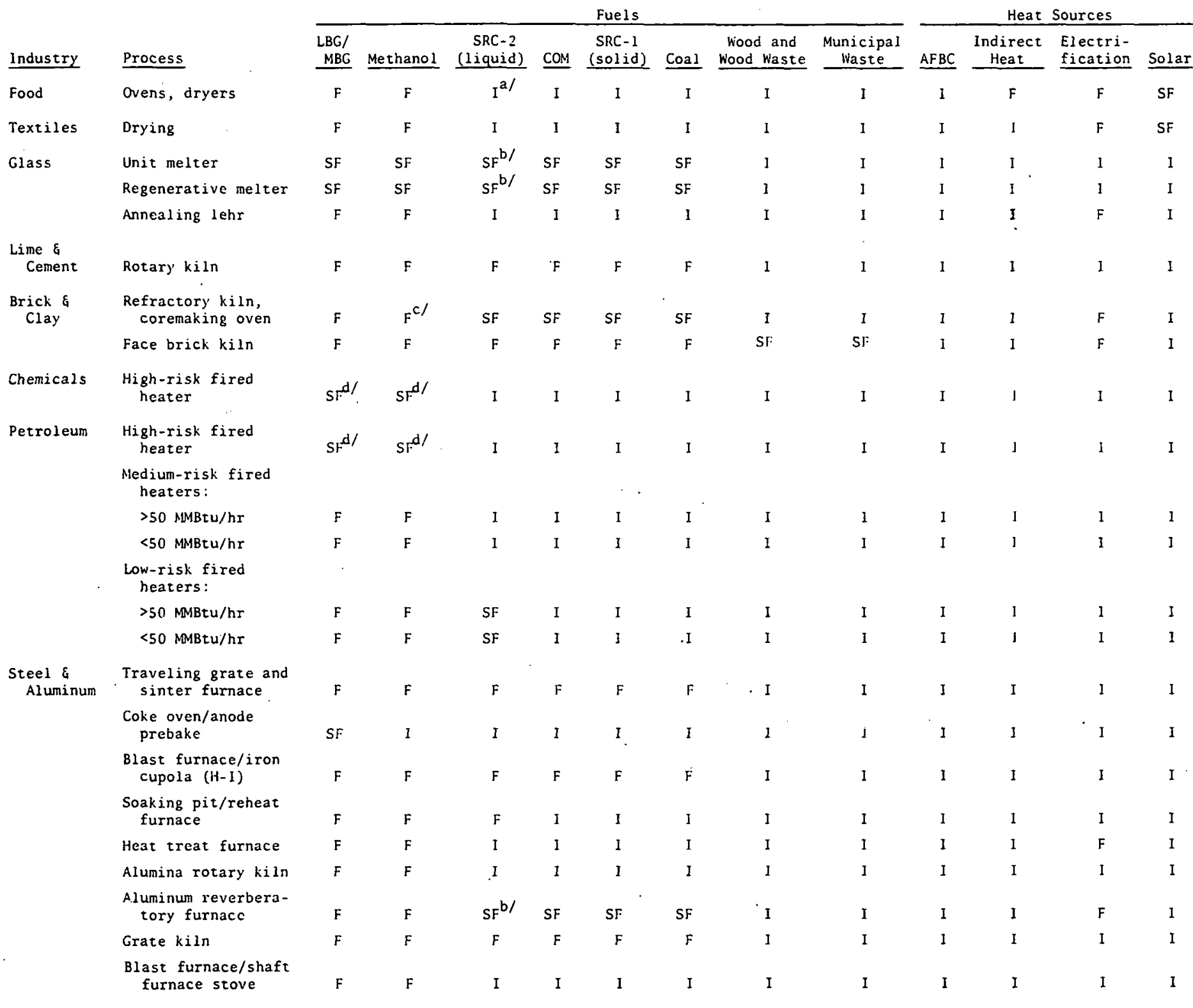

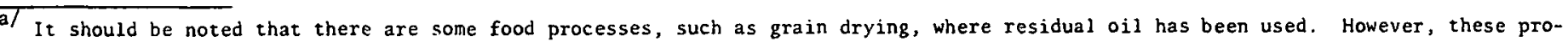
cesses account for only a small portion of food process heat use.

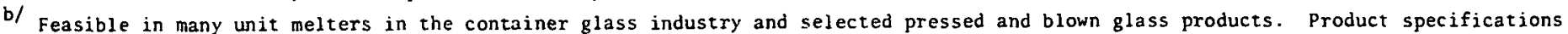
in most of the flat glass industry preclude the use of fuels with high ash content. A very rough estimate would be 75 percent feasible, 25 percent infeasible.

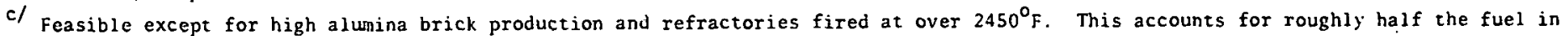
this categnry.

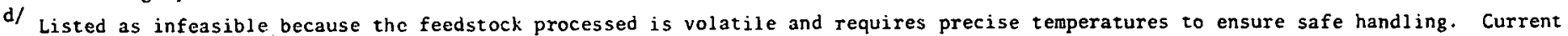
alternate fuel usc would be illadequate to ensure proper safety. 
processing. Coal, raw coal gas, COM, SRC-1, SRC-2, municipal waste, wood, and wood waste are considered infeasible because of fuel contamination. $6 /$

\section{2 .3 Textiles}

Direct firing in the textiles, industry, primarily used in singeing, drying, and heat setting, requires clean and highly controllable heat to maintain proper product quality. In some processes, the use of soot-forming fuels is not detrimental since products are or can be washed subsequent to firing. Final processing, however, would not permit soot contamination, In addition, many fuels containing soot and ash are not highly controllable and, thus, would not be appropriate for the textile industry.

Natural gas currently is the dominant fuel used in the textile industry. During natural gas curtailments, many mills simply shut down. ${ }^{7 /}$ Mills which did switch to distillate oil, such as Riegel Textile Corporation's division in La France, South Carolina, were able to operate some units successfully, but maintenance costs were increased.

The use of clean coal gas, indirect heat, electrification, solar energy, and methanol are considered feasible in new units. Retrofits to indirect. heating would not be possible, ${ }^{8 /}$ and retrofit to solar energy uses would be limited to supplying hot water. Coal, COM, SRC-1, SRC-2, raw. coal gas, municipal waste, wood, and wood waste are considered infeasible for use in textile nonboilers due to fuel contamination levels. $9 /$

\subsubsection{Stone, Clay and Glass}

The industries considered as stone, clay and glass industries are cement, lime, clay, brick, and glass manufacture. The major energy-consuming processes considered in the following discussion are cement and lime rotary kilns, unit melters and regenerative melters in the glass industry, annealing lehrs, refractory kilns, coremaking oyens, and face brick kilns. The aluminum reverberatory furnace and the grate furnace in the aluminum 
and steel industries are discussed in this section because their technical requirements are similar to the requirements of equipment in the stone, clay and glass industries.

\subsubsection{Unit Me1ter/Aluminum Reverberatory Furnace}

Unit melters in the glass industry are smaller furnaces which operate continuously and usually do not have heat recovery equipment. Glass melters operate between 2500 and $2900^{\circ} \mathrm{F}$ and require a radiant flame to achieve desired rates of heat transfer. Since this process is a melting application, there are no strict constraints on even heat flux, although. the process temperature must be maintained at about $\pm 25^{\circ} \mathrm{F}$. Some heavy hydrocarbon fuels contain metal oxides that can cause glass discoloration, but unit melters usually produce low grade glass products, eliminating contamination as a serious constraint. Currently, natural gas is the predominant fuel used in unit melters; both distillate and residual oil are used in small quantities. Historically, "producer gas" from coal gasification units was used before natural gas became widely available. ${ }^{10 /}$

Aluminum reverberatory furnaces are similar in design to the glass unit melter and are used to melt aluminum scrap and ingots of new metal prior to casting operations. This unit is the second largest consumer of energy in the aluminum industry, with natural gas the primary fuel source. The major constraint in reverberatory furnace operation is that particles from the flame must not pierce the aluminum oxide skin which forms over the melt and acts to protect the metal from contamination and further oxidation.

The use of raw and clean coal gas is considered feasible based on past use in glass melters. However, the refractories now used in glass melters may not function as well or as long as they do with natural gas use due to the incompatibility of basic-type refractories with the reducing atmospheres sometimes created by coal gas combustion. In new units, it may be necessary to use conventional fireclay refractories which have a lifespan four to five times shorter than typical modern refractories but are not affected 
by reducing atmospheres. In retrofit cases, raw and clean coal gas are considered sometimes feasible, depending on the type of refractory used. Refractory manufacturers are researching the performance of basic refractories in reducing atmospheres. Only after this research has achieved definite positive results will the industry accept the risks involved in coal gas use.

While electric melters are considered feasible throughout the industry, there is considerable disagreement about the future of electricity use. Some glass producers are moving away from electric technology, citing the gredler efficiency of natural gas; othcrs are pursuing electric furnace research and expect electricity use to become more important in the future. The use of methanol as a substitute for natural gas or fuel oil is considered feasible in both new and retrofit applications. Electrification of these units with arc heating is considered technically feasible in new units, but retrofitting is considered impractical due to expensive required furnace changes. The present use of fossil fuel-electric hybrid furnaces is $110 \mathrm{~L}$ uncominon. $11 /$

The hydrocarbon fuels which rontain ash (SRC 1, SRC $=2$, residual oil, LUM, and coal) are considered sometimes technically feasible in both new and retrofit units because of potential contamination problems. Feasibility will depend on how the quantity of ash in the fuel affects the quality of the glass produced.

In general, container glass has less stringent specifications than flat glass (i.e., windshield glass). Specifications for presser and blown glnas vary with the product. Almost half the glass melter fuel use in pressed and blown glass and most of the container glass may be able to burn low quality fuels by charging the batch to compensate for the discoloration due to the metallic and ash content of the fuels. The discoloration effects of metal oxides on glass often can be negated by adding contrasting colorants; 
unfortunately, since the content and rate of deposition vary, this is a difficult and uncertain operation. Partial coal firing has been used on an experimental basis by Columbine Glass Company, but no commercial facilities presently exist.

Municipal waste, wood, and wood waste are considered infeasible because of contamination levels and the pelletized form of the fuel which could pierce or melt the surface. AFBC, indirect heat, and solar energy are considered infeasible because they cannot reach sufficiently high process temperatures. In addition, $A F B C$ requires an inappropriate mode of material charging.

\subsubsection{Regenerative Melters/Open Hearths}

Large furnaces used in the glass industry are regenerative furnaces which operate similarly to unit melters but also have heat recovery devices (regenerators) which preheat combustion air with heat extracted from the flue gas stream. Open hearth furnaces in the steel industry are similar in design to regenerators; they melt iron rather than glass and operate at $2700^{\circ} \mathrm{F}$. Due to the heat recovery devices, these furnaces are sensitive to the presence of ash in the fuel because ash can coat the heat transfer surface of the regenerator, cause the refractory to spall or drip, or physically plug the flue gas channels in the device. In addition, sulfur in the fuel can combine with sodium from the raw materials used in glass manufacturing to form sodium sulfate which will condense out of the flue gas stream at about $900^{\circ} \mathrm{F}$. This contaminant adds to the plugging problem caused by ash.

Currently, natural gas and some fuel oil are used in glass melters. Open hearths are fueled by natural gas or an internally-generated fuel such as coke oven gas. Open hearth steelmaking has been decreasing for a number of years and is being phased out across the industry; any capital investment in these units would be highly unlikely, especially for a fuel conversion, since gas from coal already may be used. It is not anticipated that any new open hearth furnaces will be constructed. 
As in unit melters for the glass industry, raw coal gas, clean coal gas, and electrification are considered feasible. Raw coal gas and clean coal gas are only sometimes feasible in retrofit units due to the contamination of basic refractories used in regenerative chambers. Switching away from basic refractories and returning to the traditional fireclay-type refractories would shorten. furnace lives from six years to about 18 months, thus imposing a severe economic burden on the glass manufacturer. ${ }^{12 /}$ Consequently, retrofitting to coal gas is extremely unlikely. The retrofit of conventional melters to electricity is considered infeasible due to the extensive and expensive changes required.

The heavy hydrocarbon fuels that contain ash (SRC-1, SRC-2, residual oil, COM, and coal) are considered sometimes feasible, as in unit melters, due to fuel contamination. Coal has been combusted on a very short-term basis in a regenerative melter with moderate but inconclusive success. ${ }^{13 /}$ The use of coal and COM is considered infeasible in retrofit applications since the high ash content of these fuels would cause serious operating difficulties.

Municipal waste, wood, and wood waste are infeasible due to the form of the fuel. Indirect heating and solar energy are infeasible due to process temperature limitations. AFBC is infeasible due to process temperature and the mode of material charging.

\subsubsection{Annealing Lehr}

Lehrs are continuous furnaces used to relieve stress in glass products by slowly heating the product to $800-1200^{\circ} \mathrm{F}$ and then allowing it to cool slowly. Most glass products must be cosmetically unflawed, requiring the heat source in lehrs to be both clean and controllable. Presently, natural gas and propane are the only fuels used in annealing. 14/ 
Clean coal gas and methanol are the only fossil fuels which might be feasible in this process. 15/. It may be necessary to vaporize the methanol to achieve proper combustion. The variability of coal gas composition may result in some increased breakage of the product. Electricity is feasible and commercially proven for use in annealing lehrs. All of the technologies which are feasible in new units also are feasible in retrofitted units.

Raw coal gas, SRC-1, SRC-2, residual oil, COM, and coal are considered technologically infeasible due to fuel contamination. Solar energy and indirect heating are considered infeasible due to process temperature limitations. Municipal waste, wood, and wood waste are infeasible due to the form of the fuel and contamination. $A F B C$ is infeasible due to the mode of the material to be charged.

\subsubsection{Cement and Lime Rotary Kilns/Grate Kilns}

The fired units in all of these processes consist of long cylindrical refractory-lined chambers which rotate slowly and are fired from one end of the chamber axially towards the other end. The temperature in the chamber is maintained between 2800 and $3000^{\circ} \mathrm{F}$, the temperature required to dry and calcine the material being processed. A long radiant-type flame generally is desired to provide the most efficient heat transfer throughout the entire length of the kiln. Fuel contamination sometimes poses a problem in these process heaters. However, ash dcposition in the calcined cement is not harmful and, in fact, reduces the raw material requirements of the cement. Lime is usually not significantly degraded by ash from fuels. The amount of ash allowable in the lime varies with the use of lime; uses demanding minimal impurities and processes requiring the recycling of lime through the kiln (as in the paper industry) could not withstand significant ash deposition. Grate kilns, however, arc not affected by ash deposition. In 1974, natural gas provided 45 percent, coal provided 38 percent, and oil supplied 10 percent of the fossil fuel used in cement manufacturing. $17 /$ 
Recently, coal consumption has been increasing, and the Portland Cement Association has estimated that, by the end of 1980 , coal will proyide 75 percent of kiln energy. ${ }^{18 /}$

The use of SRC-1, SRC-2, residual oil, raw coal gas, clean coal gas, and methanol are feasible in these kilns. The use of coal, COM, wood, wood waste, and municipal waste is sometimes feasible in lime manufacture under the ash contamination limits discussed above. ${ }^{19 /} \mathrm{AFBC}$, indirect heat, and solar energy are infeasible due to temperature limitations.

The use of electricity in rotary kilns is considered infeasible since resistance heating could nul deliver sufficicnt lieat flux. In addition, the configuration of the kiln would make it difficult to install. Arc heating is inappropriate since it would melt the produst and furnace walls. It may be possible to design a nonrotary electric kiln for calcining, but since direct coal firing is feasible, it is not a practical option.

\subsubsection{Refractory Kiln/Coremaking Oven}

Thèse units are both continuous and periodic furnaces which fire ceramic products to be used in subsequent industrial and high temperature equipment. Since refractorics are subject to severe conditions over extended periods of time, manufacturers are concerned with any factor. which may affect the performance of the product in its end use.

Flame requirements are not a factor limiting use of various fuel types. Temperature control also is not as critical to refractory kilns as other processes, although reasonable tempcrature control is necessary to fire the loads properly. Furnace temperatures can valy botwcen 2300 and $3400^{\circ} \mathrm{F}$, depending on the product.

Product contamination is a critical factor in burning various fuel alternalives. Some refractory products absorb contaminants from combustion gases 
of heavy fuels; depending. on the effect on product integrity, this may or may not be a desirable occurrence. Other refractories and foundry cores are fired at temperatures above normal ash fusion temperatures so that if a fuel contains ash, it can settle on the surface of the ware and fuse to the outer surface. This is not acceptable to most products and must be avoided by "furniture brick," a hood covering the primary load. The use of protective hoods increases cost and reduces fuel efficiency since the hood reduces available space in the kiln and insulates the primary load from the direct flame.

Currently, the major fuel in refractory manufacture is natural gas, with some distillate fuel and electricity use. Electrification and clean coal gas are considered technically feasible in both new and retrofit units. Fuels which contain ash (coa1, COM, SRC-1, SRC-2, residual oil, and raw coal gas) are sometimes feasible in new and retrofit units, depending on the amount and type of contaminants in the fuel and the susceptibility of the product (as explained above) to ash.

Municipal waste, wood, and wood waste are infeasible due to the form of the fuel. Solar energy, indirect heat, and AFBC are classified as infeasible due to process temperature limitations. AFBC use also is constrained by the mode of material charging.

\subsubsection{Face Brick Kilns}

The periodic and continuous kilns used to fire construction quality brick are extremely flexible in the types of fuels they can utilize. In fact, the irregular burning pattern of fuels such as pulverized coal may enhance the value of the product by creating a mottled or irregular finish on the brick. Typical process temperatures are between 1800 and $2400^{\circ} \mathrm{F}$. Presently, natural gas is the predominant fuel used due to its convenience and controllable nature. Distillate oil also is used in some units. 
Coal, COM, SRC-1, SRC-2, residual oil, raw coal gas, clean coal gas, methanol, and electricity are considered technically feasible in both new and retrofit applications. Coal combustion systems presently are available from several manufacturers and are in commercial use at several locations. 20/ Municipa 1 waste, wood, and wood wastes are considered feasible in new units but require a stoker-type combustion system. These fuels are sometimes feasible in retrofit applications if the kiln can be converted to a stokerfeed configuration.

Indirect heat, solar energy, and $A F B C$ are infeasible due to temperature limitations. AFBC also is inappropriate due to the mode of material charging.

\subsubsection{Petroleum and Chemicals}

\subsubsection{Fired Heaters (tubestills, pipestills)}

Fired heaters used in chemical and petroleum processing are extremely large consumers of energy and have been divided into three categories (low-, medium-, and high-risk) based on the process and the fluid being heated. The primary characteristics considered are the temperature on the process side of the unit, the fluid's potential for coking, the reactivity of the feedstock, and the degree of heat distribution control required for proper processing.

The first category, low-risk fired heaters, consists of units which are operated at lower temperatures (below $800^{\circ} \mathrm{F}$ ), have a low potential for coking, and are, in general, the least demanding in terms of the precision and quality of the heat delivered. Units involved in alkylation, atmospheric distillation, and feed preheaters to catalytic cracking units are considered low risk. Units above and below $50 \mathrm{MMBtu} / \mathrm{hr}$ are considered separately due to different solid fuel burner constraints. 
The second group of units, medium-risk fired heaters, is typically operated at higher temperatures than the first group of units, handles more reactive feedstocks, has a higher potential for safety hazards, and has a greater chance of inducing coking. Classified in this group are hydrocracking, - vacuum distillation, hydrotreating, hydrorefining, and catalytic reforming units. Due to the value of high octane blending agents for gasoline produced in catalytic reforming units, the increased risk of unscheduled, prolonged downtime will minimize the potential for converting these units. The medium-risk units also are differentiated by size category.

The third and most sensitive group of fired heaters, classified as high risk, are the units operating at high temperatures, possessing a strong potential for coking, and requiring precise heat distribution and control. Units classified as high risk include units in the chemicals industry (primarily ammonia, ethylene, and methanol) and delay cokers, hydrogen units, thermal crackers, and visbreakers in the petroleum industry.

The fuels most commonly used in fired heaters are natural gas, refinery gas (gaseous hyproducts of refinery operation), or the heavy ends of refinery operation, a fuel similar to residual oil. The fewer the constraints on the process heat, the more likely the use of heavy ends. The replacement of these internally-generated byproduct fuels is extremely unlikely since they are available, inexpensive, and of little value to other users.

\subsubsection{High-Risk Fired Heaters}

Electrification of fired heaters (either resistance heating or a combination of resistance and induction heating) and the use of methanol are the only alternatives to the fuels presently consumed in fired heaters. However, electricity is considered infeasible only in new applications, and that use is considered extremely impractical. $21 /$

Residual oil, SRC-2, raw coal gas, and clean coal gas are considered sometimes feasible depending on the specific process requirements. At high 
temperatures, the impurities in residual oil (also in SRC-2 and raw coal gas) may be too destructive to the sensitized metal in the process tubes. The unstable flame patterns that can be produced by the variable composition of gas from a gasifier and from heavier liquid fuels at low firing rates may not provide sufficiently stable heat distribution in some cases. The retrofit of clean coal $\bar{g}$ as is considered sometimes feasible, depending on the requirements for stable heat release from the flame. It will be infeasible to sonvert existing natural gas-fired units to SRC-2, residual oil, or raw coal gas due to fuel contamination (fouling of finned tubes and corrosion induced from ash) and uneven heat distribution.

Indirect heat is feasible for these tubestills, but only in units where the process temperature is below $800^{\circ} \mathrm{F}$. It is infeasible to retrofit to indirect heat. Coal, COM, SRC-1, wood, wood waste, and municipal waste are infeasible due to fuel contamination and heat distribution problems. Solar energy is infeasible due to temperature and consistency limitations. AFBC is infeasible in these units due to heat distribution constraints and the high coking potential in AFBC units (due to high process tube temperatures).

\subsubsection{Medium-Risk Fired Heaters}

In these heaters, the use of SRC-1, SRC-2, residual oil, raw coal gas, clean coal gas, and methanol is considered feasible in new units. In retrofits, SRC-1, SRC-2, and residual oil axe infeasible due to ash problems in the finned convection section. $22 /$ Retrofits to raw and clean coal gas are feasible, but productive capacity may have to be derated due to the combustion volume and heat transfer characteristics of the coal gases. $23 /$

Electricity is feasible, as in the high-risk case, and indirect heating is feasible for units with process temperatures below $800^{\circ} \mathrm{F}$. Neither of these technologies is feasible in retrofit applications since the changes required in the combustor are too significant. 
COM, coal, municipal waste, wood, and wood waste are infeasible due to furnace degradation from the ash in the fuel and unstable heat distribution. $A F B C$ is infeasible due to heat distribution problems caused by hot tube skin temperatures that can result in coking. ${ }^{24 /}$ Solar energy is infeasible since it cannot consistently provide the temperatures required for processing.

\subsubsection{Medium-Risk Fired Heaters (below $50 \mathrm{MMBtu} / \mathrm{hr}$ )}

The only change in feasibility between large and small fired heaters in this category is that SRC-1 is infeasible in new units below $50 \mathrm{MMBtu} / \mathrm{hr}$ due to burner and flame stability requirements.

\subsubsection{Low-Risk Fired Heaters (above 50 MMBtu/hr)}

In these heaters, the use of clean coal gas, raw coal gas, methanol, coal, COM, SRC-1, SRC-2, residual oil, 'wood, wood wastes, electricity, and AFBC is considered feasible in new units designed for these fuels. However, only the use of raw coal gas, clean coal gas, and methanol is considered always feasible in retrofits of these units. Retrofits to residual oil and SRC-2 are sometimes feasible, depending on the design of the convection section of the heater and the susceptibility of the tubes, especially the finned tubes, to ash deposition. Coal, COM, SRC-1, wood, and wood wastes are infeasible in retrofit applications due to ash, sulfur, and flame impingement which could degrade the tubes in the heater. Electricity and $A F B C$ retrofits are infeasible due to the magnitude of changes required to effect the conversion.

Practically, it is not expected that these units will conyert away from the heavy refinery byproducts used. The heayy oil often is produced in the unit in which it is consumed and is an inexpensive fuel to the refiner. In addition, the problems associated with siting coal storage and handing facilities in an existing refinery probably are too costly to overcome in the $1980 / 1990$ time frame. 
Indirect heat is sometimes feasible in new units in which the process temperature is below $800^{\circ} \mathrm{F}$. Indirect heating is infeasible in retrofit units due to insufficient heat flux.

Solar energy is infeasible due to process temperature limitations and inconsistent heat delivery. Municipal waste is classified as infeasible due to the inconsistent composition of the fluel, affecting the rate of heat released to the process, and trace impurities in the fuel which may degrade furnace tubes and walls.

\subsubsection{Steel and Aluminum}

\subsubsection{Traveling Grate/Sinter Furnace}

Fuel is used in these furnaces to fire or ignite the moving beds which carry the sinter and iron ore products. Since the products of these furnaces go to the blast furnace, there are minimal constraints on contaminants. However, the burners in these furnaces tend to be small and have the potential for wide turndown. Fuels which cannot be burned in the existing combustion systems can be combusted in external combustion chambers, and supplemental gas-firing capability is feasible for operation at low firing rates. Presently; the primary fuel used in these processes is natura1 gas.

The use of COM, coal, SRC-1, SRC-2, residual oil, raw coal gas, clean coal gas, and methanol are considered feasible. Although the use of these fuels might require extensive modification to the combustion chamber of these units in some cases, all of these fuels also are considered feasible in retrotit units.

Municipal waste, wood, and wood waste are considered infeasible due to the pelletized form of the fuel which would make it incompatible with the required combustion system. Electrification is infeasible since it cannot provide the proper heat distribution or the heat flux that a flame pene- 
trating the bed can proyide. Indirect heat, solar energy, and AFBC are infeasible mainly due to process temperature limitations.

\subsubsection{Coke Oven/Anode Prebake Oven}

Coke ovens and anode prebake ovens both have long, narrow vertical combustion chambers running beside the area to be heated. There are ceramic walls between the combustion chamber and the packed furnace area. These walls provide both structural support and heat transfer. Due to the nature of their construction, the combustion chambers are inaccessible for routine maintenance; consequently, ash or soot accumulation on the combustion chamber walls or around burner parts is not permissible. This constraint also applies to the regenerative heat recovery chamber on coke ovens. Current burner design makes only gaseous fuels feasible in these ovens. Natural gas presently is burned in anode prebake ovens. Coke ovens combust internally-generated coke oven gas, a gas derived from coal with a heat content of about $500 \mathrm{Btu} / \mathrm{scf}$. Because this internal coal-based heat source exists, the potential that any alternative will penetrate this market is smal1.

Raw coal gas, clean coal gas, and methanol are considered feasible in new units. Clean coal gas is preferred over raw coal gas to reduce the risk of alternate fuel use and extend the life of the units as much as possible. In retrofit cases, clean and raw coal gas are considered sometimes feasible since these gasifiers may require an air-to-fuel ratio that may not be possible to achieve in the existing regenerative chambers of some of the units. $26 /$ Methanol is technically infeasible since present units cannot accept liquid fuels.

Coa1, COM, SRC-1, SRC-2, residual oil, municipal waste, wood, and wood wastes are all technically infeasible, primarily due to contaminants in the fuels and the form of the fuels. Electricity is considered infeasible since resistance heating cannot provide sufficient heat flux through the 
ceramic walls and arc heating cannot provide sufficiently even heat distribution. Indirect heat, solar energy, and AFBC are considered technically infeasible due to process temperature and heat flux limitations.

\subsubsection{B1ast Furnace/Iron Cupola (hydrocarbon injection)}

This process category varies significantly from others in this study because the fuel is not used solely for its heating value but also for its chemical components. The function of an injectant is to reduce the amount of coke which must be charged to a blast furnace. Presently, natural gas, fuel oil, and coal are used as injectants. COM is being tested and is expected. to perform well. Coal, $\mathrm{COM}, \mathrm{SRC}-1$, SRC-2, residual oil, raw coa1 gas, clean coal gas, and methanol are considered technically feasible. Even though these fuels are technically feasible, it may be necessary to change. the raw materials fed to the furnace to achieve good performance. ${ }^{2 \%}$ These changes may not be economical options to the producer.

Municipal waste, wood, and wood waste àre considered technically infeasible due to variable compositions and fuel contaminants. AFBC, indirect heat, solar energy, and electrification are technically infeasible since they cannot provide the chemical constituents (principally carbon) required for the process.

\subsubsection{Blast Furnace Stove/Shaft Furnace Stove}

These stoves provide hot $\left(1500-2000^{\circ} \mathrm{F}\right)$ gases for injection into their associated material processing units. Of the two units, blast furnace stoves consume far more energy than do shaft furnaces, which are a declining technology. In the blast furnace stove, a gas (usually coke oven gas, blast furnace gas, or natural gas) is combusted and the hot combustion products pass through a checker brick, heating the ceramics. The stove then is "reyersed" and air is blown through the checkerwork, heating it to about $1800^{\circ} \mathrm{F}$. The gas channels in the stoves are narrow and susceptible to plugging. A change in design of the stoves from the channeled checker 
brick to a basketweave of solid ceramics such as the regenerator in the glass industry could alleviate the ash problem but also reduce efficiency. Cleaning of the stoves during blast furnace relining also would make the furnaces more tolerant of fuels containing ash.

The use of internally-derived byproduct fuels, when available, is the most logical and economic choice for most units in the steel and aluminum industries. The use of residual oil, SRC-1, SRC-2, raw coal gas, clean coal gas, and methanol is considered feasible in new units. However, only clean coal gas and methanol are considered feasible in retrofit applications. Raw coa1 gas is considered sometimes feasible, depending on the particulate composition of the gas. Residual oil, SRC-1, and SRC-2 are infeasible in retrofit cases because of ash problems in the checkerwork, combustion chamber, and gas ducts. An electric heater would be technically feasible but also would be extremely impractical. Retrofit of an existing stove would not be feasible.

Fuel contamination problems render coal, COM, municipal waste, wood, and wood waste infeasible. The ash content of these fuels is simply too high to allow continuous operation for a six-year campaign. AFBC, indirect heat, and solar energy are considered infeasible because of temperature limitations. If an operator were willing to accept $1200^{\circ} \mathrm{F}$ blast air, AFBC might become an option, but this is an unlikely'scenario.

\subsubsection{Soaking Pit and Reheat Furnaces}

These types of furnaces are used to heat and prepare steel pieces for slabbing, rolling, forming, or other processes. Furnace temperatures vary between 1800 and $2450^{\circ} \mathrm{F}$. Ash and sulfur deposited on the load from the fuel can increase the amount of scaling (or oxidation) which occurs on the exposed metal surface. However, the incremental amount of metal loss that will-occur is not sufficient to consider the use of fuels containing ash technically infeasible. Current fuel use in these units is split between 
natural gas, coke oven gas, and blast furnace gas. As in all steel industry units in which coke oven gas or blast furnace gas is available, the penetration of other alternate fuels will be small.

The use of coa1, COM, SRC-1, SRC-2, residual oil, raw coal gas, clean coal gas, and methanol is considered feasible in new units designed for the specific fuel. Retrofits to residual oil, SRC-2, raw coal gas, clean coal gas, and methanol also are considered feasible. The use of coal, CoM, and SRC-1 is infeasible in retrofits due to an increased,flame length and fuel contamination which would increase the rate of furnace degradation. Flame impingement and ash contamination of the refractories in these furnaces could significantly reduce the operating life of the furnace. In addition, the heat recovery devices, both recuperators and regenerators, could become plugged with the ash from coal or COM. Electricity is considered feasible but extremely impractical for this type of heating which requires large heat inputs. The use of electric induction heating in new units for specific purposes (usually heating bars and rods) is proven and well accepted in industry; the retrofit of a unit to electricity is infeasible.

Municipal waste, wood, and wood waste are considered infeasible due to the form of the fuel, specifically, the stoker-type arrangement that would be required. $A F B C$, indirect heat, and solar energy are infeasible due to process temperature limitations, heat flux limitations, and, in the case of $A F B C$, the mode of material charging.

\subsubsection{Heat Treating Furnaces}

Heat treating, the final stage in the production of primary metal product.s and a step in most subsequent processing, involyes a heating process to remove the structural defects in a piece by evenly heating the metal to the appropriate temperature. Since no additional stress can be created during processing, good control over heat transfer in the process is required and, in most cases, flame impingement is intolerable. Flat flame or radiant 
tube burners often are used to eliminate flame impingement. In many operations, the flame is physically separated from the load and the load surrounded with a nonreactive atmosphere. Ash or other impurities must not contact the surface of the metal since they can cause scaling or corrosion. Temperatures vary between 300 and $1000^{\circ} \mathrm{F}$ for aluminum and 300 and $1700^{\circ} \mathrm{F}$ for stee1, depending on the type of heat treating. Currently, the predominant fuel used is natural gas because of its cleanliness and ability to be controlled. In addition, some internally-generated fuels are used in the steel industry.

Clean coal gas and methanol are considered feasible for use in heat treating ovens. Coal gas may require the use of special atmospheres not required when natural gas is used. Electrification of heat treating furnaces is feasible and has been proven in certain applications. Retrofit electrification of existing units with resistance heaters is feasible but usually not practical. Indirect heating also is feasible for those applications under $800^{\circ} \mathrm{F}$.

Solar energy is infeasible since it cannot provide the temperatures required for heat treating. $A F B C$ is not considered feasible for use in heat treating, although treating wire by running it through the bed continuously at high speed has been considered. This is not, however, a proven application, and even if proven possible, the potential uses for this type of system are minimal. Municipal waste, wood, and wood waste are infeasible for several reasons, mainly fuel contamination and the form of the fuel.

\subsubsection{Alumina Rotary Kilns}

The design of rotary kilns which calcine alumina is essentially the same as those which are used in the lime, cement, and iron industries. However, the alumina product is extremely sensitive to the deposition of ash. The subsequent use of alumina in alumina refractory and aluminum metal manufacture will not tolerate any contamination if products of acceptable quality are to be produced. 
The predominant fuel in these furnaces is natural gas. Only the use of clean coal gas and methanol are classified as feasible. The use of coal, COM, SRC-1, SRC-2, residual oil, raw coal gas, wood, wood waste, and municipal waste is infeasible, principally due to fuel contamination. AFBC, indirect heat, solar energy, and electricity are infeasible for the same reasons as other rotary kilns -- process temperature limitations and heat flux limitations.

The rotary kiln design is being replaced gradually by a fluid bed type calciner which is approximately 30 percent more fuel efficient than the rotary design. The fuel alternatives open to the fluid bed calciner are the same as the rotary kiln.

\subsection{TECHNICAL FEASIBILITY OF ALTERNATIVE FUELS IN SMALL BOILERS}

A boiler generally is classified as any unit which produces steam from water. Since this study is considering only smaller boilers, units firing a solid fuel will be confined to the stoker type. In addition, the use of indirect heat is not considered since it is not applicable to steam-raising processes.

The constraints on units which raise steam are minimal; water is not subject to contamination and the typical temperatures of the steam are below $1000^{\circ} \mathrm{F}$. The major constraint is that the materials and design of the combustor be appropriate to withstand potential attack from the heat source. This is not a difficult constraint to overcome.

\subsubsection{New Boilers}

In new units, the use of coal, COM, SRC-2, residual oil, raw coal gas, clean coal gas, methanol, wood waste, wood, municipal waste, electricity, and $A F B C$ are considered feasible. It may be difficult, however, to apply AFBC technology to processes in which the demand for steam fluctuates sharply due to the nonresponsive nature of present designs. ${ }^{28 /}$ Solar 
energy is considered feasible but is best suited to the production of lower temperature and pressure steam.

SRC-1 is the sole infeasible fuel in new boilers of this size due to the form of the fuel. The solid is highly friable and must be burned in a pulverized form. Also, due to the low melting point of the fuel, it would melt on the grate of a stoker boiler, causing considerable operational problems. $29 /$ It should be noted that it may be possible to construct a boiler burning SRC-1 in a pulverized form below $100 \mathrm{MMBtu} / \mathrm{hr}$, but this falls outside of the definition for boilers in this category (stoker boilers).

\subsubsection{Gas/0il Designed Existing Boilers}

In retrofits of boilers capable of firing only oil and gas, the following fuels are considered technically feasible: methanol, residual oil, SRC-2, raw coal gas, and clean coal gas. While the conversion of any unit away from the original fuel usually results in some loss of productive capacity, the derates involved with the use of coal gas may be significant due to differences in radiant heat transfer and combustion volume. The use of COM in these boilers is considered sometimes feasible. Acurex currently is testing COM in industrial boilers, and New England Power and Electric Company is testing COM in utility size boilers. In units in which the mixturc is foasible, a significant derate is probable.

The use of coal, wood, wood waste, and municipal waste is infeasible due to ash in the fuels; the form of the fuels, and burner size limitations. SRC$I$ is considered infeasible due to burner size limitations resulting from the low melting temperature and friable nature of the fuel. AFBC, electrification, and solar energy are considered infeasible since the heat sources would require such extensive modifications in the combustor. 


\subsubsection{Existing Coal-Designed Boilers}

In retrofits of formerly coal-capable boilers now burning oil and gas, SRC2 , residual oil, COM, coal, methanol, raw coal gas, clean coal gas, municipal waste, wood, and wood waste are considered feasible. However, the derating of boilers converted to COM and especially those converted to raw and clean coal gases may be significant (20-50 percent). It again should be noted that these assessments for coal, wood, and municipal waste have not considered the site-specific problems with rebuilding or reacivating the solids handing systems. Environmental restrictions also have been removed from consideration.

A retrofit to AFBC is considered sometimes feasible and has been accomplished in a few cases. This conversion would be considered only if the use of post-combustion pollution control equipment (scrubbers, baghouses, and ESP's) was undesirable. $j$

SRC-1 is considered infeasible since it is incompatible with a stoker boiler. Electrification and the conversinn to solar onorgy are culisidered infeasible due to the extent of modification required; the construction of new units probably would be more economical.

\subsection{SUMMARY OF TECHNICAL FEASIBILITY ASSESSMENT FOR PROCESS HEATERS}

The total technical potential for substituting alternative fuels for oil and gas use in process heaters was estimated by adding the fuel use associated with each of the "feasible" technical feasibility assessments shown in Tables 5.1 and 5.2. As mentioned at the start of this section, technical feasibility is defined as the ability of a technology to produce safely and reliably the same quality product as a conventionally-fueled unit. The feasibility assessments in this scction disregard the practicality or economic attractivenes's of using alternative technologies and cxclude any consideration of site-specific factors, environmental regulations, lead times, and industrial attitudes.' This section therefore 
presents an upper bound on the applicability of using alternative technologies for industrial process heat.

The projected fuel use (for 1990). associated with each "feasible" assessment in Tables 5.1 and 5.2 was added to determine how much fuel substitution could occur, which fuels have the highest substitution potential, and which industries consume large amounts of energy in applications capable of burning alternative fuels. Table 5.3 shows the maximum potential for using alternative fuels and heat sources in new process heat units built between 1982 and 1990. The projected energy demand in new units in each industry is based on the figures in Table 3.19. As Table 5.3 shows, electricity is ultimately the most flexible source of energy, followed closely by coal gas, methanol, and SRC-2. The stone, clay and glass industry is projected to have the greatest new energy demand that could be met with alternative fuels. Large new energy requirements in the iron and steel and petroleum refining industries technically also could be met with new sources of energy.

Table 5.4 presents the maximum potential for substituting alternate fuels for current fuel use in process heaters existing before 1982. Two major differences from Table 5.3 are apparent. For coal gas and methanol, there actually is more potential for increasing their use through retrofitting existing process heaters than through building new units designed to burn these fuels. Of course, by 1990, little of this potential could be realized. The secund llajor diffcronce between the tables is the potential for electrification in new versus existing units. Electricity is feasible in most process heaters, but in retrofit applications its feasibility is very restricted.

The figures shown in Tables 5.3 and 5.4 show the maximum potential for alternative fuel use based on process retrofits and new units built by 1990 . Those figures compare to the 5.6 quads consumed for all process heat and the roughly 3.6 quads of oil and gas consumed for process heat in the major industries in 1974. The remaining two quads consist of coal, byproduct 
TABLE 5.3

MAXIMUN TECHEICAL, POTENTIAL, FOR ALTERNATJVE YUEL USE IN NEN PROCESS HEAT UNITS ${ }^{\text {a/ }}$

$$
\left(10^{12} \mathrm{~B} \pm \mathrm{u} / \mathrm{yr}\right) \text {. }
$$

\begin{tabular}{|c|c|c|c|c|c|c|c|c|c|c|c|c|c|}
\hline \multirow[b]{2}{*}{ Industry } & \multicolumn{8}{|c|}{ Fuels. } & \multicolumn{4}{|c|}{ teat Sources } & \multirow[b]{2}{*}{$\begin{array}{l}\text { New Process Ileat } \\
\text { Demand by } 1990^{\mathrm{b}}\end{array}$} \\
\hline & $\begin{array}{r}\text { LBG/ } \\
\text { MBG } \\
\end{array}$ & Methano1 & $\begin{array}{c}\text { SFic-2 } \\
\text { (1jquid) }\end{array}$ & COM & $\begin{array}{c}\text { SRC-1 } \\
\text { (solid) } \\
\end{array}$ & Coall & $\begin{array}{l}\text { Wood and } \\
\text { Wood Waste }\end{array}$ & $\begin{array}{l}\text { Manicipal } \\
\text { Waste } \\
\end{array}$ & AFBC & $\begin{array}{c}\text { Indi zect } \\
\text { Heat }\end{array}$ & $\begin{array}{l}\text { Electri- } \\
\text { fication }\end{array}$ & Solar & \\
\hline Food & 230 & 230 & & & & & & & & $2=0$ & 2.30 & 230 & 230 \\
\hline Textiles & 9 & 9 & $\cdot$ & & & & & & . & 9 & 9 & 9 & 9 \\
\hline $\begin{array}{l}\text { Stone, clay, } \\
\text { and glass }\end{array}$ & 664 & 664 & $5 \check{26}$ & 526 & 526 & $52 \theta$ & & 145 & & & 219 & & 809 \\
\hline Chemicals & 385 & 385 & 200 & & & & & . & & 200 & 770 & & 770 \\
\hline Petroleum & 388 & 388 & 38.1 & 143 & 148 & $14 \varepsilon$ & & & 148 & 165 & 411 & & 412 \\
\hline $\begin{array}{l}\text { Iron and } \\
\text { steel }\end{array}$ & 403 & 403 & 355 & 326 & 326 & $15 \bar{z}$ & & & & & 601 & & 477 \\
\hline Nluminum & 72 & 72 & 13 & 13 & $i_{13}$ & 13 & & & & & 53 & & 155 \\
\hline TOTAL & 2151 & 2151 & 1456 & 1013 & 1013 & 839 & 0 & $445^{\circ}$ & 148 & $604^{\circ}$ & 2293 & 239 & 2862 \\
\hline $\begin{array}{l}\% \text { of total } \\
\text { demand }\end{array}$ & 75 & 75 & 51 & 35 & 35 & 29 & 0 & 16 & 5 & $2 \bar{E}$ & 80. & 8 & 100 \\
\hline
\end{tabular}

a/ Process heatcrs built between 1982 and 1990 . Now energy demand by industry is presented in Table 3.19. These figures are based on process heat demand for all fuels except metallurgical coal and coke oven gas.

b/ New process heat demand in the sevpr industries examined. The total exclindes $745 \times 10^{12}$ Btu of new denand in paper and other industries that would bring the total to $3607 \times 10^{12}$ Btu. 
TABIEE 5.4

MAXIMUM TECINICAL FUEL SUBSTITUTION POTENTIAL IN EXISTING PROCESS HEAT UNITS ${ }^{2 /}$

$$
\left(10^{12} \mathrm{Btu} / \mathrm{yr}\right)
$$

\begin{tabular}{|c|c|c|c|c|c|c|c|c|c|c|c|c|c|}
\hline \multirow[b]{2}{*}{ Industry } & \multicolumn{8}{|c|}{ Fuels } & \multicolumn{4}{|c|}{ Heat Sources } & \multirow[b]{2}{*}{$\begin{array}{l}\text { Existing Demand } \\
\text { (before 1982) }\end{array}$} \\
\hline & $\begin{array}{r}\text { LBG/ } \\
\text { MBG } \\
\end{array}$ & Methano1 & $\begin{array}{c}\text { SRC-2 } \\
\text { (1 iquid) }\end{array}$ & COM & $\begin{array}{c}\text { JRC-1 } \\
\text { (solid) }\end{array}$ & Coal & $\begin{array}{l}\text { Wood and } \\
\text { Wood Waste } \\
\end{array}$ & $\begin{array}{c}\text { Municipal } \\
\text { Waste } \\
\end{array}$ & AFBC & $\begin{array}{c}\text { Indirect } \\
\text { lleat }\end{array}$ & $\begin{array}{l}\text { Electri- } \\
\text { fication }\end{array}$ & Solar & \\
\hline Food & 101 & 101 & & & & & & . & & 101 & 101 & so & 101. \\
\hline Textiles & 6 & 6 & & & & & & & & $:$ & 6 & 3 & 6 \\
\hline $\begin{array}{c}\text { Stone, clay, } \\
\text { and glass }\end{array}$ & 614 & 614 & 543 & 543 & 498 & 498 & & & & & 64 & & 748 \\
\hline Chemicals & 50 & 50 & & & & & & & & & & & 651 \\
\hline Petroleum & 1178 & 1178 & 300 & & & & & & & & & & 1322 \\
\hline $\begin{array}{l}\text { Iron and } \\
\text { steel }\end{array}$ & 524 & 524 & 156 & 143 & 143 & 143 & & & & & 82 & & 630 \\
\hline Aluminun & 66 & 66 & 10 & 10 & 10 & 10 & & & & & 10 & & 118 \\
\hline TOTAL & 2539 & 2539 & 1009 & 696 & 651 & 651 & 0 & 0 & 0 & 101. & 263 & 53 & 3576 \\
\hline $\begin{array}{l}\% \text { of total } \\
\text { demand }\end{array}$ & 71 & 71 & 28 & 19 & 18 & 18 & 0 & 0 & 0 & 3 & 7 & 1 & 100 \\
\hline
\end{tabular}


fuels such as refinery gas, and energy used by small industries. Total process energy demand in 1990 is projected to be about 7.8 quads. The portion of that demand that will be met by coal and other alternative fuels will depend largely on the economics discussed in Section 6. 
FOOTNOTES

1. The grate kiln and reverberatory furnace are not used in the stone, clay and glass industries. The grate kiln is used in the iron and steel industry, while the reverberatory furnace is used to manufacture aluminum. Since these processes are similar in their technical characteristics to the rotary kiln and regenerative melters, respectively, they were categorized together.

2. Ibid.

3. Energy Consumption Data Base, prepared for Federal Energy Administration by Energy and Environmental Analysis, Inc., June 9, 1977.

4. "Technical Design Evaluation of Costs and Markets for Low- and MediumBtu Gas from Coal in Direct-Fired Industrial Processes," prepared for Department of Energy by Energy and Environmental Analysis, Inc., October 23, 1979.

5. "Analysis of the Economic Potential of Solar Thermal Energy to Provide Industrial Process Heat," prepared for Energy Research and Development Administration by Inter Technology Corporation, February 7, 1977.

6. "The Technical Feasibility of Coal Use in Industrial Process Heat Applications," prepared for the Office of Policy and Evaluation, Department of Energy, by Energy and Environmental Analysis, Inc., May 22,1978 .

7. "Economic Impact of Gas Curtailments on Industrial End-Users," prepared for the Office of Energy Programs, Department of Commerce, by Energy and Environmental Analysis, Inc., October 7, 1977.

8. Considerable difficulties, such as buildup of coating chemicals on cylinders and dye migration across the fabric, would accompany the replacement of direct gas-fired heat with indirect heat use through steam cylinders. See "A Study of Process Energy Requirements in the Textile Industry," American Gas Association, Inc., 1966, p. 23.

9. "Technical Feasibility of Coal Use," op. i․

10. "Technical Design Evaluation of Costs and Markets for Low- and MediumBtu Gas," op. cit, pp. 84-98.

11. J.R. Schorr, Industrial Energy Study of the Glass Industry. 
12. Ibid.

13. Two plants that have been experimenting with coal use are the Glass Container Corporation, in Dayville, Connecticut, and the Chattanooga Glass Company, in Keyser, West Virginia.

14. Energy Consumption Data Base; op. cit.

15. "Technical Design Evaluation of Costs and Markets for Low- and MediumBtu Gas," op. cit.

16. "Technical Feasibility of Coal Use," op: cit.

17. Energy. Consumption Data Base, op. cit.

18. Portland Cement Association, "Energy Conservation in the Cement Industry," draft report, January 1975.

19. Discussions with industrial representatives indicate that lime kilns in the lime industry and lime kilns in the paper industry should be treated separately in terms of technical feasibility. Lime kilns in paper technically cannot burn coal due to the mineral and ash contamination. (Conversation with A.H. Christgan, Westvaco, September 12, 1979, and private communication from Jeffrey Duke, American Paper Institute, January 23, 1980.)

20. General Shale Products Corporation, Harrop Ceramic Service Company, and Pullman-Swindell, division of Pullman, Inc.

21. Conversation with chemical industry representatives, September 18, 1979 .

22. Conversation with petroleum industry representatives, October 23, 1979 .

23. Ibid.

24. "Industrial Application Fluidized Bed Combustion Indirect Fired Heater," prepared for Division of Fossil Fuel Utilization, Department of Energy, by Exxon Research and Engincoring Cumpuny, January 1-March 31, 1979 .

25. Conversation with petroleum industry representatives, October 23, 1979.

26. Conversation with steel industry representatives, September 18 , 1979 . 
27. Ibid.

28. Conversation with chemicals industry representatives, September 19, 1979 .

29. "Market Potential of SRC-1 in the Industrial Sector," prepared for Air Products/Wheelabrator Frye by Energy and Environmental Analysis, Inc., September 21, 1979. 


\section{ECONOMIC ASSESSMENT OF ALTERNATIVE ENERGY SOURCES}

\subsection{INTRODUCTION}

The critical factors affecting alternative fuel use in small boiler and process heater applications are technical, economic, environmental, and site-specific constraints. The technical constraints have been discussed in Sections 4 and 5 . This section will discuss the economics of burning alternative fuels, integrating the technical, environmental, and sitespecific factors as they that affect economic feasibility. This analysis will not address behavioral elements or financial considerations that might impede penetration of alternative fuel types.

\subsubsection{Issues in Evaluating the Economics of Fuel Use in Process Heaters} It is more difficult to evaluate the economics of various fuels used in process heaters than to examine fuel use in boilers. This is because boiler components are relatively homogeneous across a wide range of sizes and applications, while nonboilers comprise a large number of extremely diverse combustors. For example, when reviewing a sample of customers for one gas utility, well over 100 distinct process heaters were identified, each with various sizes and firing rates. The temperature requirements alone for these combustors range from $450^{\circ} \mathrm{F}$ for baking in the food industry to over $2500^{\circ} \mathrm{F}$ in regenerative furnaces used in the glass industry.

Site-specific factors, also more difficult to assess in process heaters than in boilers, are more critical to the former than to the latter. Since few process heaters are available in packaged units, each combustor generally is designed to meet specific space requirements, temperature requirements, input fuel specifications, operating parameters, and environmental regulations. Even for similar processes, design specifications vary from company to company. 
The process heater environmental regulations that might affect the economic feasibility of alternative fuel use can be classified into four general groups :

- Standards for fuel-burning equipment

- Standards for industrial processes

- Sulfur content-1imiting standard for the input fuel

- Concentration basis standard and associated controls.

Depending on the state or local regulations, the environmental regulations may vary according to all of these designations -- industry, equipment, and input fuel. These standards and how they affect control strategies are presented in Appendix B.

It also is difficult to determine the economic feasibility of the fuels evaluated in this analysis due to their limited commercial application. Several of the fuels (methanol, SRC, and COM) have not been tested in commercial scale applications. Due to this lack of operating experience, the range of costs associated with each technology varies substantially, and the lead time until commercial availability is difficult to assess. For tuels which have been burned in limited commercial applications, such as AFBC, municipal waste, $L B G$, and MBG, wide-scale application and costs remain uncertain. Even the cost of conventional alternative fuels is uncertain when evaluated in applications that traditionally have not burned those types of fuel (i.e., coal use in regenerative glass melters).

\section{1 .2 Overview of Methodology}

Since there is considerable uncertainty surrounding the cost and application of many alternative fuels, their relative economics were evaluated. by a combined qualitative and quantitative approach. Each market area was identified and evaluated with respect to technical, relative economic, and lead time factors that are specific to that market. The major market areas considered were new small boilers, retrofit small boilers, new process heaters, and retrofit process heaters. 
The economics of direct coal use for both small boilers and process heaters were evaluated through IFCAM (described in Appendix A). The economics of firing alternative technologies which are not proven in commercial scale operations were studied by evaluating a representative set of process heat applications. This representative set of process heaters was identified because it represents a significant portion, approximately 50 percent (see Table 6.1), of the process uses discussed in this analysis (each application is discussed in detail in Appendix C). It also represents a subset of combustors that have various alternative fuel-burning capabilities. Table 6.2 describes the representative sizes and capacity utilizations that were chosen to characterize process heaters in each category.

The remaining parts of this section are organized in the following way. Section 6.2 discusses the base case scenarios, presenting the major regulatory, economic, and environmental assumptions that drive the analysis. Section 6.3 describes fuel decisions made by various segments of the industrial population. Section 6.4 summarizes the results of the analysis.

\subsection{BASE CASE SCENARIO}

The first step in evaluating the economics of alternative energy sources under various policy or regulatory incentives is to describe the relative economics under base case conditions. The following discussion outlines the macroeconomic and regulatory climate in the base case and sets up the economic framework through which various alternatives are evaluated.

\subsubsection{Macroeconomic Assumptions}

Energy demand in the industrial sector is driven by a series of macroeconomic factors. Estimated growth in real gross national product (GNP), real disposable income, prices, and industrial activity were provided to DOE by the Data Resources, Inc. (DRI) macroeconomic forecasting model. DOE ran this model in a series of interactions with DOE'S MEFS to determine the proper tradeoffs between energy system growth and the cconomy. 
TABLE 6.1

OIL AND GAS USE IN MAJOR PROCESS HEAT APPLICATIONS

$$
\left(10^{12} \mathrm{Btu}\right)
$$

Equipment Type

Low-risk fired heaters (used in atmospheric and vacuum distillaliun)

Regenerative glass melter

Rotary cement kiln

Face brick kiln

Blast furnace, hydrocarbon injection

Steel reheat furnace

Heat treating furnace

SUBTOTAL

Total process heat oil and gas use covered in analysis
1974

Oil and Gas Use

467

168

248

54

100

266

67

1370

2905

SOURCE: "Technical Feasibility of Coal Use in Industrial Process Heat Applications," draft report prepared for Office of Policy and Evaluation, DOE, by Energy and Environmental Analysis," Inc., Arlington, Virginia, May 22, 1978. 
TABLE 6.2

REPRESENTATIVE PROCESS HEATERS USED IN

SAMPLE COST CALCULATIONS

Equipment Type

1. Low risk (used in atmospheric and vacuum distillation).

2. Regenerative glass melter

3. Rotary cement kiln

4. Face brick kiln

5. Blast furnace - hydrocarbon injection

6. Steel reheat furnace

7. Heat treating furnace
Size (MMBtu/hr) Utilization Life
99 and 364

200

333

42

400

200

10
$90 \%$

25 years

$90 \% \quad 5$ years

$90 \% \quad 25$ years

$90 \% \quad 25$ years

$65 \% \quad 50$ years

$55 \% \quad 30$ years

$55 \% \quad 30$ years 
For this analysis of alternative fuel use in process heaters, an existing DRI/MEFS scenario $1 /$ was used which assumed the highest imported oil price at the time of the analysis. The world oil prices (\$1978) used for this analysis are:

- 1985: $\$ 21.50 / \mathrm{bb} 1$

- 1990: $\$ 23.50 / \mathrm{bb1}$

- 1995: $\$ 31.50 / \mathrm{bb} 1$.

These oil prices assume a real increase of two percent from 1985 to 1990 and an increase of six percent from 1990 to 1995. These imported crude oil prices are low in the wake of recent OPEC price increases, but they were the highest crude prices for documentable macroeconomic evaluations that were available at the time the analytical phase of this project was being completed.

The DRI macroeconomic forecast used in this analysis was the TRENDLONG forecast used to drive the Series $C$ energy demand scenario. This forecast assumes a 3.7 percent annual increase in real GNP from 1977 to 1985 with a 3.4 percent annual increase from 1985 to 1995 .

\subsubsection{Regulatory Incentives}

'l'he energy regulatory programs assumed in this analysis are those that were in effect on November 1, 1979. A stringent environmental regulatory program was assumed for large boilers, but small boilers and process heaters were assumed to comply with the State Implementation Plans in existence on November 1, 1979. The following summarizes the major regulatory policies relevant to this study.

\subsubsection{Natura1 Gas Policy Act}

The NGPA has two major components, wellhead pricing controls and incremental pricing. The wellhead pricing regulation sets maximum prices for various categories of natural gas sold to pipelines. It also provides for 
gradual escalation and eyentual decontrol of certain categories of natural gas.

The incremental pricing rule may impact significantly small boilers and process heaters as we11 as large boilers. Regulations have been promulgated that set an incremental price ceiling for natural gas use in boilers. The regulation specifies that, for 10 months, the gas price ceiling for nonexempt users will be set at a price determined by DOE to be two standard deviations below the mean high sulfur oil price for each region. At the end of 10 months, the incremental oil cap will be adjusted to reflect the actual backup fuel (high or low sulfur residual oil or distillate) that each boiler has in place. If no backup fuel exists, the gas price ceiling automatically will be set at distillate (the two standard deviation rule still is in effect).

Currently, the incremental pricing provision applies only to facilities which consume more than $300 \mathrm{Mcf} /$ day in boilers (roughly equivalent to one $25 \mathrm{MMBtu} / \mathrm{hr}$ boiler operating 12 hours per day at fuli capacity). Because the intent of the act was to include all but five percent of the fuel used in boilers, this size distinction is being reviewed.

$\Lambda$ Notice of Proposer Rillemaking on the coverage of nonboilers under incremental pricing was presented on November 15, 1979. Under this proposed plan, all process heaters except those specifically exempted by NGPA would be covered under incremental pricing. Although the small boiler and process heater coverage under incremental pricing has not yet been determined, this analysis assumes that both are subject to incremental pricing. As mentioned, this analysis assumes that the gas price ceiling is set at two standard deviations below the mean high sulfur residual oil price. The rate at which gas prices in each region reach the cap will depend on the wellhcad price increases, the mix of industrial customers on the major pipeline suppliers, and the initial price differential of natural gas and residual fuel oil. 
After 1985, significant wellhead price increases probably will signal the end of incremental pricing as a larger portion of high-cost gas is rolled with the rate base. Although there is considerable uncertainty. about post1985. gas prices, this analysis assumed they will stabilize, in the long run, at a price that is competitive with the least cost oil alternative.

\subsubsection{Powerplant and Industrial Fuel Use Act}

FUA provides DOE with the authority to prohibit the use of oil or natural gas in all new boilers over $100 \mathrm{MMBtu} / \mathrm{hr}$ and existing boilers over 100 MMBtu/hr that originally were designed for and still have coal burning capabilities. The prohibition also extends to new boilers between 50 and $100 \mathrm{MMBtu} / \mathrm{hr}$ if the aggregate plant boiler capacity is over $250 \mathrm{MMBtu} / \mathrm{hr}$. The act provides some discretionary authority over gas turbines, internal combustion engines, and combined cycle systems, although DOE has not yet defined the extent of that authority.

Any unit subject to the prohibitions of FUA can apply for one of several exemptions. Ihree major exemptions are:

- The economic exemption

- The environmental exemption

- The temporary exemption for those who have made a commitment to use a synthetic fuel.

Some of the small boilers between 50 and $100 \mathrm{MMBtu} / \mathrm{hr}$ may be covered by FUA under the aggregation rule. It is very difficult to estimate the portion of small boilers that will be covered by this rule because no comprehensive survey (such as the MFBI file) has been conducted for boilers under 100 . $\mathrm{MMBtu} / \mathrm{hr}$. The analysis assumed that FUA would be 100 percent effective in converting large (over $100 \mathrm{MMBtu} / \mathrm{hr}$ ) boilers lacking a valid economic or environmental exemption to an alternate fuel, but boilers in the 50-100 MMBtu/hr size range would not be converted under the program. Therefore, this analysis will partially overstate the incremental impact of a progran targeting boilers below $100 \mathrm{MMBtu} / \mathrm{hr}$ size. 


\subsubsection{Energy Tax Act}

The ETA provides financial incentives to burn alternate fuel types in both boilers and process heaters. The ETA provides for a 10 percent ITC in addition to the existing 10 percent ITC for units burning an alternative fuel type. However, the additional 10 percent ITC for capital investments is scheduled to expire in 1982. To simulate this, the base case analysis assumes that new coal and alternative fuel investments receive a 10 percent ITC while oil and gas combustors receive no ITC. The depreciation distinction also was maintained with alternative fuel investments using accelerated depreciation methods, while oil and gas investments were required to depreciate using the straight line method.

\subsubsection{Environmental Requirements for Sma11 Boilers and Process Heaters}

Small boilers and process heaters are regulated by the Clean Air Act Amendments of 1970 and 1977, under which the Environmental Protection Agency promulgated National Ambient Air Quality Standards (NAAQS) for six criteria pollutants: $\mathrm{SO}_{2}$, particulates, $\mathrm{NO}, \mathrm{HC}, \mathrm{CO}$, and photochemical oxidants. Industrial sources are subject to three classes of environmental regulations adopted to insure compliance with these standards. The regulations are:

- State Implementation Plans (SIP's)

- New Source Performance Standards (NSPS)

- Nonattainment (NA) and Prevention of Significant Deterioration (PSD) regulations.

Each source is subject to the most stringent of the standards that apply to the facility.

States are required to designate Air Quality Control Regions (AQCR's) for the entire state and to prepare.SIP's which provide for the implementation, maintenance, and enforcement of the standards in those regions. SIP's vary substantially within and between states, both in the severity of the standards and the way they are expressed. The applicable SIP's were examincd 
by AQCR, and existing small boilers and process heaters were assumed to comply with the appropriate SIP based on historical distribution of each combustor in the various AQCR's.

Emissions from new process sources are regulated through emissions standards (NSPS) for specific categories of process heaters. NSPS have been promulgated for some process categories, but individual evaluation of each standard was not possible for this study. It is assumed for the purposes of this evaluation that new process heaters will meet SIP's. Proposed revisions of the NSPS for boilers have focused primarily un boiler's above $100 \mathrm{MMBtu} / \mathrm{hr}$. For the purposes of this study, new boilers above $100 \mathrm{MMBtu} /$ hr were assumed to require the Best Available Control Technology (BACT). Small boilers, under $100 \mathrm{MMBtu} / \mathrm{hr}$, were assumed to meet the control requirements of the existing SIP.

The regulatory effect of NA/PSD requirements is as follows: if NAAQS are not met in an area, NA rules must be met for each new or expanded facility. When NAAQS are met, PSD rules apply. NA provisions, in general, require that states include in their SIP's special provisions designcd to upgrade nonattainment areas. PSD rules require that states maintain, above EPAapproved levels, the air quality of their clean air areas. In this analysis, the impact of NA regulations was considered by disallowing direct coal use in designated nonattainment regions in the $1985 / 1990$ time frame. PSD regulations were not considered.

\subsubsection{Economic Assumptions}

To determine the relative economics of using various fuel types, the total annualized cost of capital, OGM, and fuel over the life of the combustor was evaluated. The financial parameters used to annualized these costs are presented in Table 6.3. The capital and O\&M costs already have been discussed in Section 4 for each technology. This section presents the fuel prices for conventional and alternative energy options. 
TABLE 6.3

\section{FINANCIAL PARAMETERS}

Discount rate: $7 \%$ (real, after-tax)

Depreciation method:

- $0 i 1$ and gas combustors: straight line

- Alternate fuel-fired combustors: sum-of-years digits accelerated depreciation

Income tax rate: $50 \%$

Investment tax credit:

- $0 i 1$ and gas combustors: $0 \%$

- Alternate fuel-fired combustors: $10 \%$

Depreciable life:

- Boilers:

- Coal and alternative fuel: 22 years

- $0 i l$ - and gas-fired boilers: 28 years.

- Process heaters vary by industry and combustor: ${ }^{a /}$

- Food: 12-18 years

- Textiles: 7.5-11 years

- Paper: 10-13 years

- Chemicals: 11 years

- Petroleum: 16 years

- Stone, clay and glass: 11-20 years

- Primary metals: 12-14 years

a/ Range reflects different depreciable lives for different subgroups within each industry group. The range does not include special tools which have much shorter lives. 


\subsubsection{Conventional Fossil Fuel Prices}

The fuel price projections used for conventional fuels are presented in Tables 6.4 through 6.9. They were based on a MEFS run incorporating the current regulatory and imported oil price scenarios described earliex. $2 /$

The natural gas prices shown in Table 6.4 assume that incremental pricing includes process heater gas use as well as hoilers. $\Lambda$ grcat deal of uncertainty surrounds the wellhead gas prices after 1985. To generate the post-1985 prices used in this analysis, it was assumed that gas prices would stabilize at a price that was competitive with high sulfur residual oil in the long term.

0il prices are presented for distillate oil, high sulfur residual oil, and low sulfur residual oil. The end user prices shown here are city gate prices to reflect the price paid by the larger industrial users. They are based on the crude oil prices outlined in Section 6.2.1 and assume deregulation of domestic sources in 1982. The price differentials between each of these oil types represent long-term prire differentials based on 1.le differential production costs, distribution costs, and environmental premium. 3/ Short-term supply/demand imbalances are not picked up in those long-term price differentials.

A great deal of uncertainty surrounds any projection of fuel prices. The impact of external sources (OPEC) is difficult to predict, but the crude oil price trajectory and the resultant end product prices are critically tied to these external factors. Regulatory programs, including both oil and gas deregulation, also are difficult to predict. Even in natural gas, where the alluwable prices of various gas sources arc determined explicitly by the NGPA, the mix of wellhead sources and shifting sources must be known to project natural gas prices. While there is a great deal of uncertainty about conventional fuel price trajectories, there is even more uncertainty regarding the costs of alternate energy technologies. 


$$
6-13
$$

TABLE 6.4

NATURAL GAS PRICES

(1978 \$/MBtu)

\begin{tabular}{cccc}
$\begin{array}{c}\text { DOE } \\
\text { Region }\end{array}$ & $\underline{1985}$ & $\underline{1990}$ & $\underline{1995}$ \\
\hline 1 & 3.26 & 3.53 & 4.81 \\
2 & 3.25 & 3.53 & 4.81 \\
3 & 3.10 & 3.53 & 4.81 \\
4 & 3.04 & 3.53 & 4.81 \\
5 & 3.14 & 3.44 & 4.76 \\
6 & 3.16 & 3.21 & 4.03 \\
7 & 2.88 & 3.45 & 4.77 \\
8 & 2.77 & 3.09 & 3.80 \\
9 & 2.91 & 3.21 & 4.49 \\
10 & 2.82 & 3.10 & 4.39
\end{tabular}

SOURCE: Midterm Energy Forecasting Mode1, run \#CAM*913H. A11 regions except 6 and 8 are the average delivered industrial price. Since regions 6 and 8 are predominantly intrastate gas, the prices were the marginal wellhead prices. 
TABLE 6.5

HIGH SULFUR RESIDUAL OIL ${ }^{a /}$

(1978 \$/MMBtu)

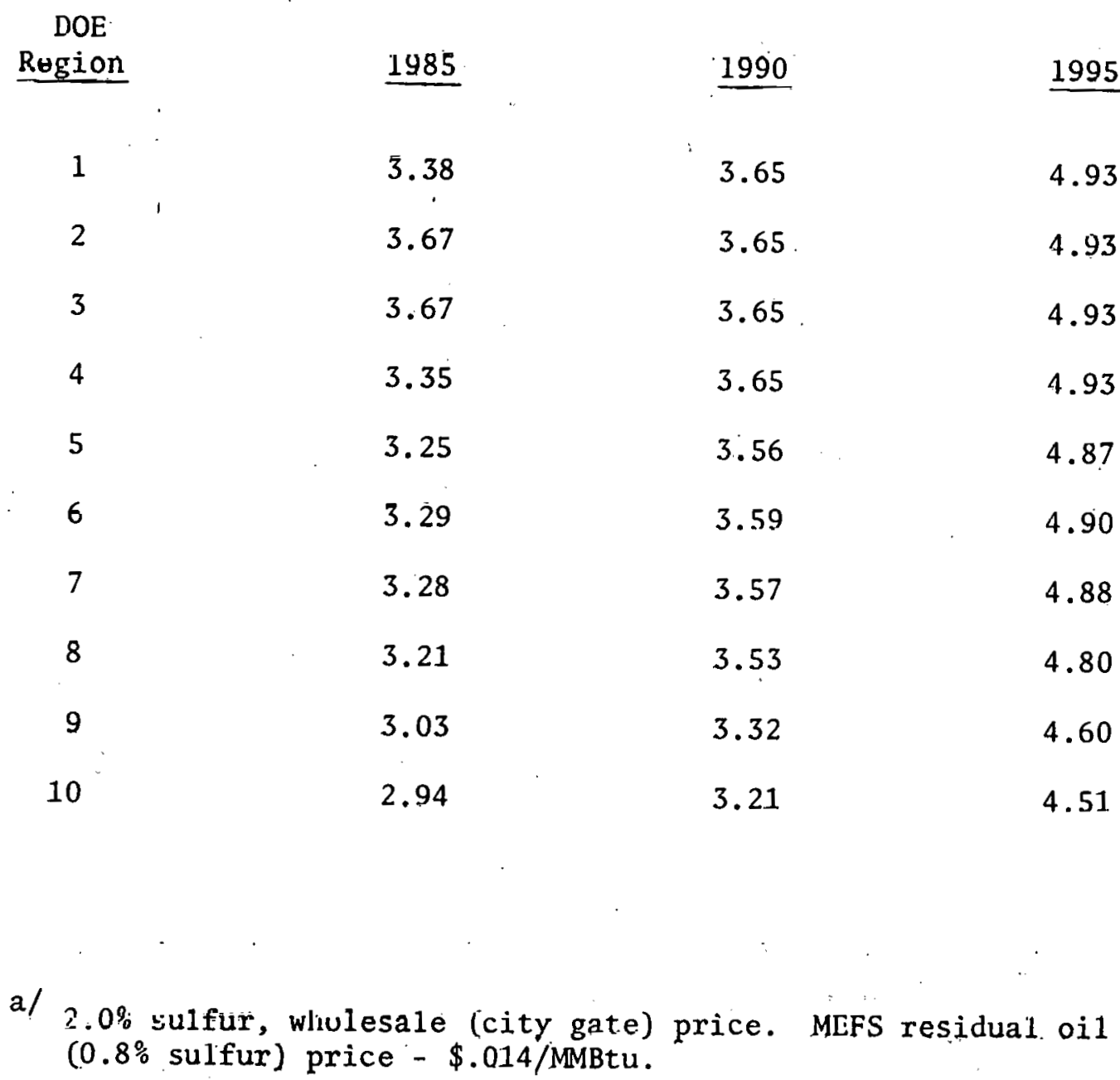

SOURCE: Midterm Energy Forecasting Model, rum \#CAM*913H. 
TABLE 6.6

LOW SULFUR RESIDUAL OIL ${ }^{a /}$

(1978 \$/MMBtu)

\begin{tabular}{cccc}
$\begin{array}{c}\text { DOE } \\
\text { Region }\end{array}$ & $\frac{1985}{3.70}$ & $\underline{1990}$ & 1995 \\
\hline 1 & 3.69 & 3.97 & 5.25 \\
2 & 3.69 & 3.97 & 5.25 \\
3 & 3.66 & 3.97 & 5.25 \\
4 & 3.57 & 3.97 & 5.25 \\
5 & 3.60 & 3.87 & 5.19 \\
6 & 3.59 & 3.91 & 5.21 \\
7 & 3.52 & 3.89 & 5.20 \\
8 & 3.35 & 3.85 & 5.12 \\
9 & 3.25 & 3.64 & 4.92 \\
10 & & 3.53 & 4.83
\end{tabular}

a/ $0.3 \%$ sulfur, wholesale (city gate) price. MEFS residual oil $(0.8 \%$ sulfur $)$ price $+\$ 0.10 /$ MMBtu.

SOURCE: Midterm Energy Forecasting Mode1, run \#CAM*913H. The city gate residual oil price shown in MEFS was adjusted by adding (or subtracting) premiums for sulfur content. These premiums were developed from earlier DOE analysis (see Footnote 1). 
TABLE 6.7

DISTILLATE OIL

(1978 \$/MMBtu)

$\begin{array}{cccc}\begin{array}{c}\text { DOE } \\ \text { Region } \\ \hline 1\end{array} & 1985 & \underline{1990} & \underline{1995} \\ 2 & 4.06 & 1.1 .7 & 5 . \dot{9} 3 \\ 3 & 4.04 & 4.46 & 5.94 \\ 4 & 4.03 & 4.46 & 5.94 \\ 5 & 4.00 & 4.44 & 5.93 \\ 6 & 3.93 & 4.36 & 5.85 \\ 7 & 3.97 & 4.39 & 5.88 \\ 8 & 3.92 & 4.34 & 5.84 \\ 9 & 3.89 & 4.33 & 5.79 \\ 10 & 3.60 & 4.02 & 5.51 \\ & 3.60 & 4.02 & 5.51\end{array}$

SOURCE: Midterm Energy Forecasing Model, run HCAM*y.13H. 
TABLE 6.8

HIGH SULFUR COAL ${ }^{\text {a/ }}$

(1978 \$/MMBtu)

\begin{tabular}{c} 
DOE \\
Region \\
\hline
\end{tabular}

1

2

3

4

5

6

7

8

9

10 $\underline{1985}$

2.35

2.08

1.82

2.04

1.66

1.90

1.47

1.14

2.51

1.97
1990

2.58

2.31

2.07

2.24

1.81

2.07

1.60

1.14

2.63

2.30
1995

2.81

2.52

2.28

2.44

3.06

2.23

1.77

1.24

2.84

2.37

a/ High sulfur coal, $>1 \%$ sulfur.

SOURCE: Midterm Energy Forecasting Mode1, run \#CAM*9.13H. 
TABLE 6.9

LOW SULFUR COAL ${ }^{\text {a/ }}$

(1978 \$/MMBtu)

\begin{tabular}{cccc}
$\begin{array}{c}\text { DÜE } \\
\text { Rr.ginn }\end{array}$ & $\underline{1985}$ & $\underline{1990}$ & 1995 \\
\hline 1 & 2.84 & 3.04 & 3.19 \\
2 & 2.59 & 2.81 & 2.95 \\
3 & 2.36 & 2.58 & 2.74 \\
4 & 2.61 & 2.83 & 2.98 \\
5 & 2.28 & 2.45 & 2.54 \\
6 & 2.30 & 2.55 & 2.65 \\
7 & 2.14 & 2.28 & 2.35 \\
8 & 1.26 & 1.30 & 1.37 \\
9 & 2.63 & 2.84 & 2.95 \\
10 & 2.07 & 2.30 & 2.37
\end{tabular}

a/ Low sulfur coal, $\leqslant 1 \%$ sulfur.

SOURCE: Midterm Energy Forecasting Mode1, run \#CAM*913H. 


\subsubsection{Alternate Fuel Technology Costs}

In order to evaluate the relative economics of alternate fuel use in small boilers, costs were developed and evaluated for all the alternative fuel options. The limited number of technologies considered explicitly in the economic analysis of process heaters were methanol, LBG, MBG, COM, SRC-1, and SRC-2. Municipal waste and wood waste are driven primarily by sitespecific factors and do not lend themselves to a generic economic comparison. $4 /$ The generic costs used to discuss the relative economics of each technology are presented as an upper and lower bound estimate to illustrate the uncertainty associated with these costs. In spite of such uncertainty, analysis of the annualized capital, OGM, and fuel cost provides insights into the types of policies and targets for incentive plans that would be most effective in encouraging new technology adoptions.

The primary source of new technology cost estimates was the DOE. The capital and OGM cost estimates for methanol, MBG, and SRC-2 were interim cost estimates used in a 1979 DOE report to Congress entitled "National Energy Plan II." $5 /$ Because COM and SRC-1 were not considered in the DOE report, independent sources were used to construct comparable technology costs. 6/ DOE sources were used whenever possible because the assumptions behind the estimates already had been standardized.

Alternate fuel costs were calculated as the price an industrial user would pay for the final delivered fuel on an annualized per MMBtu basis. For offsite technologies, this price was estimated as the sum of the annualized after-tax capital, O\&M, and input fuel costs to the producer, plus the cost of transportation to the end user, plus any derate costs if the alternate fuel replaced conventional fuel in an existing source. For. onsite technologies such as COM, there was no additional transportation cost. The components of each cost estimate (from DOE and independent sources) were broken down to ensure that they reflected comparable assumptions on input fuel price, production plant size, transportation costs, and derating. 
Table 6.10 shows the important assumptions used in calculating alternate fuel costs to industrial users. The producing plant's capita1, OGM, and fuel charges, when added to the fuel transportation charge, equal the fuel price. Critical assumptions and the sources for each estimate also are shown.

\subsection{FUEL CHOICE IN THE BASE CASE}

Industrial fuel choice patterns, assuming no change in the existing regulatory and economic environment, are discussed in the following two sections. The first section discusses current and future patterns in industrial small boiler fuel usage. The second section discusses process heaters in which coal or alternative fuels will be used under existing conditions.

\subsubsection{Alternative Fuel Use in Sma11 Boilers}

Most of the fuel alternatives considered in this analysis technically can replace oil and gas use in the new small boiler market. The critical factors that distinguish the various fuel alternatives are cost and the lead time required until commercial availability. The available technology alternatives have been listed roughly in order of cost in Table 6.11. Except for those cases noted on the table, the range of costs for each technology represents the range of cost estimates that were available from different sources for a $50 \mathrm{MMBtu} / \mathrm{hr}$ hoiler.

Municipal solid waste and wood waste are potentially the lowest cost options available for new small boilers. However, the use of these alternative fuel types in small boilers depends on several site-specific factors such as proximity to fuel source, local environmental regulations, and operating requirements of the boiler. In the paper industry, where wood waste is abundant and transportation costs are low, over half the fuel used in boilers is either wood or byproduct fuels. Waste fuels in the paper industry are used primarily in baseload and power boilers due to their low fuel cost 
and limited boiler response requirements. The use of municipal solid waste in industrial boilers often is a community decision. It requires the combined effort of the MSW supplier, the industrial boiler user, and the local environmental regulators. A long-term commitment and a large volume are required from both the MSW supplier and the industrial boiler operator in order to make the necessary capital investments pay off for both parties. For this reason, MSW boilers have been confined primarily to utility and large industrial boilers in the past. The potential for MSW use in boilers below $100 \mathrm{MMBtu} / \mathrm{hr}$ exists, but the adoption of this fuel type depends on many factors beyond the scope of a structured assessment of generic fuel decisions.

Of the other technologies considered as alternatives in small boilers, only direct coal use, AFBC, LBG, and electricity are currently commercially available. Direct coal use and AFBC essentially compete in the same market and are competitively priced with oil and gas today. Electric boilers are a high-cost boiler option which only compete in the boiler market where stringent environmental regulations or operating conditions preclude conventional fossil fuel use. LBG commands too high a premium to be burned in most boiler applications today. As is indicated by the wide cost range for $L B G$ and $M B G$, additional operating experience is required before the LBG costs can be estimated accurately. The remaining technologies, SRC-1, SRC-2, methanol, solar, and MBG, require additional lead time before commercialization.

Since coal use is generally the lowest-cost alternative fuel available on a wide scale for small boilers, it was used as a proxy to estimate alternative fuel use potential in the small boiler market.

Historically, small boilers (10-100 MMBtu/hr) have burned primarily natural gas and oil with less than 15 percent coal use. Table 3.9 (in Section 3) described the historical fuel mix used in small boilers. As shown in that table, most coal use in small boilers was consumed in boilers in the 25-100 
TABLE $\quad 6.10$

ESTIMATED COSTS AND ASSUMPTIONS FOR ALTERNATE FUEL TECHNOLOGIES

\begin{tabular}{|c|c|c|c|c|c|c|c|}
\hline \multirow[b]{2}{*}{ Alternate Fuel } & \multirow[b]{2}{*}{$\begin{array}{r}\text { Total Cost }{ }^{a /} \\
(1978 \$ / M M B t u) \\
\end{array}$} & \multirow[b]{2}{*}{$\begin{array}{c}\text { Retrofit } \\
\text { Derate } \\
\end{array}$} & \multicolumn{4}{|c|}{ Conversion Plant } & \multirow[b]{2}{*}{ Source } \\
\hline & & & Technology Type & $\begin{array}{c}\text { Size } \\
\left(10^{12} \text { Btu/yr }\right) \\
\end{array}$ & $\begin{array}{c}\text { Cafazity } \\
\text { Utilization }\end{array}$ & $\begin{array}{c}\text { Production } \\
\text { Losses } \\
(\%) \\
\end{array}$ & \\
\hline Methanol & 5.63 & None & Advanced gasifier & 32. & 0.9 & 40 & DOE NEP-II $I^{b /}$ \\
\hline MBG & 4.34 & $108^{c /}$ & $\begin{array}{l}\text { Lurgi techrology, } \\
\text { eastern coal }\end{array}$ & 50 & 3.9 & 25 & DOE NEP-II \\
\hline SRC-2 & $3.99-5.14$ & None & $\begin{array}{l}\text { Average of coal } \\
\text { liquids (SRC-2, } \\
\text { H-coal, EDS) }\end{array}$ & 118 & 0.9 & 30 & DOE NEP-II \\
\hline $\mathrm{COM}$ & 3.94 & $15 \mathrm{~d}^{\mathrm{d} /}$ & Standard & 1.5 & 0.7 & None & McKee \& Co. $^{e /}$ \\
\hline SRC-1 & $4.06-4.85$ & None & Standard & 168 & C. 3 & 30 & Radian, Inc. $f /$ \\
\hline$\Lambda F B C$ & 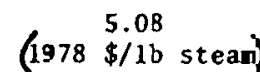 & N/A $\cdots$ & Standard & - & 0.3 & 18 & DOE NEP-II \\
\hline
\end{tabular}

a/ Costs represent feasible selling prices to industrial end users, including transportation charge. Costs were calculated using annualized fuel price streams starting in 1983.

b/ Interim costs for National Energy Plan II, May 1979, a Report to Congress required by Title 8 of the LoE Organizational Act, Public Law 95-91, U.S. Department of Energy.

c/ Ten percent derate in a previously natural gas-fired furnace.

d/ Fifteen percent deraze in a previcusly residual oil-fired furnace.

e/ Arthur McKee and Company, "Coal-Oïl Mixture: A Preliminary U.S. Market Stgdy," 1979.

f/ Radian Corporation, "Synfuels from Coal as Emission Control Techniques for Industrial Boilers," draft Einal report, January 1979. 
TABLE 6.11

COMPARISON OF THE COSTS OF FIRING ALTERNATIVE FUEL TYPES

IN SMALL BOILERS

(1978 \$/KPPH)

Low-Cost Options

Municipal solid waste

$1.63-3.82^{\mathrm{a} / \mathrm{b} /}$

Wood waste

$3.58-4.86$

Competitive

Direct coal

$4.11-6.12$

$\mathrm{AFBC}$

$4.08-5.22$

Maybe Competitive

$\mathrm{COM}$

$7.22-6.37$

SRC-2

$5.50-7.08$

SRC-1

$5.49-6.29^{\mathrm{b} /}$

LBG, MBG

$3.91-9.54$

(5.76 DOE estimate)

Methanol

$7.47-8.31$

High-Cost Options

Electric

$9.00-10.00$

Solar

$13.00-19.00$

a/ The range generally reflects the variation in cost estimates from different soruces. The underlined cost is the DOE estimate used in this analysis.

b/ For MSW and SRC-1, costs were not available for small boiler applications. The estimates shown here are large $325 \mathrm{MMBtu} / \mathrm{hr}$ boilers and reflect some economies of scale. 
MMBtu/hr range. Projected short-term estimates do not suggest a dramatic change in small boiler fuel choice in the $1985 / 1990$ time frame.

Table 6.12 presents a sample calculation to illustrate the relative economics of oil, gas, conventional coal, and AFBC for a new boiler built in 1983. The table shows that the AFBC is comparable to conventional coalfired boilers if local environmental regulations require an FGD unit to be used in conjunction with the boiler. The example also shows that, in high capacity utilization cases, both conventional coal and AFBC are competitive with oil and gas.

The last line of the table shows the annualized cost of burning conventional fuels in a smail boiler operating at low capacity utilization rates. At a 25 percent capacity utilization rate, gas is a clear winner over low sulfur residual oil and low sulfur coal. This example illustrates that under stringent environmental control requirements, high sulfur coal use is dependent on the capacity utilization rate of the boiler.

Hislorical data suggest that six percent of the fuel used in small boilers is consumed in boilers that are run at low load factors. These boilers are typically used for space heating. The vast majority, nearly 80 percent, of the fuel is used by small boilers operating 30-60 percent of the time. These are typical operating rates for process uses that may be five or six days per week operations. About 15 percent of the fuel is used in boilers operating at a capacity utilization rate over 60 percent.

The penetration of coal use in small boilers was estimated for 1985 and 1990 by evaluating a series of fuel choice decisions using IFCAM. Table 6.13 displays the projected mix of boiler fuel demand in 1990 by size as projected by IFCAM. Based on the current economic and regulatory environment, a small portion of the small boiler use (primarily new boilers with high capacity utilization rates) is projected to use coal (Table 6.14). If 
TABLE 6.12

COMPARISON OF ECONOMICS OF VARIOUS FUELS USED IN SMALL BOILERS WITH VARYING CAPACITY UTILIZATION RATES

(annualized 1978 \$/MMBtu)

\begin{tabular}{lccc}
$\begin{array}{l}\text { Natural } \\
\text { Gas }\end{array}$ & L.S. & L.S. & H.S. \\
\hline
\end{tabular}

Size: $50 \mathrm{MMBtu} / \mathrm{hr}$

Capacity Utilization: 75 percent

Capita1 Costs:

Combustor

Environmental ${ }^{\text {a/ }}$

0.20

0.25

0.74

0.74

$1.20-2.00$

OGM Costs :

Combustor

Environmental a/

N/A

N/A

0.16

0.48

$A F B C$

Fuel $\operatorname{Cost}^{c /}$

3.65

4.34

0.26

0.59

0.59

$1.15-1.49^{\mathrm{b} /}$

Total Cost

4.00

4.96

0.10

0.58

$1.15-1.49^{\mathrm{b}}$

Size: $50 \mathrm{MMBtu} / \mathrm{hr}$

Capacity Utilization: 25 percent

Total Cost

4.54

5.61

6.12

8.33

N/A

a/ Assumes that low sulfur coal requires an ESP; high sulfur oil requires an FGD system.

b/ Broad range reflects uncertainty in estimates due to limited operating experience.

c/ Fuel prices are the prices shown in Tables 6.4-6.9, annualized over a 30-year boiler life.

SOURCE: "Industrial Fuel Choice Analysis Model," draft report prepared for DOE by Energy and Environmental Analysis, Inc., Arlington, Virginia, January 1979.

"Small Atmospheric Fluidized Bed Combustor Cost Study," prepared for DOE by Energy and Environmental Analysis, Inc., Arlington, Virginia, May 1979. 
TABLE 6.13

DISTRIBUTION OF TOTAL REQUIREMENTS IN BOILERS

IN 1990 BY SIZE AND YEAR BUILT

\section{Size (MMBtu)}

$10-100$

$10 G-250$

250

TOTAL
Boilers Bidilt

before 1982

1353

1582

1432

4367
Boilers Built

from 1982 - 1990

703

1379

1353

$\underline{2785}$

34.35
2056

2961

$\underline{\text { Total }}$

7802

SOURCE: Unless otherwise cited, all industrial fuel use projections were estimated based on EEA's Industrial Fuel Choice Analysis Model runs, Dacember 17, 1979. 
TABLE 6.14

PENETRATION OF COAL IN SMALL BOILERS UNDER

A BASE CASE SCENARIO

$$
\left(10^{12} \text { Btu's }\right)
$$

Existing Boilers

(Boiler built prior to 1982)

Oil/Gas

Coal

Small Boiler (between 10 and $100 \mathrm{MMBtu}$ )

Low Capacițy utilization rate

N/A

N/A

149

Medium capacify util-

N/A

N/A

143

39

High capacity utilization rate

TOTAL

N/A

N/A

257

114

1203

150

549

Oil/Gas
New Boilers

(Boiler built between 1982 - 1990)

Coal

a/ Low $=1$ ess than 30 percent

b/ Medium $=30-60$ percent

c/ High $=$ over 60 percent

SOURCE: Unless otherwise cited, all industrial fuel use projections were estimated based on EEA's Industrial Fuel Choice Analysis Model runs, December 17, 1979. 
AFBC is allowed to compete, it would capture a subset of those high capacity boilers that are projected to use coal.

Even with the regulatory incentives provided by the FUA and the price incentives provided by the NGPA, small boilers are less likely to shift away from gas and oil for the following reasons:

- Vexy few existing small boilers have coal backup

- Capital cost is a larger proportion of total annual cost for small boilers than for large boilers

- Small boilers historically have experienced fewer gas curtailments (higher on the priority scheme).

\subsubsection{Alternative Fuel Use in Process Heaters}

The number of alternative technologies that can compete in process heaters in the short term is limited to those alternative fuels that will be commercially available by 1985/1990 and tochnically can meet lie requirements of the process. Table 6.15, which ranks each of the process heater technologies according to technical applicability, cost, and lead time, provides a reasonable framework to assess the relative competitiveness of each technology in new process heaters. The technical applicability judgment in Table 6.15 is based on the new unit assessments in Section 5. The technology lead time refers to the lead time required to develop each technology, not the actual installation time for an individual facility.

The costs were ranked according to ability to compete with conventional fuel sourcra in 1985 and 1920. Any luel that cost over \$8.00/MMBtu was classified as a high-cost alternative. The competitive cost range includes technology costs ranging from \$4-8/MMBtu, with LBG and MBG on the upper end of the range and conventinnal coal on the lower end. The alcernative fuels that fall in the competitive or "may be competitive" range are the fuels evaluated in this discussion of process heater fuel economics. 
TABLE 6.15

\section{TECHNOLOGY RANKING FOR USE IN PROCESS HEATERS}

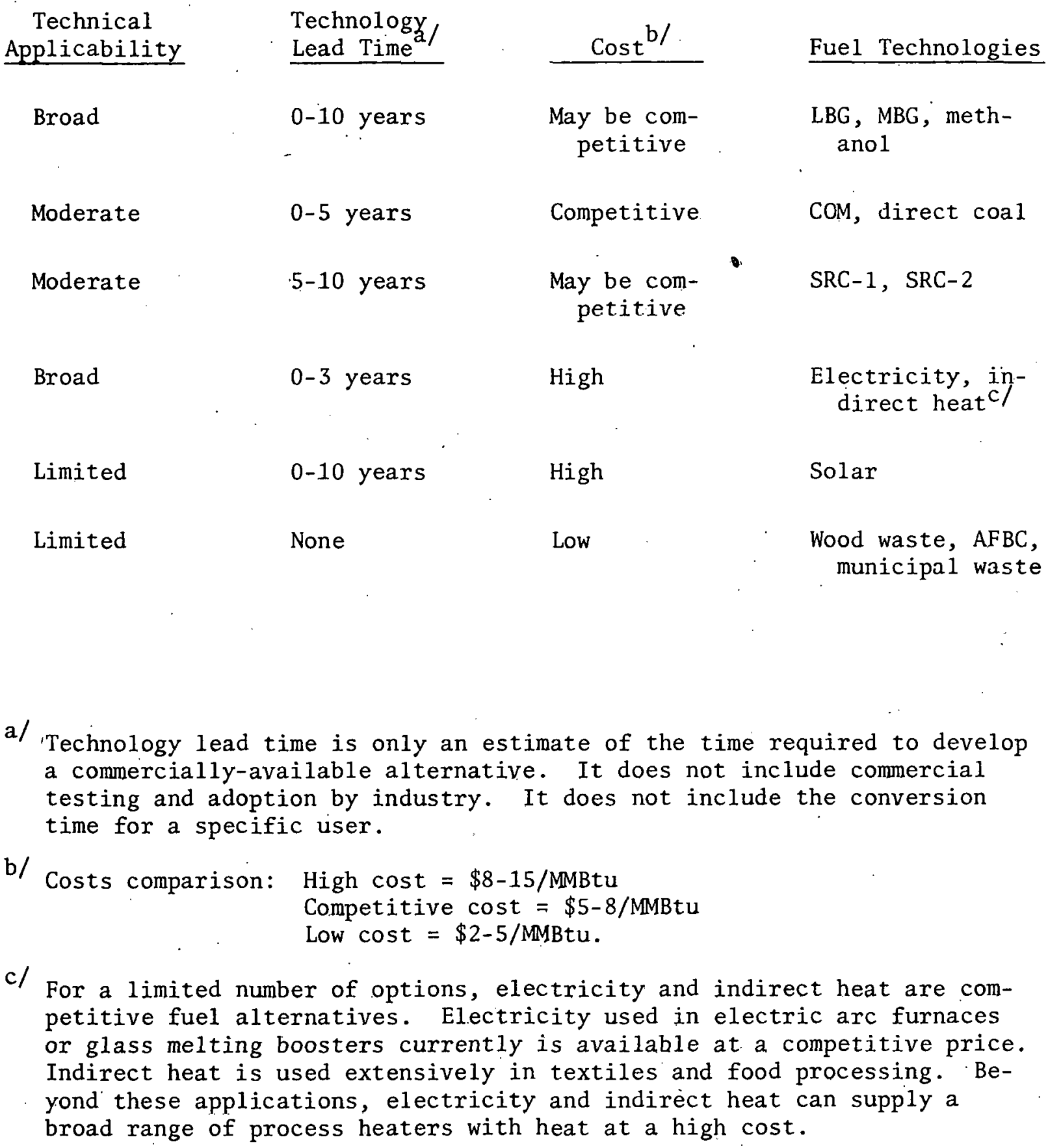


Even though municipal waste and wood waste are low-cost alternatiyes (i.e., limited potential in cement kilns), they were not coyered explicitly in the economic assessment of process heaters because technical factors preclude their use in most process heat applications. In addition, in all cases in which these fuels can compete, the economics are driven primarily by site-specific factors such as the "tipping fee" for MSW and the proximity to sources for wood waste. These issues already haye bccn raised in the earlier discussion of those technologies. AFBC also was listed as a lowcost technology with limited process applications. Although experimental work is underway, AFBC currently is primarily a boiler fuel with few process heat applications?

Electrification and indirect heat are classified in Table 6.15 as high-cost technologies with broad applications. This is somewhat of an oversimplification of the actual applicability of these technologies. Indirect heat is competitively priced and currently is used extensively in textiles and food processing; electric energy is used in glass and steel melters. These technologies also can provide an adequate heat source to a number of applications that currently do not use electricity or indirect heat, although the use of these energy technologies in most other processing operationt (i.e., resistance heating in process heaters) would entail very high costs. These technologies are not discussed explicitly in the following section, but applications where these technologies are priced competitively will be noted.

In the time frame considered for this report, 1985 and 1990, solar energy has limited applications and high cost.

The fuel technologies for which the economics were considered explicitly in process heaters are those fuel technologies identified as competitive in Table 6.15. These technologies include direct coal, COM, SRC-1, SRC-2, methanol, LBG, and MBG. The first fuel type considered is direct-fired coal in process heat applications. 
Only a small subset of process heaters currently burn coal or alternate fuels in their furnaces. The major use of coal in process heaters is in kilns in the cement and lime industries. Cement and lime kilns currently consume roughly 250 trillion Btu of coal out of a total 300 trillion Btu of coal demand in process heaters. The other current uses of nonscarce fuels in process heaters are coke oven gas used in reheat furnaces and coke ovens, blast furnace gas in blast furnace stoves and soaking pits, and refinery gas used in fired heaters.

Table 6.16 shows projected process heater coal use in 1990. The lime and cement industry continues to dominate process heat coal use in both new and retrofit applications. However, small penetration of coal may occur in low-risk fired heaters in petroleum refining and aluminum furnaces, and in the steel and brick industries.

Technical and economic factors limit the penetration of coal use in process heaters in the 1985/1990 time frame. The summary in Section 5 indicated that roughly 25 percent of the process heat applications technically could burn coa1. Table 6.16 shows that a little over 15 percent of new applications are burning coal under base case conditions. Several applications which technically could burn coal have not used coal historically because of the cheap availability of clean burning gas. In cases where coal use is technically feasible but not currently practiced (i.e., low-risk fired heaters, regenerative glass melters), a lead time would be required to develop the necessary technology (i.e., to design the equipment to minimize temperature variability or contamination of coal use).

Once the technical barriers have been removed, the use of a new technology or fuel type will depend not only on its economic attractiveness but also on its acceptance by industry and the availability of capital. A good example is the conversion to coal-fired cement kilns. Coal firing has been used since before 1900, but not until the early. 1970's was its use 


$$
6-32
$$

TABLE 6.16

PROJECTED DIRECT COAL USE IN PROCESS HEATERS IN 1985 AND 1990 $\left(10^{12} \mathrm{Btu}\right)$

1990 Fuel Demand

Oi.1/Gas Coal

Process Heaters:

\begin{tabular}{|c|c|c|}
\hline Built priur to 1981 & 3797 & 558 \\
\hline Built between 1982-90 & 3080 & 369 \\
\hline TTAL & 6877 & 927 \\
\hline
\end{tabular}

SOURCE: EEA, IFCAM run generated December 17, 1979. 
considered economically attractive. In 1971, about 16 percent of cement production came from coal-fired kilns. By 1979, through what has been considered a fast conversion program, 72 percent of production capacity had been converted to coal firing. This extensive conversion was possible because of the increasing economic attractiveness of coal and the relative ease in converting existing cement kilns.

The potential for coal use in process heaters which historically have not burned coal is subject to similar developmental and acceptance problems as other fuel alternatives covered in this report.

Direct coal use in process heaters is limited due to problems in firing a solid fuel and contaminants contained in the coal. These problems can be minimized by processing the coal into a liquid or gaseous form that is more compatible with the current fuels used in each process. However, high costs and problems in producing the synthetic products replace the application difficulties of burning and handling solid coal. In order to illustrate the economics of new technology alternatives in various process heaters, eight major process heaters were identified and economic calculations were performed for representative size combustors in each combustor type. Table 6.17 presents an economic comparison of several fuel types on an annualized \$/MMBtu basis: Appendix D describes the derivation of these cost estimates.

Table 6.17 reiterates that for those processes where direct coal use is feasible, it often is the least-cost fuel alternative on an annualized basis. Rotary cement kilns, blast furnaces, and face brick kilns all show coal as the cheapest fuel alternative in new applications.

Natural gas is the least expensive conventional fuel used in the other process heat examples presented in Table 6.17. Low-risk fired heaters, regenerative melters in glass, and the heat treating and reheat furnaces in steel historically have been fired by natural gas because of both the 
TABLE 6.17

RELATJVE EZONOMICS OF USINİ ALTERNATIVE FUEL TYPES IN NEWW PROCLSS HEATERJ

(1973 $\$$ /NMBtL)

\section{Process}

Fired heaters - distillation

$99 \mathrm{smBtu} / \mathrm{hr}$

$364 \mathrm{MMAtu} / \mathrm{hr}$

Regenerative glass melter

Blast furnace hydrocarbon injection

Steel reheat furnace

Rotary cement kiln

lace brick kiln

Heat treating furnace
Conventional Fuels

Natural
Gas Residual Distillate $\quad$ Coal

$\begin{array}{llll}4.20 & 4.82 & 5.28 & 4.02-5.03 \mathrm{~b} / \\ 4.11 & 4.37 & 5.17 & 3.40-4.25 \mathrm{~b} / \\ 4.37 & 5.22 & 5.42 & 4.97 \\ 4.84 & 5.64 & 5.92 & 3.03 \\ 5.16 & 5.76 & 6.24 & \mathrm{~N} / \mathrm{A} \\ 4.39 & 4.71 & 5.50 & 2.85 \\ 4.36 & 5.09 & 5.48 & 3.90 \\ 7.69 & \text { N/A } & 9.64 & \mathrm{~N} / \mathrm{A}\end{array}$

\begin{tabular}{|c|c|c|c|}
\hline \multirow{3}{*}{$\mathrm{MBG}$} & & & \\
\hline & jRC- $\bar{c}$ & Methanol & SRC-1 \\
\hline & $\left(\right.$ R $^{2}$ ge $\left.e^{a /}\right)$ & & (Range) \\
\hline
\end{tabular}

$4.69 \quad 4.47-5.62^{a /} \quad 6.06 \quad 5.55-6.35$

$4.60 \quad 4.6]-5.47 \quad 5.95 \quad 5.11-5.90$

$\begin{array}{llll}5.64 & 5.53-6.73 & 7.04 & 6.46-7.26\end{array}$

$5.17 \quad 4.91-6.66 \quad 6.53 \quad 5.18-5.97$

$\begin{array}{lll}5.59 & 5.27-6.42 & 6.95\end{array}$

$6.95 \quad \mathrm{~N} / \mathrm{A}$

$\begin{array}{llll}4.92 & 4.53-5.83 & 6.28 & 4.88-5.67\end{array}$

$4.85 \quad 4.77-5 . \subseteq 4 \quad 6.25 \quad 5.47-6.26$

$8.72 \quad$ V/A $\quad 9.45 \quad$ N/A

a/ The range for SRC-1 and SRC- 2 costs indicates uncertainty of cost estimates.

b/ The range of fired heater cost estimates reflects a new plant cersus an expansion of an existing plant. 
technical and economic requirements of the processes. As indicated by the range of coal costs for low-risk fired heaters, there is speculation that coal might be an economic alternative in certain new low-risk fired heaters in the petroleum industry. Studies of both direct-fired coal use and AFBC currently are underway in the petroleum industry, $8 /$ but the preliminary results indicate that the site-specific cost increases of using coal overwhelm the fuel cost savings that might be realized. Although the cost comparison for low-risk direct-fired heaters in Table 6.17 does not address these site-specific variations, it does show a range of estimates with the lower cost representing the generic cost of burning coal in a new plant and a high cost indicating the cost of burning coal as an expansion in an existing facility. Since most recent expansions of petroleum capacity have been in existing facilities, the high end of the cost range should be considered most reasonable for coal.

The nonconventional fuels shown in Table 6.17 are higher-cost options than coal. In the case of methanol, SRC-1, and SRC-2, five to seven year lead times are required before they can penetrate the market to a large extent. Coal gas facilities are the only "proven" nonconventional technology shown, and coal gas is \$0.50-1.00/MMBtu higher than conventional fuels. Current applications of LBG and MBG are in areas where a gaseous fuel is necessary for operations, and natural gas availability is uncertain. $9 /$

Representative conversion costs for retrofitting process heaters are displayed in Table 6.18. These costs include retrofit capital; O\&M, and fuel costs. As shown in the table, direct coal competes technically in only three of these retrofit markets -- rotary cement kilns, face brick kilns, and blast furnaces. Unlike new units, the conversion costs to fire direct coal are greater than the costs of conversion to other coal-based alternatives. In most of the applications shown in Table 6.18, liquified coals (either COM or SRC-2) are the least-cost alternative fuels. In heat treating furnaces, where SRC-2 and COM cannot compete, MBG is the least-cost 
TABLE 6.18

RELATIVE ECONOMICS OF RETROFITTING FROM NATURAL GAS TO

ALTERNATIVE FUEL TYPES IN EXISTING PROCESS HEATERS

(1978\$/MMBtu)

\section{Process}

Low-risk fired heaters:

$99 \mathrm{MMBtu} / \mathrm{hr}$

$364 \mathrm{MMBtu} / \mathrm{hr}$

Regenerative glass melter

Blast furnace, hydrocarbon injection

Steel reheat furnace

Rotary cement kiln

Face brick kiln

Heat treating furnace
Natural $\mathrm{Gas}^{\mathrm{a}}$
Alternative Fuel Types

Coal MBG SRC-2 Methanol SRC-1 COM

$\begin{array}{lllllll}3.65^{\circ} & \text { N/A } & 4.53 & 4.31 & 5.87 & \text { N/A } & \text { N/A }\end{array}$

$\begin{array}{lllllll}3.72 & \text { N/A } & 4.50 & 4.23 & 5.81 & \text { N/A } & \text { N/A }\end{array}$

$\begin{array}{lllllll}3.83 & \text { N/A } & 4.59 & 4.35 & 5.95 & \text { N/A } & 9.37\end{array}$

$\begin{array}{lllllll}3.81 & 4.39 & 4.57 & 4.28 & 5.90 & \text { N/A } & 4.22\end{array}$

$\begin{array}{llllll}3.86 & \text { N/A } & 4.66 & 4.43 & 5.98 & \text { N/A }\end{array}$

$\begin{array}{lllllll}3.80 & 4.40 & 4.56 & 4.27 & 5.89 & \text { N/A } & 4.22\end{array}$

$\begin{array}{lllllll}3.59 & 5.62 & 4.59 & 4.43 & 5.95 & \text { N/A } & 4.47\end{array}$

$\begin{array}{llllll}4.29 & \text { N/A } & 5.15 & \text { N/A } & 6.82 & \text { N/A }\end{array}$

a) Cost of not retrofitting is the annualized O\&M cost plus fuel cost of continuing to burn natural gas. 
alternative fuel. Under current economic conditions, this ranking of alternative fuels is academic because: 1) none of the alternative fuel types is close to competing with natural gas in these retrofit applications; and 2) each of the alternatives mentioned will require five to seven years before they are commercially proven. COM and MBG are the shortest-term alternatives; SRC-2 and methanol are longer-term technology options.

\subsection{SUMMARY}

Under the existing pricing and regulatory environment, oil and gas will continue to be the primary fuel in process heaters and small boilers through 1990. Small boilers operating at high capacity rates have an economic incentive to burn coal where coal as available at a reasonable price regardless of the environmental regulations. Boilers with lower capacity utilization rates will be more dependent on environmental regulations. In process heaters, cement and lime kilns and steel blast furnaces are the primary users of coal as an alternative to oil and gas. Some coal may be used in the aluminum and petroleum industries on an experimental basis. The total projected coal use in new small boilers and process heaters under this base case 1990 scenario is 680 trillion Btu or roughly 16 percent of the total new units. Nonconventional fuels are not projected to have a significant effect on reducing oil or gas dependence in the short term (1985/1990) due to costs and lead times required to develop the technologies. 
FOOTNOTES

1. Midterm. Energy Forecasting System (MEFS) runs used as a base case:

- 1985: CAMB913H

- 1990: CAMC913H

- 1995: CAMD91,3II.

2. Ibid.

3. "Estimated Price of Petroleum Products," prepared for Department of Energy by Sobotka and Company, February 23, 1978.

4. Note that the current differential between low sulfur residual oil and distillate is greater than the $\$ 0.36 /$ MMBtu differential shown in . Tables 6.6 and 6.7 , primarily because of short-term supply/demand imbalances.

5. In order to assess accurately the potential for wood waste and munir.ipal waste, a detailed study of specific sites and applications is recoumended.

6. Interim costs used in analysis of "National Energy Plan II, A Report to Congress," prepared by Department of Energy, May 1979.

7. Arthur G. McKee and Company, "Coal-Oil Mixture: A Preliminary U.S. Market Study," 1979; and Radian Corporation, "Synfuels from Coal as Emission Control Techniques for Industrial Boilers," draft final roport, January 1379 .

8. Exxon Research and Engineering Company, Industrial Application Fluidized Bed Combustion, "Category 3 - Indirect Fired Heaters," Quarterly Technical Report 11 (Jan. 1 - March 31: Florham Park, New Jersey), prepared for DOE.

9. Examples of some facilities operating Wellman-Galusha gasifiers:

- National Lime and Stone Company, Karey, Ohio

- Glen-Gary Corpuration, Reading, Kennsylvania

- Hazleton Brick Company, Hazleton, Pennsylvania. 


\section{ANALYSIS OF POTENTIAL INCENTIVE PROGRAMS}

The potential impact of government policies on industrial fuel use patterns has been evaluated by studying the effect of different incentive programs on several industrial fuel markets. The impact of various economic incentives to discourage oil and gas use as well as an extension of the current regulatory program were evaluated. Fuel prices and environmental controls were held constant throughout the analysis. Since changes in environmental regulations probably will affect primarily large boilers, small boilers and process heaters were evaluated under existing State Implementation Plans (SIP's). Higher oil prices were not evaluated because the oil prices used for this analysis represents the highest documentable set of prices available from DOE at the time of the study. The impact of changing these assumptions will be discussed at the end of this section.

Due to the uncertainty of technology and application costs, a great deal of caution should be exer:ised in using the results of these sensitivity runs. The overall intent of this analysis is not to quantify precisely the impacts of various incentives, but rather to identify alternate technologies and fuel markets for which certain incentives might be effective. The summary of this section not only reviews the economic and regulatory analysis presented but also ranks industrial process uses into three categories reprcsonting the technical and economic difficulty of converting from oil and gas to a nonscarce alternative.

The key focus of this discussion centers on how each market responds to different incentive programs. The four distinct markets considered are new and retrofit boilers below $100 \mathrm{MMBtu}$ and new and retrofit process heaters. Within the new and retrofit process heater market, processes are disaggregated further to illustrate the technical and economic factors discussed in preceding sections that affect fuel choice. 


\subsection{ECONOMIC INCENTIVES}

Economic incentives can encompass a variety of programs. Incentives such as fuel taxes, fuel subsidies, altered depreciation schemes, and investment tax credits (ITC) would alter the way a company evaluates the economics of various fuel choices. The benefits of an economic incentive program are that, once initiated, the program effectively runs itself. Forces within the marketplace, rather than regulatory agencies, enforce the program.

l'he major disadvantage nf an economic incentive program is that it is very difficult to target specific markets. For example, an ITC program would not unly provide an incentive for industrial users to switch fuel type, but it also would subsidize base case conversions. Note that the type of policy largely determines which technolngy options gain the biggesl incentive. For example, the ITC, evaluated in this study, has a larger impact on capital intensive technologies such as LBG than it does on fuel intensive technologies such as COM.

\subsubsection{Smal1 Bóiler Fuel Choice}

ITC's of increasing magnitude were evaluated for buth new and retrofit applications. Several cases of IFCAM were run to examine the increased use of direct-fired coal in small industrial boilers under additional 10, 30, and 50 percent ITC's. The results displayed in Table 7.1 suggest that the ITC increases coal use in new boilers and has relatively little effect on coal use in retrofit boilers.

\subsubsection{New Boilers}

Since cual is competitive with most alternative fuels burned in now boilers, it can be used as a basis to evaluate alternate fuel use potential under various ITC's. In addition, since-coal capital costs are large relative to fuel costs, an increasing ITC should have a significant impact on coalfired small boilers. 
TABLE 7.1

IMPACT OF ADDITIONAL ITC'S ON DIRECT COAL USE IN SMALL BOILERS $\left(10^{12} \mathrm{Btu}\right)$

\begin{tabular}{|c|c|c|c|c|c|}
\hline \multirow[b]{2}{*}{ Boiler Age } & \multicolumn{2}{|c|}{ Base C } & \multicolumn{3}{|c|}{$\begin{array}{l}\text { Impact of Additional } \\
\text { ITC's on Reducing } \\
\text { Base Case Oil/Gas Use }\end{array}$} \\
\hline & Oil/Gas & Coal & $10 \%$ & $30 \%$ & $50 \%$ \\
\hline $\begin{array}{l}\text { Coming on line prior } \\
\text { to } 1982\end{array}$ & 1203 & 150 & - & -10 & -44 \\
\hline Built 1982-1985 & 256 & 3.3 & -29 & -42 & -66 \\
\hline Built after 1985 & 293 & 118 & -9 & -66 & -116 \\
\hline
\end{tabular}

SOURCE: Industrial Fuel Choice Analysis Model run based on MEFS run no. $\mathrm{CAM} * 902 \mathrm{H}$, generated December 17,1979 . 
Table 7.1 suggests that as ITC's are raised, coal becomes more competitive in the new small boiler market. By increasing the ITC to 50 percent, the penetration of coal in new boilers built between 1982 and 1985 increases from 11 to 39 percent. For those boilers built between 1985 and 1990, the increase in coal penetration is more dramatic, from 29 to 57 percent. In absolute terms, this represents roughly 60 trillion Btu of decreased new boiler oil and gas use in 1980. and over 180 trillion Btu cumulative reduction by 1990 .

To a limited extent, increased coal use in new boilers resulting from the ITC can be used as a proxy to estimate the effects of an ITC on other alternative fuol type3. Fur examplè, the capital/fuel cost ratio for AFBC is similar to that for direct coal. Since the capital intensity and the annualized costs for the two technologies are similar, the impact for AFBC can be estimated to be very similar to the impact for direct coul on a national level. Municipal waste and wood waste also have relatively similar capital and O\&M cost components as coal and, therefore, would respond similarly to coal on a combustor basis. However, the specific units that would use municipal waste and wood waste as a result of an increased ITC might be different, depending on the availability and cost of these fuel alternatives. The increased municipal waste and wood waste that result. from un ITC might reduce further new oil and gas use from the estimates shown in Table 7.1.

An ITC would affect other alternative fuel options differently from the way it affects direct coal use in new boilers. The capital intensive industries such as LBG, MBG, methanol, and SRC-2 would have a greater incentive from an ITC than coal does if the production centers were allowed to reap the benefits of the additional credit. Despite the additional incentives provided by the ITC, it is not estimated that a tax credit would increase significantly alternative fuel use much above the levels of increased coal use shown in Table 7.1. Unless stringent environmental control levels are 
imposed on boilers between 50 and $100 \mathrm{MMBtu} / \mathrm{hr}$, direct coal and AFBC generaliy are the least cost alternative fuel options that will be available in the next five to 10 years. Units below $50 \mathrm{MMBtu} / \mathrm{hr}$ in which coal may have technical limitations comprise a very small portion of projected new boiler growth (less than 100 trillion Btu) and do not represent significant savings potential.

\subsubsection{Small Retrofit Boilers}

The ITC is much less effective in increasing direct coal use in the retrofit small boiler market than in the new small boiler market. Table 7.1 shows that less than five percent of the current oil and gas use would switch to direct-fired coal use under a large ITC.

COM is one of the few technologies that provides an alternative means of replacing oil and gas use in small boilers that cannot economically convert to direct coal firing. The fuel savings attributed to COM are significantly lower than those obtained with complete coal conversion, but because the capital cost required to convert each unit is also lower, the overall costs may be less in many applications. However, the ITC is not an effective policy tool to increase COM use in small retrofit boilers because COM is much less capital intensive than direct coal firing. On an annualized basis, the capital cost of direct coal firing is 25-30 percent of the total cost, whilo in COM the rapital cost is less than 10 percent of the total cost.

The low cost boiler options (municipal waste, wood waste, and AFBC) are not as competitive in the retrofit boiler market because of the large capital expense required to convert existing units to the alternative fuel. Allhough the ITC would provide a significant incentive, it would usually not be sufficient to offset the large capital expenditures required to retrofit these fuel options. 
Alternative fuel types with high capital cost of production may receive the largest incentive in the retrofit small boiler market through increasing ITC's. Technologies such as MBG, SRC-2, and methanol are ideal fuel alternatives in the retrofit market since they require the least change in the existing combustor. Also, these fuels are capital intensive (see section 4), so they should benefit from an increased ITC. The major factors that limit the penetration of these technologies in the retrofit boiler market are lead time and technology costs. MBG and SRC-2 are fivc to 10 years from commercial scale operation, and methanol is still in the developing phase. Additionally, the costs of these technologies are in the $\$ 6.50-$ 8.00/KPPH range. Although a 50 percent ITC may rcduce these cost.s hy $\$$ U. $U$ U-1.00/KPPH, they still would not compete with current gas prices.

\section{1 .2 Process llealers}

The impact of increasing ITC's on direct coal use in process heaters is shown in Table 7.2. As a result of the 50 percent ITC, direct coal use is projected to increase 62 trillion Bt.u across both retrofit and new applications. Most of this small replacement potential is in the petroleum, stone, clay and glass, and steel industries. An ITC is relatively ineffective in increasing direct coal use in either new or retrofit process heaters due to the following:

- Technical difficulties of firing direct coal in process heaters

- Lead time required to test coal use in applications that have not burned coal historically

- The sildiler portion of the process heater capital investment that would be eligible to receive an ITC.

One reason that process heat fuel use is relatively insensitive to increased ITC's is that less process heat equipment is fuel-specific and therefore eligible for an ITC. In boilers, 75-90 percent of the boiler investment can be related to a specific fuel type. Only the powerhouse and boiler support equipment would be excluded from the ITC. In most process 
TABLE 7.2

IMPACT OF ADDITIONAL ITC'S ON DIRECT COAL USE IN PROCESS HEATERS $\left(10^{12} \mathrm{Btu}\right)$ Process Heater
Age

Built prior to 1982

Built $1982-1990$ $\underline{3080}$

6877
-Impact of Additional ITC's on Reducing Base Case Oil/Gas Use

Oil/Gas Coal $10 \%$. $30 \%$ 50\%

3797

558

$-6$

$-6$

$-26$

$\underline{369}$

$-9$

$-23$

$-36$

6877.927

SOURCE: Industrial Fuel Choice Analysis Model run based on MEFS run no. CAM*902H, generated December 17, 1979 . 
heaters, however, the furnace itself is independent of the fuel type, so that only the burners, fuel handling and storage, and enyironmental control equipment, which comprise 40-60 percent of the process heater cost, would receive the tax credit.*

The technical discussion in Section 5 describes the factors that severely restrict direct coal use in process heaters in the food, chemicals, and textiles industries. In petroleum, there is the potential for direct coal use in fired heaters used for atmospheric distillation. These processes. can withstand limited heat variability and have a high rate capacity and load factor and long lives. Since the fuel price stream for coal is low relative to all other alternatives except refinery offgas, it has a competitive advantage over conventional oil and gas use. The major problems in refineries actually increasing coal use are space limitations and the proximity of large combustors within a plant site. In a report recently prepared by Exxon for DOE, coal use was evaluated as an alternative for use in several plants. ${ }^{1 /}$ The study ultimately abandoned the idea because of space limitations and the fact that all the large (over $100 \mathrm{MMBtu} / \mathrm{hr}$ ) combustors were so widely dispersed within the refineries considered that coal handling problems and cost were extremely high. As a result of these types of site-specific factors, the potential for direct coal use in the petroleum industry in the next five to 10 years is lower than projected using the generic cost factors in IFCAM.

Stone, clay and glass industries also show marginal increases in coal use (decreases in oil and gas) as a result of the additional ITC's. More significantly, stone, clay and glass accounted for most of the coal use sluwn in the base case in lable 7.2. The base case coal use is primarily in cement and lime kilns. The increase in coal as a result of the ITC's

\footnotetext{
*In petroleum refining, where the tubes used in direct-fired heaters are fuel-specific, more process heater equipment may be eligible for the additional ITC.
} 
includes not only cement and lime kilns, but also is projected to include kilns used in the face brick industry and selected furnaces used in the glass industry. Contamination problems historically have restricted conventional coal use in these industries, but process modifications and - changing product requirements may allow coal to be more competitive with oil and gas in the next five to 10 years.

The steel industry shows some penetration of coal in new and retrofit blast furnaces. The steel industry is generally familiar with the handling and use of coal as a feedstock (metallurgical coal). The additional financial incentive may shift selected process heat applications (blast furnaces and a few reheat furnaces) away from the clean low-cost oil and gas alternatives of the 1960's to coal.

Despite the fuel-shifting activity in these industries, the amount of decreased oil and gas use resulting from the additional ITC is relatively low. The slow shift toward coal reflects the technical feasibility limits, high cost of conversion in most applications, and operational problems such as space and transportation and general unfamiliarity with coal. Given the substantial financial incentive of a 50 percent ITC, some of the applications which cannot burn coal directly due to feasibility problems may be able to burn higher-cost coal-derived fuels. These fuel alternatives and the shifting in economics due to increased ITC's for eight representative process heaters are presented in the following discussion.

Table 7.3 presents the shift in relative economics of other alternative fuel types under increasing ITC scenarios. In each case the economics of nonconventional alternatives are compared to gas, since gas is universally the technically feasible least cost convention process heating fuel. As discussed earlier, the ITC has a limited effect on the relative scenarios of various process heating fuel types because they have fewer fuel related components than boilers. However, Table 7.3 also illustrates that, in most 
TA.BLE 7.3

EFFECT OF 40 PERCENT TOTAL ITC ON THE ECONOMICS OF ALTERNATIVE FIJELS IN NEW PROCESS HEATERS

(1978\$/MBtu)

\section{Process}

Low-risk fired heaters:

$99 \mathrm{MMBtu} / \mathrm{hr}$
$364 \mathrm{MMBtu} / \mathrm{hr}$

Regenerative glass melter

Blast furnace - jydrocarbon injection

Steel. reheat furiace

Rotary cement kiln

Face brick kiln

Heat treating furnace
Gas-Fired

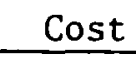

4.20

4.11

4.37

4.84

5.16

4.39

4.36

7.69
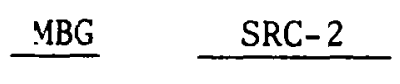

4.59

4.54

$4.36-5.50$

$4.26-5.41$

5.27

$5.14-6.25$

4.88

$4.61-5.44$

5.13

$4.88-6.03$

4.74

$4.48-5.63$

4.69

$4.58-5.73$

7.67

$\mathrm{N} / \mathrm{A}$
Methanol

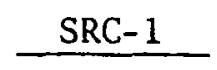

Direct Coa1

\footnotetext{
SOURCE: Derived from infarmation contained in Appendix C.
} 
applications, even a 40 percent ITC ( 10 percent regular plus 30 percent) would not be a sufficient incentive to raise the high-cost coal-based alternative to a competitive level with natural gas (or coal in cases in which coal is competitive). The primary exceptions are steel reheat and heat treating. These are capital intensive processes which could use a coal-derived gas alternative if sufficient investment incentives were available. It should be noted that the cost estimates used are generic cost estimates for sample process heaters with favorable technical and operating characteristics. In many actual cases, space limitations or provisions to pretest product quality or other process requirements would contribute to higher costs of using coal-derived alternatives.

A major difficulty with the ITC as an incentive for encouraging alternative fuel use in process heaters is that the majority of the increases in coal use in process heaters (primarily the stone, clay and glass industries) are taking place in the base case. Over 500 trillion Btu of direct coal use is projected in new process heaters in the base case, and the 50 percent ITC only increases that amount of coal use by about 10 percent. An ITC scheme would effectively subsidize these base case conversions without significantly decreasing oil or gas use overall.

\subsection{REGULATORY MEASURES}

FUA currently requires all large new industrial boilers and existing coalcapable boilers to burn coal or an alternative in place of natural gas or oil. FUA includes all boilers above $100 \mathrm{MMBtu} / \mathrm{hr}$ and boilers between 50 and $100 \mathrm{MMBtu} / \mathrm{hr}$ if the aggregate plant boiler capacity exceeds $250 \mathrm{MMBtu} /$ $\mathrm{hr}$. Among other exemptions, a facility can be exempted from the act if it can demonstrate that coal use would result in a 30 percent increase in costs.

A program that would expand the coverage of the existing FUA would affect process heaters and small boilers very differently from the way large 
boilers are affected by current regulation. The primary considerations in evaluating a regulatory program for both boilers and process heaters are the implementation problems and the associated administrative burden on the government, the economic and financial impact on industry, and the expected savings in scarce fuels. Since the issues related to expanding the regulatory program are different for small boilers and process heaters, they are discussed below, separately.

\subsubsection{Small Boilers}

Small boilers that would be covered under an expanded version of FUA would include only new boilers, since very few existing boilers have installed coal capability. The existing regulatory program covers new boilers ranging from 50 to $100 \mathrm{MMBtu} / \mathrm{hr}$ that are located in plants with over $250 \mathrm{MMBtu} /$ hr aggregate capacity. One advantage of expanding the regulatory program to include all sma11 boilers, regardless of the aggregate plant size, is that the implementation of the program would be marginally simplified.

However, a major disadvantage of the expanded coverage would be increased program costs and a probable decrease in program effectiveness. The number of boilers considered under the regulatory program would more than double, while the increased fuel coverage would increase by only one-third to onehalf. The size limit in the original program acted as a preliminary screening criterion for economic tests. Proportionately, more small boilers than large boilers will argue successfully that coal is an uneconomical alternative (even accounting for the FUA cost test) and will apply for the economic exemption.

Using IFCAM, a regulatory program was simulated for sma 11 boilers to determine the potential effect of regulating these boilers under FUA. Boilers between 50 and $100 \mathrm{MMBtu} / \mathrm{hr}$ that currently are covered by the FUA aggregation rule were not accounted. for in the base case, so the model runs overestimate the conversion potential in that size range. The results axe described in Table 7.4 . 
TABLE 7.4

IMPACT OF EXTENDING THE REGULATORY PROGRAM TO INCLUDE SMALL BOILERS

$$
\left(10^{12} \mathrm{Btu}\right)
$$

\section{Base Case}

\begin{tabular}{|c|}
\hline $\mathrm{Oil} / \mathrm{Gas}$ \\
\hline
\end{tabular}

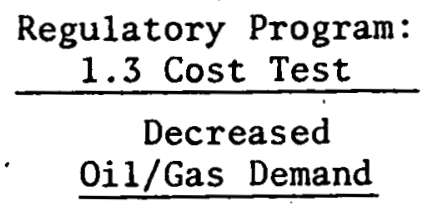

Boilers built 1982-1985:

10-50 MMBtu/hr

50-100 MMBtu/hr

Builers built 1986-1990:

10-50 MMBtu/hr

50-100 MMBtu/hr
32

226

45

248 neg.

$$
33^{2 /}
$$

$10-16$

$100-150$

a) Does not reflect FUA aggregation rule.

SOURCE: Industrial Fuel Choice Analysis Model run, generated December 17, 1979 . 
The 50-100 MMBtu/hr new boilers show the largest impact of an extended regulatory program. In both time periods shown, coal captures about 65 percent of the new boiler use that would have considered oil or gas in the base case. This result is somewhat overstated because the small boiler aggregation rule is not captured in the base case. Boilers in the 10-50 MMBtu/hr range do not show the large potential savings gained in the large boiler group.

Technical difficulties in burning direct con 1 in very small boilers and the lack of economies of scale account for this reduced impact in smaller units.

\subsubsection{Impact of a Regulatory Program on Process Heaters}

Process heaters are a more difficult market segment to affect through regulations than boilers. Although most process heat energy use is concentrated in three industry groups (petroleum, steel, and stone, clay and glass), the wide range of applications and equipment types within these industry groups would make it expensive to implement a regulatory program for process heaters. Each furnace is designed with a highly specific application and fuel type. These unit-specific characteristics would have to be considered in industry requests for exemptions from the regulatory program.

A process heater size limit to reduce the administrative costs and increase the effectiveness of a regulatory program also would be difficult to determine. In petroleum refineries, for example, many small process heaters are distributed throughout the refinery. Much of the process fuel is consumed in these small process heaters. A program that would target only the large process heaters would miss a significant portion of energy use, while a program that included the small heaters would be costly to enforce and place a high burden on industry. 
Another major problem is that there are a very limited number of fuel alternatives proven in industrial process heaters. In the existing regulatory program for large boilers, provisions extending the prohibitive authority to require COM and AFBC have been difficult to implement because of the lack of information and agreement on the availability of these alternatives. For process heaters, even direct-fired coal is not always a proven, available technology. Table 7.5 shows that when direct coal use was forced to compete with the 30 percent cost advantage allowed in FUA, very few process heaters increased coal consumption. This is because coal is not proven in many applications, and, in most cases where coal is a proven, economic alternative, it is used in the base case.

Several of the technologies considered in this study (SRC-1, SRC-2, methano1, and MBG) will not be available in five to seven years. Of the technologies considered in this study, LBG is the only proven technology with a broad range of applications. Even for LBG, the derate issues and costs would have to be better understood before LBG could be incorporated into a broad-based regulatory program. Electricity is proven but economical only in a limited number of applications: electric arc furnaces and electric boosting. Other applications of electricity are high-cost options that would place an undue burden if regulated. Similarly, indirect heat is used in a limited number of applications (food, textiles, paper drying) but is a high-cost option for the major process heat applications.

The final element to consider in evaluating the feasibility of a regulatory program for process heaters is growth in the targeted markets. The cement and lime industries are primary conversion candidates; however, most of these units are converting to coal under base case economics. Steel and petroleum refineries are large potential markets in process heater fuel use, but they are low-growth industries. Most of the oil and gas use in steel is in existing combustors since little growth is projected in the industry. In the petroleum industry, most of the growth is expansion of 
TABLE 7.5

IMPACT OF EXTENDING THE REGULATORY PROGRAM TO PROCESS HEATERS ${ }^{a /}$

Procoso heateis bullt before 1982

Process heaters built 1982-1990

$$
\left(10^{12} \mathrm{Btu}\right)
$$

\section{Regulatory Program: \\ 1.3 Cost Test \\ Decreased \\ Oil/Gas Demand}

\section{$\underline{\text { Oil/Gas } \quad \text { Coal }}$}

3797

558

3080

369

26

a/. Only direct coal was competed against oil and gas.

SOURCE: Industrial Fuel Choice Analysis Model run generated December 17, 1979. 
existing facilities. In expansions, site-specific costs are a major consideration and are not reflected accurately by the generic estimates used in the cost comparison in Table 7.3.

Steel and petroleum also are major consumers of byproduct fuels. Refinery. gas is used extensively as an energy source in petroleum refining, while coke oven gas is used.in steel processing. Prior to enacting a regulatory program that targets natural gas use in these two industries, a study of its secondary effect on byproduct fuel use should be initiated.

\subsection{OTHER OPTIONS TO ENCOURAGE REDUCTION OF OIL AND GAS USE IN PROCESS HEATERS}

The two policies evaluated up to this point, the ITC and an expanded regulatory program, would have only limited success in increasing coal use in the small boiler and process heater markets. The regulatory program would have problems due to the high implementation costs in.both markets and the lack of commercially available and technically proven alternatives in the process heater market. Also, the largest portion of the small boiler market that could be affected by a regulatory program, new boilers between 50 and $100 \mathrm{MMBtu} / \mathrm{hr}$, already are partially addressed under the current program. The major problem with the ITC is that it subsidizes more base case conversions than increased coal use in both markets.

Even if this cvaluation wcre donc using higher oil prices, it would not seriously affect these conclusions. Partially, this is because the alternative fuel costs also were understated by roughly 20-40 percent. Other factors are that technology development and behavioral factors are limiting conversion potential.

Funding of research, development, and demonstration is a policy incentive that effectively addresses some of these issues. Discussions with industry representatives in the steel, petroleum, paper, and chemical industries 
indicate a willingness to consider seriously alternative fuels if proven in commercial-scale applications. Until more clean-burning technology options are economically available, user-oriented policies will be marginally effective.

\subsection{SUMMARY}

Regardless of what policy incentives are identified, the potential market areas for coal use can be categorized according to cost and technical conversion capability to determine how much reduction in oil and gas use might be possible. The potential regulatory targets are classified into three target areas in Table 7.6 and discussed below. The categories described in l'able 7.6 range from low cost/minimal conversion processes to processes which will require significant capital outlay, alternative fuel developmental work, and long lead time before oil and gas use can be reduced. The categories take into account both the technical and economic elements discussed in Sections 5 and 6 .

The primary processes with alternative fuel burning potential are in the stone, ciay and glass, and steel industries. The specific processes are kilns in the cement, lime, and face brick industries, and the open hearth, blast furnace, and traveling grate in the steel industry. These procossos are proven coal uses which could increase coal use with relatively mild incentives, such as a 30 to 50 percent ITC. This category of users comprises 1490 trillion Btu in 1990. Since base case coal. use is projected to be 957 trillion Btu, there are only 533 trillion Btu of process heater fuel which can be affected by short-term government incentives.

The secondary candidates are processes competitively priced with major design modifications necessary to the process, or higher-cost alternatives such as coal gas with fewer modifications. These target applications are primary candidates for programs that attempt to impact fuel use in a 10-15 year time horizon. Since these options require design modifications, new 
TABLE 7.6

IDENTIFICATION OF CONVERSION CANDIDATES IN PROCESS HEATERS

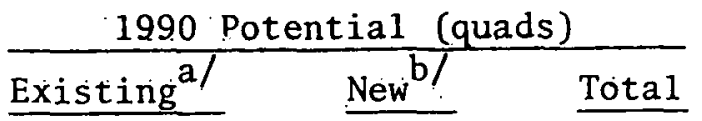

1. Primary conversion candidates in near term. Representative processes:

0.7

0.8

1.5

- Face brick kiln :

- Open hearth furnace

- Blast furnace/iron cupola

- Cement rotary kiln

2. Secondary conversion candidates (10-15 years). Representative processes:

0.3

0.5

0.8

- Regenerative glass melter

- Glass unit melter

- Low-risk fired heater

- Soaking pit/reheat furnace

- Aluminum rotary kiln

3. Long-term/high-cost conversion candidates.' Representative processes:

0.7

1.5

2.2

- Petroleum and chemical fired heaters used for specialty products

- Annealing furnace in glass

- Coke oven/anode prebake

a) Units built prior to 1982 .

- b/ Units built between 1982 and 1990. 
unit applications would be the most cost effective combustors to address with an incentive program. The estimated consumption in new units built between 1982 and 1990 is 500 trillion Btu.

The final category comprises those industrial products that were evaluated but represent long term/high cost conversion markets. The only way that oil and gas use in these markets could be significantly reduced in the next 10 years would be to enact both a large scale synthetic fuels program and a commercialization program to encourage adoption by industry. These processes comprise over two quads of process heat use in 1990. Included in this category are petroleum processing operations which are critical for plant operation and safety. Since a failure in one of these processes (i.e., catalytic crackers) might cause the loss of human life or millions of dollars, the costs to ensure reliability would be extremely high. A process such as annealing furnaces for specialty glass products would require high cost/low contamination fuel alternatives to replace this current gas demand. 
FOOTNOTES

1. In petroleum refining, where the tubes used in direct fired heaters are fuel-specific, more process heater equipment may be eligible for the additional ITC. 
APPENDIX A. INDUSTRIAL FUEL CHOICE

ANALYSIS MODEL

\section{A. 1 PURPOSE}

The Industrial Fuel Choice Analysis Model (IFCAM) is an energy demand model developed in response to the need to evaluate fuel choice decisions in the industrial scctor over a 10-15 year forecasting horizon.

The design and capabilities of IFCAM were guided by, the emphasis placed by the Department of Energy (DOE) on the analysis of the impacts on the industrial sector of energy policy measures proposed in April 1977 in the NEP and debated since that date in Congress. The model structure was developed to analyze the impacts on industrial fuel choices of four sets of factors: fuel prices, government energy policy proposals, the costs associated with firing alternative fuels, and other key model parameters such as the size distribution of new industrial boilers'or environmental regulations.

\section{A.1.1 Policy Measures}

IFCAM is capable of analyzing four classes of energy policy measures: fuel taxes, investment incentives, energy regulatory policies, and environmental regulatory policies. Fuel tax measures, considered during the debates on energy policy and analyzed with an earlier version of the model, reflected a variety of considerations affecting fuel tax rates, tax coverage, and special exemptions. Table A.1 shows the parameters considered in analyzing a variety of complex tax schemes.

A variety of tax credits and changes in the tax treatment of capital proposed to provide incentives to invest in coal-related equipment were analyzed using the model. The types of measures considered are listed in Table A.2 and re- 
TABLE A. 1

FACTORS AFFECTING FUEL TAX LIABILITY

New/existing facilities

Industrial sectur (text1les, mining)

Minimum corporate energy use

Minimúm plant encrgy use

Type of combustor (boiler, process heater)

Technical capability to use coal

Combustors already designed to fire coal

Region-specific tax rates

Combustor size

Environmental problems

Self-generating electricity

Fuel type

Intra- or interstate natural gas

Remaining depreciable life of combustor 
TABLE. A. 2

INVESTMENT INCENTIVES

Raising the investment tax credit (ITC) on coal facilities

Altering the type of capital expenditures eligible for the ITC

Eliminating the ITC for oil and gas facilities

Reducing the depreciable life of coal facilities (accelerated depreciation)

Extending the depreciable life of oil/gas facilities

Altering the depreciation method (requiring straight line methods for oil and gas facilities)

Allowing a rebate of fuel taxes as a credit for coal-related investments 
flect every (or almost every) conceivable wrinkle in the tax codes which could shift fuel choice decisions towards coal.

Energy regulatory policies were evaluated which targeted specific types of industrial energy uses including new boilers, minimum size units, existing boilers designed to fire coal, new process heaters technically capable of using coal, and indirect-fired process heaters. Special exemptions, such as when environmental problems were severe, were considered. Economic fcasibility was considered by testing the impact of various interpretations of provisions such as exemptions when the cust of using coal substantially exceeds the cost of imported oil.

Environmental regulatory policies which could affect fuel choice decisions also can be considered in IFCAM. These regulations can affect fuel choice by altering the relative costs of burning alternative fuels and/or by prohibiting coal-burning sources in certain areas with severe air quality problems. Regulations relating to particulate and sulfur dioxide emissions from fuel-burning sources included State and local regulations, Federal New Buurce Perfórmance Standards, and new source controls in nonattainment areas.

\section{A.1.2 Fuel Prices}

The model can simulate the impact of alternative fuel price scenarios on the industrial fuel mix. Fuel prices for distillate fuel oil, high and low sulfur residual fuel oil, new and "old" natural gas, and low and high sulfur coal were considered in the model.

\section{A.1.3 Capital and Operating Costs of $\Lambda 1$ tornative Fut ls}

Quite clearly, the fuel choice decision is sensitive to non-fuel costs of burning alternative fuels. While the best available cost data were used, the model can evaluate the impact of any alternative cost estimates. 


\section{A.1.4 Sensitivity to Other Key Parameters}

In addition to these three sets of factors, many other key variables affect the potential for coal use. The model is designed, for example, to test the alternative judgments of the technical capability to use alternate fuels, to evaluate the effects of varying industrial growth rates, to alter the size distribution and operating characteristics of new combustors, and to alter development lead times for new coal-using technologies.

\section{A.1.5 Model Outputs}

The model generates complete model outputs for 1985, 1990, and 1995. These outputs, providing fuel mix results in either absolute amounts or as distribution percentages, are available under several formats. The fuel use figures can be presented by new or existing combustors, functional uses (boilers vs. process heaters), nine industry sectors, and 10 regions. Boiler results also can be broken down by size and capacity utilization. Fuel choice decisions are sufficiently disaggregated so that IFCAM is capable of providing fuel.mix outputs for 244 Air Quality Control Regions (AQCR's) and 48 types of process heaters. However, this degree of disaggregation is performed to determine more realistic environmental requirements, equipment cost variations, and technical ability to fire coal; these more disaggregated results are not normally presented as model outputs.

The model also can provide outputs related to the cost, tax, and environmental impacts associated with an energy scenario. These related outputs are not included routinely in the standard format, but can be generated to satisfy specific needs.

\section{A.2 SCOPE NND COVERAGF.}

\section{A.2.1 Relationship to DOE's MEFS Mode1}

The DOE has used the Mid-range Energy Forecasting System (MEFS) model as its basic forecasting tool and as the means of insuring consistent energy 
accounting. It is a general equilibrium model which solves for energy prices, the level of energy consumption, and the mix of energy sources by region and major consuming sector. The MEFS industrial demand sector is a two-sector model (petroleum refining and other industry) based primarily on econometric relationships calculated from historical data.

IFCAM was developed in part to provide MEFS with an alternative source of forecasts of industrial fossil fuel energy demands. As a consequence of this specification, the model was designed to operate as consistently with MEI''S as pusstble. IFCAM was structured to use MEFS estimates of overall industrial fuel demands and to focus on the mixture of fossil fuel uses in this sector. IFCAM is capable of providing results for the same periods covered by MEFS, i.e., through 1995.

\section{A.2.2 Other Coverage Issues}

The model covers fuel uses in the industrial sector including manufacturing, mining, and construction. IFCAM considers only steam coal demands and excludes feedstock energy uses, including metallurgical coal and petroleumor natural gas-derived raw materials used in chemical processing.

Both the lack of time and the relatively short time horizon limit the choice of energy supply technologies covered. For coal, the model covers only technologies where coal is burned as a solid fuel. Not spccifically considered are coal $\rightarrow$ ased alternatives such as process changes, shifts from direct to indirect firing, increased electrification, nr coal conversion technologies such as gasification or liquefaction. The mid-term time horizon of IFCAM precludes significant market penetration of many of the advanced coal-based technologies which are still in the development stage. To the extent that commercially available technologies which are excluded from IFCAM, such as low-Btu gasification from coal, will be adopted, the model tends to understate the potential for coal utilization. In some specific scenarios, EEA has run its other industrial energy demand model (ISTUM), which has a longer time horizon and considers advanced technologies, 
to estimate possible market penetration by 1990 and 1995 of advanced coalbased technologies.

\section{A.3 - OVERVIEW OF MODEL LOGIC}

IFCAM is an industrial energy demand model which focuses on fuel choice decisions. Figure A.1 out lines the model structure, identifying key inputs, outputs, and major analytical steps.

Inputs 1, 2, and 3-Energy Demand and Industrial Production: The level of industrial fossil fuel demand and nine industrial production growth rates by region are critical inputs into IFCAM. Although such inputs could be derived from many sources, in the past they have been taken from the historical ECDB, MEFS projected energy use, and the macroeconomic model which drives MEFS.

Mode1 Step \#1 - Characterization of Industrial Energy Use: This initial step breaks down the projected fossil fuel use by industrial sector, new and existing facilities, type of combustor (e.g., boiler, blast furnace, glass melter), size of combustor, and a variety of other classifications. These factors, discussed below, are significant because they:

- Alter the costs of using alternative fuels (e.g., fuel costs vary according to industrial location).

- Determine the economics of fuel choice (e.g., whether the combustor operates at a high capacity utilization rate)

- Distinguish elements of energy use specifically targeted by energy policy measures (e.g., new boilers above a cutoff size)

- Are needed to generate required model outputs.

A major characteristic of industrial energy use is functional use. IFCAM breaks down fuel use by over 40 process applications such as tubestill heaters used in atmospheric distillation in petroleum refineries, cement kilns, metal reheating furnaces, glass melters, and boilers. Categorization by functional use is important because the technical capability to use 

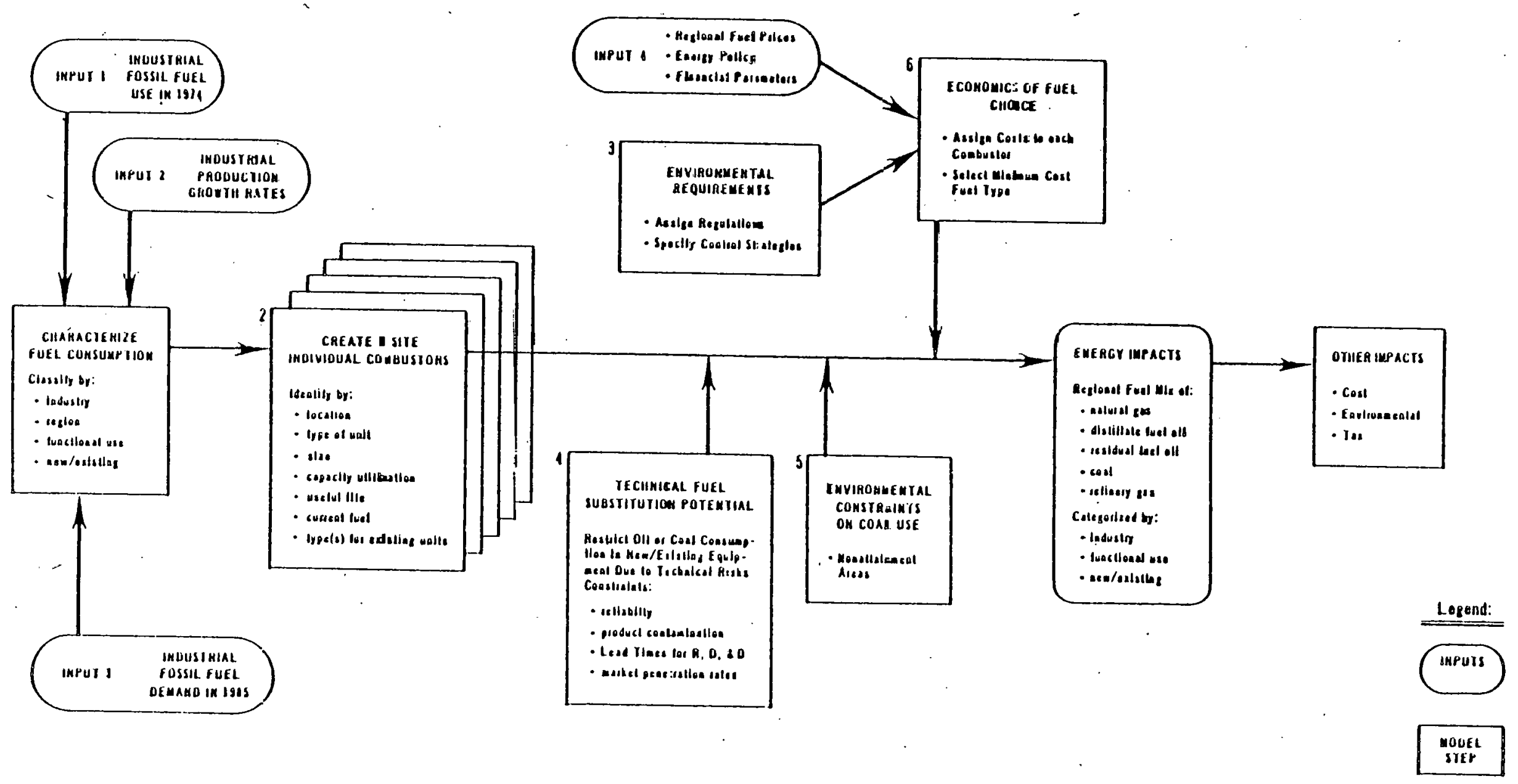
residual oil or coal in many processes varies due to problems of product contamination, corrosion, temperature control, and current equipment design. . The costs of burning alternative fuels also vary significantly among process applications.

Model Step \#2 - Create and Site Individual Combustors: Energy uses from Step \#1 are disaggregated into classes of individual combustors prior to further analysis. These combustors then are sited in 244 AQCR's according to historical patterns of industrial location. There are several reasons to proceed to this higher level of disaggregation. First, environmental regulations for all existing combustors and many new fuel-using facilities vary among states and counties within states. Since environmental control cost.s are a major factor affecting the economics of fuel choice, IFCAM is designed to reflect this variation in environmental costs.

Second, individual combustors are sited in AQCR's to avoid distortions caused by multiplying distributions of fuel use by regulation to aggregate energy use cells. Third, this more disaggregated level provides a framework to:

- Distinguish more specialized environmental requirements (as IFCAM does for nonattainment regions)

- Portray delivered fuel price variations in a more realistic manner at a future date (e.g., currently, Houston and Dallas face the same delivered coal prices).

Model Step \#3 - Assignment of Environmental Regulations and Pollution Control Strategies: Emission limits for major coal- and oil-related pollutants applicable to individual combustors are assigned based on State and Federal regulations. Possible pollution control strategies which can satisfy those regulatnry requirements are identified.

Environmental regulations play an important role in determining the level of fucl substitution. Environmental regulations may increase the capital 
and fuel costs that a coal or residual fuel oil conversion candidate would face by increasing the environmental control required or quality of fuel burned. The specific regulations vary geographically (AQCR), by combustor size and type, and by type of fuel.

Environmental regulations on a State and Federal level were examined for two pollutants: $\mathrm{SO}_{2}$ and TSP. Regulations are developed for three categories of combustors in IFCAM:, hnilers subjcct to NSPS, bollers not subject to NSPS, and process heaters.

For a given set nf regulation3, a mix of envirnnmental control equipment, such as flue gas desulfurization (FGD) or electrostatic precipitators (ESP), and low sulfur fuel which could satisfy the regulation is specified. The various possible mixes later are used to identify the capital and operating costs for different fuel types associated with each combustor.

Input 4 - Fuel Prices and Energy Policy: 'Specifications for a particular model run and projection year are input at this step. Specifications include the fuel price scenario, applicable fuel taxes, financial parameters, and energy regulatory policies.

Fuel price variations are used in IFCAM to model fuel taxes, natural gas deregulation, or variations in price trajectories. Fuel prices can be varied according to seven fuel types: distillate fuel oil, high and low sulfur residual oil, high and low sulfur coal, and average and marginal gas markets. The price of each fuel type can differ by region.

Investment incentives considered have primarily focused on differential depreciation methods for coal, oil, or gas and on increased ITC's in alternative fuels. The impacts of differential depreciation methods and investment incentives are handled within the scope of the main model logic. 
The coal conversion regulatory program established under FUA targets boilers whose rated capacity is over $100 \mathrm{MMBtu} / \mathrm{hr}$. An economic test which compares coal to an imported oil price is used to simulate legislative provisions related to economic exemptions. This and other regulatory provisions have been programmed in a special IFCAM routine and the model projects the level of increased coal use under the program, in the absence of any implementation problems.

Model Step \#4 - Technical Potential to Substitute Fue1s: In this step, a set of criteria related to the technical capability to use alternate fuels, lead time factors, and general economic considerations are applied to screen out fuel uses not technically capable of using residual oil or coal. The energy uses screened out must select either distillate oil or gas. An evaluation of technical potential considers the following factors:

- Technical capability to use coal or residual oil

- Lead times to develop new coal-firing technologies

- Lead times to order new equipment

- Supply-related constraints on coal use.

Model Step \#5 - Environmental Constraints: The costs of satisfying environmental requirements. will be factored into the economics of fuel choice in Step \#6. However, to the extent that environmental considerations may effectively block siting of new coal-fired combustors or conversions in existing units, this step screens out coal-fired units in severe air quality problem areas.

Model Step \#6 - Economics of Fuel Choice: Based on the characteristics of each combustor (size, operating rate, useful life, combustor type, pollution control requirements, etc.), capital and non-fuel operating costs are generated for the option of choosing oil, gas, or coal. The least cost 
fuel then is selected which minimizes the present value of the cost of generating energy over the combustor life. If the fuel type selected in this criterion is constrained due to technical or environmental reasons, the second least cost fuel alternative is chosen.

The components of NPV can be divided into three major subsets: policy inputs, standard model assumptions, and key model variables. Policy inputs are depreciation life and method, ITC, and fuel prices. Standard model assumptions are construction period, corporate tax rate, expensihle construction costs, and property tax. These elements do not vary by combistor characteristics and represent. standard investmont assumptions. Key model variables, capital costs, revenue life, discount rate, annual fuel consumption by capacity utilization and size, and operation and maintenance (O\&M) costs, all vary with factors considered in the model (e.g., new or existing classification or environmental regulation).

Model Outputs: The model categorizes fuel choice decisions by industry, functional use, and new/existing status. The fuel mix reflects the most economic fuel choice between natural gas, distillate fuel oil, low or high sulfur residual fuel oil, low or high sulfur coal, and refinery gas. As illustrated in Figure A.1", fuel use is determined hased on three con.. straints: technical, economic, and environmental. Note that no financial or supply-related constraint is explicitly factored into the analysis. Cost or environmental impacts also can be generated for specific objectives. 
APPENDIX B. ENVIRONMENTAL REGULATIONS AFFECTING COAL USE IN PROCESS HEATERS AND SMALL BOILERS

\section{B.1 THE CLEAN AIR ACT}

\section{B.1.1 Introduction to the Clean Air Act}

The Clean Air Act of 1970, along with the major amendments adopted in the Clean Air Act Amendments of 1977 (CAA), bring significant changes to the Federal regulatory mechanisms governing air pollution and control. A1though the complexity of the CAA precludes full discussion here, certain essential features of the statutory framework must be recognized in order to understand the manner in which the law may affect coal use in process heaters and small boilers.

\section{B.1.2 National Ambient Air Quality Standards (NAAQS)}

The CAA is intended to provide a framework to achieve and maintain good air quality throughout the nation via a concerted, comprehensive program. As part of this goal, Section 109 of the act required the Environmental Protection Agency (EPA) to develop two kinds of standards for ambient air quality -- "primary" standards necessary to protect public health, and "secondary" standards designed to protect public welfare. To date, the EPA has ostablished standards for seven major classes of pollutants: particulates, sulfur dioxide $\left(\mathrm{SO}_{2}\right)$, carbon monoxide ( $\left.\mathrm{CO}\right)$, ozone, hydrocarbons $(\mathrm{HC})$, nitrogen dioxide $\left(\mathrm{NO}_{2}\right)$, and lead $(\mathrm{Pb})$;

Scientific evidence indicates that in some cases the public health or welfare is harmed by brief exposure to high levels of pollution. Other types of damage may result fxom long-term exposure to low levels of pollution. To deal with this problem, the EPA has developed both short-and long-term standards for most of the pollutants listed above: Short-term standards cstablish limits on emissions for periods such as three hours or 21 hours. Long-term standards cannot be exceeded on an annual basis. 
To coordinate the control of air pollution, the EPA divided the country into 247. Air Quality Control Regions (AQCR's). These regions can be interstate or intrastate areas. They are formed according to meteorological, industrial, and socioeconomic factors and should be treated as a single unit for the purpose of controlling air pollution. EPA and individual states have designated areas of the country which do or do not meet NAAQS, or for which there are insufficient data to place them in either of those categories. Classification of an area determines what actions the state and the EPA w111 be required to take to regulate air pollution from existing and new emission sources. An area is classified for each pollutant with NAAQS as being in or out of compliance with those standards.

\section{B.1.3 State Implementation Plans (SIP's)}

SIP's are the mechanisms by which individual States implement, maintain, and enforce the regulations and provisions of the CAA. Each state is required to submit this plan for EPA approval. States were required to submit plans to the EPA within nine months after promulgation of the air quality standards, and final plans had to he approved or promulgaled by EFA within six months thereafter, or not later than July 31, 1972. An ultimate statutory deadline for achievement of the air quality standards was July 31,1977 .

New data and experience indicated the need to revise the original SIP's. The 1977 Amendments required a complete revision of the implementation plans in all areas where the air quality stándards have not been attained. The revisions were to be completed and approved by July 1, 1979. Construction of new major emitting sources is prohibited after-this date for any source emitting a nnnattainment pollutant ill a nonattainment area in a state without a fully or conditionally approved SIP. To date, 46 states have not received EPA approval.

The SIP's must provide for the implementation, maintenance, and enforcement of primary, and secondary, NAAQS, and must incorporate the provisions 
outlined in the CAA in relation to Prevention of Significant Deterioration (PSD) and nonattainment plan provisions. Accordingly, SIP's must include the following: an enforceable permit program for new or modified sources as described under PSD and nonattainment provisions; emission limitations and compliance schedules to assure attainment and maintenance of NAAQS; a description of how sources will be monitored; a program of emission limitation enforcement; and assurance of state funding for these programs. In addition, State plans must be flexible to account for revision of NAAQS and the availability of more expeditions or improved technological methods of achieving standards. SIP's also may establish additional emission rates for new and existing sources.

\section{B.1.3.1 State New Source Review Regulations}

Under CAA, SIPs must assure attainment of NAAQS by December 31, 1982; if severe oxidant and carbon monoxide problems exist, the deadline may be extended to December 31,1987 . As part of an effort to meet these deadlines, as well as to maintain air quality in areas meeting NAAQS, many states implement New Source Review (NSR) programs to regulate new sources of air pollution. NSR programs generally require new sources to implement BACT and to undergo air quality assessment to demonstrate that emissions from the new source will not interfere with the maintenance or attainment of any State or national ambient air quality standards. Most NSR programs cover more sources and have stricter requirements than Federal PSD and nonattainment provisions.

\section{B.1.4 Prevention of Significant Deterioration (PSD)}

PSD provisions are designed to protect air quality in areas now meeting all ambient air quality standards. PSD serves the following functions: limits the degradation of air quality of so-called "clean-air" areas; provides a mechanism to regulate pollutant emission from new sources; and allows states to determine the degree of new source growth desired in clean air areas. The functions are to be carried out through specific requirements, all of which are to be incorporated into SIP's. 
Each state must classify "clean areas" into one of three categories, govern degradation by restricting ambient pollutant concentrations arising from new sources, and require new or modified sources wishing to enter PSDgoverned regions to obtain a permit prior to commencing construction.

\section{B.1.4.1 Classification Categories}

The PSD provisions outlined in the CAA allow for three classification categories :

- Class I - where practically any air quality deterioration would be precluded

- Class II - where deterioration in air quality arising from moderate growth would not be considered significant

- Class III - where, intensive and concentrated industrial growth can occur while not departing from the intent of the PSD regulations.

The classification plans are to be executed and enforced through the revised SIP's. After states have identified those areas now meeting all NAAQS, states must initially classify such areas as either Class I or Class II. Certain areas specified in the act are automatically designated as Clàss I and are excluded from reclassification. Other areas classified as II may be later reclassified as Class I or III by the state; however, certain Class II areas (also specified in the act) are prohibited from reclassification as Class III.

\section{B.1.4.2 Increments}

Ambient pollutant increment concentrations are assigned to each classification category. When added to the "baseline concentration," this determines the maximum allowable air quality degradation for the area. The act requires that $\mathrm{SO}_{2}$ and particulates be covered by PSD regulations. At no time are maximum allowable concentrations allowed to exceed the most stringent air quality standard (primary or secondary) for the respective pollutants. Increments will be established by early 1982 for $\mathrm{HC}, \mathrm{CO}, \mathrm{NO}_{2}$, ozone, and $\mathrm{Pb}$. 


\section{B.1.4.3 Preconstruction Permits}

The PSD provisions stipulate that all major stationary sources wishing to initiate construction of a new facility or modify an existing one must obtain a permit. To obtain a permit, the source owner must fulfill several requirements. The major requiremnts are given below:

- BACT Review: A source subject to PSD regulations is required to utilize the "best available control technology". (BACT). BACT (with respect to a particular pollutant) is required for al1 sources having the potential to emit over 100 or 250 tons pèr year of that pollutant (the 100 or 250 ton limit is defined in the regulations). The states are empowered to determine BACT on a case-by-case basis. NSPS frequently are used for establishing BACT.

- Monitoring: The owner or operator of a proposed facility must agree "to conduct such monitoring as may be necessary to determine the effect" the resulting emissions have or will have on any air quality in any area affected by the facility's emissions.

- Public Hearings: The state is required to notify the public of the proposed construction and give the public the opportunity to comment on the project.

As a result of the December 14, 1979 decision in the case of Alabama Power Company v. Costle, major provisions of the PSD regulations were to have become invalid on January 4, 1980. EPA filed a petition for a stay of the court's decision and presently is awaiting a response.

\section{B.1.5 Nonattainment. Plan Provisions}

The CAA delineates provisions by which SIP's are to ensure attainment of all primary NAAQS by specified timeframes. The provisions outline mechanisms by which states can allow growth in those regions now exceeding air quality, standards, while still assuring "reasonable further progress" toward attainment.

The nonattainment provisions of the CAA outline regulations governing the introduction of new sources in regions which have been shown by monitored 
data (or calculated by air quality modeling) to exceed any NAAQS. Under the 'CAA, revised SIP's for these standards must assure attainment of primary air quality standards no later than December 31, 1982; for especially severe ozone and CO problems, the deadline may be extended to December 31 , 1987. All secondary standards are to be attined within "a reasonable time," with no specific deadline listed.

New SIP's will require permits for the construction and operatiun of new or modified major stationary sources in any nonattainment arca. In revising implementation plans, states must tighten the requirements on existing sources of pollution to eliminate the excess of emissions in the area over those that could be allowed without violating the ambient air quality standards. A state can either:

- Require reductions just sufficient enough to eliminate the violations of the air quality standards, leaving no margin for new growth, or

- Require reductions more than sufficient to achieve compliance, thus creating a margin available for new sources,

Furthermore, under the permit program, all applications must employ Lowest Achievable Emission Rates (LAER) on the proposed source and must show that all other sources in the state owned or controlled by the permit applicant are in compliance or on a compliance schedule. Existing sources are re- . quired to apply Reasonable Available Control, Technology (RACT).

\section{B.1.6 PSD-Nonattainment Overlap}

The basic rule is that PSD requirements apply in clean air regions, while nonattainment piuvisions apply to areas where the clean air requirements are being violated. Every region falls into one of the two categories. However, some regions may fall into both (i.e., an area may be attainment for one pollutant. hut not for another). 
The requirements for PSD or nonattainment are applied on the basis of individual pollutants. There will be many cases where a new plant is to be located in an area that is nonattainment for one pollutant, but is attainment for other pollutants. In such a case, the plant must satisfy the procedural and substantive requirements of both programs.

Cross-boundary effects of air emissions on nonattainment areas presents another significant complication. A new source constructed in a clean air area may have a significant effect on a nonattainment area. The reverse also may have a significant impact on a nearby clean air area. In both instances, the PSD and nonattainment requirements may be applied.

\section{B.1.7 New Source Performance Standards (NSPS)}

NSPS are Federal standards governing emissions from new or modified stationary sources. These standards comprise the least stringent emission limitations to which applicable. new sources are subject; individual states, through implementation of new source preconstruction reviews, may establish stricter pollutant emission restrictions. Emission standards are established by NSPS for categories of sources with respect to any criteria air pollutant emitted.

\section{B.1.8 National Emission Standards for Hazardous Air Pollutants (NESHAPS)} Section 112 of the CAA mandates EPA to prescribe emission or design standards for hazardous air pollutants not covered under the NAAQS. EPA must determine which pollutants are hazardous and what emission or design standard will best govern the pollutant.

Once emission standards are effective for a particular pollutant, no new or modified source may violate the standard. Existing sources are subject to compliance as well. States may develop and submit, for EPA approval, their own means for implementing and enforcing emission standards. If the EPA 
determines the plan adequately maintains the established standards, the state may assume the responsibility for implementation and enforcement.

\section{B. 2 THE CLEAN WATER ACT}

\section{B.2.1 Introduction to the Clean Water Act}

The Clean Water Act (CWA), as amended in 1977, reaffirms the committment made by Congress in 1972 to continue the cleanup of our nation's waters. The issuance of permits to point sources discharging into navigable waters remains the backbone of the CWA's regulatory mechanism. The act establishes general and specific effluent limitations and appropriate management practices for various industries.

\section{B.2.2 National Pollutant Discharge Elimination System (NPDES)}

Section 402 of the CWA, the National Pollutant Discharge Elimination System (NPDES), is the key mechanism by which EPA enforces compliance of regulations reflecting the goals set for pollution reduction. Discharge from any discrete (or "point") source is unlawful without a NPDES permit authorizing such discharge in compliance with effluent limitations and water quality standards, both Federal and state.

The EPA regional office or a designated state authority issues permits to control and limit wastewater discharges from point sources. Permits dictate present and future degree of treatment required within the term of the permit; compliance schedules are included. Other permit conditions include: construction schedules, monitoring requirements, and pretreatment and effluent limits. 
B.2.2.1 Categories of Pollutants

\section{B.2.2.1.1: Conventional Pollutants}

- Conventional - BOD (biological oxygen demand), suspended solids, fecal coliforms, $\mathrm{pH}$ acidity, and other pollutants so designated by EPA

- Treatment required - best conventional technology (BCT), currently subject to best practicable technology currently available (BPT)

- Deadline - July 1, 1984.

\section{B.2.2.1.2. Toxic Pollutants}

- Toxics - the 1977 amendments specify an initial list of toxic substances to which EPA may add or from which it may subtract

- Treatment required - best available technology (BAT)

- Deadline - July 1, 1984, or not later than three years after a substance is placed on the toxics pollutant list.

\section{B.2.2.1.3 Nonconventional Pollutants}

- Nonconventional - all other pollutants not classified by EPA as either conventional or toxic

- Treatment required - best available technology (BAT)

- Deadline - July 1, 1984, or within three years of the date EPA establishes effluent limitations but not later than 1987 .

\section{B.2.2.2 Best Management Practices (BMP)}

Industrial management of toxic and hazardous materials, which might enter the environment other than through effluent discharges also are regulated under the act. The EPA must establish BMP for the control of the plant site: runoff, leaks, spillages, sludge and other waste disposal, and drainage from raw material storage sites. 


\section{B.2.2.3 New Source Performance Standards (NSPS)}

NSPS are intended to be the most stringent effluent standards. In practice, for many industries they tend to be the same as BAT. Although NSPS are subject to revision as technology changes, control technologies applied to new sources are not required to be revised. The EPA has established a 10year grace period following construction for control technologies.

\section{B.3 THE RESOURCE CONSERVATION AND RECOVERY ACT}

\section{B.3.1 Introduction}

The Resource Conservation and Recovery Act (RCRA) regulates all aspects of solid waste with a "cradle to grave" management scheme. Under this program EPA is responsible for proposing regulatory controls to manage the treatment; storage, and disposal of solid waste. The program's basic approach is to divide the regulations of solid waste into two categories; hazardous waste and non-hazardous waste.

RCRA was enacted to achieve two basic objectives: (1) protection of public health and the environment, and (2) the conservation of natural resources. The act provides three major programs to reach these goals: 1) the establishment of a hazardous waste control program to be administered by the states, or where states choose not to do so, by EPA; 2) the establishment of a land-disposal regulatory program in each state; and 3) the initiation and support of resource conservation programs by state and local governments to conserve resources and reduce the amount of solid wast.e requiring land disposal.

RCRA is divided into eight subtitles:

- Subtitle A-General Provisions

- Subtitle B-Office of Solid Waste, Authorities of Administration

- Subtitle C-Hazardous Waste Management

- Subtitle D-State or Regional Solid Waste Plans 
- Subtitle E-Duties of the Secretary of Commerce in Resource and Recovery - !

- Subtitle F-Federal Responsibilities

- Subtitle G-Miscellaneous Provisions

- Subtitle H-Research, Development, Demonstration, and Information.

of major interest are the regulations for hazardous.waste management (Subtitle C) and land disposal of non-hazardous waste (Subtitle D).

The EPA has determined eight hazardous waste characteristics: ignitability; corrosivity; reactivity; toxicity; radioactivity; infectiousness; phytotoxicity; and teratogenicity. Testing protocols have been developed for the first four characteristics and are being developed for the others. Once EPA develops the remaining tests, a substance possessing any of the eight characteristics will be considered hazardous.

\section{B. 3.2 Hazardous Waste Management (Subtitle C)}

The major regulatory program of RCRA is contained in Subtitle C. Subtitle $C$ sets forth a management scheme that provides for "cradle to grave" regulation of hazardous wastes.

The statute itself defines the term "hazardous waste" as "a solid waste, or combination of solid wastes, which because of its quantity, concentration, or physical, chemical, or infectious characteristics, may . . pose a, substantial present or potential hazard to human health or the environment when improperly treated, stored, transported, or disposed of, or otherwise managed." The act also defines solid waste as including, "liquid, semisolid, or contained gaseous material resulting from industrial, commercial, mining, and agricultural operations." Wastewater discharges are exempt from the act's requirements.

Subtitle C provides for: 
- An identification and listing of hazardous wastes according to specified criteria (Sec. 3001)

- Standards of performance (Sec. 3004). for those who store, treat, or dispose of such wastes including bonding by the disposal site operator to provide for closure costs of the site

- Permits (Sec. 3005) for storage, treatment and disposal facilities -- not for transporters and only for generators having onsite waste-handling facilities

- A manifest system (Sec. 3002), which must be complied with by all who handle hazardous waste to ensure that the wastes are trasported from the waste generator to only a permittcd disposal facility

- Standards applicable to hazardous waste transportation ( $\mathrm{Sec}$. 3003)

- Notification requirements (Sec. 3010) for generators, transporters, and storage and/or disposal facilities

- Guidelines for establishing state programs (Sec. 3006).

In addition, the hazardous wasste program will establish standards on the basis of disposal methods (incineration, landfilling, etc.) and not by national industry-specific standards.

Wastes that are not classified as hazardous are covered by Subtitle D.

\section{B. 3.3 Non-Hazardous Waste Management (Subtitle D)}

This is basically a State regulatory program with certain Federally imposed constraints, the most significant of which is the phasing-out of open dumps. Section 4004 will set criteria for sanitary landfills and any new disposal facility not meeting those criteria will bc considered an open dump. Open dumps must be upgraded or phased out.

Thus, all land-disposal sites will have to meet the Subtitle D sanitary landfill criteria, and, if a site handles hazardous wastes, it will have to meet the additional, more stringent requirements of Subtitle $C$. 


\section{APPENDIX C. PROCESS DESCRIPTION}

\section{C.1 INTRODUCTION}

This appendix describes the processes that were evaluated in this study. The combustors considered in this study do not represent a comprehensive list of all industrial process heaters, but they do comprise a mix of industrial processes which consume over half of the fuel consumed in process heat applications. The descriptions are organized as follows:

- Glass

- Regenerative furnaces

- Glass unit melter

- Glass annealing lehr

- Steel and aluminum

- Blast furnace stove/shaft furnace

- Blast furnace/cupola - hydrocarbon injection

- Soaking pit/reheat furnace

- Coke oven/anode prebake oven

- Traveling grate/sinter furnace

- Heat treat furnace (steel and aluminum)

- Lime and cement

- Lime and cement rotary kiln/grate kiln

- Aluminum rotary kiln*

- Brick and 'clay'

- Refractory kiln/coremaking oven

- Face brick kiln

- Food and textiles

- Food processing

*The aluminum rotary kiln is presented with other kilns. 
- Petroleum and chemicals

- High-risk fired heater

- Medium- and low-risk fired heater.

\section{2 GLASS}

\section{C.2.1 Regenerative Furnace}

Approximate1y 90 percent of glass products are melted in regcnerative furnaces; in fact, the flat glass industry exclusively uses this furnace type. The regenerative furnace is basically a melting tank, and its capacity ranges from 100-750 TPD. The furnace derives its name from its regenerator chambers, called checkers, which increase furnace efficiency by preheating combustion aix. The checkers are a lattice of refractory brick. Fuel burner ports are located at the melting tank entrance of the checkers which supply the burners with preheated air. Combustion gases pass over the molten batch and, at temperatures of approximately 2400$2650^{\circ} \mathrm{F}$, continue out through and heat one set of checkers. At regular intervals (usually 20-30 minutes), the flow is reversed and the combustion air is passed through heated checkers to the opposite chamber. There are two types of regenerative furnace, the side-port and the end-port. Raw materials, consisting of silica sand, limestones, feldspars, borates, soda ash, and cullet (recycled glass scrap), are melted in the continuous furnace to produce molten liquid. Temperatures range from $2600-2900^{\circ} \mathrm{F}$, depending on the glass composition. As the melt moves into hotter sections of the furnace, viscosity is lowered and entrapped gases escape. Maximum heat transfer is obtained through long, radiant flames and radiatiun from the retiractory lining of the melt, pronoting batch homogeneity. The primary fuel used in regenerative furnaces is natural gas which is selected for its cleanliness and heating control and consistency. Temperature control is essential in glass melters. Changes of $125^{\circ} \mathrm{F}$ can cause product loss, and temperatures above $2950^{\circ} \mathrm{F}$ will cause furnace roof damage. 


\section{C.2.2 Glass Unit Melter}

The unit melter is a continuous melting furnace, generally smaller in capacity than the regenerative furnace, and not equipped with heat recovery devices. Unit melters account for approximately five percent of glass production and have an average capacity of 125 TPD. Melters, used only by the pressed and blown glass segment, are relatively inefficient because they lack regenerators. Unit melters are long and narrow and may be either cross fired or side fired. The operation is otherwise similar to that of the regenerative furnace described above. Natural gas is the primary fuel, with oil substitution presenting problems similar to those discussed for the regenerative furnace.

\section{C.2.3 Glass Annealing Lehr}

Annealing, the most important post forming step, is performed in continuous ovens called lehrs and is used for all glass products. Annealing strengthens glass by removing internal strains introduced in the forming operation. The process brings the formed glass to the critical temperature of about $1000^{\circ} \mathrm{F}$, then gradually cools the glass to prevent introduction of new stress. The average lehr (basically a tunnel oven) is 100 feet long and has gradient heat zones. A normal cycle through the lehr takes one hour. Burners are incated in the roof of the lehr and run the length of the oven. Accurate temperature control to prevent breaking and maintenance of product quality are essential. Because of these process requirements, natural gas is the primary fuel used for annealing, with propane as a substitute during curtailments. Oil firing is considered infeasible due to the production of a film on the glass, both contaminating the product and possibly causing breakage, since the glass is extremely sensitive in this process. 


\section{3 STEEL AND ALUMINUM}

\section{C.3.1'Blast Furnace Stove/Shaft Furnace}

The shaft furnace is used to fire 20 percent of all iron pellets produced. The shaft furnace consists of a rectangular shaft six to eight feet wide, 14-21 feet-long, and 45-65 feet high. Raw pellets are fed into the top of the shaft and hardened pellets romoved froul the bottom after about four hours. Heat is added to the process from two adjacont cylindrical combustion chambers which measure six feet in diameter and 15 feet in height. Fuel input per chamber is approximately $15 \mathrm{MMBtu} / \mathrm{hr}$. Combustion temperdture measures approximately $2350^{\circ} \mathrm{F}$. The preheat air and combustion products enter the furnace through multiple ports about 8.5 feet below the stockline. Natural gas or oil is burned in the combustion chambers.

Most pig iron products are made in blast furnaces. This furnace is a vertical shaft in the form of a truncated cone. The charge (iron ore; pellets, sinter, coke, scrap, limestone, dolomite, and slag) is fed into the top of the stack. Preheated blast air from adjacent stoves is blown in at the bottom of the furnace through tuyeres and ignites the coke in the charge to profire tomperaturca aluve $3000^{n} \mathrm{~F}$. Lach blast furnace is serviced by two or three stoves. The stoves are cylindrical and may be 26-28 feet in diameter and 120 feet high.

The stove consists of two parts: a combustion chamber and a brick checkerwork regenerator. Hot combustion gases heat the checkerworks in a stove. The air blast for the furnace then is heated by passing it through the chcckerworks. Each stove alternates between providing air blast and checkerwork heating such that the blast furnace receives a constant flow of blast air.

Approximately 90 percent of the fuel for the stoves is provided by blast furnace gas and coke oven gas. Oil and natural gas satisfy the remaining fue1 requirements. 


\section{C.3.2 Blast Furnace/Cupola - Hydrocarbon Injection}

In many.U:S. blast furnaces, auxiliary fuels are injected through tuyeres into the hearth in order both to saye coke and increase blast furnace productivity. In this process, preheated blast air, blown in at the bottom of the furnace, burns part of the fuel to produce heat for the chemical reactions involved and to melt the iron. The balance of the fuel and part of the combustion gas remove the oxygen which has combined with the metal in the burden. The use of supplemental fuels decreases the amount of expensive metallurgical coke required, helps control flame temperature, and increases furnace capacity for ore and limestone. Natural gas and fue1 oil predominate as fuel injectants, but coke oven gas, pulverized coal, tar, pitch, and coal/oil slurries also have been used.

The cupola is used to melt 75-80 percent of the gray iron and approximately 25 percent of the ductile iron produced. The cupola consists of a vertical shaft or shell (27-108 inches in diameter) built of steel plate and lined with refractory brick. Pig iron, scrap metal, alloys, coke, and fluxes are charged into the cupola on top of an ignited coke bed. The descending charge enters the melting zone which is preheated to $2000^{\circ} \mathrm{F}$, and molten iron and slag trickle through the coke bed. The molten iron is tapped at $2750-2900^{\circ} \mathrm{F}$. A small amount of oil and gas is used to ignite the coke bed in the cupola.

These two processes are grouped together due to the similar fuel requirements for injection into the coke bed.

\section{C.3.3 Soaking Pit/Reheat Furnace}

Some molten steel is tapped from steelmaking furnaces into ladles and then poured into tall, usually rectangular molds. Once the outside has solidified, the mold is stripped and the ingot is moved to a snaking pit. Soaking pits: 1) raise the temperature of the steel ingot until it is sufficiently hot and plastic for economic rcduction by rolling and forging, 
and 2) bring the ingot to a uniform temperature with a minimum of surface overheating. If the firing rate in the soaking pit is greater than the rate at which the heat can be transferred into the interior of the ingot, the surface of the ingot can either melt away or be oxidized severely. Soaking pits are deep rectangular, square, or circular chambers into which ingots are lowered in an upright position. Each pit has a retractable covcr. Ihe pits usually are built side-by-side sharing a common wall with a hearth area of 100-300 square feet. There are several types of soaking pits characterized according to their firing system. Variations include top or bottom fired, center or side fired, and one-way, two-way, or tangentially fired in a circular pit. About 90 percent of the soaking pits are equipped with heat recovery devices. The normal temperature range for heating ingots in preparation for rolling or forging is $2150-2450^{\circ} \mathrm{F}$. Soaking pits are designed and operated carefully to eliminate end-to-end and top-to-bottom temperature gradients. Blast furnace gas, coke oven gas, and natural gas are the fuels frequently used.

Reheat furnaces heat semifinished shapes from ambicnt temperatures to a temperature suitable for final hot rolling operations. The two general classes of reheat furnaces are batch and continuous furnaces. In batch furnaces, the charged material remains in a fixed position on the hearth as it is heated according to a definite time-temperature pattern which ensures the piece is not overheated. In continuous furnaces, the cold charged material moves through the furnace and is heated to rolling temperature progressively. Typical rolling temperatures are $2200-2250^{\circ} \mathrm{F}$, although temperatures may reach $2800^{\circ} \mathrm{F}$ in the hot end of rogenerative batch and continuous furnaces. Seventy-five percent of the fuel burned in reheat furnaces is purchased oil and gas, with the remainder being fuels produced in-house.

The fuel requirements for even, controlled heating of steel ingots in soaking pits and reheat furnaces are similar, allowing the two processes to be considered together. 


\section{C.3.4. Coke Oven/Anode Prebake Oven}

Coke, a carbonaceous nonvolatile residue formed from the destructive distillation of metallurgical grade coal, is the primary fuel and reductant essential for smelting iron ore in blast furnaces. Coke remains solid in the melting zone of the blast furnace and separates the unmelted burden from the molten metal and slag pool. Ninety percent of the coke is produced at steel mills for in-house blast furnace use. In order to form coke, metallurgical grade coal is heated in the absence of air and baked until it is porous. Each coke oven is charged with 12-25 tons of crushed coal and heated to about $2100^{\circ} \mathrm{F}$. After $12-30$ hours, the hot coke is removed and the oven is immediately recharged with coal. The gases evolved during coking are drawn off and treated for the recovery of byproduct chemicals. A byproduct coke oven is rectangular, 30-50 feet long, six to 26 feet high, and 11-22 inches wide. As many as 100 ovens, alternating with combustion chambers, may be arranged in a battery located above regenerative chambers. In the combustion chambers, gas is burned in a large number of vertical heating flues which permit uniform heating of the coking chamber walls. The heated gases pass up the coking chamber walls and back down through the regenerator chamber to preheat combustion air. Coke oven gas is the primary fuel used in coke production. Blast furnace gas and natural gas also are burned. Controlled fuel distribution to the numerous small burners in the flues is not feasible with a solid or liquid fuel.

Carbon anodes, used in aluminum smelting, are formed by baking high quality petroleum coke and a binder of coal tar or pitch in order to remove volatile impure materials. The anode prebake oven is a series of open-topped chambers 100 feet long, six to eight feet wide, and 10-15 feet deep. Each chamber is surrounded on all four sides by a flue 10-11 feet long and 5.75 inches wide. Low-capacity burners, which fire down into the flue, are positioned in the overhead cover of each flue. Two to three chambers in each section of eight to 10 chambers are fired simultaneously with the combustion gases circulated to other flues to provide preheat of the com- 
bustion air. The anode prebake oven is a batch operation, with each batch taking 24-28 hours. (On1y 63 percent of total aluminum production employs anode prebake ovens.) Over 90 percent of the fuel consumed is natural gas, with the remainder being distillate fuel oil. These two processes are grouped together because of the similar fuel requirements of the lowcapacity burners in the flues.

\section{C.3.5 Traveling Grate/Sinter Furnace}

Iron ore is mined in open pits and underground mines and is uscd to produce metallic iron. Iron ore consisting of particles less than $1 / 4$ inch largc is agglomerated before being charged to the blast furnace. Agglomeration improves the permeability of the furnace burden and prevents the loss of ore fines up the stack. Pelletizing is a method of agglomeration which usually occurs near the mines. Pelletizing agglomerates finely ground iron ore into iron oxide pellets. Pellets are formed by first mixing finely ground ore concentrate with a binder and bentonite clay and then balling the mixture and coating it with a thin layer of fuel in a balling drum. The traveling grate furnace consists of 20-60 windboxes located under a traveling grate which moves under overhead burners. The grate, six to 10 feet wide and 100-400 feet long, produces 100-300 tons of pellets per hour. The raw pellets are fed onto the grate to a depth of 13-17 inches. As the pellets pass through heat zones, they are dried, preheated, fired, and cooled. The pellets are hardened at $2400-2450^{\circ} \mathrm{F}$ by about 26 overhear burners which supply approximately $200 \mathrm{Btu} / \mathrm{hr}$ of fuel. Oil and gas are used to fire the overhead burners in the firing zone. Twenty-eight percent of all pellets are fired in traveling grates.

Sintering is the second principal method of agglomeration in the iron and steel industry. Sintering recycles and converts various iron-bearing materlals, including ore fines from screening operations, blast furnace flue dust, and ore concentrates, into a granular, relatively coarse form well suited for blast furnace use because of its permeability. Most sin- 
tering is done at the blast furnace site. Continuous sinter furnaces are 13-16 feet wide and 200-330 feet long. Iron-bearing materials are mixed with flux and fuel (coke, breeze, or anthracite) and spread evenly on the grate to a depth of six to 18 inches. Overhead burners ignite the fuel in this mix. As the combustion front moves downward through the bed of fires aided by an induced draft from the windboxes, sufficient temperatures $\left(2400-2700^{\circ} \mathrm{F}\right)$ are created to agglomerate the fine particles into coherent lumps or clinker. The clinker is cooled and reduced to pieces up to six inches in size.

Most of the fuel for sintering is provided by coke in the mix. Natural gas is used for the small amount of fuel needed to ignite the mix. The similarities in raw materials and burner characteristics determine similar fuel requirements for these two processes.

\section{C.3.6 Heat Treat Furnace (steel and aluminum)}

Heat treating, defined broadly, includes all of the controlled heating and cooling of, a metal or alloy in the solid state in order to alter its structure or properties. In the steel industry, the heat treating process changes the mechanical properties of steel by controlling the amount and distribution of its two major constituents, iron and iron carbide. Heat treating processes include annealing, tempering, normalizing, quenching, and stress relieving. There are many types of batch and continuous furnaces, which may be direct or indirect fired. Temperatures in heat treating furnaces range from $800-2100^{\circ} \mathrm{F}$. Some furnaces are heated indirectly by radiant tubes in which gaseous fuels are burned. The various heat treating furnaces are fired by oil, gaseous fuels, and electricity.

Heat treating furnace size and design tend to be highly job-specific in the aluminum industry. Direct and indirect fired batch and continuous furnaces are employed. The different heat treatments employed in aluminum fabrication (homogenizing, annealing, and aging) are a function of furnace tem- 
perature and residence time. All heat treating furnaces burn natural gas in the aluminum industry.

For both aluminum and steel heat treating, indirect firing promotes high product quality because the combustion products are segregated from the charge and the likelihood of localized overheating of the product is greatly reduced. However, direct-fired furnaces have the advantage of more efficient heat energy transfer, rediced Inad heating time, and Inwor cnpital costs. The product quality requirements and other process characteristics determine the method of firing and fuel used.

\section{C.4 CEMENT AND LIME}

\section{C.4.1 Rotary Kiln/Grate Kiln}

The single fossil fuel-consuming unit in the cement industry is the rotary kiln used to calcine the raw materials (crushed limestone, seashells, shale, silica sand, and iron ore). A rotary kiln is used for calcination. This kiln is a cylindrical refractory-lined steel chamber placed on its side and tilted slightly to allow gravitational flow of the material through the kiln. As the charge moves through the kiln, the chamber rotates at about one RPM to assure mixing and proper heat distribution during material flow. The kiln sizes vary from 12-17 feet in diameter and from 250-500 feet in length. Raw material is charged continuously into the high cold end of the kiln. As the charge moves to the lower end of the kiln, the temperature increases, producing the following reactions: free water evaporation, hydration water evaporation, decomposition of magnesium carbonate and calcium carbonate, and a lime and clay reaction. Maximum temperature in the kiln is $2800^{\circ} \mathrm{F}$. A single burner is positioned at the lower end of the kiln, so that the flame grazes the surface of the material. A slow flame whose length is approximately one-third the kiln length is used. Flame characteristics are not critical. Coal, natural gas, and fuel oil are used to fire cement rotary kilns. 
In the lime kndustry, the rotary kiln accounts for almost 80 percent of calcined lime. Crushed high-calcium or dolomitic limestone is charged to the rotary kiln where the high temperature $\left(2000-3000^{\circ} \mathrm{F}\right)$ decomposes calcium carbonate or calcium-magnesium carbonates to produce calcium oxide and calcium-magnesium oxide. This calcining operation is identical to that described for cement. Coal has been used almost exclusively in the rotary kiln.

\section{C.4.2 AIumina Rotary Kiln}

The first major process step in aluminum production refines hydrated alumina from bauxite. Ninety percent of the hydrated alumina is calcined in direct fired rotary kilns. The alumina hydrate is introduced into the kiln's elevated end. A single burner is located at the center of the end wall at the lower end. The rotary kiln structure and operation are identical to that described for the cement rotary kiln. At the discharge end of the kiln, the dried alumina enters an adjoining cooling chamber where it is cooled. Natural gas and distillate fuel oil account for 90 and 10 percent, respectively, of fuel used in rotary kilns.

\section{5 BRICK AND CLAY}

\section{C.5.1 Refractory Kiln/Coremaking Oven}

Refractory bricks are used by many industries in a variety of applications. where resistance to high temperature, severe abrasion, and chemical corrosion is required. The raw clay materials are crushed, mixed with water, formed, and dried before firing. The firing is performed primarily in tunnel kilns which are long refractory-lined chambers through which the bricks are conveyed on refractory-protected cars. The kiln is usually 400600 feet long and is set up in temperature gradient zones. Numerous low capacity (approximately one MMBtu/hr) burners, mounted on the sides or top of the kiln, run the length of the chamber. As the bricks enter the kiln, they arc prcheated, fired, and cooled slowly. Temperature distribution and 
control are essential to ensure uniform product quality. Firing temperatures vary $\left(1800-3200^{\circ} \mathrm{F}\right)$ depending on the specific product being fired. Natural gas is the preferred fuel because it is distributed easily to multiple burners and provides a greater degree of control. Both propane and No. 2 fuel oil serve as alternate kiln fuels.

Molding and coremaking is the process which makes molds and cores for casting in the foundry industry. Molds and cores are formed by compacting sand aggregates combined with a binder in a specific shape. This often is followed by drying and baking to increase hardness and refractoriness, Oven temperatures usually are $400-460^{\circ} \mathrm{F}$. The baking is done in either batch or continuous ovens. The continuous ovens are similar to the tunnel kiln described above. Batch ovens may have drawers to hold small cores, or they may be large and charged with portable racks. Fuel contaminants, whether ash or unburned carbon, on the surface of the molds may change alloy ratios or cause surface imperfections in the coating. Oil and gas currently are used to fire mold and core baking ovens. The large number of small-capacity burners in tunnel kilns determines the similar fuel requirements for these two processes.

\section{C.5.2 Face Brick Kiln}

Common (face) bricks are used by the housing and construction industry. The characteristics of a brick product are determined primarily by the nature of the constituent clays. The clay is crushed, screened, mixed with water, and formed into various shapes. The brick shapes are dried before entering the kiln for firing. The firing temperatures of $1800-2400^{\circ} \mathrm{F}$ produce a cliemical bonding of the clay product. Two-thirds of the bricks produced are fired in tunnel kilns similar to those described in the refractory brick process description. The remainder of common bricks are fired in periodic kilns. Bricks are loaded into the kiln and heated according to a firing curve resembling the tunnel kiln gradient. One type of periodic kiln is the shuttle kiln into which bricks are moved on a car 
for a firing cycle. Shuttle kilns range up to 20 feet in length and four to eight feet in width. They may be either top or side fired, generally with high velocity gas burners. Beehive kilns are large round rooms, approximately 30 feet in diameter. Beehives are either top fired or fired from two to 10 fireboxes situated around the kiln.

Natural gas is used in both continuous and periodic kilns because of its cost, control accuracy, and ease of delivery to numerous burners. 0il represents the primary substitute for natural gas. Product quality is not affected by ash or other fuel contaminants.

\section{6 FOOD AND TEXTILES}

\section{C.6.1 Food}

The food industry includes industries that manufacture or process foods and beverages for human consumption and other related products such as prepared animal feeds. The major energy-consuming direct heat applications in this industry include drying grains, dairy products, and beet pulp; cooking and smoking sausage and prepared meats; dehydrating fruits, vegetables, and alfalfa; and baking bread. Product quality is of primary importance. Any degree of food contamination by trace metals is sufficient to classify food as inedible. Gaseous fuels are the only fuels clean enlugh to contact foods directly without contaminating them. Consequently, natural gas is the only fuel used in direct heat applications.

\section{C.6.2 Textiles}

Direct heat applications in the textile industry are singeing, heat setting, and drying. All treatments involve passing the fabric directly over combustion flames. Singeing burns hairs off fabric to give a smoother appearance and to prepare the woven material for even dyeing, printing, and other finishing operations. In the drying and heat setting processes, heat is applied to the fabric which is stretched in a tenter frame. Waterproof- 
ing or permanent press chemicals may be added during heat setting. Temperatures range from $250-450^{\circ} \mathrm{F}$. Even heat flux and carefully controlled heat distribution and flame patterns are necessary to insure product quality. In addition, a clean flame is required to insure the absence of soot that might accumulate on the fabric and lodge between its fibers.

Natural gas is the sole fuel used in these processes duc to its cleanliness and controllability. Propane or butane are substituted when natural gas is unavailable.

\section{C.7 PETROLEUM AND CHEMICALS}

Fired heaters are used in the chemical and petroleum refining industries to provide process heat. The tubestill heater is an indirect-fired process. The feedstock circulates through the furnace within a network of several hundred tubes. Heat to the tubes is provided by multiple low-capacity burners mounted in banks on the sidewalls, roof, or floor of the radiant section of the furnace. In the radiant section, heat is transferred to the feedstock via the tube walls mainly from the combustion flames. In the convection section, heat is supplied to the tubes by the flue gases which pass over the tubes on route to the stack. Usually, the convection section is used to preheat the feedstock. Predictable heat release rates and even heat distribution to each radiant tube are critical to operation. Long, lazy flames may lick the tube walls, causing loral overheating and cokc deposition in the tube. Ash deposition on furnace walls and tube surfaces can lead to subsequent attacks on these surfaces by impurities in the ash. The risk designation refers to actual production and safety risks and is not intended as an economic indicator.

\section{C.7.1 High-risk Fired Heater}

The substitution of a nongaseous fuel in the following processes is classified as high risk. At least one of the following conditions unfavorable to nongaseous fuel use is present in the high-risk tubestill heaters: 
- Process temperatures over $900^{\circ} \mathrm{F}$

- High pressures

- Reactive feedstock.

High temperatures increase heat distribution problems, the risk of coking, and ash deposition on furnace surfaces. A reactive feedstock can be a safety hazard in the event of tube rupture. High pressures can increase the chance of tube rupture due to tube wall fatigue or degradation. The presence of a chemical reaction in the tubes makes even heat distribution more critical.

Tubestills used in the production of ammonia, ethylene, and methanol and in the petroleum refining processes of hydrocracking, hydrotreating, hydrorefining, delayed coking, and hydrogen. manufacture are classified as high risk. Only natural gas and refinery offgas currently are used as tubestill fuels in these processes.

\section{C.7.2 Medium- and Low-Risk Fired Heaters}

The following petroleum refining processes employ tubestill heaters as described in the low-risk tubestill description: atmospheric distillation, alkylation, and feed preheaters to catalytic reformers. The conditions of low process temperature (under $900^{\circ} \mathrm{F}$ ), stable feedstock, and the presence of hydrogen in the feedstock allow the use of nongaseous fuels in those processes to be classified as low risk. The low temperature and hydrogen in the feedstock reduce the chances of coke deposition. The stable feedstock reduces the safety hazard in the event of a tube rupture. Currently, natural gas, refinery offgas, and residual fuel oil are used as tubestill fuels.

Medium-risk fired heaters include vacuum distillation, hydrocracking, hydrorefining, and catalytic reforming units. These processes do not have the reactive properties of the high-risk units, but they are critical to refinery operation. If a medium-risk fired heater is interrupted, it would effectively shut down a major portion of production for a significant time. 
APPENDIX D. COST CALCULATIONS AND DATA USED FOR

ECONOMIC COMPARISONS

The objective of this appendix is to explain the basis for the economic comparisons of the technologies discussed in Sections 4 and 6 . Cost data not shown in the body of the report are presented and the calculations made to estimate annualized costs are explained. The appendix is divided into three parts: the first part describes how cost estimates for alternate fuel sources were annualized; the second part presents the boiler and process heater costs used; finally, the addition of the fuel and combustor costs to make economic comparisons is explained.

\section{D.1 ANNUALIZED COSTS FOR ALTERNATIVE TECHNOLOGIES}

For each alternative fuel and heat source, Section 4 shows the available cost estimates and the costs used for the economic analysis discussed in Section.6: The costs are adjusted to be on comparable bases and are shown in annualized form so that comparisons with other technology costs are meaningful. When possible, the costs used for the economic analysis were taken from DOE data in an effort to use estimates based on consistent assumptions and unbiased sources.

Other cost figures were adjusted to be on comparable bases with each other, so they are not identical to figures in the original references. Capital and operating and maintenance (OGM) costs were adjusted to 1978 dollars. OGM costs were assumed to remain constant during the life of the facility. Fuel prices were standardized so that technology cost variations are not due to different fuel price assumptions. The costs used are as follows:

- High sulfur coal: $\$ 1.08 / \mathrm{MMBtu}$

- Low sulfur residual fuel oil: \$2.81/MMBtu

- Electricity:

$\$ 0.0291 / \mathrm{kWh}$

- Limestone: $\$ 12.00 /$ ton. 
The cost of feedstock coal per MMBtu of alternate fuel produced was calculated as the cost per MMBtu of raw coal $(\$ 1.08 / \mathrm{MMBtu})$ divided by the conversion efficiency of the plant.

Using a real interest rate (or discount factor) of seven percent, a tax rate of 50 percent, and sum of years digits (SOYD) depreciation, the present value of the discounted cash flow and an equivalent annuity were calculated. To convert the annuity into a cost per MMBtu, the annuity was divided by the expected output (in MMBtu/yr) of the alternative fuel plant. This final figure (in $\$ / M M B t u$ ) can be interpreted as a selling. price (excluding transportation costs) to an industrial end user.

Table D.1 shows the capital and O\&M costs used to calculate the annualized costs used in this report. The DOE data for methanol, MBG, and coal liquids were received in annualized form. The capital cost figures for SRC-1 and SRC- 2 are stated as ranges because their estimated costs have increased substantially since the original estimates were made.

The steam cost estimates shown in Section 4 may be better figures for comparing fuel costs, because they include all the associated costs of burning each fuel, not just the fuel cost. The steam costs are estimated for boilers operating at 65 percent capacity utilization. Pollution control regulations were assumed to require 85 percent sulfur removal. Steam costs were calculated by first converting fuel costs from \$/MMBtu to \$/MPPH, as suming $1.25 \mathrm{MMBtu}$ are required to produce $1.0 \mathrm{MPPH}$ of steam. Fuel costs were then added to annualized capital and O\&M costs (see next section) to get total steam costs.

\section{D.2 BOILER AND PROCESS HEATER COSTS}

Al1 the capital and O\&M costs for boilers and process heaters used in the economic analysis in Section 6 were taken from cost data in IFCAM. Data on the cost of installing new boilers were obtained primarily by contacting boiler manufacturers. 
TABLE D. 1

CAPITAL AND O\&M COSTS FOR ALTERNATIVE FUEL PRODUCTION

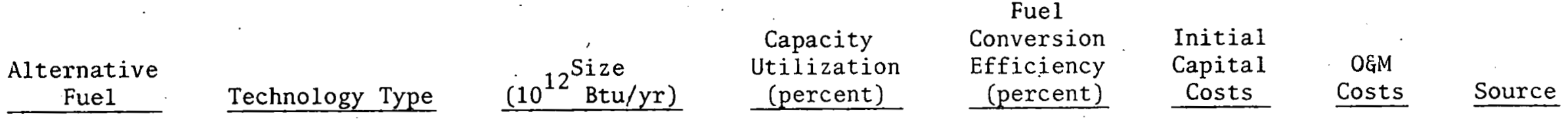

1. Costs shown in $\$ / M M B t u$ :

\begin{tabular}{|c|c|c|c|c|c|c|c|}
\hline Methanol & Advanced gasifier & 32 & 90 & 60 & 2.00 & 2.00 & $\mathrm{DOE}^{\mathrm{a} /}$ \\
\hline MBG & $\begin{array}{l}\text { Lurgi technology } \\
\text { (eastern coal) }\end{array}$ & 50 & 90 & 75 & 2.00 & 0.95 & DOE \\
\hline SRC-2 & $\begin{array}{l}\text { Average of coal } \\
\text { liquids (SRC-2, H- } \\
\text { coal, EDS) }\end{array}$ & 118 & 90 & 70 & $\begin{array}{l}1.61- \\
2.74\end{array}$ & 2.81 & DOE \\
\hline
\end{tabular}

2. Costs shown in $\$ 10^{6}$

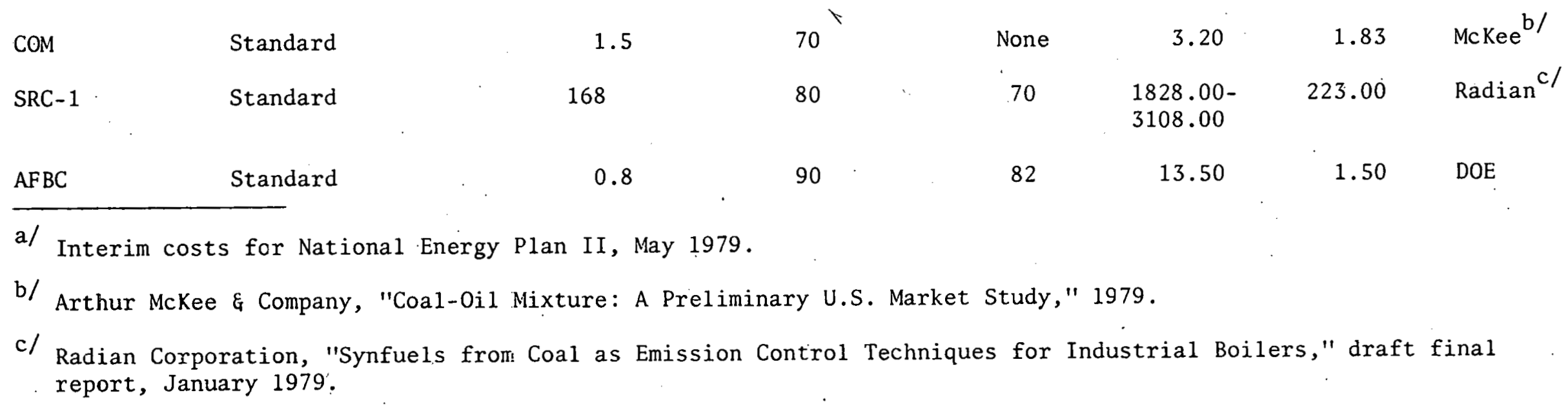


Data on process heater capital costs came from a combination of equipment vendors, process heater users, consultants, and cost manuals. The capital costs include the installed costs of all necessary equipment for process operation including ash handling, fuel handling and storage, and any necessary pollution control costs. The capital costs estimates also include indirect costs such as engineering, utilities, contingencies; and working capital.

O\&M costs are based primarily on contacts with industrial boiler users. These estimates include all annual expenses for labor, supplies, maintenance materials, and general and administrative costs. The costs of boilers and process heaters fired with alternative fuels were assumed to be the same as the costs for units fired with the conventional fuels which have very similar characteristics. Natural gas unit costs were used for MBG costs. SRC-2 (liquefied coal) costs were used for: methanol, and coal costs were used for SRC-1. New capital costs were not estimated for COM-fired units because COM is considered to be primarily an energy source for retrofit applications.

Table D.2 shows the boiler capital and O\&M costs used to estimate steam costs in Section 4. Table D.3 shows the costs for process heaters. These costs were annualized in the same way alternative fuel production costs were annualized.

\section{D.3 ECONOMIC COMPARISONS BETWEEN ALTERNATIVE FUELS IN PROCESS HEATERS}

The final step in analyzing which alternative fuels are economically attractive is to determine the total annualized cost of operating a process heater with each possible fuel. This was done by adding the annualized alternative fuel cost (or price to the industrial user) to the sum of the annualized capital and $0 \xi \mathrm{GM}$ costs for each:process heater. The results are summarized in Section 6. 
TABLE D. 2

BOILER CAPITAL AND O\&M COSTS

$$
\left(1978: 10^{3}\right)
$$

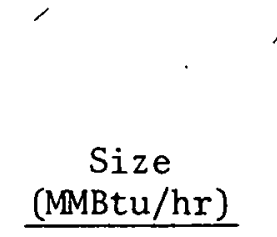

50

Capital

O\&M

175

Capita 1

O\&M

325

Capital

O\&M
5582

302
Fuel Fired

\begin{tabular}{|c|c|c|c|}
\hline \multirow{2}{*}{$\begin{array}{c}\text { Natural } \\
\text { Gas }^{a}\end{array}$} & \multirow[b]{2}{*}{ Residual Oil } & \multicolumn{2}{|c|}{ Coa 1} \\
\hline & & Pulverized & Stoker \\
\hline
\end{tabular}

674

$2215^{\mathrm{b} /} \quad 830^{\mathrm{a} /}$

324

91

- $\quad 3148^{\mathrm{b} /}$

- 436 $7775^{c /} 2904^{a / .}$

971

260
- $\quad 7878^{\mathrm{c} /}$

- 1212
a/ No FGD or ESP.
b/ Includes FGD, but no ESP.
c/ Includes both FGD and ESP.

SOURCE: "Industrial Fuel Choice Analysis Model," Appendices to Primary Model Documentation," prepared for DOE by EEA, Inc., Arlington, Virginia, January 8, 197.9 . 
TABLE D. 3

PROCESS HEATER CAPITAL AND O\&M COSTS ${ }^{a /}$

$\left(1978 \$ 10^{3}\right)$

Process Heater

Fired heaters

99 MNRT $11 / \mathrm{hr}$

Capital

O\&M

$364 \mathrm{MMBtu} / \mathrm{hr}$

Capita 1

O\&M

Regenerative

glass melter

Blase furnace

Steel reliedt

furnace

Rotary cement

kiln

Capital

O\&M

Capital

O\&M

Capital

O\&M

Capital

OEM

Face brick kiln.

Capital

OEM

Heat. treating

furnace

Capita 1

O\&M
Fue1 Fired

\begin{tabular}{cccc}
\hline $\begin{array}{c}\text { Natural } \\
\text { Gas }\end{array}$ & $\begin{array}{c}\text { Dislillate } \\
\text { Oil }\end{array}$ & $\begin{array}{c}\text { Residual } \\
\text { Oil }\end{array}$ & Coal \\
\hline
\end{tabular}

1,558

127

1,855

170

1,980

6,721

$199 \quad 1,117$

3,832

392

4,703

$4,997 \quad 16,709$

491

$576 \cdot 3,062$

6,867

8,261

445

$7,346 \quad 15,985$

381

$508 \quad 2,562$

16,709

17,422

$17,469 \quad 10,307$

507

592

656

967

10,018

10,321

316

10,478

$\mathrm{I}^{\mathrm{b} /}$

268

349

I

1,054

572

10.877

667

$11,292 \quad 12,116$

$.717 \quad 1,021$

1,078

1,190

1,45

2,848

66

95

113

214

1,581

34

1

1,604

55

\section{1} I

a/ Includes pollution control costs.

h/ Infeasibie.

SOURCE: "Industrial Fuel Choice Analysis Model," Appendices to Primary Model Documentation, prepared for DOF by EEA, Inc., $\Lambda$ rlington, Virginia, January 8, 1979. 
D-7

The effectiveness of ITC's in encouraging the construction of new alternative fuel-fired process heaters was assessed by changing just the annualized process heater capital cost. The original annualized O\&M cost and alternative fuel price were added' to the adjusted annualized capital cost to obtain a new total annualized cost. This was compared with the parallel cost for conventional fuels to determine whether the increased ITC changed the economics in favor of the alternative fuel. 
APPENDIX E. GLOSSARY OF TERMS

This glossary includes some definitions which have appeared in the following references:

Lapedes, Daniel L. (Ed.), Dictionary of Scientific and Technical Terms, 2nd Edition, McGraw-Hill Book Company, New York, 1978.

North American Combustion Handbook, 2nd Edition, North American Mfg. Co., Cleveland, Ohio, 1978.

Ash

Noncombustible mineral matter which is a constituent (to varying degrees) in liquid and solid fuels. It can cause difficulties with heat transfer surfaces, refractories, and burner ports.

Ash fusion temperature

The temperature at which ash begins to melt and blend into a glassy substance, or clinker.

Atomization .

The process of breaking a liquid fuel into a multitude of tiny droplets or a fine spray, to enhance its combustion.

Baghouse

A chamber for holding fabric filters (bag filters) used to clean flue gas streams from a furnace.

Caking coals

A type of coal which agglomerates and softens upon heating; after volatile material has been expelled at high temperature, a hard, gray cellular mass of coke remains.

Catalyst

A substance that can alter the rate of a chemical reaction, without itself entering into the reaction products or undergoing a chemical change.

Checkerworks

Refractory in furnace regenerators which recovers heat from outgoing gases and later transmits the heat to cold air or gas entering the furnace; so called because the bricks are arranged in checkerboard patterns, with alternating brick units and open spaces. 
Clinker

Coke

Coking

Compliance fuel

Convective heat transfer

Conversion efficiency

Densification process

Derate

Distillate
Burnt or glassy solid material that may form from fuel ash and refractories in process heaters.

1. The solid product, principally carbon, resulting from the destructive distillation of coal or other carbon-containing sutstances in an oven or closed chamber.

2. The carbun-containting substances which may form on furnace walls under certain circumstances.

The process of producing coke. With respect to chemirals and petroleum refining industry fircd heaters, the accumulation of unacceptable coke deposits in tubes containing feedstocks.

A fuel which when burned does not require the use of a pollution control device to meet emission control regulations.

The transfer of heat by moving masses of heated matter.

In reference to an alternative fuel production facility, the percent of the energy content in the original fuel (usually coal) that remains in the alternative fuel product.

1. With reference to refuse-derived fuels, the process in which solid wastes are mechanically pelletized or briquetted to form a denser fuel. See "solid fuel forms" section of MSW technology description.

2. With respecl to woud fuels, the process of producing wood pellets. See discussion of "combustion characteristics" in wood and wood waste section.

With respect to an industrial process, to reduce the maximum firing rate of process burners or to reduce the product throughput, or both. Often required when the primary fuel for a proccsis is changed to a heavier fuel.

1. Distillate fuel oil. A light grade of fuel oil which has a boiling point above that of gasoline. Also generally referred to as No. 2 fucl oil, but sometimes it includes No. 3 and No. 4 fuel, oils also. 
Distillate

Disililation column

Dowtherm

ESP

Excess air ratio

FGD

Flame impingement

Flame temperature

Flue gas

Fluff

Fouling

Friable

Hardgrove grindability index
2. Can refer to oil obtained by condensation of vaporized hydrocarbons.

A still in which crude oil or other liquids are separated into various fractions or parts according to their boiling points.

A trade name for any of several mixtures used in liquid form as a heat-transfer fluid.

Electrostatic precipitator. A device which removes dust or other fine particles from flue gases by charging the particles with an electric field and collecting them on charged plates.

The ratio between the amount of air existing in a combustion process and the amount theoretically required for complete burning.

Flue gas desulfurization. Usually used in reference to one of several types of devices that remove sulfur compounds from flue gases.

The unacceptable contact between a flame and a product or furnace wall.

The temperature of the products of combustion of fuel with air. Varies greatly by fuel type.

Gaseous combustion products from a furnace.

The 1ight, shredded portion of municipal solid waste, from which ferrous metals and sometimes glass and nonferrous metals have been removed. See section on solid fuel forms of MSW.

In process heaters and boilers, the accumulation of ash, dirt, corrosion, and roughness on tubes and furnace walls. See also slagging.

Easily reduced to a granular or powdery condition.

The relative grindability of materials in comparison with a standard coal, chosen as 100 grindability, as determined by a miniature ball-ring pulverizer. 
Heating value

Heat sink

\section{Heat transfer coef-} ficient

Hydrocarbon

Luminous flame

Radiant flame

Radiant heat transfer

Recuperator

Reducing atmosphere

Refractories

Regenerator
The total heat or energy content stored in a substance. Usually designated in Btu per pound, gallon, or cubic foot.

Any region or substance that absorbs heat. The material heated in an industrial process (water, oil, metal, etc.) acts as a heat sink.

A measure of the heat conduction through a material or medium. $\Lambda$ high cocfficient means heat is easily transferred or conducted.

Any of a large number of compounds composed of carbon and hydrogen. The primary source of hydrocarbons is from petroleun.

Luminous refers to the quality of being bright. However, luminous flame is sometimes used interchangeably with radiant flame.

A radiant flame refers to a situation in which the primary mode of heat transfer is radiation. Different fuels produce flames with varying radiance. Coal flames, for example, are much.more radiant than natural gae flamos.

Heat transfer in which the heat travels rapidly in straight lines without heating the intervening space. See aiso convective heat transfer.

A piece of equipment that makes use of hot flue gases to preheat air for combustion. The flue gases and air flow are in adjacent passageways so that heat is transterred from the hot gases, through the separating wall, to the cold air.

A furnace atmosphere that tends to remove oxygen from substances placed in the furnace. It results from supplying inadequate air to the burners.

Highly heat-resistant materials used to line furnaces, kilns, and boilers.

A cyclic heat interchanger which alternately receives heat from gaseous combustion products and transfers heat to air before it is used in combustion. 
Residual

Scale-up .

Slagging

Soot

Spreader stoker

Turndown ratio

Volatiles

Waterwa11 incinerator

Working fluid
Residual fuel oil. A heavy, viscous oil remaining after the lighter parts of crude oil have been removed: Includes No. 5 and No. 6 fuel oils.

In reference to developing technologies, the process of designing a large unit (usually of commercial size) based on an experimental or demonstration unit.

With reference to refractories, the destructive chemical action between refractories and combustion products at high temperatures, resulting in the formation of a liquid.

A black substance, consisting of very small particles of impure carbon or heavy hydrocarbons, which appears in smoke resulting from incomplete combustion.

A solid fuel-burning system in which the fuel is distributed over a thin bed on a grate. Has been a very common method for firing coal in boilers.

The ratio of maximum to minimum firing rates possible while maintaining proper combustion or process conditions. In some non-continuous processes, a high turndown ratio is very desirable.

The more easily vaporized components of a liquid or solid.

A combustor in which water-carrying tubes help form the sidewa11. The water absorbs radiant heat and thereby prevents excessively high furnace wall temperatures.

With respect to indirect heating, whatever fluid. is used as the heat transfer medium or substance. The working fluid carries heat from the combustor to the substance being heated. 


\section{U.S. Depa ent of Energy}

Energy Information Administration

Office of Energy Information Services

1726 M St., N.W.

Washington, D.C. 20461

OFFICIAL BUSINESS

PENALTY FOR PRIVATE USE, $\$ 300$

FIRST CLASS MAIL 